\title{
Exemplos de universalidade na física estatística de modelos aperiódicos e desordenados
}

Thomás Augusto Santoro Haddad

SBI-IFUSP

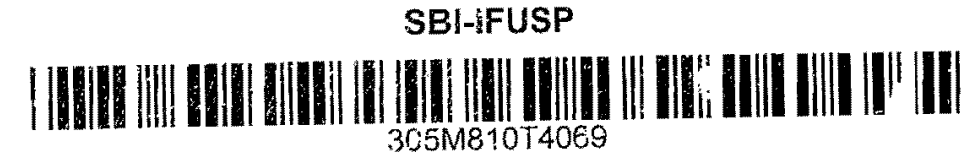

Tese apresentada ao Instituto de Física da Universidade de São Paulo para a obtenção do grau de Doutor em Ciências

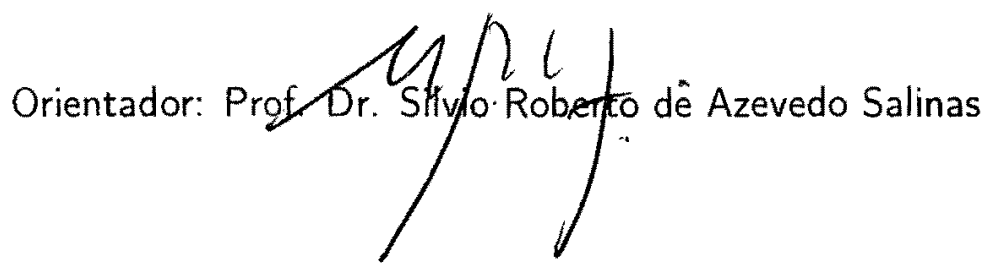

BANCA EXAMINADORA

Prof. Dr. Alessandro Paulo Sérvio de Moura (USP)

Prof. Dr. Jairo Rolim Lopes de Almeida (UFPE)

Prof. Dr. João Carlos Alves Barata (USP)

Prof. Dr. Ronald Dickman (UFMG)

Prof. Dr. Silvio Roberto de Azevedo Salinas (USP)

São Paulo 2004

INSTITUTO DE FISICA

Serviço de Bibloteca e Informação

Tombo: $4069 \quad E_{x} 1$
Prof. Armaddo Corbani Ferraz Presidente da Comissio de P6s Graduacilo 
H1260

D

Ex.́1

Este trabalho contou com o auxílio financeiro da Fapesp.

FICHA CATALOGRÁFICA

Preparada pelo Serviço de Biblioteca e Informação do Instituto de Física da Universidade de São Paulo

Haddad, Thomás Augusto Santoro

Exemplos de universalidade na física estatística de modelos aperiódicos e desordenados. Säo Paulo, 2004.

Tese (Doutoramento) - Universidade de São Paulo Instituto de Física - Depto. de Fisica Geral

Orientador: Prof. Dr. Silvio Roberto de Azevedo Salinas Área de Concentração: Fisica

Unitermos:

1. Mecânica estatística clássica;

2. Mudança de fase;

3. Sistemas desordenados;

4. Teorias da termodinâmica. 
Para Isadora, Olívia e Henrique 
$\because$

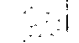

$\cdots$

$\therefore$ 


\section{Abstract}

We present in this work a series of studies on the effects of geometrical perturbations on statistical-physics models with continuous phase transitions. These perturbations are generated by random or aperiodic (deterministic) distributions of fields or microscopic couplings, along the lattices on which the models are defined. In case of non-disordered aperiodic systems, we show a wealth of examples of the changes that may be brought about on the critical behavior of Ising, Potts and interacting-polymer models. We employ non-perturbative real-space renormalization group techniques, as well as transfer-matrix methods to study the thermodynamics of such systems in the neighborhood of critical and tricritical points. Our conclusion is that although critical exponents may change appreciably in the presence of aperiodic distributions of couplings, universal classifications are nevertheless still workable. The universality classes associated to different models and the distinct wavs of implementing aperiodicity are connected to unexpected attractors in Hamiltonian parameter space, which are thoroughly described. In case of random perturbations that break translational symmetry we argue that some universal classifications should still be possible. First, because these systems are in a sense analogous to the former aperiodic ones, and also because they always seem to be associated with some form of complex dynamics (as the dynamics of vitreous, non-random materials). We make some brief comments on this connection, and present a study of a very simple disordered model, whose thermodynamics is completely solvable, and which may hide some signatures of complex dynamics. Finally, we discuss the first steps of the so-called Martin-Siggia-Rose (MSR) method, which may be emploved in advanced studies of systems undergoing Langevin-type evolutions, and which was responsible, some decades ago, for a first glimpse into the possible universality of complex dynamical behavior of disordered systems. 



\section{Resumo}

Apresentamos neste trabalho uma série de estudos sobre os efeitos de perturbações geométricas em alguns modelos da física estatística com transições (lo fase contínuas. Essas perturbações são causadas por distribuições aleatórias on aperiódicas (e determinísticas) de campos ou de acoplamentos microscópicos ao longo das redes em que os modelos são definidos. No caso do sistemas aperiódicos sem desordem, mostramos uma grande quantidade de exemplos das possíveis alterações induzidas no comportamento crítico de modelos de Ising, Potts e um modelo para polímeros em interação. Empregamos técnicas não-perturbativas de grupo de renormalização no espaço real (3) matrizes de transferência para estudar a termodinâmica desses sistemas na região crítica ou tricrítica. Concluímos que, ainda que distribuições aperódicas de constantes de acoplamento muitas vezes alterem sensivelmente os expoentes críticos associados às transições de fases, classificações univerSais ainda são possíveis. As classes de universalidade ligadas aos diferentes modelos e às várias maneiras de perturbá-los aperiodicamente estão associallas a incsperadas estruturas atratoras que surgem no espaço hamiltoniano le parametros, descritas em detalhe. No caso de modelos em presença de perturbações aleatórias à simetria translacional, argumentamos que alguns tipos de classificações universais também devem ser possíveis, primeiramente por causa de uma certa analogia com os sistemas aperiódicos anteriores, e também porque eles parecem sempre estar associados a formas de dinâmica complexa (como a que se observa em sistemas vítreos não-desordenados). Comentamos brevemente sobre esta última conexão, e apresentamos uma análise de um modelo desordenado muito simples, que tem a termodinâmica inteiramente calculável, e pode esconder alguma assinatura dessa dinâmica complexa. Finalmente, discutimos os rudimentos da chamada técnica de Martin-Siggia-Rose (MSR), que pode ser empregada para estudos avançados de sistemas com evoluções do tipo Langevin, e que permitiu o início da compreensão, já há algumas décadas, da possível universalidade da dinâmica complexa de sistemas desordenados. 



\section{Agradecimentos}

Para mim não há dúvida de que a escrita destes agradecimentos é o momento de maior prazer em toda a redação da tese. Não porque ele indica que a conclusão se aproxima, como poderia se pensar, mas sim porque é um emocionante exercício de memória - e pelo próprio ato de agradecer.

A tradição determina que o orientador do trabalho seja o primeiro da lista de agradecidos; curvo-me a ela, mas não pela simples repetição do gesto tradicional, e sim porque realmente desejo expressar minha gratidão ao Prof. Silvio Salinas antes de tudo. Ao longo de uma colaboração de dez anos, desde o início do meu curso de graduação, quando me acolheu como aluno de iniciação científica, o Prof. Salinas me orientou quase que diariamente, talvez até sem saber, inclusive nas inúmeras ocasiōes em que o tema central de nossas discussōes não era um modelo, uma conta, um resultado. Orientou-me no que há de mais valioso a respeito do exercício profissional da vida acadêmica, c que não está nos livros e periódicos e programas de computador: a defesa de valores acadêmicos sólidos, o compromisso intransigente com eles, a certeza de qual deve ser o papel e a postura do pesquisador e professor universitário. Alén disso, sua generosidade e sua infinita paciência foram essenciais para que eu conseguisse chegar nesta etapa, depois de muitos problemas pessoais que me afligiram, e que poderiam ter sido facilmente mal-compreendidos. Espero de algum modo poder honrar o privilégio que foi para mim trabalhar com ele por tanto tempo.

Muitos outros professores também contribuíram para que eu pudesse chegar aqui. Em particular, destaco o Prof. Roberto Andrade, da UFBA, que originou um dos principais trabalhos aqui apresentados, e, com a mais perfeita generosidade, cedeu-me resultados obtidos por seu próprio esforço, para que cleles en fizesse uso. Tenho muito o que agradecer à Profa. Suani Pinho, também da UFBA, por uma colaboração de longa data e que foi tão frutífera e importante. Quero expressar gratidão também ao Prof. Cirano de Dominicis, de Saclay, França, que em duas visitas ao Brasil me fez ter o desejo (le estudar problemas e técnicas muito diferentes dos que estava acostumado, e acabou sendo o propulsor de um dos capítulos deste trabalho. Todos os docentes do Grupo de Física Estatística do IFUSP também foram essenciais para que eu conseguisse finalizar este projeto, seja através de inúmeras discussões sobre os mais variados assuntos, técnicos ou não, seja pelo ambiente de trabalho que diariamente ajudam a criar aqui. Expresso aqui minha gratidão a cada um deles.

Entre muitos amigos que desejo agradecer, reservo um lugar especial a André Vieira, por mais coisas do que saberei dizer. Sua presença pode ser sentida em todas as páginas desta tese, que ele acompanhou de perto por 
longos anos. Acompanhou não apenas a tese, para a qual deu imúmeras e valiosas sugestões, chegando a trabalhar ao meu lado em problemas curo me desesperavam, mas também a mim mesmo, nos variadíssimos cstados de espírito que apresentei durante todo esse tempo. Contei com sua firmo presença para dividir momentos de empolgação e momentos de profunclo desânimo, tanto no trabalho quanto na minha vida pessoal.

Os colegas do Grupo de Física Estatística merecem muitos agradecimentos; em particular, näo posso deixar de citar nominalmente Angsula Ghosh. Darielder Ribeiro, Luiz Ozório, Masayuki Hase e Paulo Muzy.

Também sou muito grato a inúmeros funcionários do IFUSP, mas não mais que a Márcia Silvani, que já fez mais coisas para resolver meus problemas do que poderia enumerar em tão pouco espaço. E não posso deixar de lembrar dos outros funcionários da administração do Departamento de Física Geral. e também dos porteiros de nosso prédio, companheiros seguros de infindáveis noites no campus deserto.

Talvez a lista dos amigos que participaram da minha vida nos últimos anos e que acabaram, de uma forma ou de outra, sendo essenciais para que cu fosse capaz de continuar o trabalho mesmo em momentos adversos, seja maior que a capacidade da minha memória. Mas é um prazer imenso poder escrever os nomes de Arnaldo G. de Oliveira Filho, Danielli Costa, Gabriella Contoli, Guappo Sauerbeck, Henady Malarenko, Joana Gordon, Juliana Glasberg, Larissa Stempniewski, Michel Gordon, Rodrigo Chahad, Ruben Damião e Samuel Possebon. E também, de maneira especial, o nome de Lilian Leme. por tanta coisa.

Enfim, chego a minha família e minha querida Fernanda Pitta. Aqui, o exercício da memória, de que falei acima, torna-se ainda mais emocionante. $\dot{E}$ para cá que confluem as memórias de momentos muito difíceis, que poderiam ter-me afastado definitivamente deste trabalho que ora finalizo, não fosse pela existência deles, indicando a permanente possibilidade da retomada. Mas são sobretudo as lembranças das ocasiōes de maior alegria e esperança que mo inspiram a gratidão. Ao amor e ao apoio sempre inestimável do toclos eles, só posso agradecer com o desejo de dedicar-lhes um amor perfeito, mesmo que essa perfeição apenas possa realizar-se "num só instante, difuso, profuso. completo e longínquo ".

T.A.S.H. São Paulo, maio de 2004.

\footnotetext{
${ }^{1}$ Ålvaro de Campos, Passagem das horas
} 


\section{Sumário}

Prólogo 3

1 Considerações sobre modelos aperiódicos 9

1.1 Por que se importar com aperiodicidade? . . . . . . . . . . . 10

1.2 A matemática da aperiodicidade (brevíssima introdução) . . . 13

1.3 Modelos estatísticos aperiódicos . . . . . . . . . . . 18

1.3.1 Generalidades ................... . . 18

1.3 .2 O critério de Luck . . . . . . . . . . . . . 22

1.4 Excurso: da universalidade em mecânica estatística . . . . . 26

1.5 Comentários aos trabalhos publicados . . . . . . . . 30

Referências Bibliográficas . . . . . . . . . . . 4 45

2 Notas sobre dinâmica vítrea 49

2.1 Rudimentos de dinâmica vítrea . . . . . . . . . . 51

2.2 Comentário à publicação . . . . . . . . . . . . 54

Referências Bibliográficas . . . . . . . . . . . 57

3 Breve comentário ao formalismo de Martin, Siggia e Rose (MSR) $\quad 59$

3.1 Os rudimentos do método . . . . . . . . . . . 60

3.2 Alguns comentários . . . . . . . . . . . . . 64

Referèncias Bibliográficas . . . . . . . . . . . . 67

$\begin{array}{ll}\text { Epílogo } & 69\end{array}$

$\begin{array}{ll}\text { Artigos publicados } & \mathbf{7 1}\end{array}$

Artigo $1 \ldots \ldots \ldots \ldots \ldots \ldots \ldots$

Artigo $2 \ldots \ldots \ldots \ldots \ldots \ldots \ldots \ldots$

Artigo $3 \ldots \ldots \ldots \ldots \ldots \ldots \ldots \ldots$

Artigo $4 \ldots \ldots \ldots \ldots \ldots \ldots \ldots$

Artigo $5 \ldots \ldots \ldots \ldots \ldots$ 


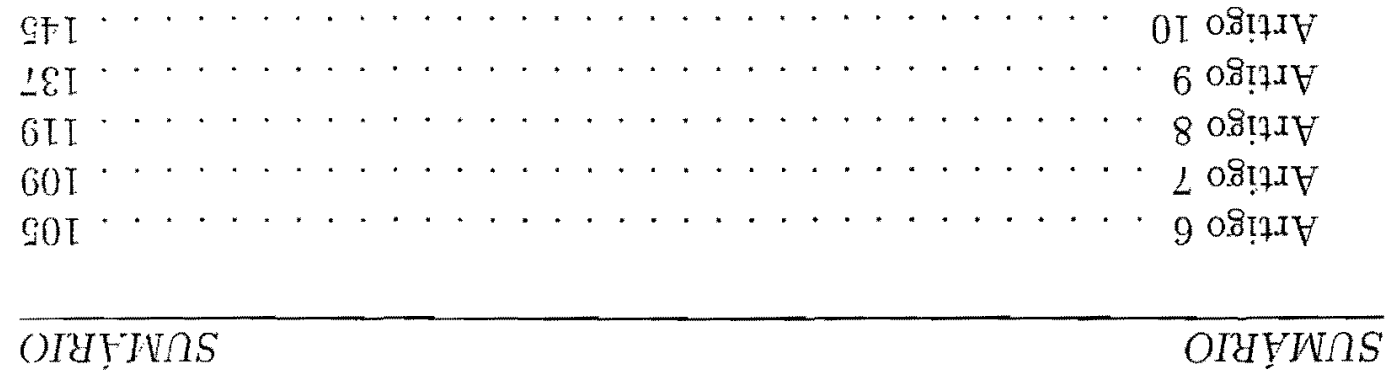




\section{Prólogo}

Muito recentemente, tive diante de meus olhos um exemplar do memorial de $11 \mathrm{~m}$ conhecido, inscrito num concurso para professor doutor na área de História. Assombra-me constatar que somente nessa ocasião, tão recente, parece ter ficarlo absolutamente claro para mim o que pretendo com este trabalho - ao mesmo tempo, creio que posso me considerar muito afortunado, por no menos saber qual é essa pretensão. Explico-me melhor: a certa altura do dito memorial, o autor, após descrever sua vida acadêmica bastante variada (gradıação num curso, mestrado em outro, doutorado num terceiro, pós-doutorado numa quarta área), sente-se compelido a dar alguma resposta para uma questão que lhe fora proposta muitos anos atrás, por um professor de quem se recorda com gratidão; a questão é "o que dá sentido à sua trajetória?"

Ao ler essa simples indagação, que em si nada tem de muito impressionante, dei-me conta de que esta tese tinha de ser a minha resposta particular à mesma questão, ainda que ela nunca tenha sido dirigida explicitamente a mim. Quero dizer que, naquele momento, percebi uma urgência própria, que talvez unnca tivesse notado com clareza, em também responder a essa pergunta. Qual é o sentido da minha trajetória acadêmica? Há algum liame concreto, identificável, entre os diversos assuntos que estudei, entre os resultados publicados, ao longo de tantos anos tentando aprender Física? Perceber que esta tese era, talvez, uma das raras oportunidades de buscar tal sentido, tais conexões, de maneira sistemática e amadurecida, foi como uma iluminação. Mais que uma coleção de contas, tabelas e gráficos, este trabalho, ficou claro para mim, deveria ser uma avaliação crítica e ponderada da minha própria trajetória de pesquisas. Em que pese sua diminuta extensão, parece-me imprescindivel submetê-la a esse exame, até mesmo como exercício de reflexão e autocrítica sobre a própria atividade científica, que não podem jamais ser esquecidas pelo pesquisador em qualquer etapa de sua carreira.

A súbita compreensão de que meu objetivo pessoal com este trabalho era esse, a consolidação e busca de sentido para uma pilha de resultados e estudos, na verdade trouxe a termo um período que se iniciara bem antes, 
desde que comecei a pensar em que forma deveria apresentar minha tese. Após muito pensar e discutir com o Prof. Silvio Salinas, concluí que a pior maneira de redigir este trabalho seria seguir a forma mais usual, isto c, diversos capítulos descrevendo contas variadas, seus resultados, e gráficos cm abundância - simplesmente porque todas essas contas, resultados e gráficos já foram apresentados nas dez publicações apensas a este volumc ${ }^{2}$. Pareciame inócuo e quase sem sentido apenas reescrever esses artigos com alguns detalhes a mais (o que é quase equivalente a uma mera tradução), e considerar que à tese bastaria ser uma nova apresentação de todos resultados de pesquisa que publicamos ao longo dos últimos anos em periódicos especializados, também já apresentados em inúmeras conferências. A altcrnatira evidente era escrever uma apreciação crítica, coerente e detallhada dlesse conjunto, e considerar este sim o novo trabalho que eu poderia apresentar nesta tese (em oposição à reapresentação do conteúdo dos artigos publicados. (1tu' seria nada mais que um velho trabalho).

Assim, a recente percepção de que uma avaliação crítica de qual é o senttido deste percurso (por mais curto que ele tenha sido), como descrevi acima. já poderia ser realizada, veio perfeitamente ao encontro da forma cue esco-lhera para apresentar a tese. Ao apreciar criticamente a coletânea cle artigos publicados, anexa ao presente trabalho, creio ter a chance de buscar e revelar alguma organicidade, alguma linha mestra da pesquisa e suas conexões com os objetos que têm ocupado a atenção da comunidade em sentido mais amplo, e ao mesmo tempo desvendar para mim mesmo o que andei fazendo nos últimos anos. Já adianto ao leitor que esses trabalhos se referem, de maneira geral, aos efeitos de geometrias não-homogêneas (aperiódicas mlils determinísticas, isto é, sem a presença de elementos de desordemi) sobro o comportamento de modelos que, em geometrias uniformes, apresentan criticalidade.

Mas é claro que o doutoramento não se resume a buscar ininterruptament. novos resultados originais - antes, é uma oportunidade única para estudar em profundidade os resultados obtidos por outros pesquisadores, mesmo que seja para concluir que eles não interessam, ou nem são aplicáveis, do traballo que se está fazendo. Nessa perspectiva, resolvi incluir dois outros pequenos capítulos, à primeira vista um pouco desconectados da temática principal.

Um deles refere-se a um único trabalho (também anexo a esta tese), que já está no prelo, tratando de um modelo desordenado muito simples. A motivação para esse estudo veio de um interesse pela área de vidros estruturais

\footnotetext{
${ }^{2} \mathrm{Na}$ verdade, dois dos artigos anexos foram publicados ainda durante o curso de mestrado, mas preferi incluí-los por completeza e para a própria avaliação de como essa linha de pesquisa foi se transformando.
} 
(que, note-se, não são necessariamente sistemas desordenados!), sobre a qual me detive por certo tempo, na tentativa de me colocar ao par da literatura atıal. Entre as muitas questões intrigantes que nos são sugeridas pelos sistemas vitreos, sobressai a que diz respeito à origem das chamadas anomalias dinâmicas, que correspondem, de modo vago, a evoluções num espaço de fases que tem uma paisagem complicada. Ou seja, o problema aqui se transfere lo estudo das não-homogeneidades geométricas, e suas conseqüências, para a questão de não-homogeneidades no tempo (a quebra da simetria por transla(̧̧̃es temporais), cujas conseqüências sistemáticas são as próprias assinaturas da dinâmica vitrea: envelhecimento, não-ergodicidade, quebra de relações de flutuação-dissipação. Na verdade, o grande interesse dos pesquisadores dessa área está na compreensão da origem das tais anomalias; isto porque, diferentementc do caso espacial, em que a quebra de simetria de translação pode ser incorporada estruturalmente aos modelos de maneira natural (através de aperiodicidade ou desordem), é pouco natural formular uma dinâmica que nā̃o seja simétrica por translações no tempo; ou seja, não é razoável, do ponto cle vista da descrição do fenômeno físico, já começar com um modelo dinamicamente heterogêneo - ele tem de ficar assim como resultado de alguma (aracterística mais básica de sua estrutura.

Contudo, um fato conhecido é que, em certos casos, uma das consequiências da desordem espacial é a produção de uma dinâmica complexa no espaço de fases. Assim, podemos pressentir uma íntima conexão formal entre o problema das heterogeneidades dinâmicas em vidros estruturais, e a dinâmica complexa apresentada por sistemas espacialmente desordenados. $\vec{E}$ neste ponto que o modelo desordenado muito simples a que me referi acima entra (aliás, temos a esperança de que entre:..) no quadro. De todo modo, note-se (que esse capítulo pretende apenas registrar muito sucintamente o resultado lo meu esforço para aprender alguma coisa sobre todas essas questôes, e discutir os modestos resultados originais que publicamos a respeito do dito modelo - que são muito preliminares, a bem da verdade, e ainda não incluem o mais importante, isto é, a própria dinâmica!

Em outro pequeno capítulo que também parece fugir à tônica principal, e que não contém absolutamente nenhum resultado original, pretendi expor um método de tratamento de problemas dinâmicos (conhecido como método de Martin-Siggia-Rose, ou MSR) cujo estudo demandou um longo tempo, e que acabou não tendo a aplicação inicialmente prevista (nem gerando uma publicação). Ainda assim, pareceu-me muito útil redigir uma exposição simples dos rudimentos dessa técnica, até mesmo porque ao tentar aprendê-la fez falta exatamente isso. Não encontrei, nem na literatura internacional nem na brasileira, qualquer "tutorial" para os recém-chegados que desejam aprender o MSR mas não têm grande familiaridade com técnicas de teoria 
de campos, integrais funcionais, ou cálculo estocástico, e sim com a mecânica estatística mais tradicional. Assim, vejo esse capítulo como registro de uma parte importante dos estudos (pelo tempo dedicado e pela amplidão das ferramentas que tive de ao menos começar a reconhecer), e também como uma modestíssima "contribuição didática", que procura dar uma introdução aos rudimentos do MSR, despertando num possivel leitor o desejo de estudar mais detidamente a questão.

A aparente falta de unidade entre esses dois pequenos capítulos, (que consistem fundamentalmente de sinteses bastante resumidas da literatura (com as minhas escolhas particulares de ênfase e importância, é claro), c o capítulo principal, que avalia meus resultados de pesquisa propriamente ditos, leva-nos à questão de qual é a tese mesma que está sendo aqui defendida. Parece-me um hábito importante, que corre o risco de ser esquecilo. ter alguma tese a defender quando se está escrevendo um trabalho desta natureza. Infelizmente, muitas vezes ocorre que não se descobre claramente cual é a tese proposta, talvez pela sua ausência, talvez por ficar soterrada sob espessas camadas de cálculos complicados, que parecem ter como fim a sua própria realização.

Pois bem, assumindo os riscos, digo que minha proposição (pouco original. devo admitir) é que a introdução de não-homogeneidades em modelos que, na ausência delas, apresentam criticalidade, produz resultados que podem ser (genericamente) submetidos a classificações universais, seja do ponto de vista da própria criticalidade, seja do comportamento dinâmico. Isto é, perturbações nas simetrias de translação (como é o caso de sistemas estruturalmente aperiódicos ou desordenados) têm resultados que são em certo sentido provisíveis - ou classificáveis, talvez seja melhor dizer. Todos os problemas apresentados neste trabalho se referem, em maior ou menor grau, creio cu. a tentativas de estabelecer algum tipo de universalidade no comportamento de sistemas desse tipo. E a aparente desconexão entre os capítulos se resolvo quando notamos que todos eles giram em torno do único problema: como sistematizar os possiveis efeitos das não-homogeneidades sobre as teorias que descrevem os sistemas em questão. Assim, de início tratamos os sistemas aperiódicos determinísticos, em que uma descrição completa da estrutura dos fluxos do grupo de renormalização pode ser apresentada, e classificações universais são explicitamente possíveis; daí um sistema desordenado muito simples, cuja termodinâmica também é completamente calculável, para 0 qual ainda pretendemos realizar um estudo da dinâmica, na esperança de encontrar marcas da evolução complexa que parece sempre estar associada a modelos dessa natureza (ou seja, universalmente presente); e, por fim. apresentamos os rudimentos de um método que foi criado essencialmente para permitir o cálculo de funções de correlação e resposta (dependentes do 
tempo) em modelos estatísticos, mas que acaba permitindo uma primeira compreensão da origem da dinâmica complexa de sistemas espacialmente desordenados.

Também sou da opinião que, às vezes, modelos altamente artificiais, que podern ser estudados com métodos muito simples, são capazes de fornecer informações interessantes sobre a estrutura da teoria que os descreve (quando uão sobre os próprios fenômenos). Pelo menos essa é a experiência que tive cm grande parte das minhas pesquisas nos últimos anos, e que intento transmitir para o leitor nas próximas páginas. É claro que há modelos complicados que são muito importantes (especialmente quando o objetivo é a compreensão quantitativamente precisa de aspectos da própria natureza), bem como métodos matemáticos muito difíceis, mas também muito relevantes. No caso clesses últimos tcmos, por exemplo, o árduo campo de sistemas exatamente integráveis em mecânica estatística, que costuma lidar com modelos muito simples e artificiais, mas com técnicas incrivelmente difíceis, que tem nos ensinado coisas profundas sobre a teoria - coisas tão importantes quanto o que aprendemos sobre a natureza quando estudamos modelos mais "aplicáveis", como o de Ising, com quaisquer métodos. Eu diria que alguns modelos têm a boa sorte (ou a boa intuição de seus propositores) de capturar os aspectos essenciais de um fenômeno físico; outros têm a sorte também auspiciosa de capturar os aspectos essenciais da própria teoria.

Creio que a minha tese diz respeito muito mais ao potencial que a teoria possui para desvelar comportamentos universais, usando modelos e métodos simples. do que sobre a verdadeira presença dessas universalidades em sistemas naturais, ou em modelos caoncretamente aplicáveis à descrição de fcnomenos específicos. No caso dos sistemas aperiódicos, a interpelação que se faz à teoria é a respeito de sua capacidade de classificar modelos em que abrimos mão de uma das hipóteses tradicionais (a simetria de translação); no caso dos sistemas desordenados, a interpelação também toca na questão da universalidade: até que ponto a dinâmica complexa está universalmente presente em modelos com desordem? Isto é, qual seria o "modelo mínimo" necessário para produzi-la? Não é minha opinião que questionar a teoria a respeito de suas próprias capacidades seja um desvio da "verdadeira" tarefa do físico teórico - que seria, para alguns, a compreensão dos fenômenos naturais referenciados por seu discurso, que é a teoria. O estudo desse próprio discurso, de suas regras e práticas, de suas "estruturas gramaticais", também é digno de nossa atenção, porque revela algo sobre nós mesmos e sobre a construção e as condições de produção e validade de nossas teorias científicas - uma tarefa tão elevada quanto o estudo das coisas da natureza, e tão adequada ao filósofo quanto, por que não, ao cientista praticante. 



\section{Capítulo 1}

\section{Considerações sobre modelos aperiódicos}

Neste Capítulo, que constitui o centro do trabalho, pretendemos apresentar ao leitor uma análise - ou melhor, uma síntese - das pesquisas que realizamos com vistas a entender os efeitos da aperiodicidade sobre o comportamento crítico de modelos da mecânica estatística. Antes de passarmos à descrição dos resultados contidos nos artigos anexos, entretanto, parece-nos ser útil apresentar alguns conceitos fundamentais que lá são descritos muito sucintamente, como convém a trabalhos daquela natureza, mas que devem ser mais detalhados aqui, para a conveniência do leitor ${ }^{1}$. Assim, primeiramente discutiremos a idéia de aperiodicidade e as técnicas mais simples que permitem a criação de estruturas matemáticas aperiódicas, bem como a maneira mais usual de quantificar o "grau de aperiodicidade" de tais estruturas. A seguir, indicamos como associar essas estruturas a modelos estatísticos simples, (uebrando sua invariância translacional (uniformidade), e apresentamos um critério heurístico geral para avaliar os efeitos dessa quebra de simetria sobre as propriedades críticas de tais sistemas. Discutimos brevemente, então, a idéia fundamental de universalidade em fenômenos críticos e, enfim, passamos a comentar os resultados exatos que obtivemos para diversos modelos diferentes, que nos permitiram entender em detalhes como a aperiodicidade pode ser capaz de alterar seus comportamentos críticos, através de profundas mudanças da topologia dos fluxos do grupo de renormalização (que é a ferramenta básica de todos os nossos estudos), mas ainda assim permitindo classificaçôes universais muito simples.

\footnotetext{
${ }^{1}$ Convém registrar que nossa dissertação de mestrado [Haddad (1999)] apresenta com grande detalhe os conceitos de que nos ocuparemos neste Capítulo, e também toda a tếcnica de grupo de renormalização e análise de energia livre que utilizamos em diversos artigos (inclusive aqueles publicados depois dessa dissertação, que são maioria).
} 


\subsection{Por que se importar com aperiodicidade?}

Antes de mais nada, cumpre explicar o que entendemos por aperiodicidlade. para daí justificar nosso interesse. Alguns exemplos podem anxiliar nessia tarefa; consideremos, primeiramente, uma longa cadeia do massas o molas: imaginemos que há dois valores possiveis para as massas, ou duas diferentess constantes elásticas para as molas. Podemos distribuir as massas (ou alternativamente as molas) de modo periódico: alternando um tipo com outro. ou duas de um tipo com uma de outro, ou seis de um tipo e quatro de outro. ou qualquer outra célula básica, contanto que a configuração se repita inclefinidamente. Mas poderíamos também ir distribuindo os dois tipos possíveis de massas ou molas sem jamais formar uma célula básica de repetição, do modo a quebrar a invariância translacional do sistema. Lma mancira de fazer isso é escolher a massa que ocupará cada posição (ou a constante clástica de cada mola) através de um sorteio, em que cada valor possível ocorre com uma probabilidade determinada. Mas será possível encontrar uma mancila de escolher o valor da massa em cada posição de mancira completamente determinística, sem produzir com isso uma estrutura periódica?

Antes de responder a essa pergunta (afirmativamente!), e, tão importantc quanto isso, antes de entender qual é a razão de fazê-la, podemos exemplificar com uma outra situação mais próxima do que será tratado nestas páginas. Imaginemos uma cadeia clássica de spins de Ising, com hamiltoniano dado por

$$
\mathcal{H}=-\sum_{i} J_{i} \sigma_{i} \sigma_{i+1}-\sum_{i} H_{i} \sigma_{i},
$$

em que $\sigma_{i}= \pm 1$ para qualquer sítio $i=1,2,3 \ldots$ da cadeia. Os acoplanentos $J_{i}$ ou os campos $H_{i}$ (ou ambos) assumem valores num conjunto finito; podkmos ter, por exemplo, dois valores possíveis para a constante de troca, $J_{1} \mathrm{e} . J_{2}$. e analogamente para o campo magnético. Cada ligação da rede pode então estar associada a um dos dois valores de $J$ (ou cada sítio pode estar sujeito a um dos campos), e essa associação pode ser feita de modo não-periódico. sem repetição de células primitivas. Sabemos quão usual é em mecânica estatística considerar problemas em que o valor de uma grandeza desse tipo é escolhido aleatoriamente, conforme uma distribuição de probabilidades: nesse caso, evidentemente a simetria translacional é quebrada. Novamentc. indagamos se é possível fazer isso de modo totalmente determinístico.

Mas por que essa insistência em aperiodicidade sem desordem? Uma das lições mais fundamentais da física experimental do estado sólido é que a regra, e não a exceção, é que a natureza (e mesmo nosso engenho) não produz materiais perfeitamente homogêneos - sempre há uma certa desordem microscópica em qualquer sistema real. Aprendemos também que, en 
algumas situações, essa desordem acaba por se mostrar irrelevante do ponto le vista teórico: o comportamento previsto para o sistema (e confirmado no laboratório, dentro de inúmcros limites) é o mesmo que se obtém fazendo os cálculos sem considerá-la. Em outros casos, somente ao se levar em conta esse fator é que a teoria é capaz de produzir resultados "razoáveis". Mas então cssa argumentação parece levar a um corolário oposto ao que esperávamos: o bom teórico deve se preocupar com os efeitos da introdução de desordem cm seus modelos, pois às vezes ela pode ser relevante e explicar por que seus resultados estão em discrepância com o laboratório (visto que neste último cla está sempre presente); às vezes ela não é necessária, e tanto melhor; e 6́ claro que em outras vezes mesmo o próprio modelo pode não ser muito bom, ou as aproximações envolvidas nos cálculos - não no modelo - é que são muito radicais, e muitos outros fatores. Seja como for, parece não haver razão para o estudioso da natureza importar-se com aquilo que descrevemos acima, a tal aperiodicidade determinística.

Não mesmo? O fato é que, na empreitada teórica, ao tentar descrever com precisão o mundo natural e prever seu comportamento, deparamos com lificuldades técnicas de enorme magnitude (para não falar nas dificuldades (onceituais). No caso em questão, talvez baste escrevermos "vidros de spin" para que o leitor com alguma familiaridade com física estatística e do estado sólido entenda o que queremos dizer. Há trinta anos da compreensão de que a desordem é um fator relevante nesses sistemas, e deve ser incluída explicitamente em qualquer modelo, nenhuma das teorias importantes (e mutuamente excludentes) produziu uma previsão que permita colocá-la à prova (lefinitivamente no laboratório, e o debate segue em frente [cf., a esse respeito, Nordblad (2004)], seja a respeito da natureza do estado fundamental, seja a rcspeito clas características da região de escala da transição. As dificuldades matemáticas envolvidas na mecânica estatística de sistemas desordenados costumam ser enormes, e podem até parecer proibitivas. Admitindo-se que eles sejam deformações (no sentido matemático) dos sistemas homogêneos, pode-se recorrer a teorias de perturbação; mas em muitos casos parece que i introdução de desordem num modelo gera fenômenos não-perturbativos importantes, que não estão de modo algum suavemente conectados com os resultados para o sistema puro [Feldman (2002)].

Como exemplo concreto dos problemas da análise perturbativa, temos o importante e notável caso do modelo de Ising (ferromagnético) num campo magnético aleatório. Em todas as ordens de teoria de perturbação, é possível provar [Parisi e Sourlas (1979)] que os expoentes críticos desse sistema, em $d$ dimensões, correspondem aos do modelo uniforme em $d-2$ dimensões (a chamada redução dimensional) - o que implica, de pronto, que a dimensão crítica inferior é três. Isso contradiz o famoso argumento heurístico de Imry 
e Ma (1975), segundo o qual a dimensão crítica inferior deveria ser dois: mas, com efeito, um resultado exato (e não-perturbativo) de Imbrie (1984) vindicou Imry e Ma, e tornou inevitável a conclusão de que deve ocorrer uma falha grave da teoria de perturbação, que Parisi e Sourlas (2002) creditam ì formação de um estado ligado na teoria de campos subjacente ao modkelo de: Ising no campo aleatório (de modo que o estado de "vácuo" sobre o (qual se aplica a teoria de perturbação não é verdadeiro).

Apenas os comentários do parágrafo anterior, que não são nada conjecturais, e se aplicam a um dos modelos mais importantes na teoria estatística de sistemas desordenados, já nos mostram os complicados problemas que assolam o estudioso dessa área. Mas nesse momento ocorre uma questão muito natural: será que não há sistemas de algum modo "parecidos" com eless o mais propícios à análise teórica? Talvez até mesmo modelos sem correspontência no mundo experimental, contanto que, ainda que indiretamente, nos revelem alguma coisa sobre o funcionamento da teoria, com a possibilidade de postsriormente esclarecer como ela é afetada pela desordem (esta sim importantc do ponto de vista da conexão com o mundo exterior!).

E precisamente neste ponto entram em cena nossas estruturas aperióclicas determinísticas. A esperança (que será confirmada, como veremos) é que elas se prestem a análises não-perturbativas simples e possivelmente exatas, que permitam uma compreensão completa de qual é o mecanismo pelo qual sua característica mais importante afeta a criticalidade de um sistema. Qual é essa "característica mais importante"? A quebra de simetria de translação, e aqui finalmente fazemos a conexão com os sistemas desordenados. De um ponto de vista "fundamental", é inescapável considerarmos que quaisquer quo sejam os efeitos da desordem sobre um sistema, eles devem estar rolacioniados ao fato básico de ela quebrar uma simetria importante; om nosso caso. queremos apenas quebrar essa simetria de modo mais controlado, mas aincla assim esperamos encontrar marcas de seus efeitos essenciais e a cstrutura básica pela qual essa quebra pode afetar o sistema.

Feita essa longa justificativa de qual o interesse que temos pelo estudo clos efeitos dessa ainda indefinida aperiodicidade determinística (um interesse que pode ser sintetizado na fórmula: estudar, de maneira bem controladla. os efeitos da quebra de simetria translacional e seus mecanismos de atuação em uma classe de cenários para a criticalidade), cumpre agora explicar como ela pode ser produzida e como analisar seus efeitos. Antes, vale a pena dar alguma explicação ao leitor que pode estar se perguntando por que não mencionamos que existem na natureza materiais aperiódicos não-desordenados. De fato, a importante descoberta dos quase-cristais [Shechtman et. al. (1984)] abriu uma enorme nova área de pesquisa, especialmente para os cristalógrafos, que se viram com a tarefa de explicar a existência e a estabilidade de fases com 
simetrias proibidas pela teoria tradicional (simetrias proibidas exatamente porque não podem coexistir com ordem translacional de longo alcance, daí a aperiodicidade dos quase-cristais). Dois fatores, no entanto, tornam a relação de nosso trabalho com esses sistemas remota, na melhor das hipóteses: primeiro, o tipo de aperiodicidade que vamos aplicar aos modelos que serão rstudados não tem qualquer semelhança com a aperiodicidade gerada pelas simetrias quase-cristalográficas verdadeiras; segundo, e mais importante, não parece haver qualquer evidência de fenômenos críticos em quase-cristais, c nosso interesse é explicitamente o estudo dos efeitos da aperiodicidade sobre tais fenômenos; mais que isso, o problema específico do magnetismo em (quase-cristais muito provavelmente envolve elétrons itinerantes, visto que a maioria deles constitui-se de ligas de metais de transição, e nossos modelos são estritamente localizados.

\subsection{A matemática da aperiodicidade (brevís- sima introdução)}

A criação de uma estrutura aperiódica pelo chamado método das regras de substituição é muito simples, familiar aos matemáticos há décadas, e foi o que empregamos em todos os nossos estudos. Um exemplo concreto ilustra a essência do procedimento. Imaginemos que dispomos de dois tipos de objetos (as massas de valores diferentes, como acima, por exemplo), que possam ser identificados pelas letras $A$ e $B$. Queremos fazer uma seqüência infinita de $A$ 's e $B$ 's dispostos lado a lado, sem a repetição periódica de neuhum agrupamento básico de letras. Isto é, queremos montar uma sucessão (lo tipo $A B A+A A B A A B A A B \ldots$ (suponhamos que esta seqüência seja realinente aperiódica, por enquanto!), e não algo evidentemente periódico como $A B B A B B A B B A B B \ldots$ Uma maneira de fazer isso, que se mostra muito eficaz, ć criar uma regra de substituição das letras $A$ e $B$, como, por exemplo, $A \rightarrow A B, B \rightarrow A$. A regra funciona da seguinte maneira: dada a letra $A$, nós a substituímos pelo par $A B$; este, por sua vez, é substituído por $A B A$ (que corresponde a pôr $A B$ no lugar da letra $A$, e $A$ no lugar do $B$ ); novamente, cada letra de $A B A$ é substituída segundo a regra, de modo que se obtém $A B A A B$, e assim sucessivamente. A operação pode ser esquematizada como

$$
A \rightarrow A B \rightarrow A B A \rightarrow A B A A B \rightarrow A B A A B A B A \rightarrow \ldots
$$

Cada seqüência de letras que vai sendo sucessivamente obtida é uma geração do processo iterativo de aplicação da regra. Aplicando-se infinitamente a lei de substituição, deveremos obter uma seqüencia infinita de $A$ 's e $B$ 's. 
Notemos que o processo é completamente deterministico, como desejávamos: sabemos perfeitamente qual é a letra que ocupa cada posição na seqüencia. E o importante é que se pode demonstrar rigorosamente que essa seqüência é aperiódica [Queffélec (1987)], isto é, não há nenhuma célula básica que s' repete, mesmo que imaginássemos uma célula muito grande. Além disso. demonstra-se que essa sequiência infinita é um ponto fixo dla substituição o que implica sua auto-similaridade, isto é, uma simetria de escala realizadla pela aplicação inversa da regra. Uma classe muito grande de regras do substituição, envolvendo inclusive "alfabetos" com mais letras, compartillia clessas propriedades essenciais - a geração de seqüências infinitas verdadleirument aperiódicas e auto-similares. Qualquer análise de grupo de renormalização no espaço real de modelos estatísticos com aperiodicidade gerada por regrass de substituição está baseada nessa auto-similaridade.

Entre as regras binárias (isto é, envolvendo apenas duas letras). clestacamos a do exemplo anterior, conhecida como regra de Fibonacci. a ds: Thue-Norse, que se escreve $A \rightarrow A B, B \rightarrow B A$, a regra de dobramento do período, representada pela substituição $A \rightarrow A B, B \rightarrow A A$, e a regra dr triplicação de período, dada por $A \rightarrow A B B, A \rightarrow A A A$. Uina regra năobinária que também estudamos em detalhes é a de Rudin-Shapiro, dada por $A \rightarrow A C, B \rightarrow D C, C \rightarrow A B, D \rightarrow D B$. Pinho (1998) analisou com rigor e generalidade as propriedades de muitas outras regras desse tipo, de modo que evitaremos a formalização exaustiva que seria necessária se quiséssemos fornecer demonstrações de aperiodicidade e auto-similaridade.

Sem pretender formalidade, apenas consideremos algumas características gerais importantes das regras de substituição. Por simplicidade, tomaremos regras binárias, escrevendo-as na forma geral

$$
\sigma:\left\{\begin{array}{l}
A \rightarrow A^{\alpha} B^{\beta} \\
B \rightarrow A^{\gamma} B^{\delta}
\end{array}\right.
$$

com $\alpha, \beta, \gamma$ e $\delta$ inteiros não-negativos, e não simultaneamente mulos. Essia notação indica que na regra $\sigma$ a letra $A$ deve ser substituída por uma palavra básica com $\alpha$ letras $A$ e $\beta$ letras $B$, e analogamente para a palavra que substitui a letra $B$; não nos importamos com a ordem exata em que as letras aparecem nas substituições, mas apenas com sua quantidade ${ }^{2}$. Supomos ainda que $\sigma$ resulta numa palavra infinita auto-similar, isto é, um ponto fixo da regra. Consideremos então os números $N_{n}^{A}$ e $N_{n}^{B}$ de letras $A$ e $B$ na sequiência formada na geração $n$, respectivamente; é simples perceber que

${ }^{2} \bar{E}$ bom registrar que a ordem das letras tem grande importância nas demonstraçóes de aperiodicidade e auto-similaridade da palavra infinita; apenas para nossos propósitos genéricos é que não precisamos considerar a ordem exata. 
des devem ser dados por

$$
\left(\begin{array}{c}
N_{n}^{A} \\
N_{n}^{B}
\end{array}\right)=\left(\begin{array}{ll}
\alpha & \gamma \\
\beta & \delta
\end{array}\right)\left(\begin{array}{c}
N_{n-1}^{A} \\
N_{n-1}^{B}
\end{array}\right)
$$

Definimos então, para qualquer regra do tipo (1.1), a matriz de substituição

$$
\mathbf{M}=\left(\begin{array}{ll}
\alpha & \gamma \\
\beta & \delta
\end{array}\right)
$$

Se começarmos o processo de aplicação da regra com a letra $A$, podemos mostrar que

$$
\left(\begin{array}{c}
N_{n}^{A} \\
N_{n}^{B}
\end{array}\right)=\mathrm{M}^{n}\left(\begin{array}{l}
1 \\
0
\end{array}\right)
$$

Le fato, a demonstração segue por indução finita e é óbvia a partir da definição lo. M. dada pela Eq.(1.2). Vale uma relação análoga para o processo iniciado com a letra $B$. Por simplicidade, admitiremos que a letra inicial será sempre A; o leitor não terá dificuldade em adaptar os resultados para o outro caso.

Se $\mathrm{M}$ for uma matriz primitiva (isto é, se os elementos de alguma potência de $\mathrm{M}$ forem estritamente positivos), o teorema de Perron-Frobenius garante um ordenamento dos seus autovalores, isto é, assegura que eles obedecem as desigualdades estritas $\lambda_{1}>1$ e $\lambda_{1}>\left|\lambda_{2}\right|$. Evidentemente, há muitas escolhas "razoáveis" de $\alpha, \beta, \gamma$ e $\delta$ que resultam numa matriz de substituição primitiva, de modo que vale esse ordenamento dos autovalores. Esse fato t.erá conseqüências que logo poderemos compreender.

Agora podemos introduzir o conceito de freqüencia (ou densidade) de letras a a b na palavra infinita, isto é,

$$
\rho_{A} \equiv \lim _{n \rightarrow \infty} \frac{N_{n}^{A}}{N_{n}}
$$

e

$$
\rho_{B} \equiv \lim _{n \rightarrow \infty} \frac{N_{n}^{B}}{N_{n}}
$$

com $N_{n}=N_{n}^{A}+N_{n}^{B}$ representando o número total de letras na geração $n$. Mostra-se que [Haddad (1999)]

$$
\rho_{A}=\frac{\lambda_{1}-\delta}{\lambda_{1}+\beta-\delta}
$$

bem como

$$
\rho_{B}=\frac{\beta}{\lambda_{1}+\beta-\delta}
$$


É imediato que $\rho_{A}+\rho_{B}=1$, como esperado. Esses resultados são muito interessantes, pois na realidade o vetor

$$
\mathbf{u}_{1}=\left(\begin{array}{c}
\rho_{A} \\
\rho_{B}
\end{array}\right)
$$

é exatamente o autovetor da matriz de substituição $\mathrm{M}$ associadlo ao maior autovalor $\lambda_{1}$. Além disso, também vale a relação

$$
\lim _{n \rightarrow \infty} \frac{N_{n}}{N_{n-1}}=\lambda_{1} .
$$

Assim, chegamos a uma primeira conclusão importante: o maior altovalor da matriz de substituição está associado, assintoticamente, à razão cntre os "comprimentos" das palavras que vão sendo geradas conforme a substituição é aplicada. Poderíamos escrever

$$
N_{n} \sim \lambda_{1}^{n} .
$$

Pinho (1998) mostrou que essa relação é exata, em qualquer geração, para sequiências de substituição tais que $\alpha+\beta=\gamma+\delta$. Com efeito, nosse caso cada letra é levada para palavras com o mesmo comprimento, $(\alpha+\beta)$, e, no caso, $\lambda_{1}$ é precisamente esse número inteiro.

Agora podemos nos aproximar do conceito de futuação geométrica cle uma estrutura aperiódica gerada por uma regra de substituição. De posse cla idéia de freqüência de uma letra na palavra infinita, e das expressōes $(1 . t)$ e (1.5), podemos supor que um conceito razoável de flutuação seja a difcrença entre o número real de letras $A$ ou $B$ numa certa geraçióo e o número (nu seria esperado se as frequiências das letras fossem sempre iguais às cla palarra infinita. Isto é, a flutuação deve indicar o quanto uma certa geração sc: desvia do comportamento esperado. Podemos definir, assim, a flutuação $y_{n}^{\prime}$ no número de $A$ 's na geração $n$ como

$$
g_{n}^{A}=N_{n}^{A}-\rho_{\mathcal{A}} N_{n} .
$$

Na verdade, tanto faz pensar em $g_{n}^{A}$ ou em seu análogo $g_{n}^{B}$, pois, cono $\rho_{A}+$ $\rho_{B}=1$ e $N_{n}^{A}+N_{n}^{B}=N_{n}$, é evidente que $g_{n}^{A}=-g_{n}^{B}$, de maneira que escreveremos simplesmente $g_{n}$. Já foi demonstrado [Haddad (1999)| que vale a relação exata

$$
g_{n}=\rho_{B} \lambda_{2}^{n},
$$

um resultado que pode ser escrito também na forma

$$
\left|g_{n}\right| \sim\left|\lambda_{2}\right|^{n} .
$$


Uma maneira elegante e poderosa de escrever este resultado a respeito da flutuação consiste em combiná-lo com a Eq.(1.6), para obter

$$
\left|g_{n}\right| \sim N_{n}^{\omega},
$$

onde definimos o chamado expoente das futuações geométricas,

$$
\omega=\frac{\log \left|\lambda_{2}\right|}{\log \lambda_{1}} .
$$

Esse número tem um papel central em nossos resultados subseqüentes. Note que se $\omega>0$, a flutuação tem um caráter ilimitado; de certa forma, a estrutura aperiódica fica cada vez mais distante do comportamento médio que 'sperávamos conforme a regra de substituição vai sendo aplicada. Se $\omega<0$, por ontro lado, a flutuação é de algum modo limitada. O caso $\omega=0$ é mais (c)licado, marginal, e merece atenção especial, pois é uma situação em que a ordem com que as letras aparecem tem suma importância.

Notemos que o sinal de $\omega$ está diretamente relacionado com os autovalores (la matriz de substituição. Como já afirmamos anteriormente, essa matriz deve, em geral, possuir um autovalor $\lambda_{1}$ real positivo maior que a unidade e maior que o módulo do outro autovalor, $\lambda_{2}$ (que esperamos ser real também). A definição de $\omega$, Eq.(1.9), mostra que somente o caso $\left|\lambda_{2}\right|<1$ corresponde a uma estrutura com flutuação limitada.

Podemos olhar para esse conceito de flutuação de uma outra maneira, de modo a tornar mais convincente o uso do adjetivo "geométricas". Generalizando a definição de flutuação introduzida acima, escrevamos [Grimm e Baake (1097)|

$$
g(M)=N^{A}(M)-\rho_{A} M,
$$

onde $N^{-1}(M)$ representa o número de letras $A$ na palavra que é obtida pelo truncamento da seqüência infinita em sua $M$-ésima letra. Imaginemos agora, como Bombieri e Taylor (1986), que a letra $A$ esteja associada a um comprimento $\ell_{A}, \circ B$ a um comprimento $\ell_{B}$. A partir de uma palavra infinita aperiódica, podemos construir uma rede unidimensional com sítios localizados em posições $x_{M}$ tais que

$$
x_{M}=N^{A}(M) \ell_{A}+N^{B}(M) \ell_{B},
$$

onde $N^{A}(M)$ é o número de $A$ 's no truncamento da palavra infinita na $M$ ésima posição, como definido acima, e analogamente $N^{B}(M)$. Podemos então clefinir um espaçamento médio da rede, dado por

$$
\ell=\rho_{A} \ell_{A}+\rho_{B} \ell_{B} \text {. }
$$


Agora a definição de flutuação que foi apresentada ganha um sentido verdadeiramente geométrico. Com efeito, a posição esperada do sítio $M$ scria simplesmente $x_{M}=M \ell$; a flutuação $g(M)$ está então claramente relacionalı̀ com o desvio da posição real, dada pela Eq.(1.10), em relação a esse valor esperado. No caso de flutuaçöes ilimitadas, a idéia de uma rede média, da qual a rede aperiódica é apenas uma pequena perturbação, perdo o sentido. mesmo que os comprimentos $\ell_{A}$ e $\ell_{B}$ sejam parecidos.

Esperamos que tenha ficado claro o conceito de flutuação geométrica para estruturas aperiódicas unidimensionais, geradas por regras de substituição, c o papel preponderante do expoente $\omega$ na classificação das flutuaçōes. Regras não-binárias, como a de Rudin-Shapiro, descrita no item anterior: também se prestam à análise de flutuações baseada na matriz de substituição (basta considerar os dois maiores autovalores, dentre todos os possiveis). Para estruturas aperiódicas em maiores dimensões, que não podem em geral ser formadas a partir de regras de substituição, existe uma conceitıação equivalente: de flutuação geométrica; na próxima seção, quando falarmos do chamaclo critério de Luck (que avalia o efeito da aperiodicidade sobre a termodinâmica de modelos estatísticos), comentaremos a possibilidade de definir um expoente de flutuação de modo geral, através de hipóteses de escala sobre certas propriedades espaciais dos sistemas em estudo. Antes disso, porém, devemos dizer como aplicar o formalismo que apresentamos a modelos da mecânica estatística em redes.

\subsection{Modelos estatísticos aperiódicos}

\subsubsection{Generalidades}

Como quebrar a simetria de translação de um modelo estatístico na rede usando esse formalismo? Consideremos novamente o problema mais simples, isto é, a cadeia de spins de Ising, cujo hamiltoniano é dado por

$$
\mathcal{H}=-\sum_{i} J_{i} \sigma_{i} \sigma_{i+1}-\sum_{i} H_{i} \sigma_{i} .
$$

O primeiro exemplo específico de introdução da aperiodicidade nesse modelo usando uma regra de substituição (Fibonacci) foi apresentado por Achiam et al. (1986). Nesse caso, consideram-se os campos $H_{i}$ uniformes, isto é, iguais para qualquer $i$, e distribuem-se os acoplamentos $J_{i}$, que podem assumir um entre dois possiveis valores, $J_{A}$ e $J_{B}$, segundo a seqüência de $A$ 's e $B$ 's nia palavra infinita gerada pela regra de Fibonacci; lembrando que essa palavra é $A B A A B A B A A B A A B \ldots$, basta substituir cada $A$ por um $J_{.1}$ e cadla $B$ 


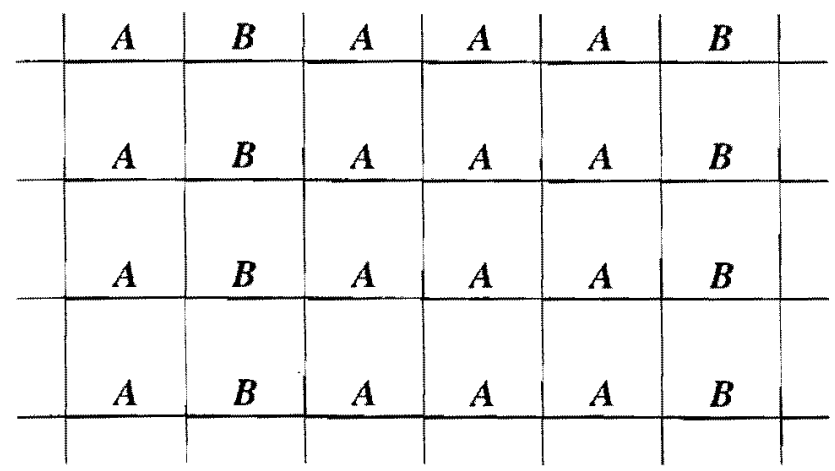

Figura 1.1. Exemplo de aperiodicidade em camadas numa rede quadrada bidimensional.

por um $J_{B 3}$. de modo a se obter uma cadeia de spins com acoplamentos uscilanclo aperiodicamente entre dois valores possíveis. O procedimento é análogo para qualquer outra regra de substituição: basta associar a cada letra cla palavra infinita aperiódica um valor diferente da constante de troca. . vo caso de regras binárias, que são as mais comuns, teremos evidentemente duas possíveis constantes de troca, que podem até mesmo ter sinal oposto, gerando interessantes efeitos de competição, visíveis no estado fundamental [Tsunetsugu e Ueda (1987)]. Já se considerou também o caso em que os acoplamentos são uniformes, e o campo magnético tem seu valor em cada sítio escolhido segundo as letras de uma palavra infinita aperiódica [Luck (1987)|.

A maneira mais natural e imediata de aplicar esse formalismo a um sistoma numa rede bidimensional é considerar um modelo em camadas: na rede ruadradia. por exemplo, cada linha pode ser vista como uma cadeia com distribuição aperiódica de acoplamentos, segundo alguma regra de substituição previamente escolhida (e idêntica para todas as linhas), enquanto os acoplamentos nas colunas são homogêneos. A Fig. 1.1 ilustra uma construção desse tipo. O hamiltoniano de um tal sistema poderia ser escrito como

$$
\mathcal{H}=-J \sum_{i, j} \sigma_{i, j} \sigma_{i+1, j}-\sum_{i, j} K_{j} \sigma_{i, j} \sigma_{i, j+1} .
$$

Nesse modelo, a constante de acoplamento numa das direções da rede (a vertical, digamos) é uniforme e tem sempre valor $J$; na direção horizontal, o valor do acoplamento $K_{j}$ depende da coluna, $j$, e pode ser escolhido segundo regras aperiódicas [Iglói (1993)]. O interesse desse problema é que ele permite que todo o esquema das regras de substituição, tão adequado para estruturas unidimensionais, seja aplicado a um modelo bidimensional, que é muito mais 
rico. Num limite fortemente anisotrópico, o sistema equivale à cadeia de Ising quântica num campo transverso, com interações aperiódicas |Luck (1993a)|: o que permite a adaptação de muitas técnicas de análise clesenvolvidas par:a esses sistemas; pode-se também estudar esse modelo diretamente. fora (lo limite altamente anisotrópico, através de métodos de aproximações perióclicas sucessivas. Muitos cálculos numéricos e alguns resultados exatos indicanl que se a aperiodicidade é gerada por regras com flutuações geométricas limitadias os expoentes críticos são os da classe de universalidade de Onsagcr; flutuaçôess ilimitadas aparentemente suavizam a transição; o caso marginal conduz ì não-universalidade (isto é, expoentes críticos que dependem do valor clos acoplamentos microscópicos). Resultados rigorosos de Tracy (1988a, 1988b) mostram que as flutuações ilimitadas devem de fato eliminar por completo in criticalidade.

Notemos que um modelo de Ising em camadas, construido de maneira análoga a essa, mas com os acoplamentos horizontais escolhiclos alcatoriamente. com uma distribuição de probabilidades (com probabilidade nula para vialores negativos, bem entendido, para não incluirmos antiferromagnetismo), foi estudado com grande sucesso por McCoy e Wu (1968), que aprescintaram uma notável solução exata. A quebra de invariância translacional (em uma direção) induzida pela desordem tem o interessante efeito de enfraquecer ainda mais a singularidade crítica, tornando-a essencial, com calor específico infinitamente diferenciável (na solução de Onsager para o modelo uniforme a singularidade já é fraca, de caráter logarítmico). Ainda em relação ao modelo de McCoy-Wu, vale notar que ele apresenta o fenômeno de singulariclacles de Griffiths [Griffiths (1969)], que consiste na existência de singularidades essenciais (não-críticas) na magnetização a campo nulo, em temperaturas alsaixo da temperatura crítica do modelo sem desordem, e acima da temperatura crítica do modelo desordenado (que é sempre menor que a primcira). Isso se deve essencialmente à formação de aglomerados de spins em estado quasecrítico, que aproximam arbitrariamente do eixo real os zeros de Lee-Yang da função de partição mesmo acima da temperatura crítica do sistema desordenado. Um pouco ingenuamente, diversos pesquisadores procuraram evidências de singularidades de Griffiths em modelos aperiódicos não-desordenados; naturalmente, nunca foram encontradas, simplesmente porque elas não se devem à característica fundamental que os modelos aperiódicos compartilham com os desordenados, isto é, a quebra de simetria translacional, mas sim à formação de aglomerados de percolação que ocorre nesses últimos, e não $10 s$ primeiros.

Vale a pena dizer também que muitas cadeias quânticas de spins com acoplamentos distribuídos aperiodicamente, segundo regras de substituição, têm sido estudadas com grande sucesso através de diversos métodos /Vieira 
(2004)|. A comparação das propriedades dessas cadeias com suas contrapartidas desordenadas, já largamente analisadas na literatura, leva ao domínio (quântico uma série de consideraçōes que faremos adiante, em torno da noção de universalidade e do papel da quebra de simetria translacional sobre esse conceito.

Podemos neste momento introduzir um conceito útil, relacionado à flutuação dlas constantes de troca de uma cadeia, clássica ou quântica, adaptando o formalismo que desenvolvemos anteriormente. No caso da aperiodicidade implementada através de regras de substituição binárias, em que cada letra está associada a um possível valor da constante, escrevemos o acoplamento médio, $J$, como

$$
J=J_{A} \rho_{A}+J_{B} \rho_{B}
$$

am cue $\rho_{A}$ e $\rho_{B}$ são as densidades de letras $A$ e $B$ na palavra infinita. Truncando essa palavra em sua $M$-ésima letra, é imediato definirmos uma flutuação total nos acoplamentos através de

$$
\Delta J(M)=\left|J_{A} N^{A}(M)+J_{B} N^{B}(M)-J M\right|,
$$

onde $N^{A, B}(M)$ conta o número de $A$ 's ou $B$ 's no truncamento, como antes. Com as técnicas que apresentamos acima, demonstra-se facilmente que, se $M=N_{n}$, para algum $n$ (isto é, se o truncamento corresponde exatamente à n-ésima geração da palavra), deve valer que

$$
\Delta J_{n} \sim\left|\lambda_{2}\right|^{n} \sim N_{n}^{\omega},
$$

com o cxpoente de flutuação $\omega$ definido anteriormente (note que escrevemos $\triangle J_{n}$ nesse caso). Esse resultado é interessante, pois liga diretamente a idéia le flutuação geométrica com a flutuação nas constantes de troca, que é a medida relevante para sistemas magnéticos aperiódicos.

Em cluas dimensões, a aperiodicidade poderia ainda ser aplicada a um modelo de Ising de maneiras mais complicadas, não baseadas no formalismo clas substituições. Uma possibilidade, por exemplo, é considerar estruturas em que a flutuação possui uma natureza topológica mais profunda, como a famosa rede de Penrose, ou diferentes recobrimentos do plano por polígonos em padrões aperiódicos (essas estruturas costumam receber a denominação de tilings, e seu estudo já se tornou uma nova área de pesquisas matemáticas [cf. Kellendonk (1995)]). Nesses casos, ocorre uma flutuação aperiódica do próprio número de coordenação de cada sítio, que, associada à presença de diversos valores possiveis dos acoplamentos, torna o problema muito mais sutil e clelicado [Godrèche et al. (1986)]. Os resultados para o modelo de Ising na rede de Penrose, baseados num esquema aproximado de grupo de 
renormalização, indicam que a classe de universalidade do sistema i a do Onsager.

Nosso interesse, contudo, está nos primeiros exemplos apresentados. isto é, o modelo bidimensional em camadas. Foi neles que se verificou, inequivocamente, que a aperiodicidade gerada por regras de substituição era capaz tle: mudar propriedades críticas usuais, retirando os sistemas das "classes de universalidade uniformes" e destruindo as singularidades críticas (sem contar o caso das flutuações marginais). Mas esse cenário é aparentemente muito pobre: flutuações limitadas não importam, ilimitadas simplesmente destroem a transição - ao menos para o modelo de Ising na rede quadrada com aperiodicidade em camadas. Entretanto, analisando o problema de modo mais geral, inclusive pela ampliação do conceito de flutuação geométrica (tomando-o) independente da existência de uma regra de substituição na origem (la al)eriodicidade), Luck (1993a, 1993b) foi capaz de ampliar bastante esse quadro. incluindo sistemas em dimensões superiores e modelos diferentes do de Ising. $O$ resultado de suas investigações, que passaremos a aprescntar. foi un critério geral para testar a relevância (já usando uma linguagem to grupo di renormalização) da aperiodicidade sobre o comportamento dos nodelos por ela afetados.

\subsubsection{O critério de Luck}

Em sua análise dos efeitos da aperiodicidade sobre as propriedades críticas de modelos estatísticos, Luck baseou-se fortemente num critério devido a Harris (1974), que dava conta da relevância da desordem temperadla sobro modelos ferromagnéticos de spins. A apresentação que Luck faz do critério de Harris é um passo importante em seu próprio raciocinio sobre a aperiodicidade, e vale a pena ser comentada. Consideremos pois um modelo de Ising ferromagnético, na ausência de campo, com hamiltoniano dado por

$$
\mathcal{H}=-\sum_{\langle i, j\rangle} J_{i, j} \sigma_{i} \sigma_{j},
$$

numa rede regular qualquer, de dimensão $d$, em que os $J_{i, j}$ são positivos e restritos a pares de vizinhos mais próximos, e de outro modo arbitrários. O modelo uniforme é aquele para o qual $J_{i, j}=J_{0}$ para qualquer par do vizinhos. Ele deve apresentar uma transição de fases de segunda ordem a uma temperatura crítica $T_{c}$, proporcional a $J_{0}$ (essa hipótese é razoável tendose em vista os muitos resultados já conhecidos, e é fisicamente aceitável). Representaremos a distância do sistema ao ponto crítico pela variável usual. $t=\left(T-T_{c}\right) / T_{c}$, e a região crítica (ou de escala) pela condição $|t|<<1$. 
Suponhamos agora o caso de desordem temperada nos acoplamentos; eles serão do tipo $J_{i, j}=J_{0}\left(1+\epsilon_{i, j}\right)$, com os $\epsilon_{i, j}$ representando variáveis aleatórias independentes e identicamente distribuídas, tais que $\overline{\epsilon_{i, j}}=0$ e $\overline{\epsilon_{i, j}^{2}}=\Delta^{2}$. A largura da distribuição, $\Delta$, deve ser tão pequena quanto se deseje. Para $\Delta=0$, recuperamos o modelo uniforme. Na região crítica, o sistema deve se (lividir em dominios de correlação, com volumes da ordem de $\xi^{d}$, onde $\xi$ é o comprimento de correlação, que obedece a lei de escala usual $\xi \sim|t|^{-\nu_{u}}\left(\nu_{u}\right.$ é o expoente crítico do comprimento de correlação do modelo uniforme). $O$ número de spins correlacionados no domínio é proporcional a esse volume, já que estamos tratando de redes regulares. Na presença de uma pequena desordem, cada domínio de correlação deve ser caracterizado por um acoplamento "típico", $J$, que se desvia do valor médio $J_{0}$ por uma pequena quantidade dada por $\left(J-J_{0}\right) / J_{0} \sim \xi^{-d / 2} \Delta$; isso é razoável se tivermos em mente o teorema contral do limite, que deve se aplicar à distribuição em questão. Na prática, csse acoplamento típico desvia a temperatura efetiva de cada domínio de correlação do valor uniforme, $t$; algumas regiões do sistema podem efetivamente se "desmagnetizar" em conseqüência da flutuação do acoplamento (isto é, podem apresentar uma temperatura efetiva superior à crítica), e a transição de fases pode ser eliminada, ou bastante alterada. Devemos portanto estimar $o$ desvio local da temperatura, $\delta t$, induzido pela flutuação das constantes de troca. Ora, esse desvio deve ser proporcional ao próprio desvio do acoplamento típico, de modo que obtemos $\delta t \sim \xi^{-d / 2} \Delta \sim|t|^{d \nu_{u} / 2} \Delta$ (onde usamos a lei de escala para o comprimento de correlação). A variação de temperatura efetiva devida à desordem será capaz de eliminar a criticalidade original no caso em que $\delta t>>|t|$; podemos avaliar em que condições isso ocorre através la razão

$$
\frac{\delta t}{|t|} \sim|t|^{-1+d \nu_{u} / 2} \Delta
$$

Lembrando a condição $|t|<<1$, vemos que, para $2-d \nu_{u}>0$, os desvios locais tornam-se arbitrariamente grandes e o comportamento crítico deve sofrer mudanças profundas. Se usarmos a relação de hiperescala, $d \nu_{u}=2-\alpha_{u}$, em que $\alpha_{u}$ é o expoente crítico do calor específico do sistema uniforme, válida para $d$ menor que a dimensão crítica superior do modelo, podemos dizer que a alteração na criticalidade ocorre se $\alpha_{u}>0$; se $\alpha_{u}<0$, as flutuações locais na temperatura crítica, devidas à desordem das ligações, não são suficientes para perturbar o sistema; se $\alpha_{u}=0$, o resultado da desordem é imprevisivel nessa aproximação.

Este é o critério de Harris para a relevância da desordem na alteração da criticalidade, na apresentação de Luck. Veja que ele é totalmente baseado em um raciocínio perturbativo, e, com efeito, a variável importante para 
a classificação dos efeitos da desordem é o expoente crítico $a_{11}$ do modelo uniforme que está sendo perturbado por essa mesma desordem. Essa obscrvação é extremamente importante, pois contém a essência do algumentio.). " vai reaparecer na extensão do critério a sistemas aperiódicos que faremos agora.

Suponhamos mais uma vez que estamos estudando um modelo de Ising ferromagnético com hamiltoniano dado pela Eq.(1.13), numa rede regular genérica. A diferença agora é que vamos considerar que as constantes de troca entre primeiros vizinhos, $J_{i, j}$, não são necessariamente aleatórias: basta-nos que possam assumir mais de um valor e que se distribuam aperiodicamente. pelas ligaçōes. A origem dessa aperiodicidade é arbitrária, podendo estar relacionada a qualquer método apresentado na seção anterior. métodos mais gerais ou mesmo à presença de desordem. O importante é que seja possívol caracterizar a intensidade da aperiodicidade por alguma grandeza $J^{\prime}$. análogal à largura da distribuição do caso anterior. Essa grandeza está associada ao desvio dos valores possíveis das constantes de troca em relação a um valor médio, $J_{0}$; não vamos defini-la precisamente, e sua existência faz parte da natureza heuristica do argumento. $O$ valor de $J_{0}$ está novamente relacionado à temperatura crítica, $T_{c}$.

Considere que tomamos uma certa região $\Omega$ da rede, de comprimento característico $L$; ela deve conter um certo número $N_{\Omega}$ de ligações, proporcional ao volume $L^{d}$ da região. A soma das constantes de troca associadas a cadi uma das ligações dessa região, dada por

$$
\Sigma_{\Omega}(J)=\sum_{\langle i, j\rangle \in \Omega} J_{i_{i},},
$$

também deve ter um comportamento do tipo $\Sigma_{\Omega}(J) \sim L^{d}$. A razão $\Sigma_{\Omega}(J) / N_{\Omega 2}$ corresponde ao acoplamento típico na região; quanto maior for a região conlsiderada, mais próximo de $J_{0}$ deve estar esse valor. Agora, no espírito dals considerações que fizemos sobre flutuações em seqüências de substituição. vamos imaginar que a flutuação (de origem geométrica) no acoplamento. obedece a lei de escala

$$
\Delta J=\left|\Sigma_{\Omega}(J)-J_{0} N_{\Omega}\right| \sim L^{d \omega},
$$

onde $\omega$ é um expoente de flutuações geométricas generalizado. Veja que essa é exatamente a definição que apresentamos na Eq.(1.12), para o caso de aperiodicidade gerada por regras de substituição. O que estamos fazendo aqui é simplesmente supor que uma forma semelhante àquela vale de modo geral, através de uma razoável hipótese de escala para as flutuações. 
Agora, suponhamos que estamos na região crítica do modelo uniforme, isto é. $\Delta^{\prime}=0$ e $|t|<<1$. O comprimento de correlação $\xi$, que obedece a lei de escala $\xi \sim|t|^{-\nu_{u}}$, determina um comprimento característico $L$. Uma pequena modulação aperiódica nesse sistema deve ser tal que o desvio induzido no acoplamento típico seja dado por $\left(J-J_{0}\right) / J_{0} \sim \xi^{d(\omega-1)} \Delta^{\prime} \sim|t|^{-d \nu_{u}(\omega-1)} \Delta^{\prime}$. $O$ desvio causado na temperatura efetiva, $\delta t$, terá portanto o mesmo comportamento. Como já fizemos para o critério de Harris, devemos comparar a magnitude desse desvio com a própria distância ao ponto crítico, $|t|$. Resulta, assim, que

$$
\frac{\delta t}{|t|} \sim|t|^{-d \nu_{u}(\omega-1)-1} \Delta^{\prime}
$$

Definindo um expoente de cruzamento $\phi$ como

$$
\phi \equiv 1+d \nu_{u}(\omega-1)
$$

segue da $E_{1 .} .(1.14)$ que, se $\phi>0$, a aperiodicidade deve causar desvios arbitrariamente grandes na temperatura efetiva de cada região de correlação, ( assim destrói ou altera profundamente o comportamento crítico (é o dito (aso relevante). Se $\dot{\phi}<0$, a aperiodicidade não deve ser capaz de mudar as características universais da criticalidade (caso irrelevante), e se $\phi=0$ não podemos prever o que ocorrerá (caso marginal). Eis o critério de Luck, na sua forma mais geral, e, ao mesmo tempo, simples e intuitiva. Com o uso da relação de hiperescala, $d \nu_{u}=2-\alpha_{u}$, que deve valer para todo $d \leq 4$, e da limitação termodinâmica $\alpha \leq 1$ para transições contínuas, podemos enunciar a condição de relevância como

$$
\omega>\omega_{c}=\frac{1-\alpha_{u}}{2-\alpha_{u}}
$$

onde introduzimos um "valor crítico" (ou limiar) do expoente de flutuação, $\omega_{c}$, a partir do qual a aperiodicidade afeta de maneira relevante o sistema.

Veja que em toda essa argumentação estivemos supondo que a aperiodicidade é de algum modo "isotrópica", isto é, perturba o sistema em todas as suas direções. Mas poderíamos considerar casos "anisotrópicos", como os sistemas em camadas, nos quais a aperiodicidade age sobre um número de dimensões, $d_{m}$, menor que a dimensão, $d$ da rede em consideração. $\overrightarrow{\mathrm{E}}$ trivial adaptar o critério de Luck para essa situação, bastando redefinir $\phi$ como $\phi=1+d_{m} \nu_{u}(\omega-1)$.

Imediatamente vemos que o critério está correto para o caso das cadeias (quânticas. Naquele caso, a dimensão é $d=1$, e o expoente crítico do comprimento de correlação é $\nu_{u}=1$, de modo que o critério se reduz simplesmente 
a $\omega>0$ para o caso de aperiodicidade relevante (isto é, flutuaçoes geométricas ilimitadas) e $\omega<0$ para a aperiodicidade irrelevante (que corresponde a flutuações limitadas). O caso $\omega=0$, marginal, corresponde ao caso peculliar de não-universalidade. Isso está em perfeito acordo com os resultados exatos e de extrapolação numérica que citamos anteriormente. Igualmentc para o caso do modelo em camadas, para o qual $\nu_{n}=1 \mathrm{c}$ a apcriodicidarc se distribui ao longo de apenas uma das direções $\left(d_{m}=1\right)$. A novidade clo critério de Luck está em suas previsões para sistemas com aperiodicidade em mais dimensões, ou com um expoente crítico uniforme $\nu_{u} \neq 1$. Torna-se então menos direta a relação entre limitação das flutuações geométricas e stla relevância para a criticalidade; de fato, pode haver situaçōes em que mesmo para $\omega>0$ o sistema não sai da classe de universalidade uniforme.

Alguns comentários finais sobre o critério de Luck são necessários. Enımeremos, em primeiro lugar, em que condições ele deve valer: o morlelo deve ser ferromagnético, as interações têm de ter curto alcance, o sistema unifornı" (na ausência de aperiodicidade) deve ter um ponto crítico à temperatura tinita e a rede deve ser regular. Essas hipóteses são razoavelmente restritivas. e fazem com que cada caso deva ser estudado com cuidado. Em scgundo lugar, o critério é incapaz de prever o comportamento do sistema no caso do expoente de cruzamento ser nulo. Por fim, mesmo no caso relevante, em que esse expoente é positivo, o critério de Luck não informa se havcrá uma mudança de classe de universalidade (mas ainda assim com uma transição contínua presente no sistema), ou se haverá uma total eliminaçĩo cla criticalidade, tornando a própria noção de classe de universalidade imprecisa. Isto é, a idéia de relevância diz respeito apenas ao surgimento de mais unı campo de escala (associado à própria aperiodicidade; reja a próximia seçăo) que deve ser ajustado precisamente para colocar o sistema ua criticaliclade: usual. Devido a todas essas questões é que nos propusemos a estudar modclos altamente simplificados, em que é possível acompanhar passo a passo os efeitos de pelo menos alguns tipos de aperiodicidade.

\subsection{Excurso: da universalidade em mecânica estatística}

Antes de passarmos à descrição dos resultados que obtivemos a respeito dessa questão que acaba de ser proposta, isto é, o que significa propriamente a relevância da aperiodicidade, quais os seus mecanismos de atuação, convém fazer um breve excurso pelo próprio conceito de universalidade, que está lna base interpretativa de todo o nosso trabalho posterior. Recomendamos o 
excepcional ensaio de Kadanoff (1973) para uma discussão mais profunda.

Já é parte da sabedoria da mecânica estatística, depois do advento do grupo do renormalização de Wilson, falar que o valor dos expoentes críticos de qualquer sistema que possui uma transição de fases contínua depende apenas de uns poucos fatores: dimensão do sistema, grupo de simetria do parámetro de ordem, e natureza e alcance das interações microscópicas. Por "natureza" das interações entende-se seu caráter atrativo ou repulsivo, ferroou antiferromagnético, ou, mais precisamente, qual o tipo de ordem que elas favorecem. Esse é um paradigma extremamente bem estabelecido, fundamentado por resultados teóricos e experimentais numa impressionante variedade de modelos e sistemas físicos. O último dos três fatores determinantes de uma classe de universalidade (isto é, uma classe de sistemas com os mesmos índices críticos), que diz respeito às interações microscópicas, talvez seja o mais inesperado: afirma-se que características detalhadas da interações entre as constituintes do sistema, ou dos parâmetros de um modelo, têm pouca importáncia na região crítica. Entretanto, sabemos que algumas perturbações na 11atureza desses parâmetros podem afetar de maneira relevante a criticalidade do sistema; não é outro o conteúdo dos critérios de Harris e de Luck acima expostos. Distribuições de acoplamentos que violem a simetria translacional podem impedir um sistema de realizar seu ponto crítico usual (isto é, aquele correspondente ao sistema homogêneo, ou uniforme). Nosso objetivo fundamental em todo este trabalho é mostrar que, ainda assim, o conceito de universalidade mantém sua importância, mesmo quando essa importante simetria é violada. Notemos que, em sua enumeração usual, os fatores determinantes da classe de universalidade não incluem a ausência de simetria translacional como um dado relevante, muito menos o esquema segundo o (unal cssa invariància é quebrada; o que pretendemos mostrar, e eis a tese que foi enunciada no Prólogo, é que sistemas desprovidos dessa simetria também podem ser classificados de acordo com seus expoentes críticos de maneiras universais, e que, portanto, a presença ou ausência da simetria também é um fator determinante da universalidade.

Para tanto notemos que, em primeiro lugar, ao falar de universalidade, em seus fundamentos teóricos, necessariamente estamos supondo que os modelos da mecânica estatística podem ser descritos como pontos num espaço hamiltoniano abstrato, e que esses pontos caminham nesse espaço com uma dinâmica muito peculiar, que é dada pelas equações do grupo de renormalizaçäo. Afirmar então que diversos modelos pertencem a uma mesma classe de universalidade é equivalente a dizer que os pontos que os representam nesse nspaço abstrato se movem, segundo o grupo de renormalização, em direção 
a um mesmo atrator da dinâmica ${ }^{3}$. Mas há sutilezas escondidas por trás đla generalidade grosseira dessa afirmação: a rigor, um modelo envolve um certo conjunto de operadores de escala, junto a uma escolha de parámetros microscópicos e "parâmetros de controle" (temperatura, campo externo, pressão...): os últimos se combinam entre si para formar campos de escalra. Assim. 11a verdade, um ponto do espaço hamiltoniano tem como coordenadas os campos de escala correspondentes àquele modelo nas condições externas impostas determinados valores dos parâmetros microscópicos, em determinarkas tomperaturas, ou campos etc. Escolhido então um modelo (isto é, um conjunto de operadores), e escolhidos os valores de seus parâmetros microscópicos, a. variação dos parâmetros externos gera um conjunto no espaço abstrato. e elo deve possuir interseç̧ão não-vazia com a bacia de algum atrator da dinảnica..

Quando temos, por exemplo, um hamiltoniano de Ising numa cleterminada rede, e escolhemos o valor de cada um dos acoplamentos. nma temperatura e um campo externo marcam um ponto no espaço abstrato. (Outra temperatura e outro campo correspondem a um ponto difercuts: todas as temperaturas e todos os campos possíveis geram um conjunto de pontos. Outra escolha do valor de cada acoplamento gera outro conjunto de pontos. Assim, um modelo é na realidade descrito por uma infinidade de conjuntos de pontos no espaço abstrato.

A idéia de universalidade ganha então diferentes níveis de interpretação. No nível mais geral, ela corresponde à situação em que um modelo, com todas as possíveis realizações de seus parâmetros microscópicos, pode tcr os parâmetros externos ajustados de modo a colocar seus pontos representativos na bacia de um mesmo atrator. Esse é um nível muito forte de universaliclacle. O nível seguinte diz respeito ao caso em que modelos diferentes possincm algumas escolhas de parâmetros microscópicos compativeis com o fluxo para um mesmo atrator. Essas escolhas correspondem, em geral, mais ao tipo de distribuição dos parâmetros microscópicos do que a seus valores específicos. Assim, qualquer distribuição periódica de acoplamentos ferromagnéticos para um modelo de Ising tridimensional (em todas as redes cle Bravais com essa dimensão), permite que se ajuste a temperatura e o campo externo em valores críticos, de modo a fazê-lo fluir para um único atrator; esse atrator é exatamente o mesmo para o qual fluem os pontos que representam um modelo contínuo para um fluido homogêneo de uma componente. Essa é a universalidade a que usualmente nos referimos quando falamos desse conceito. Notemos, entretanto, que se permitíssemos que os acoplamentos nesse modelo de Ising assumissem valores de sinais diferentes, o atrator não seria

\footnotetext{
${ }^{3}$ Usamos o termo "atrator" de modo bastante vago, para indicar qualquer conjunto invariante, ou limite, da dinâmica de grupo de renormalização no espaço hamiltoniano.
} 
atingido.

Mas existem ainda outros níveis nos quais podemos falar de universali(lade. Por exemplo, distribuições não-periódicas de acoplamentos ferromagnéticos podem deixar o mesmo modelo de Ising do parágrafo anterior incapaz le atingir aquele atrator, por mais que se ajustem o campo externo e a temperatıra. Mas isso não quer dizer que ele não possa atingir outro atrator! E: mais que isso, um tipo de universalidade pode se preservar, em outro nível, 110 sentido em que modelos com valores diferentes de acoplamentos, inas com o mesmo tipo de distribuição, podem acabar fluindo para esse novo atrator. Neste ponto entram em cena os resultados da maior parte de nossos esforços. O que mostramos foi exatamente que, para duas grandes classes de sistemas diferentes (modelos de Potts e Ising e modelos para polímeros interagentes atrativamente), a quebra de simetria translacional promovida pela introdução de aperiodicidade por camadas resulta em novas classes de niniversalidade, independentes dos valores dos acoplamentos, mas apenas da regra de substituição utilizada para gerar a aperiodicidade.

Essa afirmaçào é demonstrada através da análise de inúmeras instân(ias desses modelos com o esquema de grupo de renormalização de MigdalKaadanoff (e, em um caso específico, com um método de matrizes de transferência). Uma crítica que se poderia fazer à primeira vista a esse método de abordagem do problema é que o esquema de Migdal-Kadanoff (MK) possui uma realização exata nas chamadas redes hierárquicas (nos trabalhos que publicamos, de fato alternamos entre apresentar o problema como um grupo de renormalização aproximado para redes de Bravais com aperiodicidade em camadas, c diretamente como modelos já definidos em redes hierárquicas) (: llessas redes a questão da simetria translacional é bastante delicada. Com (feito. a simetria natural dessas redes é a de escala, e não a translacional; isso poderia fazer crer que, mesmo com acoplamentos uniformes, já estaríanoos numa situação de ausência de simetria translacional, e a introdução da aperiodicidade apenas se somaria a isso. $O$ fato é que, em suas versões uniformes, as redes hierárquicas apresentam uma forma peculiar de invariância por translação: em primeiro lugar, porque são formadas por células básicas idênticas. que podem ser permutadas à vontade; ainda há infinitas simetrias de reflexão: e, o mais importante de tudo, sítios com cada número de coordenação possível estão sempre a uma distância finita e invariável de sítios com a mesma coordenação. Isto significa que todos os sítios de coordenação determinada podem ser transladados por uma distância fixa para encontrarem uma vizinhança equivalente; mudando a coordenação, muda a distância necessária para encontrar uma vizinhança localmente equivalente, mas essa ‘listância é sempre finita. Há, então, uma simetria translacional generalizada, composta pelas classes de sítios equivalentes em termos do número de coor- 
denação; cada classe tem um número infinito de sítios, e cada um deles porle ser levado num equivalente através de uma translação mínima de tamanho fixo (para cada classe).

\subsection{Comentários aos trabalhos publicados}

Nesta seção, finalmente passamos à apreciação do conjunto de trabalhos (1ne publicamos nos últimos anos a respeito dos efeitos da aperiodicidade solbre o comportamento crítico de modelos da mecânica estatística. Como já anunciamos no Prólogo, os dois primeiros trabalhos foram publicados antes do início do doutoramento, mas optamos por inclui-los nesta tese e aqui avaliálos porque são essenciais para a compreensão de como evoluiu essa linha to pesquisa. Todos estão anexos a este trabalho e constituem. com cfeito. o corpo dos estudos "técnicos" que realizamos, devendo ser lidos com maior ou menor atenção dependendo do interesse do leitor em se aprofundlar nass questões matemáticas, nos métodos empregados, e nos resultados clctalliados, que aqui são apresentados apenas na medida em que são neccssários para a elaboração de nossa tese a respeito da universalidade. Notamos que uma exposição meticulosa da técnica de grupo de renormalização que empregamos abundantemente (Migdal-Kadanoff), desde sua formulação como método aproximado no espaço real até sua aplicação exata às chamadas redes hierárquicas, encontra-se em nossa dissertação de mestrado |Haddad (1999)|, no contexto genérico do modelo de Potts. Esse trabalho pode ser um complemento proveitoso aos artigos em discussão, que são talvez muito económicos na apresentação da técnica e dos cálculos envolvidos em sua aplicação.

\section{Artigo 1 (p. 73)}

Pinho, Haddad e Salinas - Braz. J. Phys. 47, 567 (1997)

Este foi o primeiro trabalho que publicamos a respeito de sistemas aperiódicos. Estudamos o modelo de Ising na ausência de campo externo, com distribuições aperiódicas de acoplamentos, segundo regras de substituição binárias: apresentamos cálculos exatos em uma dimensão, e cálculos na aproximação de MK para dimensões superiores.

O problema do modelo de Ising em uma dimensão é sua criticalidade altamente artificial, presente apenas à temperatura zero. Qualquer aperiodicidade, mesmo dotada de flutuações geométricas intensas, não deve produzir alterações importantes no comportamento do modelo. dada a ausência de um ponto crítico verdadeiro. De fato, como mostramos no artigo, uma 
simples transformação de dizimação permite estudar cadeias de Ising aperiódicas, construídas a partir de regras de substituição binárias genéricas; a análise das relações de recorrência obtidas pela dizimação mostra que a única alteração introduzida pelas flutuações geométricas é uma mudança, termodinamicamente imperceptivel, do caráter do ponto fixo de temperatura nula (esse ponto fixo ganha mais um autovalor relevante, mas a nova variedade instável fica contida numa região fisicamente inacessivel do espaço bidimensional do parametros). É importante que, neste ponto, o leitor perceba qual $\therefore$ o papel cla auto-similaridade no processo de renormalização. Como des(rito no artigo, os spins dizimados são sempre aqueles localizados "dentro" las seqüências fundamentais que compõem a regra de substituição; o proresso de dizimação é, na realidade, a aplicação inversa da regra, e, sendo a seqiiência infinita auto-similar, sempre obteremos uma estrutura na qual os acoplamentos renormalizados seguem a mesma ordem.

Para empregar a aproximação de MK em modelos com aperiodicidade por camadas, tivemos de nos restringir a regras de substituição que se "encaixassem" nas células básicas das redes hierárquicas equivalentes, como ilustrado 110 artigo. Notemos que a rede empregada nesse artigo, e em muitos dos subseqüentes, pertence à chamada família do diamante; a célula básica de sua construção pode ter um número arbitrário de "ramos" e de ligações ao longo de cada ramo. Existe uma dimensão fractal associada à célula, que pode variar de maneira contínua; seus valores inteiros correspondem à aproximação de $M K$ em redes hipercúbicas de dimensão correspondente. Além disso, as células da família do diamante correspondem à versão da aproximação de YK nà qual ocorre dizimação de spins internos à célula de renormalização, seguirla de deslocamento de ligações (bond-moving). Esse processo pode ser inverticlo. clando origem às células da chamada família necklace, que também (studamos cm uma de nossas publicações. Para mais detalhes sobre a relação cntre diversas redes hierárquicas e o esquema de MK, veja Burkhardt (1982).

Estudamos os efeitos de duas sequêencias aperiódicas sobre o modelo de Ising (as sequiências de duplicação e de triplicação de periodo, descritas anteriormente). Neste artigo, consideramos redes muito simples: para a seqüência de duplicação, a rede do diamante mais simples, com dois ramos e duas ligações por ramo; para a outra, a rede com dois ramos e três ligações ao longo de cada um. Nessas condições, o que conseguimos provar no trabalho, através da análise dos fluxos das relações de recorrência de MK, foi que a aperiodicidade gerada pela regra de dobramento de período é irrelevante para o modelo de Ising, e a outra é relevante. O que significam essas afirmações? No caso do dobramento de período, ocorre que o ponto fixo uniforme, que se localiza na diagonal do espaço de parâmetros, com cada coordenada tendo o mesmo valor que teria no caso sem aperiodicidade (em que esse espaço é uni- 
dimensional), é um ponto de sela: a forma linear das relações de recorrência em torno dele possui um autovalor de módulo maior que a unidade, o outro menor. O autovalor dominante, térmico, é igual ao do caso uniforme $(c i$ ele que determina os expoentes críticos); o outro, irrelevante, garante (ure o) ponto fixo pode ser alcançado, pois representa uma direção atrativa. a partir de condições iniciais arbitrárias - ou seja, para qualquer razão cntre as duas possiveis constantes de acoplamento, $J_{A}$ e $J_{B}$. No caso rclevante, ocorre que? os dois autovalores têm módulo superior à unidade, de modo que o ponto fixo não pode ser alcançado, exceto para condições iniciais que coloquom o sistema exatamente nele - isto é, se a razão entre os acoplamentos for um, de modo que o sistema seja uniforme!

Dessa maneira, nesse artigo conseguimos precisar o conccito de releváncia ou irrelevância da aperiodicidade. traduzindo-o para a linguagem do grupo de renormalização: no caso irrelevante o ponto fixo uniformo is acessírcl. com caráter de ponto de sela; no caso relevante ele é um nó completamente instável, que não pode dessa forma ser alcançado, exceto se o sistema jâ começar uniforme. Em termos mais adequados, o que mostramos foi clite a aperiodicidade pode se tornar um campo de escala rclevante, devendo ter seu valor precisamente ajustado para a realização da criticalidade uniforme: o outro campo de escala é naturalmente a temperatura, sempre relevante, com seu autovalor determinando os expoentes críticos térmicos.

Esses resultados nos levaram a uma conclusão errônea, contudo: acroditamos que, no caso relevante, com o ponto fixo inacessivel, a transição de fase poderia simplesmente desaparecer. Veremos adiante que ocorre algo muito mais interessante, com o surgimento de outros atratores, que não o ponto fixo uniforme. Ainda consideramos que a aperiodicidade gerada pelo dobramento de período seria sempre irrelevante, o que também se mostrou falso: descobrimos posteriormente que, aumentando o número de ramos da célula do diamante, ela se torna relevante. Por fim, ainda propusemos um critério análogo ao de Luck, para julgar a relevância da aperiodicidade de mancira exata (dentro do esquema de MK), que veio a ser modificado cin trabalho subseqüente.

\section{Artigo 2 (p. 81)}

\section{Pinho, Haddad e Salinas - Physica A 257, 515 (1998)}

Neste trabalho demos prosseguimento às investigações anteriores, incluindo na análise o modelo de Ising com aperiodicidade gerada pela sequiencia de Rudin-Shapiro, de quatro letras (que exige um espaço de parâmetros quiadridimensional, portanto). O avanço em relação ao artigo anterior vrio nia 
forma de uma dedução exata do critério de relevância da aperiodicidade (no nivel MK), baseada em uma análise geral da forma das relações de recorrência. () critério é baseado na idéia de que a relevância da aperiodicidade equivale à instabilização completa do ponto fixo uniforme (diagonal), que se torna assim inacessivel. Esse panorama foi confirmado no exemplo concreto cla seqüência de Rudin-Shapiro, que é relevante para o modelo de Ising na rede do diamante simples.

Entrctanto, ainda não foi neste artigo que percebemos o fato central de (ue, nos casos relevantes, a transição de fases não é simplesmente eliminada (por causa da inacessibilidade do ponto fixo), mas passa a ser determinada por outro atrator no espaço de parâmetros - este é o fato que permitirá una classificação universal das transições associadas a modelos em que a aperiodicidade é relevante. Também não nos demos conta, ainda, de que a seciiência de dobramento de período poderia se tornar relevante para o modelo do Ising se tomássemos células com mais ramos (isto é, para sistemas de mais climensões, analisados na aproximação de MK).

\section{Artigo 3 (p. 87)}

\section{Haddad, Pinho e Salinas - Phys. Rev. E 61, 3330 (2000)}

Neste trabalho podemos dizer que houve um claro salto no nivel de compreensão do problema da aperiodicidade. Inspirados em um trabalho anterior de Magalhães, Salinas e Tsallis (1998), apresentamos um estudo completo, na aproximação cle MK, do modelo de Potts de $q$ estados com acoplamentos forromagnéticos distribuídos aperiodicamente, segundo regras de substitui(aĩo binárias, na ausência de campo externo. Os resultados mostraram que as flutuaçôcs geométricas, associadas à aperiodicidade, sempre podem ocasionar uma mudança no comportamento crítico do modelo a partir de certos valores limiares do número de estados, $q$, ou a partir de valores diferentes do número de ramos na célula básica de MK. Os valores de $q$, ou do número de ramos, a partir dos quais as flutuações geométricas têm a capacidade de alterar o comportamento crítico do sistema, dependem um do outro e também do expoente de flutuação da seqüência de substituição utilizada para implementar a aperiodicidade. Mostramos que essa alteração do comportamento crítico se dá, sem qualquer dúvida, pela transformação do caráter do ponto fixo não-trivial uniforme das relações de recorrência de Migdal-Kadanoff, no espaço de parâmetros bidimensional; esse ponto fixo tem, no caso de aperiodicidade irrelevante, a forma de uma sela, com a variedade instável associada no comportamento crítico do modelo uniforme; no caso relevante (isto é, para q maior que o limiar do sistema específico) o ponto fixo torna-se totalmente 
instável, de modo que não é acessivel a partir de nenhuma condição inicial não-uniforme.

Também fomos capazes de mostrar que, nos casos de apcriodicidade relovante, a criticalidade não é simplesmente eliminada por causa da inacessibilidade do ponto fixo uniforme; na verdade, nesses casos surge un ciclo-dois no espaço de parâmetros; a análise linear da segunda iterada clas relaçõo's de recorrência mostra que cada ponto do ciclo tem uma variedarle estável c: outra instável. Supondo que o ciclo-dois realmente governa a transição do fases nesses modelos, mostramos como uma adaptação simples da teoria do escala usual, baseada em idéias de Derrida, Eckmann e Erzan (1983), pode dar conta da análise desse tipo de estrutura (que é diferente de um ponto fixo normal); isso nos permitiu o cálculo de um expoente crítico do calor específico, $\widetilde{\alpha}$, hipoteticamente associado a essa transição. cujo valor vlifere daquele do caso uniforme correspondente.

Para testar essa hipótese, analisamos diretamente a singulariclarle da energia livre dos modelos em consideração, por um método numérico (detalliadidmente discutido em nossa dissertação de mestrado, já citada). A cnergia livrr pode ser escrita como uma série infinita, e manipulaçôes numéricas cuidadosas devem ser realizadas. Dentro dos limites de nossa precisão, verificamos a igualdade entre o expoente $\widetilde{\alpha}$ previsto pela teoria de escala adaptada ao ciclo-dois e o valor obtido da análise direta da singularidade (com a coincidência entre os resultados tanto melhor quanto mais forte a singulariclarle). Sugerimos que as discrepâncias entre os cálculos numéricos e as previsōes cla teoria de escala adaptada, visiveis nos casos de singularidades mais fracas. têm como origem correções ao scaling, que estamos deixando de considerax em nossa adaptação "ingênua". Os cálculos numéricos mostraran também o surgimento de anomalias de Schottky nas curvas do calor específico dos modelos aperiódicos, além de oscilações log-periódicas (com período compatível com a previsão do grupo de renormalização), como é usual em sistemas com invariância de escala discreta [cf. Sornette (1999)].

Testamos a universalidade dos comportamentos criticos observados, fiazendo variar os valores dos acoplamentos ferromagnéticos, $J_{A}$ e $J_{B}$, nos cálculos numéricos da energia livre. Para os casos de aperiodicidade irrelevante. inúmeros testes mostraram que o valor do expoente crítico $\alpha$ não depencle dessas constantes de troca, sendo sempre igual ao do modelo uniforme na rede hierárquica em consideração. Como esperado, $\alpha$ é, de fato, totalmente determinado pela análise de escala em torno do ponto fixo uniforme, que envolve apenas os parâmetros geométricos da rede e o número de estados do modelo. Para os casos relevantes, a análise numérica da energia livre para diversos valores dos acoplamentos também indicou, dentro dos limites dia precisão dos cálculos, que o expoente crítico $\alpha$-que é diferente clo uniforme 
não depende dos valores das interações, sendo completamente determinado pela análise de escala do ciclo-dois (que também depende apenas da geometria e do númcro de estados). Assim, nossos exemplos indicam claramente a possibilidade da classificaçäo universal das transições de fase em sistemas nos quais a quebra de simetria translacional induzida pela aperiodicidade é relevante.

\section{Artigo 4 (p. 91)}

Ghosh, Haddad e Salinas - Int. J. Mod. Phys. B 14, 1473 (2000)

Neste trabalho podemos dizer que se cumpriu uma praxe, uma reverência à tradição: introduzimos um campo magnético externo, uniforme, para analisar scus possíveis efeitos (sobre o modelo de Ising, não o de Potts). Na rerdade. essa dita "tradição" é absolutamente justificada, pois o campo externo, mesmo sendo uniforme, pode estabilizar ou instabilizar uma transição ferromagnética, além de ser essencial para uma compreensão completa de transições antiferromagnéticas. Em nosso caso, era bastante razoável esperar que o campo não tivesse nenhum efeito, e foi isso mesmo que verificamos. Ainda assim, o trabalho revelou-se bastante interessante em seus aspectos mais técnicos, pois a transformação de grupo de renormalização, mesmo no caso do esquema de Migdal-Kadanoff, torna-se bastante não-trivial. $O$ que ocorre é que o campo, apesar de estar acoplado a spins individuais, recebe, na renormalização, contribuições das constantes de acoplamento que "cercam" (adla spin; como essas constantes não estão distribuídas uniformemente, a distribuiçăo de campos locais renormalizados torna-se imediatamente nãouniforme (o aperiódica) com apenas um passo de renormalização, mesmo que inicialmente ela fosse homogênea.

De modo mais preciso, pode-se afirmar que a vizinhança de cada spin individual pode se apresentar de diversas maneiras, dependendo da regra de substituição escolhida; isto é, o número de acoplamentos de cada tipo possível $\mathrm{cm}$ torno dos spins individuais varia, de modo que temos vários tipos de spins, classificados conforme seu ambiente local. Cada tipo contribui de maneira diferente para o traço parcial que é feito na renormalização, e os spins não dizimados ficam submetidos a campos efetivos variados.

Além disso, o tratamento de campos externos é uma particularidade importante do esquema de Migdal-Kadanoff, mesmo no caso de acoplamentos uniformes. A realização exata do método de $\mathrm{MK}$ nas redes hierárquicas mostra que, como o número de coordenação efetivamente varia dentro de uma célula, o campo deve ser aplicado proporcionalmente ao número de vizinhos de cada spin [cf. Yeomans e Fisher (1981)], para compensar o fato de que 
a suscetibilidade local diminui no caso de spins fortemente acoplados aos adjacentes (assim, o campo precisa ser maior nessas regiôes). Dessa formin. o campo magnético nunca é propriamente uniforme quando se trata clo essquema de $\mathrm{MK}$, mas é localmente proporcional ao número de coordenaçāo.o que produz uma dificuldade técnica extra com a qual tivemos de liclar. Há ainda uma dificuldade extra que deve ser levada em conta: as relaçócs de recorrência só formam um sistema algebricamente fechado quando incluinos um campo alternado (staggered) no hamiltoniano.

De todo modo, como dissemos, não houve qualquer novidade con relação aos efeitos da aperiodicidade; em termos mais precisos, os autovalores associados aos operadores pares (térmicos) são exatamente aqueles já encontrados nos trabalhos anteriores, para todas as sequiencias aperiódicas estudadlas: os autovalores dos operadores ímpares (magnéticos) mostram que o campo cxterno é relevante, como tem de ser em qualquer transição ferromagnética (mesmo que a classe de universalidade dessa transição não seja a mesma (lo modelo uniforme).

\section{Artigo 5 (p. 99)}

\section{Haddad, Ghosh e Salinas - Phys. Rev. E 62, 7773 (2000)}

Neste artigo resolvemos ampliar o escopo de nossos interesses, com o objetivo de considerar os possiveis efeitos da aperiodicidade sobre um ponto tricrítico, e sobre a linha de transições de primeira ordem que o acompanhia. A motivação veio, podemos dizer que de modo natural, de toda uma literatura a respeito dos efeitos da desordem sobre tais fenômenos. Desde um trabalho pioneiro de Imry e Wortis (1979), resultados rigorosos |Aizcnman a Wohn (1989)| e análises perturbativas via grupo de renormalização no espaço real [Hui e Berker (1989)] têm evoluído no sentido de fornecer um quadro coerente: e abrangente dos efeitos da desordem sobre sistemas que apresentam pontos tricríticos. Já está muito bem estabelecido que vale a conjectura original do Imry e Wortis: para modelos ferromagnéticos em duas dimensões, qualquer intensidade de desordem elimina completamente as transições de primeira ordem, e, consequientemente, os pontos tricríticos. Em dimensões superiores, é necessária uma intensidade finita de desordem para a ocorrência desse fenômeno; em geral, ocorre uma supressão gradual das regiões de primeira ordem no diagrama de fases, acompanhada de diminuição da temperatura tricrítica.

Em situações concretas, esses resultados têm mostrado seu valor. $O$ modelo de Potts de $q$-estados, por exemplo, em sua versão uniformc (1ћãodesordenada), sofre uma transição de primeira ordem para $q>4$. em reck's 
planarcs. Espera-se então que a presença de desordem nesse modelo enfra(1neça a transição, tornando-a contínua para qualquer valor de $q$; de fato, isso 6 o que tem se verificado, através de simulações de Monte Carlo [Chen, Ferrenberg e Landau (1992)| ou análises de grupo de renormalização |Cardy c Jacobsen (1997)]. Também no caso do modelo de Blume-Emery-Griffiths, (que apresenta um rico diagrama de fases em sua versão uniforme, com linhas (lo primeira ordem, pontos tricríticos e pontos críticos terminais, o efeito de clesordem nas ligações [Falicov e Berker (1996)], no campo magnético [Kabakçioglu e Berker (1999)| ou no campo cristalino [Branco e Boechat (1997)] c exatamente esse.

Mas, novamente. ainda falta uma compreensão completa da questão da universalidade nos modelos desordenados: destruindo (ou enfraquecendo) as transições de primeira ordem e os pontos tricríticos, a desordem gera outras 'lasses de universalidade? Em outras palavras, não está claro se há um "atrator desordenado" que passa a responder pela transição contínua que sempre resta. No caso de sistemas com criticalidade simples, conseguimos mostrar concretamente a existência de novos atratores, aceitando a substituição da lesordem pela aperiodicidade determinística, como discutido anteriormente; assim, o realmente natural tentar encontrar informações detalhadas para os casos tricríticos e de primeira ordem mais uma vez substituindo a desordem pela aperiodicidade. A analogia com nossos trabalhos anteriores é precisa: o critério de Harris e o de Luck dizem em que situação a desordem, ou, genericamente, a aperiodicidade, são relevantes para afastar um sistema do ponto fixo uniforme - nós conseguimos dizer para onde o sistema vai, ao menos no "aso de aperiodicidade determinística; então, se o critério de Imry-Wortis diz quando a desordem altera ou suprime a tricriticalidade (e a linha de primeira ordem associada), talvez possamos dizer qual estrutura no espaço de parâunetros passa a comandar o sistema, ao menos no caso aperiódico simples.

Da inesma forma, o "critério de Imry-Wortis" avalia o efeito da desordem sobre pontos tricríticos e transições de primeira ordem, e tem-se procurado cutender a estrutura possivelmente universal dos fenômenos que os substituem. No contexto exclusivo de transições de primeira ordem, sem ponto tricrítico, um primeiro passo foi dado com o estudo do efeito da aperiodicilade em camadas, gerada por regras de substituição binárias, sobre o modelo de Potts de 8 estados na rede quadrada, através de simulações de Monte Carlo [Berche, Chatelain e Berche (1998)]; verificou-se que alguns tipos de aperiodicidade, geometricamente mais intensas (o que se mede através do expoente de flutuação da seqüência de substituição), de fato tornam a transição contínua. Nosso estudo, incluindo também o fenômeno tricrítico, é então bastante desejável no contexto descrito.

Utilizamos um modelo de spins mistos muito simples, mas bastante ade- 
quando para a análise de MK. Esse modelo, em sua versão uniformo. já foi estudado com uma grande variedade de técnicas, que indican a prosenç; de um ponto tricrítico no diagrama de temperatura versus campo cristalino (este último está presente porque uma das espécies de spins pode assunin três valores, de modo que um campo de anisotropia pode se acoplar a eless). Para dimensões maiores que 2.1(lembremos que no esquema MK a dimensão é um parâmetro contínuo, correspondente à dimensão da rede hicrárquica associada), uma análise da estrutura de fluxos e atratores das relaçôs ck recorrência do modelo uniforme indica a existência desse ponto 110 diagrama [Quadros e Salinas (1994)], como rediscutimos no artigo. Uma crítica que foi feita a esse estudo do modelo uniforme é que o ponto fixo de descontinuidarlc. associado à linha de primeira ordem, não parece satisfazer o chamaklo critério de Nienhuis-Nauenberg (1975). Esse conhecido critério diz que um certo ponto fixo de relações de recorrência no espaço real está associado a transições descontínuas se algum autovalor da forma linearizada dessas relaçoes em torno desse ponto valer $b^{d}$, com $b$ representando o fator de reescalia clas distâncias $\mathrm{c} d$ a dimensão do sistema. Essa forma linearizada das rolaçós de recorrência deve ser automaticamente uma soma direta de blocos. cada 1111 contendo os campos de escala de mesma simetria. O autovalor $b^{t}$ deve estar associado ao bloco que contém o campo conjugado à densidade que varia descontinuamente na transição; em outras palavras, o autovalor de Nienluiss e Nauenberg deve estar associado ao bloco par, se a transição de primeila ordem em questão envolver calor latente e descontinuidade na densidade ck entropia, ou ao bloco ímpar (campos magnéticos), se a transição onvolver 1111 salto numa grandeza do tipo magnetização. Evidentemente; o lamiltoniano de partida deve conter termos com todas as simetrias, para t,mnos chanc" de detectar um autovalor de Nienhuis e Nauenberg em torno de algum ponto fixo.

No modelo de spins mistos uniforme, incluindo campos externos, verificimos que, de fato, nenhum autovalor da linearização em torno desse suposto ponto fixo de descontinuidade tem o valor previsto. Para garantir (fus liaio) estava ocorrendo nenhuma confusão, verificamos que os autovalores em torno de todos os outros pontos fixos também não possuem o valor esperado pelo critério. Mais que isso, todos têm autovalores diferentes, de modo que uma situação de falso crossover também tem de ser descartada. Entretanto, a estrutura de fluxos não é compatível com qualquer outro cenário. Inclisive, cálculos numéricos que realizamos em conjunto com André Vicira, do IFUSP, usando o método da análise da série de energia livre, indicain claramente uma descontinuidade na magnetização (que é a derivada da série em relação ao campo), de modo que insistimos na interpretação do digrama dk fluxos proposta por Quadros e Salinas (1994). 
Introduzindo a aperiodicidade nos acoplamentos, o resultado foi plenamente do acordo com o esperado, e análogo ao que se sabe sobre efeitos de desordem sobre o ponto tricrítico. A partir de determinada dimensão, algumas sequiências aperiódicas binárias tornam o ponto fixo associado à tricriticaliclade completamente instável (inacessivel), substituindo-o por um riclo-clois. A temperatura tricrítica, que pode ser calculada numericamente, torna-se sempre menor que no sistema uniforme, qualquer que seja a razão entre os valores dos dois acoplamentos possíveis; notemos que essa temperatura depende clo valor dessa razão. Mas, para uma dada seqüência e uma dada limensão, o expoente tricrítico tem um valor único (diferente do uniforme), independentemente da razão entre os acoplamentos. Assim, como previsto no ("iso klesordenado. em dimensões maiores que duas não ocorre supressão completa da regiăo de primeira ordem, e, analogamente a tudo que discutimos anteriormente, uma classificação universal dos pontos tricríticos na presença de aperiodicidade torna-se possivel.

\section{Artigo 6 (p. 105)}

\section{Haddad, Pinho e Salinas - Braz. J. Phys. 30, 741 (2000)}

Este traballho é uma revisão dos resultados anteriores, de modo que não há muitos comentários a fazer, exceto o fato de termos incluído na discussão uma comparação de nossos resultados de grupo de renormalização com os de Andrade $(1999,2000)$, que utilizou um método de matrizes de transferência para analisar o modelo de Ising aperiódico em redes hierárquicas [para o mesmo método aplicado a um sistema desordenado, cf. Andrade, Nogueira Ir. c Coutinho (2003)|. As duas abordagens se mostraram totalmente compatíveis. "a equivalência foi reforçada por um trabalho de Nogueira Jr., Andrade o Coutinho (2001). que calcularam os expoentes críticos através do método de matrizes de transferência e através de um método de grupo de renormalização distinto do nosso, baseado no estabelecimento de relações de recorrência para a magnetização local nos sítios da rede hierárquica e sua subsequiente caracterização multifractal.

\section{Artigo 7 (p. 109)}

\section{Haddad e Salinas - Physica A 306, 98 (2002)}

Neste trabalho optamos por estudar os efeitos da aperiodicidade sobre um outro sistema, bastante diferente daqueles que tratamos anteriormente. $O$ modclo com que trabalhamos, proposto inicialmente por Mukherji e Bhatta(harjee (1995), refere-se a dois polímeros numa rede hipercúbica, interagindo 
atrativamente. Considera-se como polímero uma caminhada aleatória clirigida ao longo de uma direção da rede, isto é, uma caminhada aleatória com flutuações apenas nas direções transversais. As ligações la rede quo unem dois sítios visitados em seqüência pela caminhada constituem os monomeros componentes do polímero. A interação atrativa é introduzida fazcnclo-so com que se cada ligação ocupada por dois monômeros, um de cada polímero. climinua a energia total do sistema de um valor que pode depender dia posição ao longo da rede. Esse é um modelo interessante para polímcros intcragentes, pois apresenta, na versão uniforme (energia atrativa igual cm tolla a rede) uma transição contínua entre uma fase de altas tempcraturas. cm cuc os polímeros estão livres, e uma fase de baixas temperaturas. em que estão emaranhados.

Mukherji e Bhattacharjee (1995) estudaram algumas versões desordenidas desse modelo, em que a energia de interação é distribuída aleatoriancnto. A técnica empregada foi justamente o grupo de renormalizaçào no espaço real, na aproximação de MK. A principal constatação é que o critério ke Harris para a relevância da desordem sobre a criticalidade cle ferromagnctos não necessariamente se aplica ao problema de polimeros. Neste caso. uma distribuição completamente aleatória e não-correlacionada de energias do interação é irrelevante mesmo para $\alpha>0$, contrariando portanto o que diria o critério. $\mathrm{Na}$ realidade, entretanto, esses autores cometem um equívoco as considerar que o critério falha; ocorre de fato que, para o modelo do polímoros, como eles mesmos argumentam, não vale a relação de hiperescula (pois os polímeros são objetos unidimensionais, e as grandezas termodinâmicas são extensivas no comprimento linear, e não no volume). Então. apesal de $\alpha$ ser positivo, $2-d \nu$ não é; como mostramos anteriormente, este é o expoente dr cruzamento que aparece primeiro no critério de Harris, com $\alpha$ entrando so usarmos a relação de hiperescala.

Em nosso artigo introduzimos aperiodicidade na distribuição de cnergias de interação, exatamente como nos sistemas de spins estudados anteriormente, associando cada ligação a uma letra da seqüência aperiódica. A trícnica de MK gera relações de recorrência extremamente simples para o modelo de polímeros, que podem ser analisadas com grande facilidade. Vorificamos que, no caso da seqüência de duplicação de período, o ponto fixo correspondente ao sistema uniforme é sempre acessivel, mesmo aumentando o número de ramos da célula hierárquica; isso já torna o problema claramente diverso dos sistemas de spin, em que, até no modelo de Ising, a aperiodicidade pods se tornar relevante quando se aumenta a dimensão. No caso da seqüencia de triplicação de período temos outro cenário: a aperiodicidade se torna relevante com o aumento da dimensão, instabilizando o ponto fixo uniforme. e surge o ciclo-dois já esperado. O valor do expoente do calor específico i 
diferente do caso uniforme, como convinha, mas não depende da razão entre as energias do atração - outro exemplo de comportamento universal, ainda que diferente do uniforme.

Também estudamos sistemas de spins em redes hierárquicas um pouco diferentes da que vínhamos empregando sempre. Empregamos a rede necklace, sobre a qual já comentamos anteriormente, e que está ilustrada no artigo. Como dissemos antes, ela corresponde a um processo de Migdal-Kadanoff no qual a movimentação de ligaçōes ocorre antes da dizimação de spins internos. Sem surpresas, todos os resultados obtidos com essa aproximação equivalem aos anteriores (relevância da aperiodicidade, surgimento de ciclos-dois, valor dos expoentes críticos das classes de universalidade aperiódicas).

\section{Artigo 8 (p. 119)}

Haddad, Andrade e Salinas - J. Phys. A: Math. Gen. 37, 1499 (2004)

Neste artigo estudamos em grande detalhe o modelo de polímeros interagentes introduzido no artigo anterior, apresentando cálculos de grupo de renormalização completos e também, pela primeira vez, recorrendo a cálculos de matrizes de transferência. Restringimos nossas análises à aperiodicidade gerada pela regra de quatro letras de Rudin-Shapiro, pois ela apresentou um atrator surpreendente no espaço de parâmetros quadridimensional, diferente de todos os que encontráramos até aqui.

A análise de MK do modelo de polímeros com essa aperiodicidade é tão simples (11anto no caso anterior; verifica-se sem dificuldades que o ponto fixo uniforme fica completamente instável a partir de certa dimensão fractal. Surgem. uo entanto, dois pontos fixos fora da diagonal, um caso que nunca havíamos detectado antes. A linearização em torno de ambos fornece os mesmos autovalores, ocorrendo aqui outro fenômeno importante: qualquer que seja o número de ramos da célula hierárquica, um deles sempre tem módulo igual à unidade - ou seja, representa um campo de escala marginal. Naturalmente, um autovalor como esse sugere a existência de uma linha de pontos fixos; para nossa surpresa há, entretanto, uma curva contínua e fechada de ciclos-dois! Os dois pontos fixos não-diagonais são pontos degenerados dessa linha, que é mapeada identicamente em si mesma pela segunda iterada das relações de recorrência. Os autovalores da segunda iterada, linearizada em torno de qualquer ponto da curva de ciclos-dois, também incluem um marginal, como era esperado, e de resto têm o mesmo valor em torno de qualquer ponto.

U'm atrator tão pouco usual naturalmente causa uma certa insegurança 
na análise de escala. Um indício de comportamento universal. entretanto. já é fornecido pelo fato de que o expoente crítico do calor sispecífico tom um único valor, seja ele calculado usando o autovalor térmico dos pontos fixos não-diagonais, seja utilizando o maior autovalor da segunda itcrada. Naturalmente, esse valor difere do uniforme. Contudo, para clispersar quaisquer dúvidas, resolvemos recorrer a um cálculo de matrizes de transferçncial. completamente independente do grupo de renormalização, para chocal in consistência dos resultados.

Essa análise se mostrou uma interessante aventura do cálculo matricial, como o leitor pode verificar no longo artigo em discussão. Alguns pontos merecem destaque: em primeiro lugar, foi necessário encontrarmos unn liamiltoniano explícito para o modelo de polímeros, que nunca fora expresso dessa forma; o hamiltoniano é. naturalmente. o ponto de partida necessário para o estabelecimento das matrizes de transferência; em segundo ligar. essats matrizes possuem uma complexa estrutura hierárquica (que foi desvendarlin pelo nosso co-autor, Prof. Roberto Andrade, da UFBA). que torna os cálc:11los bastante delicados. Como resultado final, estabelecemos uma rolação di recorrência para o maior autovalor da matriz de transferência completa (isto) é, a matriz que conecta os dois sítios extremos da redo hierárquica, que ć composta por um complicado produto tensorial de sub-matrizes). Essa relação conecta o maior autovalor numa dada geração de crescimento da hierarquia com o seu correspondente na geração anterior. Assim, um processo itcrativo permite calcular a energia livre com grande precisão, para tamanhos arbitı́ários da rede, até o ponto em que numericamente já se está no linito termodinâmico. Esse método dá acesso à energia livre em qualquer tempcratura. não apenas na região crítica (da mesma forma que a série infinita da encrgia. sobre a qual falamos anteriormente). Ocorrem oscilações log-periólicas no calor específico, como é esperado em estruturas com invariancia discreta do escala e, curiosamente, ele se anula acima da temperatura cíítica (isso so deve, na verdade, ao fato de a entropia ser constante quando os polímeros se desenroscam). O resultado da análise da singularidade confirma plonirmente a previsão do grupo de renormalização, e, portanto, confirma também a universalidade do comportamento crítico na presença de aperiodicidade.

\section{Artigo 9 (p. 137)}

\section{Haddad, Andrade e Salinas - Physica A 000, 000 (2004)}

A novidade neste trabalho bastante recente foi que, pela primeira vez, consideramos explicitamente um sistema desordenado correspondente ao modelo aperiódico em estudo, com o objetivo de comparar os efeitos desses diferentess 
'squemas de quebra da simetria translacional. O modelo escolhido foi, mais uma vez. o de polímeros interagentes. dada a forma simples de suas relações de recorrência de MK.

Para estudar o caso desordenado. empregamos um esquema perturbativo simples, expandindo a distribuição de probabilidades das energias de atração em seus momentos. Mostramos que a desordem totalmente nãocorrelacionada pode se tornar relevante quando o número de ligações por ramo na célula hicrárquica é maior que dois (Mukherji e Bhattacharjee (1995) haviam se restrito ao caso com duas ligações por ramo, no qual a desordem c, de fato, sempre irrelevante, mesmo que o número de ramos aumente). A desordem correlacionada por camadas, entretanto, é mais próxima de nosso esquema de quebra de simetria translacional com sequências aperiódicas. $\mathrm{O}$ rue se verifica é que, nesse caso, mesmo na rede com duas ligações por ramo, o aumento do número de ramos pode tornar a desordem relevante (o que é sinalizado por uma falha na expansão perturbativa em momentos, que acaba prevendo $u m$ segundo momento negativo para a distribuição das energias). Como mostra a análise anterior da sequiência de Rudin-Shapiro, a aperiodicirlade também pode se tornar rolevante em células com apenas duas ligações por ramo. quando aumenta o número deles. Dessa forma, demos um primeiro (e pequeno) passo para a conexão de todos os nossos resultados para sistemas aperiódicos com os resultados para sistemas desordenados; se nesses últimos classificações universais do comportamento crítico não-uniforme também forem possiveis, cremos que um grande passo terá sido dado. 


\section{Referências Bibliográficas}

AChiam Y., Lubensky T.C. e Marshall E.W. (1986), Phys. Rev. B 33. 6460 .

Aizenalan M. e Wehr J. (1989), Phys. Rev. Lett. 62, 2503.

ANdrade R.F.S. (1999), Phys. Rev. E 59, 150.

ANdrade R.F.S. (2000), Phys. Rev. E 61, 7196.

Andrade R.F.S., Nogueira, Jr. E. e Coutinho S. (2003), Phys. Rev. $B$ 68, 104523.

Berche P.-E., Chatelain C. e Berche B. (1998), Phys. Rev. Lett. 80, 297.

Bombieri E. e Taylor J.E. (1986), J. Phys. (France) Colloque C 3, 19.

Branco N.S. e Boechat B. (1997), Phys. Rev. B 56, 11673.

BURKhaRDT T.W. (1982), "Bond-moving and Variational Methods in Real-space Renormalization". In: T. W. Burkhardt e J.M.J. van Leeuwen (eds.). Real-space Renormalization, Topics in Current Physics 30, SpringerVerlag, Berlin, p.33.

Cardy J.L. e Jacobsen J.L. (1997), Phys. Rev. Lett. 79, 4063.

Chen S., Ferrenberg A.M. e Landau D.P. (1992), Phys. Rev. Lett. $69,1213$.

Derrida B., Eckmann J.-P. e Erzan A. (1983), J. Phys. A: Math. Gen. 16,893 .

Falicov A. e Berker A.N. (1996), Phys. Rev. Lett. 76, 4380.

Felditan D.E. (2002), Phys. Rev. Lett. 88, 177202. 
Godrèche C., Luck J.-M. e Orland H. (1986), J. Stat. Phys. 45. TT. Griffiths R.B. (1969), Phys. Rev. Lett. 23, 17.

Grimm U. e BaAke M. (1997), "Aperiodic Ising Models". In: R. V. Mooly' (ed.), The Mathematics of Long Range Aperiodic Order. Kluwer Academic Publishers, Amsterdan, p.199.

HADDAD T.A.S. (1999), Comportamento crítico universal em ferromagnetos de Potts com interaçöes aperiódicas. Dissertação de Mestrado. IFUSP. São Paulo.

Harris A.B. (1974), J. Phys. C 7, 1671.

Hui K. e Berker A.N. (1989), Phys. Rev. Lett. 62, 2507.

Iglói F. (1993), J. Phys. A: Math. Gen. 26, L703.

Imbrie J.Z. (1984), Phys, Rev. Lett. 53, 1747.

IMRY Y. e MA S.-K. (1975), Phys. Rev. Lett. 35, 1399.

ImRY Y. e Wortis M. (1979), Phys. Rev. B 19, 3581.

Kabakçıŏ́lu A. e Berker A.N. (1999), Phys. Rev. Lett. 82, 2572.

KADANOFF L.P. (1973), "Scaling, universality and operator algebras". In: C. Domb e M. S. Green (eds.), Phase Transitions and Critical Phenomenu v. 5A, Academic Press, London, p. 1.

KeLlendonk J. (1995), Rev. Math. Phys. 7, 1133.

LuCK J.-M. (1987), J. Phys. A: Math. Gen. 20, 1259.

LuCK J.-M. (1993a), J. Stat. Phys. 72, 417.

LuCK J.-M. (1993b), Europhys. Lett. 24, 359.

Magalhães A.C.N., Salinas S.R. e Tsallis C. (1998), J. Phyjs. A: Math. Gen. 31, L567.

McCoy B.M. e Wu T.T. (1968), Phys. Rev. Lett. 21, 549.

Mukherui S. e Bhattacharjee S.M. (1995), Phys. Rev. E. 52. 1930.

Nienhuis B. e Nauenberg M. (1975), Phys. Rev. Lett. 35. 4it. 
Nogueira. Jr. E., Andrade R.F.S. e Coutinho S. (2001), Eur. Phys. J. B 23. 373 .

Yordilad P. (2004), J. Phys.: Condens. Matter 16, S715.

Parisi G. o Sourlas N. (1979), Phys. Rev. Lett. 43, 744.

Parisi G. e Sourlas N. (2002), Phys. Rev. Lett. 89, 257204.

Pinho S.T.R. (1998), Modelo de Ising em Redes Aperiódicas e Criticalidade Auto-organizada. Tese de Doutorado, IFUSP, São Paulo.

Quadros S.G.A. e Salinas S.R. (1994), Physica A 206, 479.

QUefFÉlec M. (1987), Substitutional Dynamical Systems - Spectral Analysis, Lecture Notes in Mathematics 1294, Springer, Berlin.

Shechtian D., Blech I., Gratias D. e Cahn J.W. (1984), Phys. Rev. Lett. 53. 1951.

Sornette D. (1998), Phys, Rep. 297, 239.

Tracy C.A. (1988a), J. Stat. Phys. 51, 481.

Tracy C.A. (1988b), J. Phys. A: Math. Gen. 21, L603.

Tsunetsugu H. e Ueda K. (1987), Phys. Rev. B 36, 5493.

VIEIRA A.P. (2004), "Low-energy properties of aperiodic quantum spin chains". cond-mat/0403635.

YEomians J.M. e Fisher M.E. (1981), Phys. Rev. B 24, 2825. 


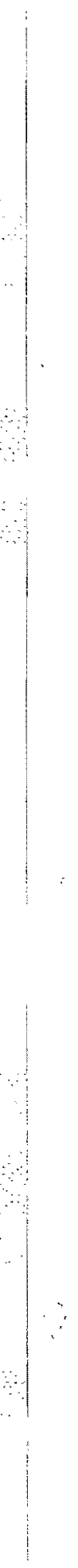




\section{Capítulo 2}

\section{Notas sobre dinâmica vítrea}

Nas últimas chuas décadas ocorreu uma formidável explosão de atividades do: posquisa cm torno de das propriedades de una longa série de sistemas, convencionalmente designada por "matéria mole" (soft matter), ou mais raramonte por "fluidos complexos" (ainda que esta última terminologia se refira normalnente a uma classe mais específica de sistemas). Materiais de uso cotidiano, que apresentam comportamentos interessantes em escalas macroscópicas, caíram na atenção de físicos de todo o mundo: vidros, espumas, grãos c pó, géis, colóides de toda a sorte, polímeros, emulsões, fluidos injetados em meios (micro)porosos, materiais fibrosos e inúmeros outros sistemas jassaram do domínio exclusivo das ciências da engenharia, com um interesse no máximo marginal para os físicos, para o centro de um esforço roncertarlo de estudo de suas propriedades fundamentais. Entre elas, há uma profusão do fonómenos comuns, porém mal-compreendidos, que atendem por nomes como onvelhecimento, molhagem, visco-elasticidade, plasticidade, fratura. jomming: arresting, depinning, creeping e uma infinidade de outros comportamentos característicos, muitos dos quais ainda nem possuem um nome cm nossa língua. As técnicas de análise experimental incluem sondagens estruturais por meios espectroscópicos variados, ensaios mecânicos e reológicos: além de caracterizações das propriedades elétricas e magnéticas cm termos de suscetibilidades complexas e funções de resposta [cf. Hamley (2000) e Witten (1999), para interessantes panoramas sobre esses problemas e muitos outros].

Apesar da enorme disparidade de sistemas (em termos de suas unidades constituintes e das interações entre elas) e fenômenos que citamos, parece ser possível fazer uma boa caracterização de todos eles com apenas duas grandes classes de comportamentos dinâmicos característicos. Uma delas, sobre a qual teremos alguns comentários um pouco mais detalhados a seguir, é repre-

sentada polos sistemas com a chamada dinâmica vítrea: os próprios vidros 
estruturais e coloidais, espumas, géis, e inúmeros líquidos super-resfriados. A outra classe, que não tem um nome próprio, ao menos até o presente momento, é representada por sistemas cuja dinâmica recai no paradigma de uma interface elástica $d$-dimensional sendo arrastada num meio $(d+1)$ dimensional que possui uma distribuição aleatória de contros do pinning isto é, pontos que podem "segurar" a interface, do modo a gerar curvatura (pois ela está sendo continuamente arrastada) e assim custar energia clástica. Essa longa definição, que se encontra por exemplo em Fisher (1998), alo menos já dá uma boa idéia do problema; ainda assim, algumas característicals muito interessantes desses sistemas não são evidentes à primeira vista. Em primeiro lugar, devido à distribuição aleatória dos centros de pinninu, a interface pode apresentar dobras, ou curvaturas, em todas as escalas - isto ci. cla pode assumir uma configuração rugosa ou auto-afim; além disso, os processos de desprendimento (depinning) ocorrem também em todas as escalas. 11 ão só no espaço real como também em termos de energia, pois dobras com inúm(:ras curvaturas diferentes (ou seja, inúmeras energias elásticas armazchadas) podem se desprender em processos de avalanche cxtromannente interessantos. Sistemas reais que recaem nesse paradigma dinâmico inclucm os fluidos injetados em meios porosos, linhas de vórtices em supercondutores do tipo II na presença de impurezas e campos magnéticos externos, placas tectônicas, pilhas de grãos em determinadas situações mecânicas (pressão, chacoalhamento), materiais fibrosos amassados sob pressão, materiais fraturáveis sob estresse mecânico e muitos outros.

Antes de nos determos um pouco mais precisamente sobre o problema da dinâmica vítrea, cabe notar que uma diferença profunda entre essas cluas classes de dinâmicas (ambas bastante complexas, no sentido de apresentarcm profundas anomalias e não possuirem simetrias de translação no tcmpo) salta aos olhos do observador mais atento: as interfaces elásticas são urrastudas através de meios desordenados; isto é, existe um influxo contínuo de energia que dirige a dinâmica. É o caso de todos os sistemas com que exemplificamos essa classe: os campos magnéticos continuamente arrastam as limhas de vórtices, os fluidos são forçados através dos meios porosos, os grãos não param de ser chacoalhados. Como veremos, o influxo constante de energia não parece desempenhar qualquer papel na geração da dinâmica vítrea, que agora passamos a descrever um pouco melhor. 


\subsection{Rudimentos de dinâmica vítrea}

() paradigma da dinâmica vítrea ${ }^{1}$ encontra sua mais perfeita realização, como Cóbvio. nos vidros - os vidros comuns, sim, os de janelas, copos, e tantos outros objetos comuns. Na realidade, deveríamos ser mais rigorosos e lalar da clinâmica dos líquidos formadores de vidros em condições de superresfriancnto, pois eles é que, de fato, apresentam as características que vamos brevemente descrever. Seja como for, é melhor nos fiarmos à terminologia consagrada.

A característica mais marcante da dinâmica vítrea é sua escala de tempo: em baixas temperaturas, os processos de relaxação são extremamente lentos. Tão extrema é essa lentidão, na verdade, que as escalas usuais de tempo são dias. meses. muitas vezes anos. Verifica-se essa enorme lentidão na relaxação dielétrica. por exemplo, de muitos vidros comuns, após a aplicaçăo de um ampo pequeno por curto intervalo de tempo. Da mesma forma, a relaxa(jão estrutural ocorre nessas escalas enormes, com as funções de correlação linàmicas de dois pontos (por exemplo) no espaço real apresentando caudas larguissimas, claramente não exponenciais.

Funçōes de correlação e de relaxação (ou resposta) na verdade guardam surpresas inuito maiores nos sistemas que possuem dinâmica vítrea. Um dos fenômenos mais marcantes é conhecido por envelhecimento (aging), e sua definição é o próprio enunciado do fato de a dinâmica vítrea não possuir simetria por translações temporais. A rigor, o envelhecimento é um fenômeno letectado primordialmente nas funções de resposta, ou suscetibilidades: sua forma cle decaimento ao longo do tempo depende do intervalo durante qual o sistema foi exposto a um campo externo DC (que vai provocar a resposta a ser modirla). Isto é, o sistema é capaz de dizer por quanto tempo foi perturbado, pois cle "envelhece" durante a aplicação do campo de sondagem, respondendo (le maneiras diferentes a perturbações de mesma intensidade mas de durações diferentes. Note que isso é um fenômeno altamente não-trivial, pois não se trata re suscetibilidades $\mathrm{AC}$, em que alguma dependência na freqüência da sonda ó sempre esperada; estamos falando de uma dependência no próprio rlomíliio do tempo. Nas funções de correlação dinâmicas de dois pontos e lois tempos, o envelhecimento se manifesta trivialmente como uma quebra (la simetria por translação temporal: essas funções dependem explicitamente dos dois argumentos temporais, e não apenas de sua diferença, como seria o caso $\mathrm{em}$ qualquer dinâmica "comum".

Inúmeras propostas já foram feitas para tentar organizar os dados expe-

\footnotetext{
${ }^{1}$ Para discussões completas e profundas de todas as idéias que apenas tangenciaremos nesta Seção, consulte Angell (1995), Cugliandolo (2002) e Debenedetti e Stillinger (2001).
} 
rimentais a respeito do envelhecimento em diversos sistemas. Muitas leis de escala, que pretensamente levariam ao colapso das diferentes curvas de relaxação com o uso das coordenadas adequadas, foram propostas ao longo clos anos, mas seus domínios de validade são sempre restritos a algumas clécadas - e, como dissemos, os fenômenos associados à dinâmica vítrea varrem muitús.s décadas (literalmente, às vezes).

Outro fenômeno dinâmico característico é a dependência de diversas grauldezas físicas na taxa de resfriamento do sistema; o volume que uma amostra pode atingir ao fim de um processo de resfriamento é um exemplo notácol dessa dependência na taxa. Ainda mais importante é o fato cle a entropia do estado final depender da taxa de resfriamento, com valores carla vez menores sendo obtidos conforme o resfriamento fica mais vagaroso. Esse fato que gera o famoso e ainda muito debatido paradoxo de Kauzmann (1948). segundo o qual um líquido formador de vidros poderia sempre ser resfriaclo de modo suficientemente lento (entrando no regime metaestável do superresfriamento) a ponto de ficar com uma entropia mais baixa que o cristal. que é a fase verdadeiramente estável em baixas temperaturas. Outra consequiência importante é que a própria transição de vitrificação é assinalacla por uma descontinuidade no calor especifico, e a temperatura en que isso ocorre depende ela própria da taxa de resfriamento.

Verifica-se ainda em sistemas com dinâmica vítrea a freqüente falha do teorema de flutuação-dissipação, que usualmente estabelece uma relação linear entre as funções de resposta e de correlação, com o coeficiente sendo a temperatura. Ocorrem muitas vezes relações de flutuação-dissipação com duas regióes de linearidade com coeficientes distintos entre si, e distintos da temperatura imposta ao sistema. Isto é na verdade uma marca de outra característica importante dos sistemas vítreos: a existência de duas cscalas ch: tempo muito distintas, cada uma com sua "temperatura efetiva"; uma delas corresponde a tempos curtos, de rearranjos locais das configurações moleculares; a outra corresponde aos tempos excessivamente longos associados a mudanças globais de configurações. Esses tempos longos parecem ter origem no enorme número de estados cineticamente bloqueados que os sistemas com dinâmica vítrea apresentam; são configurações em que qualquer rearranjo exige um movimento coordenado de inúmeras componentes microscópicas, $\mathrm{c}$ podem assim perdurar por tempos longos.

Além dessas configurações bloqueadas, os vidros muitas vezes podem apresentar superfícies de energia potencial (landscapes) extremamente complicadas, com uma profusão de armadilhas (vales profundos) e túneis muito estreitos (isto é, regiões de entropia muito baixa para que eles consigam atravessar). Neste ponto começa a vir à mente de alguns leitores unla outra imagem, mais antiga, de uma superfície de energia muito complicadla. que 
parece ser responsável por causar anomalias dinâmicas em um outro sistema seu vellıo conhecido. Estamos falando, sem dúvida, dos vidros de spin, o paradigma máximo do sistema desordenado em mecânica estatística, e sua 'omplexa estrutura de mínimos de energia, alvo permanente de discussão (utre os especialistas [cf. o trabalho recente de Crisanti et. al. (2003), por (xemplo|.

Notemos que, até o momento, não havíamos falado sobre a existência (le desordem nos tais sistemas vítreos; e, de fato, o que se sabe experimentalmente é que eles raramente são sistemas desordenados em sentido estrito (eviclentemente possuem impurezas, mas sua concentração, até certos limites, pouco influi na dinâmica observada). Entretanto, um sistema desordenado (anónico da física estatística surgiu naturalmente - bastou que nossos vidros nos conduzissem à idéia de superfícies de energia muito complicadas. A conexão é reforçada (mesmo que não seja esclarecida) se revelarmos que há uma versão muito especial de um vidro de spin cuja dinâmica (imposta ad hoc, (leve-se dizer) pode ser semi-analiticamente resolvida - o chamado vidro de p-spins no limite esférico - e se revela incrivelmente semelhante à verdadeira dinàmica vítrea.

Antes de explicar melhor essa conexão, cumpre ao menos definir o que é um vidro de $p$-spins, e o que se sabe de fundamental sobre ele. O hamiltoniano é dado por

$$
\mathcal{H}=-\sum_{1 \leq i_{1} \leq i_{2} \leq \ldots \leq i_{p} \leq N} J_{i_{1} i_{2} \ldots i_{p}} S_{i_{1}} S_{i_{2}} \ldots S_{i_{p}}
$$

com $S_{i}= \pm 1$, os acoplamentos escolhidos segundo uma distribuição de probabiliclades congelada, e a soma se estendendo por todas as $p$-uplas de spins la rede. que possui $N$ sítios. O que se sabe é que esse sistema tem uma transição de cle primeira ordem para uma fase vidro de spin a baixas temperaturas, para qualquer $p>2$, e essa fase é estável (numa faixa finita) com apenas um passo de quebra de simetria de réplicas [Gross e Mézard (1984), Gardner (1985)|; a temperaturas ainda mais baixas, ocorre outra transição, ngora contínua, para uma fase em que infinitos passos de quebra de simetria são necessários. O limite esférico do modelo corresponde a permitir que os spins assumam valores reais quaisquer, com a subseqüente imposição do vínculo esférico ou esférico médio; a estabilidade com um passo de quebra de simetria se mantém nesse limite [Crisanti e Sommers (1992)]. A primeira sugestão de que o modelo de $p$-spins submetido a uma dinâmica de Langevin puramente relaxacional (veja o Capítulo 3) poderia apresentar fenômenos comuns aos vidros reais, como envelhecimento e quebra da relação de flutuação-dissipação, foi dada por Kirkpatrick e Thirumalai (1987). No entanto, foram Cugliandolo e Kurchan (1993) que conseguiram dar um 
passo decisivo, no limite esférico, mostrando que realmente essas anomalias dinâmicas estão presentes.

Mas a verdadeira contribuição desse trabalho foi mostrar que o conjunto de equações que deve ser resolvido para calcular as funções de correlação " resposta do vidro de spin é formalmente equivalente às equações da chamada teoria de acoplamento de modos (mode coupling), que é a principal teoria microscópica disponível para a descrição de líquidos super-resfriados |Götze e Sjögren (1992)|. Assim, a idéia de alguma conexão muito profuncla cntre sistemas desordenados e vidros reais, através da dinâmica complexa cqu? ambos compartilham, parece ser inevitável.

\subsection{Comentário à publicação}

\section{Artigo 10 (p. 145)}

\section{Haddad, Vieira e Salinas - Physica A 000, 0000 (2004)}

Nosso objetivo neste trabalho foi dar início a um modesto programa de pesquisa que visa a buscar alguma alternativa mais simples aos modelos desordenados que têm sido tradicionalmente estudados por apresentarem dinâmicas complexas, semelhantes à de vidros reais. Utilizamos uma versão do modelo de $p$-spins extremamente simplificada, mas que se mostrou muito apropriada para o tratamento analítico. O modelo que propusemos não considera a possibilidade de acoplamentos aleatórios, apenas o campo magnético externo sendo dessa forma. Com isso, o termo de interação do hamiltonianu pode ser escrito numa simples forma de Curie-Weiss, que nada mais é que al potência $p$ da magnetização, exatamente como no caso do modelo de Ising usual. O termo do hamiltoniano em que comparece o campo aleatório pode ser considerado como um parâmetro de ordem adicional, de modo que o problema do cálculo da função de partição se reduz a uma contagem de estados, para cada valor fixo da magnetização e desse parâmetro extra; cm outras palavras, podemos considerar que basta calcular a contribuição entrópica à energia livre.

Essa contagem de estados pode ser realizada apelando a alguns pequenos truques matemáticos discutidos no artigo, e resulta que a energia livre pode ser expressa de forma fechada em diversos casos de interesse. Além do mais, verifica-se que a densidade de estados é auto-mediante, o que torna o cálculo da média da energia livre sobre a distribuição do campo trivial. Em particular, no limite esférico do modelo, a energia livre não depende dessa distribuição de probabilidades, e assume uma forma muito simples. A função de partição é dada por uma integral de Laplace com essa energia livir! 
como argumento, c facilmente se obtêm as equações de estado do sistema, que podem ser resolvidas semi-analiticamente para qualquer valor de $p$. É possível ainda demonstrar que a transição de fase é de primeira ordem para (11alquer $p>2$, de modo semelhante ao modelo tradicional.

Evidentemente, o objetivo real deste estudo é a introdução da dinâmica, na esperança de encontrarmos alguma assinatura das anomalias presentes (:m sistemas vítreos. É conhecido que determinados modelos muito simples podem apresentar alguns fenômenos dessa natureza [cf. Cannas, Stariolo ( Tamarit (2001)|, de modo que podemos ter alguma surpresa quando os rálculos forem efetuados. 


\section{Referências Bibliográficas}

ANGELl C.A. (1995), Science 267, 1924.

Cannas S.A., Stariolo D.A. e Tamarit F.A. (2001), Physica A 294, 362 .

Crishnti A. e Sommers H.-J. (1992), Z. Phys. B. 87, 341.

Crisanti A., Leuzzi L., Parisi G. e Rizzo T. (2003), Phys. Rev. B 68, 174401 .

Cugliandolo L.F. e Kurchan J. (1993), Phys. Rev. Lett. 71, 173

CUgliandolo L.F. (2002), Slow relaxation and nonequilibrium dynamics in condensed matter. Les Houches Session 77.

Debenedetti P.G. e Stillinger F.H. (2001), Nature 410, 259.

Fisher. D.S. (1998), Phys. Rep. 301, 113.

Gardner E. (1985). Nucl. Phys. B 297, 74.

Götze W. e Sjögren L. (1992), Rep. Progr. Phys. 55, 241.

Gross D.J. e Mézard M. (1984), Nucl. Phys. B 240, 431.

Hamley I.W. (2000), Introduction to Soft Matter: Polymers, Colloids, Amphiphiles and Liquid Crystals. John Wiley, London.

KauzMann W. (1948), Chem. Rev. 43, 219.

Kirkpatrick T.R. e Thirumalai D. (1987), Phys. Rev. Lett. 58, 209.

Witten T.A. (1999), Rev. Mod. Phys. 71, S367. 


\section{Capítulo 3}

\section{Breve comentário ao formalismo de Martin, Siggia e Rose (MSR)}

() formalismo MSR Martin, Siggia e Rose (1973)] surgiu no contexto da lidrodinamica, com o objetivo de permitir a aplicação do maquinário dos cílculos perturbativos das teorias quảnticas de campos a um problema clássico. En sua forma inicial, o método consistia num mapeamento das compouentes do campo clássico (o campo de velocidades de um fluxo na descrição euleriana, ou um campo escalar passivo qualquer) em termos de operadores "quânticos" na representação de Heisenberg. Para tanto, era necessário construir um espaço de Hilbert abstrato para servir de domínio a esses operadores. o posteriormente introduzir operadores conjugados fictícios, para fornecel as relações de comutação. Com isso, podia-se escrever formalmente uma versão do tcorema de Wick, que é o ponto de partida para a teoria de perturbacào sistemática. De Dominicis (1976) e Janssen (1976) ofereceram uma versão equivalente do método, baseada em integrais funcionais, muito mais adequada para problemas de mecânica estatística, e logo ficou claro que cle poderia ser aplicado também ao estudo da dinâmica de sistemas desordenados |De Dominicis $(1978,2000)]$. A abordagem dinâmica de sistemas desordenados acabou por se mostrar uma alternativa muitas vezes eficiente ao método das réplicas. Tal fato não chega a ser surpreendente, visto que o parâmetro de ordem de Edwards-Anderson, geralmente identificado com um overlap estático no espaço fictício das réplicas,

$$
q=\max _{\alpha, \beta}\left\langle S_{i}^{\alpha} S_{i}^{\beta}\right\rangle
$$

cm que $S_{i}^{\alpha}$ representa o spin $i$ da réplica $\alpha$, e $\langle\cdot\rangle$ a média térmica, é, na verdade, dado pela autocorrelação dinâmica

$$
q_{E A}=\lim _{t \rightarrow \infty} \overline{\left\langle S_{i}(0) S_{i}(t)\right\rangle}
$$


onde $S_{i}(t)$ é o valor do spin localizado em $i$ no instante $t$, e a barra indica al média sobre as variáveis congeladas de desordem (cf. Fischer c Hcrtz (1991); Dotsenko (2001)|. O parâmetro de Edwards-Anderson, pode. clessa forma. ser colocado no contexto geral do problema da persistência de uma função dke correlação, e as fases ordenadas de baixas temperaturas podem ser caracterizadas por um valor não nulo dessa persistência; além disso, toda a questão cla dinâmica fora de equilíbrio dos sistemas desordenados corresponde alo estudo da parte transiente deste parâmetro.

\subsection{Os rudimentos do método}

De maneira sucinta, podemos afirmar que o método MSR é capaz do fornecer, perturbativamente (em geral após renormalização). funçōes de correlação dinâmicas de $n$-pontos e funções de resposta linear, para teorias do campos clássicas submetidas a uma grande classe de dinâmicas clo tipo Langevin. Consideremos um problema muito simples, para a apresentação do formalismo, inspirado em notas de aula de J. Hertz (1998). Seja $\varphi$ um campo escalar de uma componente, em $d+1$ dimensöes, com um lingran1geano de Landau-Ginzburg-Wilson associado, denominado $\mathcal{L}$. Suponhamos que o campo $\varphi(\mathbf{x}, t)$ obedeça a uma dinâmica de Langevin "puramente rẹlaxacional" (o chamado modelo A na terminologia de Hohenberg e Halperin [1976]), dada genericamente por

$$
\frac{d \varphi}{d t}=-\Gamma \frac{\delta \mathcal{L}}{\delta \varphi}+\eta(t) \equiv-f(\varphi)+\eta(t),
$$

com $\Gamma$ um coeficiente cinético que tomaremos igual a um, e $\eta(t)$ unn ruílo branco gaussiano, com média

$$
\langle\eta(t)\rangle=0,
$$

e covariância

$$
\left\langle\eta(t) \eta\left(t^{\prime}\right)\right\rangle=2 \Gamma T \delta\left(t-t^{\prime}\right),
$$

em que $T$ é a temperatura $\left(k_{B}=1\right.$, para facilitar), e $\langle\cdot\rangle$ é uma média sobre a distribuição do ruído. Para o modelo de Ising, a dinâmica determinada pela Eq. (3.3) corresponde ao limite contínuo do conhecido modelo cinético de Glauber [Hohenberg e Halperin (1977)]. A origem fisica dessa dinâmica, bem como de diversas outras, está detalhadamente discutida no já citado trabalho de Hohenberg e Halperin, e também em Chaikin e Lubensky (1995).

Para o caso especifico de um campo $0+1$ dimensional, com lagrangeano de Landau-Ginzburg-Wilson dado por

$$
\mathcal{L}=m \varphi^{2}+\frac{g}{4 !} \varphi^{4},
$$


com $g>0$, a equação de Langevin toma a forma muito simples

$$
\frac{d \varphi}{d t}=-\mu \varphi-\frac{g}{3 !} \varphi^{3}+\eta(t),
$$

onde $\mu=2 m$. Tomando inicialmente $g=0$ (a teoria livre, harmônica ou gaussiana), ó fácil resolver a Eq. (3.7) via transformada de Fourier. Definindo a) transformada de uma função através de

$$
\hat{f}(\omega)=\int_{-\infty}^{+\infty} f(t) e^{-i \omega t} d t,
$$

a Eq. (3.7) fica simplesmente

$$
\hat{\varphi}(\omega)=\frac{\hat{\eta}(\omega)}{\mu+i \omega},
$$

onde $\hat{\eta}$ i a transformada do ruído branco. No caso da função de correlação de duplo tempo, temos

$$
\begin{aligned}
\left\langle\varphi(t)_{\varphi}\left(t^{\prime}\right)\right\rangle & =\frac{1}{(2 \pi)^{2}} \iint d \omega d \omega^{\prime} e^{i \omega t+i \omega^{\prime} t^{\prime}}\left\langle\hat{\varphi}(\omega) \hat{\varphi}\left(\omega^{\prime}\right)\right\rangle \\
& =\frac{1}{(2 \pi)^{2}} \iint d \omega d \omega^{\prime} e^{i \omega t+i \omega^{\prime} t^{\prime}} \frac{\left\langle\hat{\eta}(\omega) \hat{\eta}\left(\omega^{\prime}\right)\right\rangle}{(\mu+i \omega)\left(\mu+i \omega^{\prime}\right)},
\end{aligned}
$$

lembrando que $\langle\cdot\rangle$ é uma média sobre o ruído. Fazendo a transformada da Eq. (3.5), obtemos

$$
\left\langle\hat{\eta}(\omega) \hat{\eta}\left(\omega^{\prime}\right)\right\rangle=4 \pi T \delta\left(\omega+\omega^{\prime}\right),
$$

de modo cue se pode calcular facilmente a correlação expressa na Eq. (3.9), obtendo-se

$$
C\left(t-t^{\prime}\right) \equiv\left\langle\varphi(t) \varphi\left(t^{\prime}\right)\right\rangle=\frac{T}{\mu} e^{-\mu\left|t-t^{\prime}\right|} .
$$

Podemos, por completeza, antes de entrar no formalismo MSR, apresentar também a função de resposta linear a uma força externa, obtida quando acrescentamos à Eq. (3.7) um termo $h \delta\left(t-t^{t}\right)$. Nesse caso, o mesmo método de transformação de Fourier permite escrever

$$
\frac{\partial\langle\varphi(t)\rangle}{\partial h} \equiv G\left(t-t^{\prime}\right)=e^{-\mu\left(t-t^{\prime}\right)} \theta\left(t-t^{\prime}\right),
$$

onde $\theta(t)$ é a função degrau de Heaviside. O problema de um método desse tipo aparece quando queremos levar em conta a perturbação, isto é, quando y não é zero. 
O formalismo MSR entra exatamente nesse ponto. Ele começa com a observação de que a distribuição gaussiana do ruído branco, determinada pelas Eqs (3.4) e (3.5), é normalizada, isto é,

$$
\int D \eta(t) \exp \left[-\frac{1}{4 T} \int d t \eta^{2}(t)\right]=1 .
$$

se tomarmos

$$
D \eta(t)=\lim _{\Delta t \rightarrow 0} \prod_{i} \frac{\sqrt{\Delta t} d \eta\left(t_{i}\right)}{\sqrt{4 \pi T}} .
$$

O intervalo de integração em $t$ vai depender das condições de contorno. c não vamos nos preocupar em especificá-lo. Para entender o significado dessas expressões, lembremos que $\eta$ é uma função aleatória $(\eta(t)$, com $t$ fixo. é uma variável aleatória gaussiana tradicional). As funçóes aleatórias aulmissiveis são aquelas que, para cada $t$ e $t^{\prime}$ fixos. satisfazem as Eqs (3.4) " (3.5). Dado um conjunto $\left\{\eta\left(t_{i}\right)\right\}_{i=1}^{N}$, a probabilidade normalizadla de obtê-lo é evidentemente a gaussiana multidimensional

$$
P\left[\left\{\eta\left(t_{i}\right)\right\}_{i=1}^{N}\right]=\frac{1}{\sqrt{(2 \pi)^{N}(2 T)^{N}}} \exp \left[-\frac{1}{4 T} \sum_{i=1}^{N} \eta^{2}\left(t_{i}\right)\right] .
$$

No limite $N \rightarrow \infty$, o conjunto $\left\{\eta\left(t_{i}\right)\right\}_{i=1}^{N}$ representa uma função de ruíclo completa, e $P[\eta]$ se torna um funcional de cada "realização" de $\eta$. A normalização tem de ser expressa em termos de uma integral funcional, : a cliscretização correta é evidentemente a da Eq. (3.14), onde o fattor $\sqrt{\Delta t}$ surge porque transformamos a soma que aparecia no argumento da exponencial numa integral.

Podemos agora encontrar a distribuição funcional do próprio campo $\zeta$ : notando que, pela regra de mudança de variáveis,

$$
\int D \varphi P[\varphi]=\int D \eta(\varphi) J[\varphi] P[\eta(\varphi)],
$$

onde $J[\varphi]$ é um jacobiano funcional, dado por

$$
J[\varphi]=\operatorname{det}\left(\frac{\delta \eta}{\delta \varphi}\right)=\operatorname{det}\left(\partial_{t}+f^{\prime}(\varphi)\right),
$$

obtido expressando $\eta$ em função do campo, isto é,

$$
\eta=\dot{\varphi}+f(\varphi) .
$$


Esse tipo de jacobiano funcional deve ser calculado, evidentemente, discretizando o tempo, de modo que o operador $\partial_{t}$ se torna uma simples matriz de diferenças finitas. Na realidade, o importante seria o módulo do jacobiano, r"omo cm qualquer mudança de variáveis em integrais, mas não vamos nos preocupar com isso por enquanto. Obtemos, então

$$
P[\varphi]=J[\varphi] \exp \left[-\frac{1}{4 T} \int d t[\dot{\varphi}+f(\varphi)]^{2}\right] .
$$

Com isto, podemos escrever a média de qualquer funcional $F[\varphi]$ diretamente ula forma

$$
\langle F[\varphi]\rangle=\int D \varphi(t) F[\varphi] P[\varphi] .
$$

Em particular, podemos escrever um funcional gerador para função de correlaçào en $n$ instantes (que nada mais é que um funcional de $\varphi$ ), simplesmente acrescentando a $P[\varphi]$ um termo fonte,

$$
P[\varphi]=J[\varphi] \exp \left\{-\frac{1}{4 T} \int d t[\dot{\varphi}+f(\varphi)]^{2}+\int \tilde{h}(t) \varphi(t) d t\right\}
$$

Definindo o funcional gerador $W[h]$ como

$$
W[\tilde{h}]=\int D \varphi J[\varphi] \exp \left\{-\frac{1}{4 T} \int d t[\dot{\varphi}+f(\varphi)]^{2}+\int \tilde{h}(t) \varphi(t) d t\right\},
$$

$\therefore$ imediato que

$$
\left\langle\varphi\left(t_{1}\right) \varphi\left(t_{2}\right) \ldots \varphi\left(t_{n}\right)\right\rangle=\left.\frac{\delta^{n} W[\tilde{h}]}{\delta \tilde{h}\left(t_{1}\right) \delta \tilde{h}\left(t_{2}\right) \ldots \delta \tilde{h}\left(t_{n}\right)}\right|_{\tilde{h}=0} .
$$

() grande passo do método MSR ocorre neste ponto; utilizando a identidade gaussiana

$$
e^{-a^{2}}=\frac{1}{\sqrt{\pi}} \int_{-\infty}^{+\infty} d x e^{-x^{2}-2 i a x}
$$

a possivel reescrever o funcional gerador, Eq. (3.22), como

$$
\begin{aligned}
W[h] & =\int D \varphi D \tilde{\varphi} J[\varphi] \exp \left\{-\int d t\left[T \tilde{\varphi}^{2}+i \tilde{\varphi}(\dot{\varphi}+f(\varphi))-\tilde{h} \varphi\right]\right\} \\
& =\int D \varphi D \tilde{\varphi} J[\varphi] e^{-A[\varphi, \tilde{\varphi}]}
\end{aligned}
$$

onde definimos a ação

$$
A[\varphi, \tilde{\varphi}]=\int d t\left[T \tilde{\varphi}^{2}+i \tilde{\varphi}(\dot{\varphi}+f(\varphi))-\tilde{h} \varphi\right]
$$


Note que o campo gaussiano auxiliar $\tilde{\varphi}$ (conhecido às vezes como campo ghost) é um campo escalar livre de massa $\sqrt{T}$, sem auto-interação, apenas acoplamento externo. Toda a dificuldade que pode haver na análise clessal ação está contida, portanto, em $f(\varphi)$, que pode envolver auto-interaçăo.

A utilidade dessa formulação está na possibilidade de obtermos tambóm as funções de resposta linear (suscetibilidades dinâmicas); veja que à adição de uma força $h(t)$ ao hamiltoniano se reflete no surgimento de um tcrmo

$$
\int d t i \tilde{\varphi} h(t)
$$

na ação, de modo que a função de resposta linear se escreve como

$$
G\left(t-t^{\prime}\right)=\frac{\delta\langle\varphi(t)\rangle}{\delta h\left(t^{\prime}\right)}=\left\langle i \tilde{\varphi}\left(t^{\prime}\right) \varphi(t)\right\rangle .
$$

Assim, além das funções de correlação dinâmicas "diagonais" (cntre o (amplo $\varphi$ em diferentes instantes), obtidas diretamente a partir do funcional geraclor. as funções de correlação não-diagonais (entre o campo $\varphi$ e o campo auxilial. $\tilde{\varphi}$ ) fornecem diretamente a função de resposta linear. Se houver qualquer tipo de desordem congelada no hamiltoniano de Landau-Ginzburg-Wilson. basta tomarmos a média sobre essa desordem, sem necessidade de recorrer ao truque das réplicas.

Assim, vemos que todo o problema do cálculo dos observáveis dinàmicos relevantes (correlações e resposta) está contido no cálculo dis diversas funções de correlação de $n$-pontos da ação $A[\varphi, \tilde{j}]$. Este cálculo envolvo. vvidentemente, todo o formalismo de perturbação e renormalização de teorias de campos, podendo ser realizado até mesmo numa versão supersimćtrica [Hertz (1998)]. De posse dos observáveis dinâmicos, temos acesso até mesmo às propriedades estáticas, definidas como a parte persistente de tais observíveis, além de toda as propriedades de não-equilíbrio.

\subsection{Alguns comentários}

Neste ponto, muitos caminhos poderiam ser seguidos. Um mergulho mais profundo no formalismo, por exemplo, seria muito bem-vindo do ponto de vista de contribuir para a literatura didática sobre o MSR; a esse propósito, vale referir o leitor a um trabalho recente de Dickman e Vidigal (2003), que faz exatamente a apresentação muito didática de um método aparentado do MSR, e que teríamos desejado conseguir fazer para este com a mesma clareza e profundidade. Deveríamos incluir tópicos como a representaçăo 
matricial da ação; a introdução de variáveis de Grassmann para representar o determinante funcional (que muitas vezes é um elemento delicado do (álculos): a demonstração de que o funcional gerador é na verdade solução cle uma equação diferencial parcial parabólica, através do uso de uma forma generalizada da fórmula de Feynman-Kac (conhecida como o lema de Cameron-Martin-Girsanov); a conexão com o cálculo estocástico de Itô; e, não menos importante, os próprios fundamentos da teoria de perturbação cliagramática adequada ao estudo de ações do tipo MSR, bem como o grupo (le renormalização dinâmico, necessário para dar sentido à série perturbativa. É lastimável que todos esses tópicos não se encontram de modo algum sistematizados na literatura, no que se refere ao MSR.

Outro caminho a seguir seria a apresentação de aplicações simples do método. que não necessitam, de modo algum, de mais do que o exposto acima. A mais notável parece-nos ser a proposta por De Dominicis (1978); o que ele mostrou foi que, tomando um lagrangeano que contém elementos de desordem congelada. c postulando uma dinâmica de Langevin com ruído aditivo, a mais simples possivel, pode-se tomar uma média sobre a desordem congelada diretamente no funcional gerador, de modo a obter uma ação efetiva - que é nada mais que a ação replicada do sistema original! Trocando em miúdos, o poderoso resultado de De Dominicis mostrou que a ação dinâmica (suposta de Langevin, numa hipótese absolutamente ad hoc) de um sistema desordenado, após o traço sobre a desordem congelada, é matematicamente equivalente à ação do sistema com réplicas, sem qualquer dinâmica envolvida. Parece inevitável a conclusão de que há uma relação muito profunda entre o fato de un sistema ser desordenado e sua dinâmica poder ser, de alguma forma, complexa.

Outra aplicação do MSR que poderíamos mostrar utilizando apenas o (lue descrevemos anteriormente (mais um pouco de grupo de renormalização à moda da teoria de campos) foi dada por Janssen e Oerding (1994). Eles estuclaram um lagrangeano de Landau-Ginzburg-Wilson com termos até $\varphi^{6}$, adequado para a descrição de pontos tricríticos, com o objetivo principal de determinar a forma da relaxação da magnetização no ponto tricrítico e sua dependência na dimensão do sistema, incluindo correções logarítmicas nas vizinhanças da dimensão tricrítica superior (que vale 3). Nesse trabatho eles foram capazes de determinar analiticamente a forma da relaxação e até mesmo o valor do expoente $\theta^{\prime}$, associado à relaxação da magnetização no ponto tricrítico em tempos curtos [Janssen, Schaub e Schmittmann (1989)| após o instante inicial, em que o sistema fora preparado com uma magnetização não nula. 


\section{Referências Bibliográficas}

Chaikin P.M. e Lubensky T.C. (1995), Principles of Condensed Matter Physics. Cambridge University Press, Cambridge.

Dickinan R. o Vidigal R. (2003), Braz. J. Phys. 33, 73.

Dotsexko VIK. (2001), Introduction to the Replica Theory of Disordered Statistical Systems. Cambridge University Press, Cambridge.

De Dominicis C. (1976), J. Physique (Colloq.) C 37-1, 247.

De Dominicis C. (1978), Phys. Rev. B 18, 4913.

DE Dominicis C. (2000), notas de aula do curso "Théorie des champs du désordre figé via l'approche des répliques et l'approche dynamique". Saclay, França (não publicado).

Fischer. K.H. e Hertz J.A. (1991), Spin Glasses. Cambridge University Press. Cambridge.

Hertz J.A. (1998), notas de aula do curso "Spin Glass Physics". Nordita, Dinantarca (não publicado).

hohenberg P.C. e Halperin B.I. (1977), Rev. Mod. Phys. 49, 436.

Janssen H.K. (1976), Z. Phys. B 23, 377.

Janssen H.K., Schaub B. e Schmittmann B. (1989), Z. Phys. B 73, 539 .

Janssen H.K. e Oerding K. (1994), J. Phys. A: Mat. Gen. 27, 715.

Martin P.C., Siggia E.D. e Rose H.A. (1973), Phys. Rev. A 8, 423. 


\section{Epílogo}

Tendo já tomado a liberdade de iniciar este trabalho com um Prólogo, é natural encerrá-lo com um Epílogo, e também parece-me aceitável voltar a me clirigir diretamente ao leitor, sem o abrigo dos verbos conjugados no plural. Nessa volta ao estágio inicial, após um percurso talvez longo demais para alguns. talvez lacônico para outros, possivelmente monótono, não posso me furtar a convidar o leitor para uma reflexão sincera, cujo resultado terei de ustar pronto para aceitar: será que consegui cumprir aquilo a que me propus no início? A tese que eu dizia possuir foi satisfatoriamente defendida? Pensar nisso é a última coisa que peço a quem me acompanhou até aqui. E, pedindo também um pouco mais de paciência, posso aproveitar e expor as minhas impressōes a respeito desses pontos.

O ponto de partida do trabalho foi, parafraseando o que eu disse no início, o desejo de mostrar que a idéia de universalidade em mecânica estatística é bastante robusta, isto é, mesmo sistemas que são extraídos de classes de universalidade bem conhecidas por causa de perturbações geométricas acabam por encontrar seu lugar em outras classes, diferentes, mas num sentido (precisamonte (lefinido) tão universais quanto as de seus parentes não perturbados. Creio que no caso dos sistemas com quebra de simetria translacional gerada por clistribuições aperiódicas de acoplamentos (aperiódicas, mas não desor(lenadas!), mostramos à exaustão como se dá esse processo de escape das classes de universalidade correspondentes aos modelos homogêneos, e como o espaço de paràmetros ganha diferentes (e às vezes altamente inesperadas) estruturas atratoras que passam a controlar as novas classes.

Os modelos empregados para mostrar essa permanência da universalidade são extremamente simples, e as técnicas que permitem sua análise completa também (com a possível exceção do método de matrizes de transferência, que exige certa sofisticação matemática); ao menos, são muito mais simples que as técnicas usuais necessárias ao estudo dos sistemas desordenados. Supondo que realmente seja a quebra de simetria translacional trazida pela desordem o mecanismo mais eficiente pelo qual ela altera o comportamento dos sistemas nos quais se faz presente, os modelos com aperiodicidade determinís- 
tica têm seu valor: mostram que a teoria continua permitindo dassificaçós universais. Evidentemente, a desordem pode atuar de maneira muto mais sutil, engendrando efeitos que não podem. em absoluto. scr captados por sua contrapartida aperiódica determinística; as singulariclades de Griffiths. quo: descrevi no Capítulo 1, são um exemplo notável. Assim. não tenho qualquner pretensão de dizer que o estudo de um sistema aperiódico simples. com $\mathrm{um}$ método facílimo, pode substituir a análise dos problemas com desordent. estes verdadeiramente importantes do ponto de vista de conexão experimental e do ponto de vista da riqueza de fenômenos que apresentam para a tcoria. Mas, ainda assim, a análise dos modelos aperiódicos mostrou que a icléia do: universalidade é inteiramente preservada em seu caso, e permite classificaçóc's muito interessantes; por que não supor que ela possa estar preservada tanllbém no universo dos sistemas desordenados, no qual seria de cnormo valor. permitindo sistematizar a enorme variedade de comportanentos aparentemente distintos por eles apresentada?

Quanto ao Capítulos 2 e 3 , realmente devo dizer que näo passaram do breves ensaios, fotografias pouco nítidas de mundos que tangenciei cm mons anos de estudo de física estatística. Mas, ainda assim, considero que oles apresentam idéias que realmente têm uma ligação orgânica profunda com in temática principal. Como sugeri em outros momentos, a dinâmica de umin enorme classe de sistemas físicos é perturbadoramente semelhante à dinâmica de alguns sistemas desordenados que passeiam pela mecânica estatística lá décadas. Também me parece inevitável concluir que há uma conexão entre a desordem espacial e a dinâmica complexa, uma conexão universal, quo não pode de maneira alguma ser desprezada. Mas muitos dos sistemas que apresentam dinâmica complexa simplesmente não são clesordenados no (spacos! Se a única forma de gerar tal dinàmica for a desordem. então ó forçoso fluc: esses sistemas, de algum modo, "auto-induzem" algum tipo de aleatoricladlo. De algum modo eles têm de compartilhar propriedades universais com os sistemas desordenados tradicionais.

Assim, a idéia de universalidade é a que acredito estar no centro dos 111011s interesses, e é uma versão dela que pretendi expor ao longo deste trabalho. Introduzida em física estatística há muitas décadas, ela não perde sua for ça e seu potencial unificador, e continua a ser buscada numa variedade impressionante de modelos e sistemas, constituindo, ao mesmo tempo, instrumento valioso para a compreensão do mundo e da própria teoria que construímos in respeito desse mundo. Cabe agora ao leitor avaliar se tive algum sucesso c11 comunicar-lhe minha própria empolgação com essa idéia. 


\section{Apêndice}

\section{Artigos publicados}

Estão contidos neste apêndice os dez artigos que foram analisados no presente trabalho. () leitor deve notar que os dois primeiros (e apenas eles) foram publicados ainda durante o programa de mestrado; os dois últimos estão no prelo. 



\title{
Critical Behavior of an Ising Model with Aperiodic Interactions*
}

\author{
S. A. R. P'inho, T. A. S. Haddad, and S. R. Salinas \\ Instituto de trisica, Ciniversidode de São Paulo

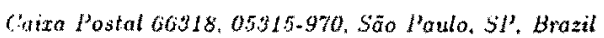

Received April 22.1997

\begin{abstract}
We write exact renormalization-group recursion rolations for a ferromagnctic lsing nodel an thr diamond hicrarchical lattice with an aperiodic distribution of cxchange interactions areoling to a dass of generalized twometter fibonacci sequences. Lor small geometric Huctuations. the critical bohavior is unebanged with respect to the uniform case. lor large fluetuations. the unifom fixed point in the parameter space becomes fully unstable. Ho analyz some limiting cascs. and propose a heuristic criterion to check the relevance of the illatuations.
\end{abstract}

1. Introsluction

The exprimental discovery of quasi-crystats motirated many inerstigations of the oflects of geometric Huctuations produed by fliferent types of aperiodic structurs. There are sewral specific results for phonon and clectronic spectra of lincar problems[1]. "There arc also some rosults for more difficult non-lincar problems. th the analysis of the critical propertics of a ferromaguctic bing mokl on a layered lattice with apcriodic "xchange intractions along an axial direction[2].

In a wem publication[?]. Luck presented a detailed Nidy af len critical bohaver in the ground state of lor quantum lsing chain in a transverse ficld which ix known of be polated to the transition at finite temperatures of the twodimensional lsing model). The nearst-ncigtabor forromagnetic exchange interactions are chosen according to some (generalized) libonacci equeners. The mometric fluctuations are gauged by a "andering aponent w associated with the exgenvalues whe substiturion mat rix of sach sequence. The critical behavior remains unchanged (that is. of Onsager type) for bounded ductuations (small valucs of $w$ ). Large lluctuations induce much weaker singularitics. similar to the case of a disordered lsing ferromagnet.

In this paper. we take advantage of the simplificaions introduced by a hicrarchical lattice to give an- other example of the effects of geometrical fluctuations on the critical bchavior of a forromagnetic model. It should be pointed out that hicrarchical lattices have bren widely used as a toy model to test critical propertics. In some cases the (approximatc) Migdal-Kadanoff renormalization-group transformations on a Bravais lattice are identical to the (exact) transformations on a suitable hierarchical structurc[4]. There are rathor detailed studics of these cxact transformations for the ising model on a variety of hicrarchical structures[5]. there are also some recent investigations of an ising spin-glass on the diamond hicrarchical lattice[6].

This paper is organized as follows. In Section II, wo make some comments on libonacei sequences and introduce a ncarest-ncighbor ferromagnetic lsing model on a diamond hierarchical lattice with of branches. To simulate a layered system, the exchange interactions $\left(I_{A}>0\right.$ and $\left.I_{B}>0\right)$ are distributed along the branches according to the same aperiodic rule. Lor a largo class of two-letter libonacci scquences. we write exact rcnormalization-group rccursion rclations in terms of two parancters, $x_{A}=\tanh K_{A}$, and $x_{B}=\tanh K_{B}$, where $K_{A}=\beta J_{A}, K_{B}=\beta J_{B}$, and $\beta$ is the inverse of the temperature. In Sections 111 and $I V$, we ana lyze two typical and distinct cxamples. Wo obtain the fixed points and the flows of the recursion relations for

\footnotetext{
*This paper is dedicated to Prof. Roberto Luzai in his both aumiversary,
} 
these specific cases. In the first example. for small is: the critical behavior is unchanged with respect to the unitorm case $\left(J_{A}=f_{B}\right)$ : the physical fixed point in parameter space is a saddle point. In the example of Section IV. however. the luctuations turn the physical fixed point futly unstable. We also analyze some limiting cases. For $q=1$ (Ising chain), there is no transition at finite temperatures. The fixed point at zero tenperature. however. may change its character depending on the value of the wandering exponent. In a particular infinitebranching linit $(q-\infty)$, we obtain rather simple results. In Section $V$, we present some conclusions. as well as a heuristic adaptation for the diamond hierarchical hatice of Luck's criterion[7] for the relevance of geometric Huctilations.

\section{Definition of the model}

Consider a particular two-letter generalized Fibonacci sequence given by the substitutions

$$
\begin{aligned}
& A-A B \\
& B-A A
\end{aligned}
$$

If we start with letter $A$, the successive application of this inflation rule produces the sequences

$$
A-A B-A B A A-A B A A A B A B \rightarrow \cdots
$$

$A$ each stage of this construction, the numbers $A_{A}$ and $N_{B}$, of letters $A$ and $B$, can be obtained from the re cursion relations

$$
\left(\begin{array}{l}
N_{A}^{\prime} \\
N_{B}
\end{array}\right)=\mathrm{M}\left(\begin{array}{l}
N_{A} \\
N_{B}
\end{array}\right)
$$

with the substitution matrix

$$
\mathbf{M}=\left(\begin{array}{ll}
1 & 2 \\
1 & 0
\end{array}\right)
$$

The eigenvalues of this matrix, $\lambda_{1}=2$ and $\lambda_{2}=-1$, govern most of the geometrical properties. In a more general case (that is. for a more general rule), at a large order $n$ of the construction. the total number of letters is given by the asymptotic expression

$$
N^{n}=N_{A}^{n}+N_{B}^{n} \sim \lambda_{i}^{n}
$$

where $\lambda_{1}>\left|\lambda_{2}\right|$. The smaller eigenvalue governs the fluctuations with respect to these asymptotic values.

$$
\Delta X^{n} \sim \Delta N_{A}^{n} \sim \Delta N_{B}^{n} \sim\left|\lambda_{2}\right|^{n}
$$

From these equations. we can writ. th" aspmptotic axpression

$$
\Delta N \rightarrow X^{2}
$$

with the wandering exponent

$$
w=\frac{\ln \left|x_{2}\right|}{\ln \lambda_{!}}
$$

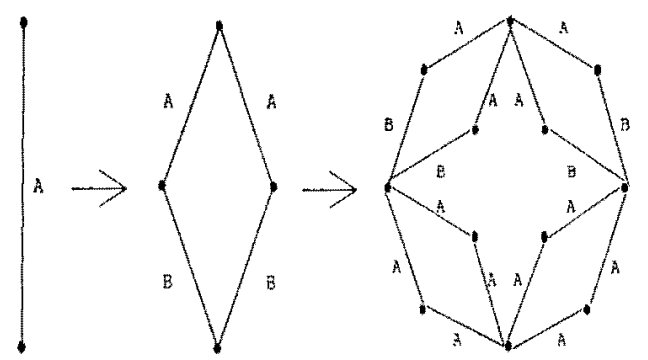

Figure 1, Some stages of the construction of a thamomal hicrarchical lattec with $\theta=2$ hanches. Lecters. I and $b$ indicate the cxchange interactions $\left(J_{4}\right.$ and $\left.f_{\|}\right)$.

Now we considet a nearesturighbor lsing modet. given by the Hamilonian

$$
H=-\sum_{(i, j)} J_{i, j} \sigma_{i} \sigma_{j}
$$

with the spin variables $\sigma_{i}= \pm 1$ on the sites of a diamond hierarchical structure. In Fig. 1 , which is suitable for the period-doubling Fibonacci rule of Eal(1). we draw the first stages of the construction of a dia mond lattice with a basic polyon of tome bonds (ramification $q=2)$. As indicated in this ligute. wintulat a layered system by the introduction of the interations $J_{A}>0$ and $J_{B}>0$ along the branches of the structure. Considering the elementary transformations of Fig. 2 . and using the rules of $\mathrm{Eq}$. (1), it is straightorward to establish the recursion relations

$$
\tanh K_{A}^{*}=\tanh \left[2 \tanh ^{-1}\left(\tanh \kappa_{A}\left(\tanh K_{B}\right)\right]\right.
$$

and

$$
\tanh K_{B}^{\prime \prime}=\tanh \left[2 \tanh ^{-1}\left(\tanh ^{2} K_{A}\right)\right] .
$$

where $K_{A_{i} B}=3 J_{A, B}$. In this particular case, these equations can also be written as

$$
x_{A}^{\prime}=\frac{2 x_{A} x_{B}}{1+x_{A}^{2} x_{B}^{2}}
$$


;i11i]

$$
r_{B}^{2}=\frac{2 x^{2}}{1+x^{2}}
$$

wher:

$$
R_{A B}=\tanh K A B
$$

In Siection 3. We analyze the fixed points associated with flese simple rectrsion relations.
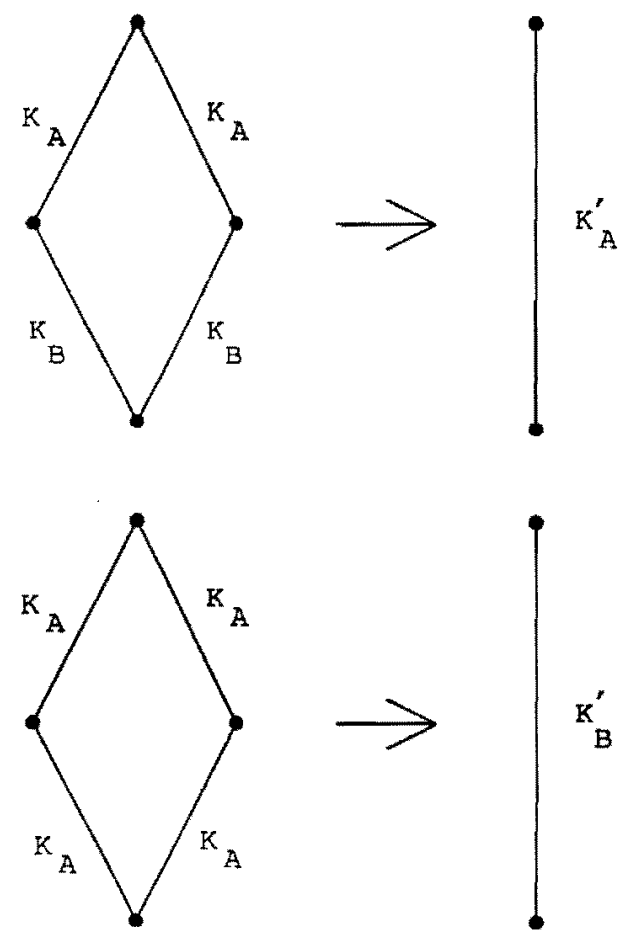

Higute 2. Basic graphs to obtain the recursion relations lor an lsing model on a diamond hierarehical latice with $q=2$ and exchange interactions given by the generalized Pibonacci rules, $A \rightarrow A B$, and $B-A$.

Wo can use similar procedures to consider much more general libonace rules. To avoid any changes in tho grometry of the hicrarchical lattice. in this papor wo restrict the analysis to period-multiplying libonace inHation rules of two let ters (the largest cigenvalue of the substitution matrix. $\lambda_{1}$, gives the multiplication factor of the period). For example, let us consider the substiIutions

$$
\begin{aligned}
& A-A^{k} B^{d} \\
& B-A^{k+1}
\end{aligned}
$$

where $k, l \geq 1$ are two integers. From the substitution matrix.

$$
\mathbf{M}=\left(\begin{array}{ll}
k & k+1 \\
1 & 0
\end{array}\right)
$$

we have the cigenvalues, $\lambda_{1}=k+l$ and $\lambda_{2}=-l$, and the wandering exponent, $\omega=\ln l / \ln (k+l)$. Now we consider a diamond lattice with $q$ branches and a basic polygon of $q(k+1)$ bonds. Ithe exchange interactions are chosen according to the general libonacci rule of Lq. (15). Wo then write the recursion relations

$$
\tanh K_{A}^{\prime}=\tanh \left[q \tanh ^{-1}\left(\tanh ^{k} K_{A} \tanh ^{\prime} K_{D}\right)\right]
$$

and

$$
\tanh K_{B}^{\prime}=\tanh \left[q \tanh ^{-1}\left(\tanh ^{k+1} K_{4}\right)\right]
$$

\section{Irrelevaut fluctuations}

Consider again the libonace inflation rules given by $\mathrm{Eq}$. (1). From the cigenvalues of the substitution matrix. $\lambda_{1}=2$ and $\lambda_{2}=-1$, we have $w=0$. For the branching number $q=2$. the recursion relations are given by Lis. (12) and (13). The fixed points and some orbits of the sccond itcrates of this nap are shown in Fig. 3. Besides the trivial fixed points, there is also a non-trivial fixed point, given by

$$
x_{A}^{*}=x_{B}^{\approx}=0.543689 \ldots
$$

which comes from the solution of the polynomial cquation

$$
x_{A}^{x}+2 x_{A}^{4}-4 x_{A}^{2}+1=0 .
$$

The lincarization about this uniform fixed point yiclds the asymptotic expression

$$
\left(\begin{array}{c}
\Delta x_{A}^{t} \\
\Delta x_{B}^{t}
\end{array}\right)=C M^{T}\left(\begin{array}{c}
\Delta x_{A} \\
\Delta x_{B}
\end{array}\right)
$$

where

$$
\mathrm{M}^{T}=\left(\begin{array}{ll}
1 & 1 \\
2 & 0
\end{array}\right)
$$

is the transpose of the substitution matrix and

$$
C=\frac{1-\left(x_{A}^{*}\right)^{4}}{2 x_{A}^{*}}=0.839286 \ldots
$$

The diagonalization of this linear form gives the cigenvalues

$$
A_{1}=C \lambda_{1}=2 C=1.678573 \ldots
$$


and

$$
\lambda_{2}=C \lambda_{2}=-C^{\circ}=-0.839286 \ldots .
$$

As $A_{1}>1$ and $-1<A_{2}<0$, the fixed point is a saddle point with a llipping approximation (in Fig. 3. we draw the trajectories of some second iterates of this map). Moreover, if we make $I_{A}=J_{B}$, it is easy to see that the same eigenvalue $A_{1}$ characterizes the (unstable) fixed point of the unilorm model (see the diagonal How in Fig. 3). Therelore. in this particular example the geometric fluctuations are unable to change the critical behavior of the uniform system.

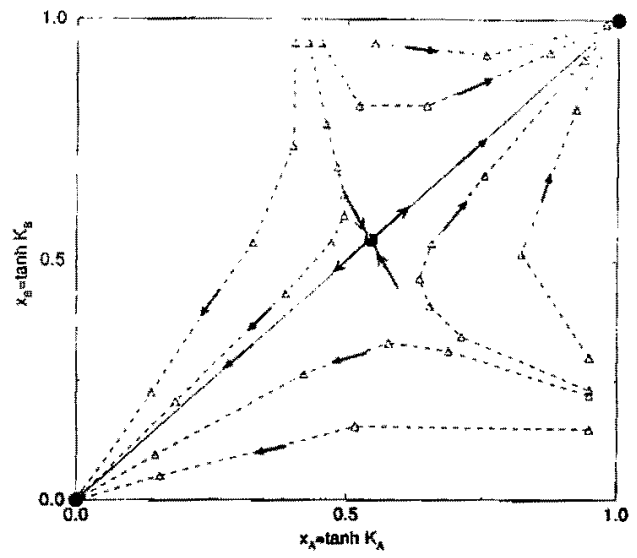

Figure 3. Second itcrates and fixcd points (black circles) of the rccursion relations in the parametcr space. $x_{A}=$ tanh $K_{A}$ versus $x_{B}=\tanh K_{B}$, far an Ising model an a diamond hicrarchical lattice with $q=2$ and cxchange interactions given by the generalized Fibonacci ralcs. $A-A D$, and $B \rightarrow$. Wit (irclevant fluctuationsi. We draw the sta ble trivial fixcd points (at zero and infinite temperatures) and the plysical saddte point. The dashed lines and the black arrows indicate the Hlows of the sccond iterates of the map. The uniform model is recovered along the diagonal. $x_{A}=x_{i z}$. The light arrows indicate the stable dirction in the neighborhood of the physical fixed point.

It is not difficult to check that the same sort of behavior (saddle point: largest eigenvalue associated with the uniform system) still holds for all finite values of the branching number $q$ of the diamond structure. In the limit of infinite branching $\left(q-\infty, K_{A}, K_{B}-1\right)$, with $q^{2} K_{A}$ and $q^{2} K_{B}$ fixed), the recursion relations are particularly simple.

$$
y_{A}^{\prime}=y_{A} y_{B}
$$

and

$$
y_{B}^{\prime}=y_{A}^{z}
$$

where $y_{A}=q^{2} K_{A}$ and $y_{n}=q^{2} K_{B}$. Iho. Linearizarion

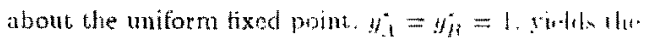
relations

$$
\left(\begin{array}{c}
\Delta y_{4}^{\prime} \\
\Delta y_{B}^{\prime}
\end{array}\right)=\mathrm{M}^{T}\left(\begin{array}{c}
\Delta y_{1} \\
\Delta y_{3}
\end{array}\right)
$$

which correspond to a limiting case of liq. (21), with (: - 1. As the limiting eigenvalues ate given by $\lambda_{1}=\lambda_{1}=2$ and $\lambda_{2}=\lambda_{2}=-1$, a lindar andyis is not enough to check the (llipping saddle-print) dharacter of this marginal cast.

Another particular cate of intersis is the simplo lsing chain $(q=1)$. The recursion whations are giten bỵ:

$$
x_{1}^{\prime}=x_{1}+13
$$

and

$$
x_{B}^{\prime}=x_{1}^{z}
$$

with the sane form of Eqs. (26) and (25), but wh th. parameters $x_{A}$ and $x_{B}$ given ly bit. (1.4) is shown in Fig. 1(a) the zero-temperature lixed point displays the character of a saddle point. Is there is 100 phats transition at finite temperatures. it cannot be rached from physically acceptable initial conditions.

\section{Rolcvant fluctuations}

To give an example of relevant fluctuations. considin the generalized Fibonacci sulsstitutions.

$$
\begin{aligned}
& A-A B B \\
& B-A . A
\end{aligned}
$$

From the substitution matrix.

$$
M=\left(\begin{array}{ll}
1 & 3 \\
2 & 0
\end{array}\right)
$$

we have the eigenvalues. $\lambda_{1}=3$ and $\lambda_{2}=-2$. and the wandering exponent. $w=\ln 2 / \ln 3=0.633042 ! 1 .$. for th general branching number q. we can use Eqs. (17) and (18), to write the recursion relations

$$
\tanh K_{A}^{\prime \prime}=\tanh \left[q \tanh ^{-1}\left(\tanh K_{A} \tanh ^{2} K_{B}\right)\right] .
$$

and

$$
\tanh K_{B}^{\prime}=\tanh \left[4 \tanh ^{-1}\left(\tanh ^{33} K_{4}\right)\right]
$$



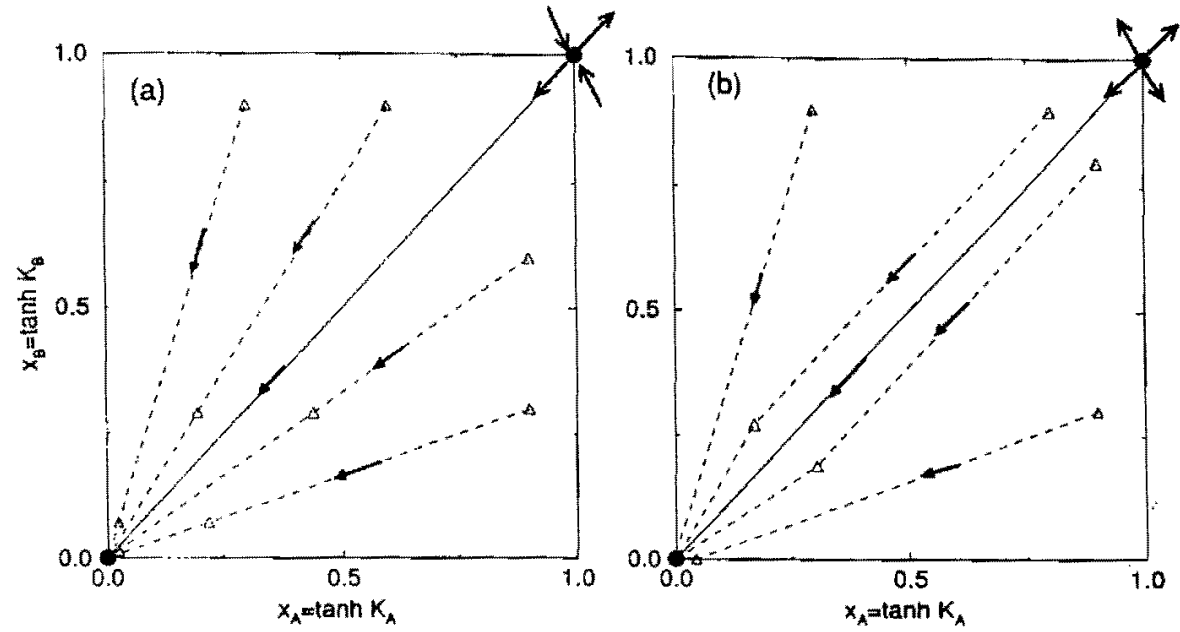

Figure 4. Second iterates and fixed points for the Ising chain: (a) exclange interactions according wo the rules $A \rightarrow A B$, and $B-A$ (irrelevant liuctuations): (b) exchange interactions according to the rules $A-A B B$, and $B \rightarrow A A A$ (relevant thetuationst.

For the particular fase $q=2$, Eqs. $(33)$ and (34) redure to the simple relations

$$
x_{A}^{\prime}=\frac{2 x_{A} x_{B}^{2}}{1+x_{A}^{2} x_{B}^{4}}
$$

and

$$
x_{B}^{\prime}=\frac{2 x_{A}^{3}}{1+x_{A}^{\sigma}},
$$

where the parameters $x_{A}$ and $x_{B}$ are given by Eq. (14). $f_{11}$ Fig. 5. we show the fixed points and some second ibrates associated with these recursion relations. The nontrivial fixed point, given by

$$
u_{A}^{*}=w_{b}^{*}=0.786151 \ldots
$$

comes from the plysical solution of a polynomial equation. The linearization about this uniform fixed point yiclds the relations

$$
\left(\begin{array}{l}
\Delta x_{A}^{\prime} \\
\Delta x_{B}^{i}
\end{array}\right)=C \mathrm{M}^{t}\left(\begin{array}{c}
\Delta x_{A} \\
\Delta x_{B}
\end{array}\right)
$$

where die substitution matrix is given by $\mathrm{Eq} .(32)$, and

$$
C=\frac{2\left(x_{A}^{*}\right)^{2}\left[1-\left(x_{A}^{*}\right)^{6}\right]}{\left[1+\left(x_{A}^{*}\right)^{n}\right]^{2}}=0.618033 \ldots
$$

From the diagonalization of this linear form we have the eigenvalues

$$
\Lambda_{1}=C \lambda_{1}=1.854101 \ldots
$$

and

$$
\Lambda_{2}=C \lambda_{2}=-1.236067 \ldots
$$

The absolute values of $\Lambda_{2}$ and $\Lambda_{2}$ larger than unit indicate the relevance of the geometric fuctuations. The uniform fixed point is fully unstable (and there might be no transition for $J_{A} \neq J_{B}$ ).

Again, it is not difficult to check that the uniform fixed point remains unstable for all values of the branching number $q$. In particular, for $q-\infty$, and $K_{A}, K_{B}-0$, with $q^{1 / 2} K_{A}$ and $q^{1 / 2} K_{B}$ fixed, we have the limiting recursion relations,

$$
y_{A}^{\prime}=y_{A} y_{B}^{3}
$$

and

$$
y_{D}^{\prime}=y_{A}^{3},
$$

where $y_{A}=q^{1 / 2} K_{A}$ and $y_{B}=q^{1 / 2} K_{B}$. The linearization about the uniform fixed point, $y_{A}^{*}=y_{B}^{*}=1$, yields the relations

$$
\left(\begin{array}{c}
\Delta y_{A}^{\prime} \\
\Delta y_{B}^{\prime}
\end{array}\right)=M^{T}\left(\begin{array}{c}
\Delta y_{A} \\
\Delta y_{B}
\end{array}\right)
$$

with the substitution matrix given by Eq. (32). We then have the limiting eigenvalues, $\Lambda_{1}=\lambda_{1}=3$, and 
$\Lambda_{2}=\lambda_{2}=-2$, which confirm the unstable character of this fixed point.

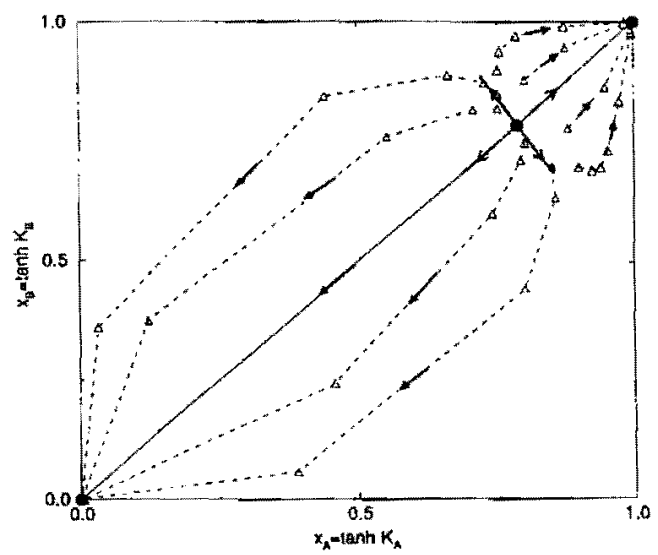

Figure 3. Second iterates and fixed points (black circles) of the recursion relations in the parameter space, $x_{\lambda}=$ $\tanh K_{A}$ versus $x_{B}=\tanh K_{B}$, for an Ising model on a diamond hierarchical lattice with $q=2$ and exchange interactions given by the generalized Fibonacei rules, $A-A B B$ and $B \rightarrow A A A$ (relevant finetuations). We draw the stable trivial fixed points (at zero and infinite temperatures) and the unstable node. The uniform model is recovered along the diagonal, $x_{A}=I_{B}$. The dashed lines are indications of the flow associated with the second iterates of the rnap. The light arrows indicate the directions of the eigenvectors in the neighborhood of the physical fixed point.

For the particular case of the linear chain $(q=1)$ we have

$$
x_{A}^{3}=x_{A} x_{B}^{3}
$$

and

$$
x_{B}^{\prime}=x_{i}^{3} .
$$

In agreemenl with the lack of a phase transition, the fixed point at zero temperature is unstable [see Fig. $4(\mathrm{~b})]$.

\section{Conclusions}

From the analysis of the exact renormalizationgroup recursion relations associated with an Ising model on a variety of hiecarchical diamond structures, we show that aperiodic fluctuations of the ferromagnetic exchange interactions may change the character of a (uniform) fixed point. In a particular example, with a small wandering exponent, the fluctuations are irrelevant. In this case, the critical behavior is still characterized by the same exponents of the corresponding uniform system. In another example, however, stronger geometric fluctuations turn the physical fixed point unstable in the parameter space. Bven in onc dimension, although there is no phase transition at finite tomperatures. we show that the geometric fluctuations changr the stability of the uniform fixed point at zero temper. ature.

As in the work of Luek[7], it should be interesting to devise a general critcrion to gauge the infuence of the geometric fluctuations on the critical behavior of the Ising model on the diamond hicrarrhical lathice. For a large lattice, with $q$ branches, the total fluctuation $\triangle J$ in the exchange interactions should be proportional th $\Delta N$. Thus we can write the asvmptutic rolation

$$
\Delta d \sim \Delta N \sim N^{* *} \sim 1^{4 \omega} .
$$

where $L$ is a measure of the rotal length. The critical temperature, $T_{c}$, should be proportional to the total value of the exchange (that is. to $L^{4}$ ). We can then define a reduced remperature, $t=\left(T-T_{B}\right) / T_{\mathrm{r}}$. whose fluctuations are given by the asymptotic form

$$
\delta t \sim \frac{L^{q \omega}}{L^{q}}=L^{q\{\omega-1\}} .
$$

In the neighbortwood of the critical point, wo have $L \sim \xi \sim t^{-\nu}$, where $\xi$ is a correlation length, and $\nu$ is a critical exponent. Thus, we can write

$$
\frac{\delta t}{t} \sim \frac{t^{-x q} q(\omega-1)}{t}=t^{\text {के }},
$$

with the exponent

$$
0=-\nu q(\omega-1)-1
$$

If $\phi>0$, the fluctuations are irrelevant. If $\phi<0$, however, the critical behavior is changed drastically. To calculate a suitablc value of $\nu$, we consider the largest eigenvalue of the diagonal form about the physical fixed point, and write the usual renormalization-group expression

$$
\Lambda_{1}=C \lambda_{1}=b^{y_{1}}=b^{1 / v} .
$$

As the largest eigenvalue $\lambda_{1}$ of the substitution matrix gives the multiplication factor of the Fibonacci rulo, we write

$$
b=\left(\lambda_{1}\right)^{1 / a} .
$$


Fom Los. (51) and (52), we have

$$
v=\frac{\ln \lambda_{!}}{y \ln \left(C \lambda_{1}\right)}
$$

Inerting ints by (50). wo tinally have

$$
\therefore=-\frac{\ln \lambda_{1}}{\ln \left(x \lambda_{1}\right)}(\omega-1)-1 \text {. }
$$

Whe Huctunions are redovant for

$$
\omega>-\frac{\ln C}{\ln \lambda_{1}}
$$

where the prefactor "can be obtained from the linwhalysis of the unstable fixed point of the uniform $\left(t_{A}=f_{n}\right)$ systom. Nllapugh the existence of somo isunterexample shonld not be rild out, the validity of llis criterion las been contimed by the application to at fair number of rase fincluding the examples of Secfinn: : 3 and 1). In the limit of infinite branching. the

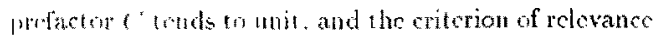

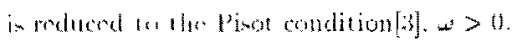

\section{Acknow leidgnents}

Wro thank a suggestion of D. Mukamel and sevral discussions with R. $\mathrm{Y}$. S. Andrade. STRP is on leave from Instituto de Física. liniversidade Federal da Bahia. and thanks a fellowship from the program CAPES/PICD. 'LASII and SIRS are partially supported by fellowships from $\mathrm{CN \textrm {Pq }}$. This paper is dedicated to the sixticth birthday of Prof. Hoberto Luzzi.

\section{References}

[1] See tor exanple, the reviews by ' $l$. Janssen and $\downarrow$ Loos. Phase lransitions $32 .{ }^{29}(1991)$ and by H. Hixamoto and M. Kohmoto. Int. J. Mod. Phys. B6. 281 (1992).

[2] See, lor example, $O$. A. Tracy, d, Phys. A21. Lo03 (1988), V. Benza. M. Kiolar, and M. K. Ali. Mhys. Rev. B41. 9578 (1990).

[3] J. M. Luck, J. Stat. Phys. 72, 117 (1993).

[1] A. N. Berker and S. Osthund. A. Phys, O12, 4961 (1979); P. M. Heher and E. Zalys. Comm. Nath. I'hys. 07. 17 (1979).

[5] M. Kautman and R. B. Kuffiths. Pyys. Rev. B24, 496 (19k1): R. B. Criffiths and M. liaufuan. Mhys. Rev. B20. 5022 (1982): M. Kautman and 1 t. B. Girfiths. Phys. Hev, B28. 3864 (1983)

[6] E. Nogueira Jr. S. Coutinho, F. D. Nobre, E. M. F', Curado, and J. R. L. de Almeida. l'hys. Rev. E55, 3934 (19y7).

[7] J. M. Luck, Europhys, Lett. 24. 359 (1993), 

PHYSICA /

\title{
Critical behavior of the Ising model on a hierarchical lattice with aperiodic interactions
}

\author{
S.T.R. Pinho. T.A.S. Haddad. S.R. Salinas*

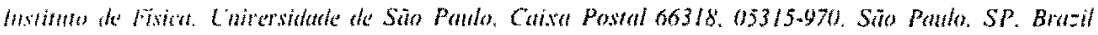

\section{Abstract}

He wite the exact renormalization-group recursion relations for nearest-neighbor ferromaghenc lsing models on Migdal-Kadanofl hierarchical lattices with a distribution of aperiodic sishange interactions necording to a class of substitutional sequences. For small geometric fuctuations. the critical behavior is unchanged with respect to the unitorm case. For large fluctuations. its in the case of the Rudin-Shapiro sequence, the uniform fixed point in the parameter space cannot be reached from any physical initial conditions. We derive a criterion to check the relevance of the seometric fluctuations. (C) 1998 Elsevier Science B.V. All rights reserved.

P.1CS: $05.50 ; 64.60 ; 75.10 . \mathrm{H}$

Kallords: Ising model: Critical phenomena; Magnetic ordering

There are a number of recent investigations on the critical behavior of ferromagnetic spin systems with the inclusion of aperiodic exchange interactions [I]. In particular. there are detailed studies of the critical behavior in the ground state of the quantum lsing chain in a transverse field $[2-5]$ (which is known to be related to the transition at linite temperatures of the two-dimensional Ising model). The nearest-neighbor ferromagnetic exchange interactions are chosen according to some substitution sequences. and the geometric fuctuations are gauged by a wandering exponent ( 1 ) associated with the eigenvalues of the substitution matrix of the sequence. According to a heuristic criterion proposed by Luck [3], the critical behavior remains unchanged (that is. of Onsager type) for bounded fluctuations (small values of $(0)$ ), but large fluctuations should induce much weaker singularities, similar to the case of a disordered Ising ferromagnet.

In a very recent publication [6], we took advantage of the simplifications brought about by a Migdal-Kadanof hierarchical (MKH) lattice [7] to perform some exact calculations for characterizing the critical behavior of aperiodic ferromagnetic Ising

\footnotetext{
"Corresponding auhor. Tel: +550118186931; fax: +550118134334; e-mail: ssalinas@if.usp.br.

0378-437198:\$19.00 Copyright (C) 1998 Elsevier Science B.V. All rights reserved.

PII: $50378-4371(98100185-\mathrm{X}$
} 
models. The (layered) exchange interactions between nearest neighbors were chosen according to a certain class of generalized Fibonacci sequences [8]. In this paper. 11 review some of these calculations, discuss the well-known case of the Rudin-Shapiro sequence, and present an exact derivation of an analog of Luck s criterion to check whether the geometric fluctuations are strong enough to change the eritical behavior of the uniform system.

Consider a particular two-letter generalized Fibonacci sequence given by the substitutions

$$
A \rightarrow A B . \quad B \rightarrow A d .
$$

If we start with letter $A$, the successive application of this inllation rule produces the sequences

$$
A \rightarrow A B \rightarrow A B A A \rightarrow A B A A B A B \rightarrow \cdots .
$$

At cach stage of this construction. the numbers $N_{A}$ and $N_{B}$, of letters if and $B$. can be obtained from the recursion relations

$$
\left(\begin{array}{l}
N_{t}^{\prime} \\
N_{B}^{\prime}
\end{array}\right)=\mathrm{M}\left(\begin{array}{l}
N_{4} \\
N_{B}
\end{array}\right)
$$

with the substitution matrix

$$
\mathbf{M}=\left(\begin{array}{ll}
1 & 2 \\
1 & 0
\end{array}\right)
$$

The eigenvalues of this matrix, $\lambda_{1}=2$ and $\lambda_{2}=-1$, govern most of the geometrical properties. For any sequence, the total number of letters, at a large order $n$ of the construction. depends asymptotically on $\lambda_{1}^{3}$. The fluctuations are of the order $\left|i_{2}\right|^{n}$. I1 is interesting to define the wandering exponent [3]. .

$$
(1)=\frac{\ln \left|i_{2}\right|}{\ln i_{1}}
$$

that expresses the asymptotic dependence of the fluctuations with the total number of letters, $\Delta N^{(n)} \sim N^{(4)}$.

The nearest-neighbor Ising model is given by the Hamiltonian

$$
\mathscr{H}=-\sum_{i, j)} J_{i, j} \sigma_{i} \sigma_{j}
$$

with the spin variables $\sigma_{i}= \pm 1$ on the sites of a hierarchical diamond structure. In Fig. 1, which is suitable for the period-doubling Fibonacci rule of Eq. (1), we draw the first stages of the construction of a diamond lattice with a basic polygon of four bonds (that is, of a MKH lattice with cell length $b=2$, and number of branches $q=2$. which amounts to 4 bonds in the diamond unit cell). As indicated in this figure. $w$ simulate a layered system by the introduction of the interactions $J_{i}>0$ and $J_{B}>0$ allong 


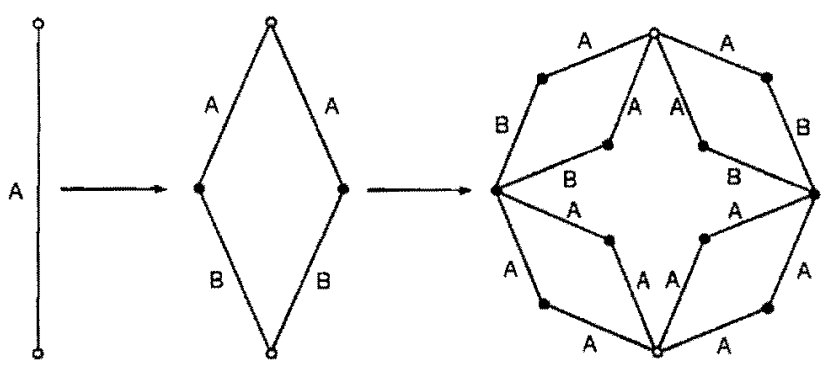

Fig. 1. Sonte stuges of the construction of a Migdal-Kadanoff hierarchicat lattice with bond length $b=2$ and $y=2$ branches (which is talled a dimond lattice) for the period-doubling sequence $A \rightarrow A B$ and $B \rightarrow A A$ (letters $A$ and $b$ indicate the exchange interactions. $J_{A}$ and $J_{B}$ ).

the branches of the structure. If we keep in mind the rules of Eq. (1), and decimate the intermediate spins, $i$ is straightforward $[6]$ to establish the recursion relations

$$
x_{1}=\frac{2 x_{A} x_{B}}{1+x_{1}^{2} x_{B}^{2}}
$$

and

$$
x_{B}^{\prime}=\frac{2 x^{3}}{1+x_{-1}^{4}}
$$

where $r_{1}=\tanh K_{A}, r_{B}=\tanh K_{B}, K_{A}=\beta J_{A}, K_{B}=\beta J_{B}$, and $\beta$ is the inverse of the temperature.

It should be remarked that a similar procedure can be used to consider much more general substitutional sequences. However, to avoid any changes in the topology of the hicrarchical lattice. we restrict the analysis to period-multiplying substitutions. In these cases. the largest eigenvalue of the inflation matrix, $\lambda_{1}$, gives the multiplication factor of the period. Therefore, $b=i_{i}$ for all casẹs under consideration (and, in particular, $h=i_{1}=2$. for the diamond lattice of the figure).

In the uniform case. $J_{A}=J_{B}=J$, Eqs. (7) and (8) reduce to the simple recursion relation

$$
x^{\prime}=\frac{2 x^{2}}{1+x^{4}}
$$

With two trivial and stable fixed points, $x^{*}=0$ and $x^{*}=1$, and a non-trivial and unstable lixed point. $x^{*}=0.543689 \ldots$, which come from the polynomial equation

$$
x^{5}-2 x^{2}+x=x\left[x^{4}-2 x+1\right]=0 \text {. }
$$

In the aperiodic case $\left(J_{A} \neq J_{B}\right)$ under consideration, the $A$ components of the coordinates of the fixed points in the physical sectors of the $x_{A}-x_{B}$ space $\left(0 \leqslant x_{A}, x_{B} \leqslant 1\right)$ come from the solutions of the equation

$$
x_{A}^{19}+2 x_{A}^{5}-4 x_{A}^{3}+x_{A}=x_{A}\left[x_{A}^{4}-2 x_{A}+1\right]\left[x_{A}^{4}+2 x_{A}+1\right]=0
$$


Therefore, a comparison with $\mathrm{Eq}$. (10) shows that the only fixed points are locatid along the $x_{A}=x_{B}$ direction, and given by the same values as in the uniform unse. $x_{A}^{*}=x_{B}^{*}=0, x_{A}^{*}=x_{B}^{*}=1$, and $x_{A}^{*}=x_{B}^{*}=0.543689 \ldots$ The linearization about the nontrivial uniform fixed point yields the asymptotic equations

$$
\left(\begin{array}{l}
\Delta x_{A}^{\prime} \\
\Delta x_{B}^{\prime}
\end{array}\right)=C \mathbf{M}^{r}\left(\begin{array}{l}
\Delta x_{t} \\
\Delta x_{B}
\end{array}\right)
$$

where $\mathbf{M}^{T}$ is the transpose of the substitution matrix, and the structure factor $C^{\prime}$ is given by

$$
C=\frac{1-x_{i}^{*}}{x_{i}^{*}}=0.839286 \ldots
$$

The diagonalization of this linear form gives the eigenvalues

$$
A_{1}=C_{1}=2 C=1.678573 \ldots
$$

and

$$
A_{2}=C \lambda_{2}=-C=-0.839286 \ldots
$$

where $\lambda_{1}=2$ and $\lambda_{2}=-1$ are the eigenvalues of the substitution matrix. $A_{s}, \lambda_{1}>1$ and $\left|A_{2}\right|<1$, the fixed point is a saddle node with a flipping approximation. Therefore. given the ratio $r=J_{B} / J_{A}$ between the exchange interactions. the critical temperature is defined by the flow into this uniform fixed point. From Eqs. (9) and (10), we see that the same eigenvalue $A_{1}$ characterizes the (unstable) fixed point of the uniform model. Thus, in this particular example, with the wandering exponent $b=0$, the geometric fluctuations are unable to change the critical behavior with respect to the uniform system. We can draw a phase diagram, in terms of the ratio $r$ and the temperature $T$. where the critical line displays the same (universal) exponents of the uniform calse. Also, it is not difficult to check that the same sort of behavior (saddle point: largest eigenvalue associated with the uniform system) still holds for all finite values of the branching number $q$ of the diamond $(b=2)$ structure.

To give an example with another value of the wandering exponent (1). where the geometric fluctuations become relevant. consider the (four-letter) Rudin-Shapiro sequence [8], $A \rightarrow A C . B \rightarrow D C, C \rightarrow A B$, and $D \rightarrow D B$. The substitution matrix is given by

$$
\mathbf{M}_{R S}=\left(\begin{array}{llll}
1 & 0 & 1 & 0 \\
0 & 0 & 1 & 1 \\
1 & 1 & 0 & 0 \\
0 & 1 & 0 & 1
\end{array}\right)
$$

with eigenvalues $\lambda_{1}=2, \lambda_{2}=-i_{3}=\sqrt{2}$, and $\lambda_{4}=0$, and the wandering exponent (') $=1 / 2$. For the Ising model on the diamond hierarchical lattice of the figure, it is easy to write the set of recursion relations

$$
x_{A}^{\prime}=\frac{2 x_{A} x_{C}}{1+x_{A}^{2} x_{C}^{2}} . \quad x_{B}^{\prime}=\frac{2 x_{D} x_{C}}{1+x_{D}^{2} x_{C}^{2}},
$$




$$
x_{C}^{\prime}=\frac{2 x_{A} x_{B}}{1+x_{A}^{2} x_{B}^{2}} \quad x_{D}^{\prime}=\frac{2 x_{D} x_{B}}{1+x_{D}^{2} x_{B}^{2}} .
$$

Again. there are two trivial fixed points. $x_{-4}^{*}=x_{B}^{*}=x_{C}^{*}=x_{D}^{*}=0$ and 1 , and the nontrivial uniform fixed point, $x_{A}^{*}=x_{B}^{*}=x_{C}^{*}=x_{D}^{*}=0.543689 \ldots$ as in the uniform case. The linearization about this uniform fixed point gives a matrix relation of the same form as Eq. (12),

$$
\left(\Delta x^{\prime}\right)=C M_{R S}^{T}(\Delta x)
$$

with the same structure factor $C$, given by Eq. (13), and the eigenvalues

$$
\begin{aligned}
& \left.A_{1}=C\right\rangle_{1}=2 C=1.678573 \ldots \\
& A_{2,3}=C \lambda_{2,3}= \pm C \sqrt{2}= \pm 1.186930 \ldots
\end{aligned}
$$

and

$$
A_{4}=C \ddots_{4}=0
$$

Therelore. besides being unstable along the diagonal direction $\left(x_{A}=x_{B}=x_{C}=x_{D}\right)$, this uniform lixed point is also unstable along two additional directions in the fourdimensional $x_{4}-x_{8}-x_{C}-x_{D}$ parameter space. Given the ratios between the exchange interactions, there is no temperature associated with any physical initial conditions in this parameter space so that we can reach the uniform fixed point. The critical behavior is of a much more subtle character as compared with the uniform case.

Now it is interesting to devise an analog of Luck's criterion to gauge the influence of the geometric fluctuations. As we have seen in the previous examples, the largest cigenvalue in the neighborhood of the uniform fixed point is given by

$$
i_{1}=i_{1} C=b c
$$

where it is important to remark that the calculations are always performed for substitutional sequences and MKH lattices such that $i_{1}=b$. The second largest eigenvalue is given by

$$
A_{2}=i_{2} C=\frac{i_{2}}{b} \lambda_{1}
$$

Therefore, the fluctuations are relevant if

$$
\left|A_{2}\right|=\frac{\left|A_{2}\right|}{b} A_{1}>1
$$

From the exact recursion relations between the free energies associated with successive generations of a uniform ferromagnetic Ising model on a MKH lattice [7], we can write

$$
A_{1}=b^{b}=b^{\frac{D}{2-x}} .
$$


where $x$ is the critical exponent of the specific heat of the uniform nodel and $D$ is the fractal dimension of the lattice. From the definition of the wandering exponent. given by Eq. (5), we can also write

$$
\left|i_{2}\right|=b^{\prime \prime \prime} \text {. }
$$

Inserting these expressions into incquality (25). we show that the geonetric luctuations are relevant for

$$
(a)>()_{c}=1-\frac{D}{2-\alpha} \text {. }
$$

In the particular case of the diamond hierarchical lattice $(b=2$ and $q=2)$ the fractal dimension is given by

$$
D=\frac{\ln (a b)}{\ln b}=2 \text {. }
$$

so the criterion is reduced to the inequality

$$
\text { (a) }>\left(\omega_{c}=-\frac{x}{2-x}\right. \text {. }
$$

As $A_{1}=2 C=1.678573 \ldots$ we have $*=-0.676533 \ldots$ and $\theta>0.252764 \ldots$ which explains the universal behavior of the first example $(\omega=0)$ and the relevance of the fluctuations in the case of the Rudin-Shapiro sequence $(\omega=1 / 2)$. This same criterion explains the change in the critical behavior of an aperiodic Potts model on the diamond hierarchical lattice above $4+2 \sqrt{2}$ states, as recently shown by Magalhães. et al. [9].

We thank discussions with R.F.S. Andrade and E.M.F. Curado. STRP is on leare from Instituto de Fisica, Universidade Federal da Bahia. and thanks a fellowship from the program CAPES/PICD. This work has been supported by grants from the Brazilian organizations Fapesp and $\mathrm{CNPq}$.

\section{References}

[1] See, for exanple. U. Grimm. M. Bake. Aperiodic Ising modets. in: R. V. Moody (Ed.). The Nahemaths of Long-Range Aperiodic Order. Kluwer Academic Publishers, Ansterdim, 1997. pp. 199...37.

[2] C.A. Tracy. J. Phys. A 21 (1988) L603: V. Benza. M. Kolar. M.K. Ali. Phys. Rev. B +1 (1990) 9578.

[3] J.M. Luck. J. Stat. Phys. 72 (1993) 417; J.M. Luck. Europhys. Lett. 24 (1993) 359.

[4] F. Igloi, L. Turbat. Phys. Rev. Lett. 77 (1996) 1206: B. Berche. P.E. Berche. M. Henkol. H. IHloi. P. Lajko, S. Morgan. L. Turban, J. Phys. A 28 (1995) LI65: F. lgiói. L. Turban. Europhys, Lett. 27 (1994) 91: F. Iglói. J. Phys. A 26 (1993) L703: F. Iglöi. D. Karevski. H. Rieger. Rantom and apetwalic quantum spin chains: a comparative study. cond-mat 9707185 .

[5] J. Hermisson. U. Grimm. M. Bake. Aperiodic Ising quantum chains, condimm 9706106.

[6] S.T.R. Pinho, T.A.S. Haddad. S.R. Salinas, Braz. J. Plys. 27 (1997) 567 ; conal-mat 9706234.

17] A.N. Berker. S. Ostlund. J. Phys. C 2 (1979) 4961: M. Kaufman. R.B. Grilitis. Plys, Res, B it (1981) 496: R.B. Griftiths, M. Kaufman. Phys. Rev. B 26 (1982) 5022: J.R. Melrose. J. Phys. A If (1983) 1041. and J. Plyss. A 16 (1983) 3077.

[8] M. Queffelec, in: A. Dold. B. Ecknann (Eds.). Substitutional Dymumical Systems. Lexture Notes in Mathematics, vol. 1294, Springer, Berlin. 1987.

[9] A.N. Magalhäes, S.R. Salinas. C. Tsallis, Potts nodels witl aperiodic intenctions on the diannond hierarchical lattice. to be published. 


\title{
Universal critical behavior of aperiodic ferromagnetic models
}

\author{
T. A. S. Haddad. ${ }^{*}$ S. T. R. Pinho. ${ }^{\dagger}$ and S. R. Salinas

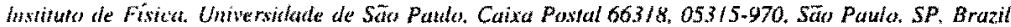 \\ (Received 30 June 1999; revised manuscript received 22 September 1999)
}

We investigate the effects of geometric fluctuations. assoctated with aperiodic exchange interactions. on the critical bethavior of $y$-state ferromagnetic Potts models on generalized diamond hierarchical lattices. For hy ered exchange interactions according to some two-letter substitutional sequences, and itrelevant geometric fluctuations. the exact recursion relations in parameter space display a nontrivial diagonal fixed point that governs the universal critical behavior. For relevan fluctuations. this fixed point becomes fully unstable, and we show the apperance of a two-cycle, which is associnted with a novel critical behavior. We use scaling arguments to calculate the critical exponent $\alpha$ of the specific heat. Which turns out to be different from the value for the uniform case. We check the scaling predictions by a direct numerical analysis of the singularity of the thermodynamic free energy. The agrement between scaling and direct calculations is excellent for stronger singularities (large values of a). The critical exponenis do not depend on the strengths of the exchange interactions.

PACS number(s): $05.50+q .05 .10 . \mathrm{Cc}, 05.70 . \mathrm{Fh}, 64,60 . \mathrm{Ak}$

Quenched disorder may change the critical behavior of ienomagnetic spin systems [1]. Although disorder provides the more usual exanples. there are altemative ways to break Inanslational invariance. For instance. the imerest in the study of quasicrystals [2] inspired a number of proposals of therministic schemes to build spalially aperiodic structures. In analogy with the Haris criterion to account for the effects of quenched disorder. Luck [3] developed a heuristic reasoning to gatuge the relevance of geometric fluctuations (associated witl" aperiodic interactions) on the critical behavior of ferromanetic models on Bravais lattices. In a recent publitation [4]. Luck's criterion has been exactly derived for a $q$-state ferromagnetic Potts model on a diamond-type hierarchical lattice. Now, we revisit this problem to show the existence of an atractor that gives rise to a novel class of critical behavios.

Many investigations of aperiodic classical [5] and quan[utn [6] Ising chains. and two-dimensional Ising models with aperiodic laycred interactions [7], use the formalism of substitution rules on alpiahets for the construction of infinite aperiodic sequences of elements. which are then associated vith coupting constants along a direction of the lattice. We have aken advantage of the structure of hierarchical latices [8] to build layered aperiodic models [9]. which are then anenable to simple (and exact) renormalization-group calculations. In parameter space. there is always a "diagonal." nontrivial. fixed poin of the renomalization-group recursion relations. For relevant geometric fuctuations, this diagonal fixed point. associated with the critical behavior of the uniform (equal couplings) model. becotnes fully unstable. and liertore. cannot be reached from any nonuniform initial conditions in putameter space [4]. The critical behavior of the aperiodically perturbed system, in case of a phase transition. should then be governed by another atuactor in parameter space.

*Electronic address: thaddad@if.usp.br

"Permanent address: Instituto de Fisica, Universidade Federal da Bahia. 40210 340. Salvador. BA, Brazil.

$1063-651 \times / 2000 / 61(4) / 3330(4) / \$ 15.00$
Relevant aperiodicity is believed to drastically weaken, or eventually suppress, the critical singularities [6]. Recenly conyincing Monte Carlo evidence [10] has been presented to indicate that relevant layered aperiodicity in the 8-state Potts model on the square latice drives the phase transition from first to second order (with critical exponents independent of the strength of the couplings). In the present paper, we also detect a weakening of the critical singularities for relevant geometric fluctuations. Besides being numerically exact, our results can be regarded as equivalent to a Migdal-Kadanoff approximation for the analogous problems on Bravais lattices, and may thus be put in perspective with the Monte Carto findings [10].

The $q$-state Pots ferromagnet is defned by the Hamiltonian

$$
H=-q \sum_{(i, j)} J_{i, j} \delta_{r r_{j} \cdot \sigma_{j}}
$$

where $\sigma_{i}=1,2 \ldots, q$ for all sites of a latice, $f_{i, j}>0$, and the sum over $(i, j)$ refers to nearest-neighbor pairs of sites. We issume that the couplings can take only two values. $J_{A}$ and $J_{B}$. associated with the sequence of letters $A$ and $B$ of an aperiodic substitutional word. To generate this sequence, we can use, for example, the successive iterations of a perioddoubling rule, given by $(A, B) \rightarrow(A B, A A)$. In Fig. 1, we show a simple diamond hierarchical lattice with aperiodic interactions according to this sequence (the letters, and the corresponding coupling constants, are chosen to mimic a lay-

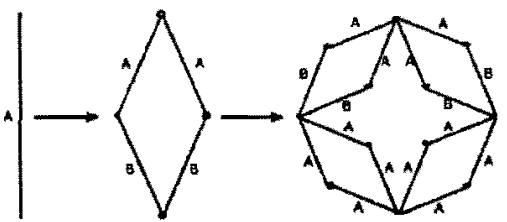

FIG. 1. Three successive generations of the simple diamond fattice $(b=m=2)$.

\section{0}

Q 2000 The American Physical Society 
ered structure). In general. we may consider basic "diamonds" with $m$ branches and $b$ bonds along each branch, and generate hierarchical lattices with intrinsic, or fractal. dimension, $D=\ln (m b) / \ln (b)$. In each one of these structures. aperiodicity may be implemented by a substitution rule of the form $(A, B) \rightarrow\left(A^{n_{1}} B^{i j-n_{1}}, A^{n_{2}} B^{b-n_{2}}\right)$, with $0 \leqslant n_{1}, n_{2}<b$. These sequences are characterized by a substitution matrix with eigenvalues $\lambda_{1}=b$ and $\lambda_{2}=n_{1}-n_{2}$. The asymptotic form of the fluetuations in the number of letters depends on the wandering exponent.

$$
\omega=\frac{\log \left|\lambda_{2}\right|}{\log \lambda_{1}}
$$

Now, we decimate the internal degrees of freedom of the diamonds to write exact recursion relations for the reduced couplings. There is always a nontrivial fixed point on the diagonal of parameter space, which is associated with the critical behavior of the uniform model. This fixed point becomes fully unstable for [4.9]

$$
\omega>1-\frac{D}{2-\alpha_{i t}} .
$$

where the critical exponent $\alpha_{u}$, associated with the specific heat of the underlying uniform model, depends on $q, m$, and $b$ (note that the transition is always continuous for the ferromagnetic Pous model on these hierarchical lantices [II]). Therefore. Ec. (3) is an (exact) alternative statement of Luck's original heuristic criterion of relevance of the geo metric fluctuations. Irrelevancy of the fluctuations corresponds to accessibility of the nontrivial symmetric fixed point, whatever the initial conditions. In the irrelevant cases, the critical behavior of the aperiodic systems remains unchanged with respect to the corresponding uniform models.

The problem now consists in the characterization of the new critical behavior under relevant geometrical fiuctuations. Andrade [12] has recently used a mapping for the succession of partition functions of aperiodic Ising models $(q=2)$ on hierarchical lattices to investigate this question. For irrelevant geometric fluctuations. the critical behavior seems to remain unchanged with respect to the uniform system. Although the results are not conclusive, the critical behavior does seem to change for an ising model on a diamond-type lattice with $m=b=3$, and layered aperiodic exchange inter actions according to the rule $(A, B) \rightarrow(A B B, A A A)$. To go beyond this work, we analyzed some families of aperiodic $q$-state Potts ferromagnets on diamondlike lattices to show that they do present a novel critical behavior (different from the uniform case, but universal) under relevant geometric fluctuations. This novel critical behavior can be exactly traced to new fealures in parameter space, exclusively related to the relevant geometric fluctuations.

Consider the Potts model on a lattice with $b=2$ bonds per branch, and interactions according to the period-doubling rule. From Eq. (3), for $m=2$, fluctuations are relevant if $q$ $>4+2 \sqrt{2}$ (for $m=3$, the threshold value of $q$ turns out to be somewhat lower, and so on). The recursion relations are given by

$$
x_{A}^{\prime}=\left(\frac{x_{A} x_{B}+q-1}{x_{A}+x_{B}+q-2}\right)^{m}
$$

and

$$
x_{n}^{t}=\left|\frac{x_{A}^{2}+q-1}{2 x_{A}+q-2}\right|^{\prime \prime}
$$

where $\left.x_{A, B}=\exp (q \beta)_{A, B}\right)$ with $\beta=1 / k_{B} T$. Besides the uniform (diagonal) fixed point. we have found a cycle of period two in the relevant regime (that is. the isvo-cycle is present when the nontrivial diagonal fixed point is fully unstable) Moreover, the two-cycle appears clenty is a bifurcution. its points runting away from the symmetric fixed point as 4 increases. In terms of the second iterate of the recursion relations lof which each point of the two-cycle is a tixed point). it displays a saddle-point character, with stable and unstable manifolds. Supposing that this two-cycle is associated with a novel critical behavior. we use standard scaling arguments to predict the critical exponent at of the specitic heat. Let us call $x$ the single relevant variable describing the parameter space in the neighborhood of the wo cycle. In the thermodynamic limit, we write the reduced free energy per bond in the scaling form $[13]$.

$$
f(x)=g(x)+\frac{1}{b^{2} b} f\left(x^{n}\right)
$$

where $g(x)$ is a regular function related to the five energy of the decimated spins. $x^{\prime \prime}$ is a second iterate of the remsion relations. and $b$ is the litiear rescaling factor of the renormalization-group transformation (which coincides. For diamondlike lattices, with the parameter $b$ of the basic tiamonds [14]). Note the presence of the factor $\left.b^{2} t\right)$. related to the need of two iterations to go back to the neighborhood of the starting point in parameter space. Equation (5) has the asymptotic solution

$$
f(x)=\left|x-x^{*}\right|^{2-u p}\left(\frac{\ln \left|x-x^{*}\right|}{\ln \Lambda_{t i n}}\right)
$$

where $x^{*}$ is one of the points of the awo-cycle. $\lambda_{1,4}$ is the largest eigenvalue of the linearization of the sccond iterate of the recursion relations about any one of the points of the cycle, $P(\theta)$ is an arbitrary function of peried onc. and the critical exponent $\alpha$, associated swith the specific heat. is given by

$$
\alpha=2-2 \frac{\ln b^{\prime}}{\ln A_{\text {cic }}}=2-2 \frac{\ln (m b)}{\ln A_{t+i c}}
$$

The values of $\alpha$ predicted by Eq. (7) are anequivocally different from the values $\alpha_{13}$ for the specilic heat exponemt in the uniform cases. as can readily be seen in Table 1 . for the simple diamond iatlice. $m=b=2$. with layered exchange itteractions according to the period-doubling sequence. As in the Monte Carlo simulations for the aperiodic 8-state Potts model on the square lattice [10], there is a clear weakening of the critical singularities due to the geometric fluctuations (a feature also presemt in disordered systems). Similar conclusions can be drawn for $b=2$ diamond-fype lattices with different values of $m$ and $q$, and the period-doubling substitution. 
TABLE 1. Results for the location of the two-cycle, eigenvalues of the second iterate of the recursion relations about the points of the wo-eycle and the specific-heat critical exponent, $\alpha$, as predicted by Eq. (7), for some values of $a$, in the case of the $m=b=2$ diamond with inc period-doubling substitution. The value of the exponent in the uniform $\left(J_{A}=J_{n}\right)$ case, $\alpha_{i f}$, is also shown for comparison.

\begin{tabular}{|c|c|c|c|c|c|c|}
\hline \multirow[b]{2}{*}{; } & \multicolumn{2}{|c|}{ Lowation of the two-cycle } & \multicolumn{2}{|c|}{ Eigenvalues of 2 nd iterate } & \multirow[b]{2}{*}{$a$} & \multirow[b]{2}{*}{$\alpha_{i t}$} \\
\hline & $\left(x_{A}, x_{B}\right)_{1}$ & $\left(x_{A}, x_{B}\right)_{2}$ & $\Lambda_{1}$ & $\Lambda_{2}$ & & \\
\hline 7 & $(5.285 \ldots 7.642 \ldots)$ & $(6.697 \ldots 4.750 \ldots)$ & $3.993 \ldots$ & $0.985 \ldots$ & $-0.0022 \ldots$ & $0.010 \ldots$ \\
\hline 25 & $(6.942 \ldots .234 .34 \ldots)$ & $(39.023 \ldots .3 .831 \ldots)$ & $4.243 \ldots$ & $0.343 \ldots$ & 0.0817 & $0.404 \ldots$ \\
\hline 100 & $(181.71 \ldots .5 .721 \ldots)$ & $(13.753 \ldots, 5151.84 \ldots)$ & 4.975 . & $0.074 \ldots$ & 0.2720 . & 0.648 . \\
\hline
\end{tabular}

We pettormed the same analysis for the Potts model on the $b=3$ generalized diamond lattice. with interactions acconding to the rule $(A, B) \rightarrow(A B B . A A A)$. Now, the recursion relations are given by

$x_{A}=\left[\frac{x_{A} x_{B}^{2}+(q-1) x_{A}+2(q-1) x_{B}+q(q-3)+2}{x_{B}^{2}+2 x_{A} x_{B}+(q-2) x_{A}+2(q-2) x_{B}+q(q-3)+3}\right]^{A}$.

ind

$$
v_{n}^{\prime}=\left[\frac{x_{A}^{3}+3(q-1) x_{A}+q(q-3)+2}{3 x_{A}^{2}+3(q-2) x_{A}+q(q-3)+3}\right]^{m}
$$

For all values of $m$, the condition of relevance. given by $\mathrm{Eq}$ (3), is satisfied for $(p \geqslant 2$ (including the Ising model, $q=2$ ). Again. besides the fully unstable fixed point, we have detected the presence of a two-cycle. The same sort of scaling analysis has been performed. Table 11 gives some results for $b=3$ and $m=2$. We see that the weakening of the critica singularities is again indicated by these data, the same trend heing present for $m=3$.

The presence of these two-cycles seems to be associated with the alternance of two energy scales, given by $J_{A}$ and $l_{l l}$. The iteration of the recursion relations leads to the altermative dominance of each one of them (as it can already be seen in the behavior of the fuctuations in the number of Luters $A$ and $B$ along a substitution sequence). To check this argument, we performed some calculations for the ferromag. netie Pots model on a simple diamond lattice, $m=b=2$, with aperiodic interactions according to the four-letter Rudin-Shapiro rule $(A, B, C, D)-(A C, D C . A B, D B)$, whose fuctuations are known to be relevant even in the Ising cisse [9]. Indeed, we have found a cycle of period four, along with fully unstable two-cycles, in regions of parameter space issociated with the symmetries of the sequence.

To test the validity of the scaling arguments, and of the vole of the tworeycle as the responsible for the new critical hehavior. we have pertormed a direct numerical analysis of the singularity of the free energy. In real-space renormalization-group calculations, it is well known that the (reduced) free energy can be expressed as an infinite series [15]. For the Potts model on the $b=2$ diamond-type lattice, with the period-doubling rule, it takes the form

$$
\begin{aligned}
f\left(x_{A}, x_{B}\right)= & \sum_{A=0}^{\infty} \frac{1}{(2 m)^{n}}\left[\frac{1}{3} \ln \left(x_{A}^{(n)}+x_{B}^{(n)}+q-2\right)\right. \\
& \left.+\frac{1}{6} \ln \left(2 x_{A}^{(n)}+q-2\right)\right]
\end{aligned}
$$

where $x_{A, B}^{(n)}$ indicate the $n$-th iterates of the recursion relations. Eq. (4). If we assume uniform convergence, this series can be differentiated term by term, and then summed in a computer, to obtain the specific heat per bond. We also used direct numerical differentiation as a control of this assumption of uniform convergence. The critical temperature can be determined with high precision by making use of the existence of the trivial paramagnetic fixed point at $T=0$, corresponding to $x_{A, B}=\infty$, which causes the apparent divergence of the series (9) if summed without the use of any regularization trick. Fixing the parameters $q$ and $m$, and also the strengths of $J_{A}$ and $J_{B}$, the critical temperature thus calculated in fact places $x_{A, B}$ in the attraction basin of the twocycle. For irrelevant aperiodicity, as well as for the uniform model, this method yields a critical temperature that locates the system on the stable manifold of the uniform fixed point.

The singularity in the specific heat can be analyzed by a (fonlinear) fitting of a function to the data over a somewhat arbitrary scaling region. For the uniform and irrelevant cases, we have always obtained very good fittings. in excellent agreement with the values of $\alpha_{u}$ predicted by the usual scaling theory around the uniform fixed point. As it should be anticipated, these fitted values did not present any detectable sensitivity on the values of $J_{A}$ and $J_{n}$. The particular prob. lem of the Ising model $(q=2)$ on the simple $m=b=2$ diamond lattice, with exchange interactions according to a period-doubling sequence, had already been studied by Andrade [12], with the same conclusions. In the relevant cases,

\begin{tabular}{|c|c|c|c|c|c|c|}
\hline \multirow[b]{2}{*}{4} & \multicolumn{2}{|c|}{ Location of the two-cycle } & \multicolumn{2}{|c|}{ Eigenvalues of 2 nd iterate } & \multirow[b]{2}{*}{$\alpha$} & \multirow[b]{2}{*}{$\alpha_{u}$} \\
\hline & $\left(x_{A}, x_{n}\right)_{1}$ & $\left(x_{A}, x_{A}\right)_{2}$ & $A_{1}$ & $\Lambda_{2}$ & & \\
\hline 2 & $(6.446, \ldots, 35.10 \ldots)$ & $(34.794, \ldots, 5.224 \ldots)$ & $3.255 \ldots$ & $0.311 \ldots$ & -1.0358 & $-0.902 \ldots$ \\
\hline 7 & $(11.469 \ldots .1649 .66 \ldots)$ & $(126.59 \ldots, 8.525 \ldots)$ & $4.755 \ldots$ & $0.075 \ldots$ & $-0.2981 \ldots$ & $-0.185 \ldots$ \\
\hline 100 & $(\$ 7.223 \ldots, 1121275,02 \ldots)$ & $(3272.70 \ldots, 34.683 \ldots)$ & $9.808 \ldots$ & $0.001 \ldots$ & $0.4304 \ldots$ & $0.898 \ldots$ \\
\hline
\end{tabular}
the situation is much subtler, and demands a more refined

TABLE II. Same as Table I, for the lattice with $b=3$ and $m=2$, with the rule $(A, B) \rightarrow(A B B, A A A)$. 
analysis. For large values of $q$, in which cases the scaling analysis predicts positive values of $\alpha$ (although. of course. smaller than the corresponding values of $\alpha_{z}$ ), the fittings presented excellent agreement with the scaling predictions. For weaker singularities (manly $\alpha$ negative), the fitted values were always somewhat bigger than the scaling predictions. with better agreement for increasing values of 4 . For $m=b=2$, and the period-doubling sequence, let us give some results of the fttings of the specific heat data to a function of the form $A+B|t|^{-a}$, where $t$ is the reduced temperature. and the parameters $A$ and $B$ must not be universal. For $q=7$. we obtained $\alpha=-0.005(4)$, which should be compared with $\alpha=-0.0022 \ldots$. For $q=25$, we have $\alpha$ $=0.08(2)$. to be compared with the scaling value $\alpha$ $=0.0817 \ldots$ For $y=100$, we have $\alpha=0.27(1)$, to be com. pared with $\alpha=0.2720 \ldots$ Even in the cases of disagreement with the scaling predictions, the fittings indicate no sensitivity on the particular values of $J_{A}$ and $J_{B}$, and thus characterize the universal nature of the critical behavior. For weak singularities. the discrepancies in the results cannot probably be explained in terms of lack of numerical precision, although it is in fact difficult to obtain a fully reliable fitting in these cases. This behavior can be probably traced to corrections to scaling that we are not considering in the direct application of the scaling ideas to the two-cycles. It should be pointed out that the free energy takes different values in each point of the two-cycle, in such a way that it may be ill defined in terms of just a simple scaling field.

We have performed the same kind of numerical check for a lattice with $b=3$, and with the aperiodic rule $(A, B)$ $\rightarrow(A B B, A A A)$. Now, aperiodicity is already relevant for $q$
$=2$ (Ising model), and the two-cycle can be found for $q \geq 2$. and all values of $m$. The situation turns out to be exactly the same as before. The numerical value of the critical temperature indeed locates the system on the attracion basin of the two-cycle. The agreement between the numerical litings and the scaling predictions for $\alpha$ improves as the critical singtularity grows stronger, which happens with incretsing values of $q$. In the special case $q=2$. and $n=h=3$. wh and All drade [12] have calculated similar values. $\mathrm{e}=-0.90(9) . \mathrm{t}$ be compared with the scaling prediction. $x=-0.9684 \ldots$

From the numerical calculations, we have observed an oscillatory behavior in the specific heat as a lunction of lemperature above $T_{1}$. The period of these uscillations is roughly given by Eq. (6). wilh better agreement for increasing values of $q$. These oscillations have also been lound by Andrade [12], and are well known phenomena related to hierarchical structures [16].

In conclusion, we have given a number of examples of ferromagnetic Potts models on diamond-type hierarchical Inttices to show that irrelevant geometric fluctuntions do not change the (universal) critical betavion with respect the uniform cases. On the other hand. for two-letter substitutional sequences. relevant geometric lluctualions give rise to a novel universal critical behavior assoetaled with at lavecycle in parameter space.

We are thankful for discussions with $R$. F. S. Andinde and very helpful suggestions and comments by $A$. P. Vicita and R. M. Damino. This work has been supported by the Brazillan agencies FAPESP, CAPES. and CNPq.
[1] A.B. Harris, I. Phys. C 7, 1671 (1974).

[2] D. Sehechtman, 1. Blech, D. Gratias, and J,W. Cahn, Phys. Rev. Lett. 53, 1951 (1984).

[3] J.M. Luck, Europhys, Lett. 24, 359 (1993).

[4] A.C.V. de Magalhäes, S.R. Salinas, and C. Tsallis, J. Phys, A. 31. $L 567$ (1998)

[5] Y. Achiam. T.C. Lubensky, and E.W. Marshall. Phys. Rev, B 33. $6460(1986)$.

[6] J.M. Luck, J. Stat. Phys. 72, 417 (1993); F. Iglói. L. Turban, and F. Szalma, Phys Rev. B 56, 11031 (1997); J. Hermisson U. Grimm, and M. Banke, J. Phys. A 30, 7315 (1997).

[7] C.A. Tracy, J. Phys. A 21, L603 (1988); F. Iglói, ibid. 21, L91) (1988): L. Turban, P.E. Berche, and B. Berche, ibid. 27, $6349(1994)$
[8] A.N. Berker and S. Osthund, I. Plyys, C 12, 4961 (1979): R.13 Griffiths and $M$. Kaufman. Phys. Rev. B 26. 5022 11982).

[9] S.T.R. Pinho. T.A.S. Haddad. and S.R. Salimas. Plysien A 257. $515(1998)$

[10] P.E. Berche, Ch. Chatelain, and B. Berche. Pinss. Rev. Leth 80, 297 11998); Ch. Chatekin. P.E. Berche. and B. Berche. Eur. Phys. J. B 7, $439(1999)$.

[11] B. Hu. Phys. Rev. Lett. 55, $21(1 \% \mathrm{x} 6$.

[12] R.F.S. Andrade. Phys. Rev. E 59.150 (1949).

[13] B. Derrida. J.P. Eckmann, and A. Erzan. I. 113ys. A $16.8 \%$ (1983).

[14] J.R. Melrose, J. Phys. A 16. 3077 (1983)

[15] M. Nauenberg, J. Phys. A 8. 925 (1975).

[16] B. Derrida, C. Itzykson, and J.M. Luck, Commm. Math. Plys. 94, $115(1934)$. 
International Journal of Modern Physics B, Vol. 14, No. 14 (2000) 1473-1480

(C) World Scientific Pubiishing Company

\title{
FIELD BEHAVIOR OF AN ISING MODEL WITH $A P E R I O D I C$ INTERACTIONS
}

\author{
ANGSULA GHOSH," T. A. S. HADDAD and S. R. SALINAS \\ Instituto de Física, Universidade de São Paulo, \\ Cakixa Postal 66318, 05315-970, Sāo Panto, SP, Brazil
}

Received 3 March 2000

\begin{abstract}
We derive exact renormalization-group recursion relations for an Ising model, in the presence of external fields, with ferromagnetic nearest-neighbor interactions on MigdaiKadanoff hierarchical lattices. We consider layered distributions of aperiodic exchange interactions, according to a class of two-letter substitutional sequences. For irrelevant geometric fluctuations. the recursion relations in parameter space display a nontrivial iniform fixed point of lyperbolic character that governs the universal critical behavior. For relevant fluctuations, in agreernent with previous work, this fixed point becomes fully unstable, and there appears a two-cycle attractor associated with a new critical universality class.
\end{abstract}

PACS Number(s): $05.50,64.60,75.10 . \mathrm{H}$

The discovery of quasicrystals has motivated the investigation of the effects of geonntric: Huctuations, associated with aperiodic interactions, on the critical behavior of spin systems.' According to the heuristic Harris criterion, ${ }^{2}$ it is known that. fluctuations produced by disordered interactions change the critical behavior of ferromagnetic systems whose uniform counterparts are characterized by a diverging specific heat at the transition. Although aperiodic interactions come from deterministic rules, and are thus highly correlated, they also introduce extra fluctnations that may lead to drastic changes in the critical behavior. As proposed by Luck. ${ }^{3}$ there is indeed a criterion of relevance of the geometric fluctuations, which has been confirmed by calculations for quantum spin chains with aperiodic exchange interactions. ${ }^{4}$

Taking advantage of the structure of the Migdal-Kadanoff hierarchical lattices, it is relatively easy to write exact recursion relations to analyze the critical behavior of ferromagnetic Ising and Potts models, in zero field, with layered aperiodic exchange interactions that are chosen according to a large class of substitutional sequences. ${ }^{5-8}$ There is an exact analog of the Harris-Luck criterion to gauge

-Email: angsula@if.usp.br 
the relevance of the geometric fluctuations in terms of the wandering exponent of the substitutional sequence, the number of states (of the Potts model), and somo structural features of the particular hierarchical lattice. ${ }^{6.7}$ For irrelevant Huctuations, the (universal) critical behavior is governed by a nontrivial uniform fixed point in parameter space of the recursion relations. For relevant fluctuations. at least in the case of two-letter substitutional sequences, this nontrivial uniform fixed point becomes fully unstable, and there appears a two-cycle hyperbolic attractor that gives rise to a new class of universal critical behavior. ${ }^{8}$

In the present publication, we report an extension of these calculations to analyze the field behavior of an Ising model with layered aperiodic exchange interactions on Migdal-Kadanoff hierarchical lattices. In one dimension, we regain results; of previous work by Achiam, Lubensky and Marshall ${ }^{9}$ for the ferromagnetic Ising chain with aperiodic exchange interactions (according to the standard two-lettcr Fibonacci sequence). In the uniform limit, we recover the results of Bleher and Zalys ${ }^{10}$ for the field behavior of the Ising model on the diamond hierarchical lattice. It should be mentioned that spin models with uniform interactions on genrral hierarchical lattices have been thoroughly investigated in a series of papers by katufmann and Griffiths. ${ }^{11}$

As in the work of Pinho, Haddad and Salinas, ${ }^{5,6}$ we initially consider a periorldoubling two-letter sequence,

$$
\begin{aligned}
& A \rightarrow A B, \\
& B \rightarrow A A,
\end{aligned}
$$

so that the successive application of this inflation rule on letter $A$ produces the sequence

$$
A \rightarrow A B \rightarrow A B A A \rightarrow A B A A A B A B A \rightarrow \cdots .
$$

The Hamiltonian of the nearest-neighbor Ising model is written in the form

$$
\mathcal{H}=-\sum_{(i, j)}\left(J_{i, j} \sigma_{i} \sigma_{j}+\frac{1}{2} h_{i, j}\left(\sigma_{i}+\sigma_{j}\right)+\frac{1}{2} h_{i, j}^{\dagger}\left(\sigma_{i}-\sigma_{j}\right)\right)
$$

where $\sigma_{i}= \pm 1$ is a spin variable on site $i$ of a hierarchical diamond structure, $\left\{J_{i j}\right\}$ is a set of exchange interactions, $h_{i j}$ and $h_{i j}^{\dagger}$ are external fields associated with the bonds of the structure, and the sum is over all pairs $(i, j)$ of nearest-neightbor sites. As in the one-dimensional problem, ${ }^{9}$ it is essential to take into account the staggered external field $h^{\dagger}$ in order to avoid any inconsistency in the final recursion relations. In Fig. 1, we show three successive stages of the construction of a diamond lattice (bond length $b=2$, and number of branches $m=2$ ) for the period-doubling sequence given by Eq. (1). As indicated in the figure, we construct a layered distribution of both the exchange parameters, $J_{A}$ and $J_{B}$, and the external fields, $h_{A}$, $h_{A}^{\dagger}, h_{B}$ and $h_{B}^{\dagger}$, along the branches of the simple diamond lattice. By decimating the intermediate spin variables (see Fig. 1), it is straightforward to write the recursion relations 


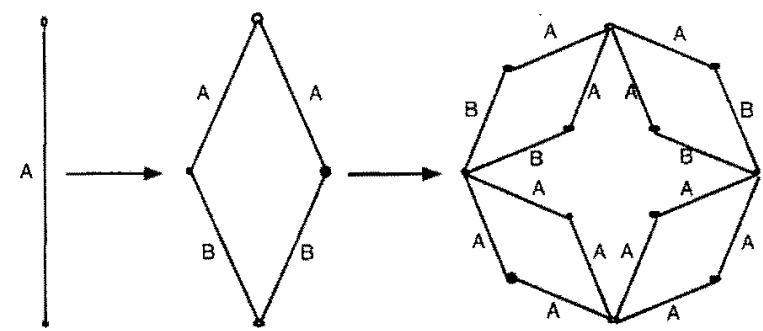

Fig. 1. Some generations of the simple diamond hierarchical lattice $(b=2$ bonds and $m=2$ branches). The layered exchange interactions are chosen according to the period-doubling twoletter substitution sequence, $A \rightarrow A B, B \rightarrow A A$.

$$
\begin{aligned}
& x_{A}^{\prime}=\frac{x_{A} x_{B}\left(1+y_{A}^{2} y_{B}^{2} z_{A}^{2} z_{B}^{2}\right)+y_{A} y_{B} z_{A} z_{B}\left(x_{B}^{2}+x_{A}^{2}\right)}{x_{A} x_{B}\left(1+y_{A}^{2} y_{B}^{2} z_{A}^{2} z_{B}^{2}\right)+y_{A} y_{B} z_{A} z_{B}\left(1+x_{B}^{2} x_{A}^{2}\right)} \\
& x_{B}^{\prime}=\frac{x_{A}^{2}\left(1+y_{A}^{4} z_{A}^{4}\right)+2 x_{A}^{2} y_{A}^{2} z_{A}^{2}}{x_{A}^{2}\left(1+y_{A}^{2} z_{A}^{4}\right)+y_{A}^{2} z_{A}^{2}\left(1+x_{A}^{4}\right)} \\
& y_{A}^{\prime}=\frac{y_{A} y_{B}\left(x_{A} x_{B}+y_{A} y_{B} z_{A} z_{B}\right)}{z_{A} z_{B}\left(1+x_{A} x_{B} y_{A} y_{B} z_{A} z_{B}\right)} \\
& y_{B}^{\prime}=\frac{y_{A}^{2}\left(x_{A}^{2}+y_{A}^{2} z_{A}^{2}\right)}{z_{A}^{2}\left(1+x_{A}^{2} y_{A}^{2} z_{A}^{2}\right)} \\
& z_{A}^{\prime}=\frac{y_{A} z_{B}\left(x_{B}+x_{A} y_{A} y_{B} z_{A} z_{B}\right)}{y_{B} z_{A}\left(x_{A}+x_{B} y_{A} y_{B} z_{A} z_{B}\right)}
\end{aligned}
$$

and

$$
z_{B}^{\prime}=1
$$

where $x_{A, B}=\exp \left(-2 \beta J_{A, B}\right), y_{A, B}=\exp \left(-\beta h_{A, B}\right), z_{A, B}=\exp \left(-\beta h_{A, B}^{\dagger}\right)$ and $\beta$ is the inverse of the temperature.

In the uniform case, $J_{A}=J_{B}=J, h_{A}=h_{B}=h$, and $h_{A}^{\dagger}=h_{B}^{\dagger}=h^{\dagger}$, Eqs. (5)(10) reduce to the recursion relations

$$
\begin{aligned}
& x^{\prime}=\frac{x^{2}\left(1+y^{4} z^{4}\right)+2 x^{2} y^{2} z^{2}}{x^{2}\left(1+y^{4} z^{4}\right)+y^{2} z^{2}\left(1+x^{4}\right)}, \\
& y^{\prime}=\frac{y^{2}}{z^{2}} \frac{x^{2}+y^{2} z^{2}}{1+x^{2} y^{2} z^{2}},
\end{aligned}
$$

and

$$
z^{\prime}=1
$$


which can be compared with the expressions obtained by Bleher and Zalys ${ }^{10}$ for the simple Ising model in a (uniform) field. For the aperiodic model, but in the absence of the external fields, we recover the equations obtained by Pinlo et al. 5.6 Due to the presence of a staggered field, it is important to see that the form of the recursion relations depends on the way we label the bonds on the diamoud lattice. To be consistent with the calculations of Bleher and Zalys, we assume a positive staggered field at the intermediate spins $\left(\sigma_{i}\right)$ of the polygon, and an opposite tiels at the nodes $\left(\sigma_{j}\right)$. With a change of order, there is no automatic cancellation of the staggered field associated with the $B$ bonds.

The nontrivial uniform fixed point of the recursion relations $(5)-(10)$ is given by $y_{A}=y_{B}=z_{A}=z_{B}=1$, corresponding to an Ising model in zero ficld $\left(h_{A}=\right.$ $h_{B}=h_{A}^{\dagger}=h_{B}^{\dagger}=0$ ), and

$$
x_{A}^{*}=x_{B}^{*}=x=0.295598 \ldots,
$$

which comes from the cubic equation $x^{3}+x^{2}+3 x-1=0$, and is the usual result for the uniform model. The trivial fixed points are located at $y_{A}=y_{B}=z_{A}=z_{B}=1$. with $x_{A}^{*}=x_{B}^{*}=0$ or 1 . The linearization of the recursion relations abont the nontrivial uniform fixed point, yields the block-diagonal form

$$
\left(\begin{array}{l}
\Delta x_{A}^{\prime} \\
\Delta x_{B}^{\prime} \\
\Delta y_{A}^{\prime} \\
\Delta y_{B}^{\prime} \\
\Delta z_{A}^{\prime} \\
\Delta z_{B}^{\prime}
\end{array}\right)=\left(\begin{array}{cccccc}
C & C & 0 & 0 & 0 & 0 \\
2 C & 0 & 0 & 0 & 0 & 0 \\
0 & 0 & 1+C & 1+C & -1+C & -1+C \\
0 & 0 & 2+2 C & 0 & -2+2 C & 0 \\
0 & 0 & 1 & -1 & -1 & 1 \\
0 & 0 & 0 & 0 & 0 & 0
\end{array}\right)\left(\begin{array}{l}
\Delta x_{A} \\
\Delta x_{B} \\
\Delta y_{A} \\
\Delta y_{B} \\
\Delta z_{A} \\
\Delta z_{B}
\end{array}\right),
$$

where $C=\left(1-x^{2}\right) /\left(1+x^{2}\right)=0.839286 \ldots$ The thermal eigenvalues, given $\mathrm{by}$

$$
\Lambda_{1}=2 C=1.67857 \ldots, \quad \text { and } \quad \Lambda_{2}=-C=-0.839286 \ldots \text {, }
$$

are identical to the findings of Pinho, Haddad and Salinas, ${ }^{5}$ in zero external field. The magnetic eigenvalues are given by

$$
\begin{aligned}
& \Lambda_{3}=2(1+C)=3.678572 \ldots, \quad \Lambda_{4}=-2, \\
& \Lambda_{5}=-C=-0.839286 \ldots, \quad \text { and } \quad \Lambda_{6}=0 .
\end{aligned}
$$

For the Ising model on the diamond lattice with a uniform distribution of exchange interactions (as in the work of Bleher and Zalys), the linearization about the nontrivial fixed point of Eqs. (11) and (12) leads to the set of three uniform eigenvalues, $\Lambda_{1}=2 C=1.67857 \ldots, \Lambda_{3}=2(1+C)=3.678572 \ldots$, and $\Lambda_{6}=0$. Therefore, as in the work of Pinho, Haddad and Salinas, and in agreement with the analog of the Harris-Luck criterion, we see that the geometric fluctuations associated witl the period-doubling sequence are unable to change the ferromagnetic critical beliavior 
of the Ising model on the diamond lattice. The absolute value of the smaller thermal rigenvalue is less than 1 . The absolute values of the eigenvalues associated with the uniform field are both larger than one. The staggered field is irrelevant as in the uniform case. Also, it should be noted that the same kind of behavior still holds for a more general diamond-type lattice, with $b=2$ bonds and $m>2$ branches.

Due to the peculiar structure of the diamond hierarchical lattice, there is a change in the magnetic eigenvalues if we make another choice for the sign of the staggered field. This effect is already present in the model with uniformly distributed exchange interactions. In fact, if we linearize the new recursion relations of the uniform model, in direct and staggered applied fields, we obtain the same values for $\Lambda_{1}$ and $\Lambda_{3}$, but $\Lambda_{6}=-2$, instead of $\Lambda_{6}=0$. For the aperiodic model, we obtain the new values $\Lambda_{4}=-1.78151 \ldots, \Lambda_{5}=-0.942221 \ldots$, and $\Lambda_{6}=-2$. Hence, we see that we cannot attribute this change of magnetic eigenvalues to the introduction of aperiodic exchange interactions. It is evident that aperiodicity is not the cause for these changes.

To give an example of relevant geometric fluctuations, we now consider the perioci-thrce two-letter sequence,

$$
\begin{aligned}
& A \rightarrow A B B, \\
& B \rightarrow A A A .
\end{aligned}
$$

The nearest-neighbor Ising model is defined on a Migdal-Kadanoff lattice with $b=3$ bonds and $m=2$ branches. Although somewhat tedious, it is straightforward to write the recursion relations

$$
\begin{aligned}
& x_{A}^{\prime}=\frac{F_{1}\left(x_{A}, x_{B}, y_{A}, y_{B}, z_{A}, z_{B}\right) F_{2}\left(x_{A}, x_{B}, y_{A}, y_{B}, z_{A}, z_{B}\right)}{F_{3}\left(x_{A}, x_{B}, y_{A}, y_{B}, z_{A}, z_{B}\right) F_{4}\left(x_{A}, x_{B}, y_{A}, y_{B}, z_{A}, z_{B}\right)} \\
& x_{B}^{\prime}=\frac{F_{1}\left(x_{A}, x_{A}, y_{A}, y_{A}, z_{A}, z_{A}\right) F_{2}\left(x_{A}, x_{A}, y_{A}, y_{A}, z_{A}, z_{A}\right)}{F_{3}\left(x_{A}, x_{A}, y_{A}, y_{A}, z_{A}, z_{A}\right) F_{4}\left(x_{A}, x_{A}, y_{A}, y_{A}, z_{A}, z_{A}\right)} \\
& y_{A}^{\prime}=\frac{y_{A} y_{B} z_{A} F_{A}\left(x_{A}, x_{B}, y_{A}, y_{B}, z_{A} z_{B}\right)}{z_{B} F_{3}\left(x_{A}, x_{B}, y_{A}, y_{B}, z_{A}, z_{B}\right)} \\
& y_{B}^{\prime}=\frac{y_{A}^{2} F_{4}\left(x_{A}, x_{A}, y_{A}, y_{A}, z_{A}, z_{A}\right)}{F_{3}\left(x_{A}, x_{A}, y_{A}, y_{A}, z_{A}, z_{A}\right)} \\
& z_{A}^{\prime}=\frac{y_{A} z_{A} z_{B} F_{1}\left(x_{A}, x_{B}, y_{A}, y_{B}, z_{A}, z_{B}\right)}{y_{B} F_{2}\left(x_{A}, x_{B}, y_{A}, y_{B}, z_{A}, z_{B}\right)} \\
& z_{B}^{\prime}=\frac{z_{A}^{2} F_{1}\left(x_{A}, x_{A}, y_{A}, y_{A}, z_{A}, z_{A}\right)}{F_{2}\left(x_{A}, x_{A}, y_{A}, y_{A}, z_{A}, z_{A}\right)}
\end{aligned}
$$


1478

A. Ghosh, T. A. S. Haddad \& S. R. Salinas

where

$$
\begin{aligned}
F_{1}\left(x_{A}, x_{B}, y_{A}, y_{B}, z_{A}, z_{B}\right)= & x_{A} z_{A} z_{B}+x_{A} x_{B}^{2} y_{B}^{2} z_{A} z_{B}^{3} \\
& +x_{B} y_{A} y_{B}+x_{B} y_{A} y_{B}^{3} z_{B}^{2}, \\
F_{2}\left(x_{A}, x_{B}, y_{A}, y_{B}, z_{A}, z_{B}\right)= & x_{B} z_{A} z_{B}+x_{A} x_{B}^{2} y_{A} y_{B} \\
& +x_{B} y_{B}^{2} z_{A} z_{B}^{3}+x_{A} y_{A} y_{B}^{3} z_{B}^{2}= \\
F_{3}\left(x_{A}, x_{B}, y_{A}, y_{B}, z_{A}, z_{B}\right)= & z_{A} z_{B}+x_{A} x_{B} y_{A} y_{B} \\
& +x_{A} x_{B} y_{A} y_{B}^{3} z_{B}^{2}+. x_{B}^{2} y_{B}^{2} z_{A} z_{B 3}^{3} .
\end{aligned}
$$

and

$$
\begin{aligned}
F_{4}\left(x_{A}, x_{B}, y_{A}, y_{B}, z_{A}, z_{B}\right)= & x_{A} x_{B} z_{A} z_{B}+x_{A} x_{B} y_{B}^{2} z_{A} z_{B 3}^{33} \\
& +x_{B}^{2} y_{A} y_{B}+y_{A} y_{B}^{3} z_{13}^{2} .
\end{aligned}
$$

Besides the trivial fixed points, there is a nontrivial (uniform) fixed point. given by $y_{A}=y_{B}=z_{A}=z_{B}=1$ (zero direct and staggered fields), and

$$
x_{A}^{*}=x_{B}^{*}=x=0.119726 \ldots,
$$

which comes from the equation

$$
x=\left(\frac{1+3 x^{2}}{3+x^{2}}\right)^{2}
$$

and is identical to the fixed point associated with the uniform model. We now linearize the recursion relations about this nontrivial fixed point. Again. we have a block-diagonal form involving separate thermal and magnetic contributions.

$$
\left(\begin{array}{l}
\Delta x_{A}^{\prime} \\
\Delta x_{B}^{\prime}
\end{array}\right)=\left(\begin{array}{cc}
D & 2 D \\
3 D & 0
\end{array}\right)\left(\begin{array}{l}
\Delta x_{A} \\
\Delta x_{B}
\end{array}\right),
$$

where

$$
D=\frac{2\left(1-x^{2}\right)^{2}}{\left(3+x^{2}\right)\left(1+3 x^{2}\right)}=0.618033 \ldots
$$

and

$$
\left(\begin{array}{l}
\Delta y_{A}^{\prime} \\
\Delta y_{B}^{\prime} \\
\Delta z_{A}^{\prime} \\
\Delta z_{B}^{\prime}
\end{array}\right)=\left(\begin{array}{cccc}
2\left(1+x^{2}\right) E & 4 E & 4 x^{2} E & -4 x^{2} E \\
2\left(3+x^{2}\right) E & 0 & 0 & 0 \\
4 F & -4 F & 2\left(1+x^{2}\right) F & 4 x^{2} F \\
0 & 0 & 2\left(1+3 x^{2}\right) F & 0
\end{array}\right)\left(\begin{array}{c}
\Delta y_{A} \\
\Delta y_{B} \\
\Delta z_{A} \\
\Delta z_{B}
\end{array}\right),
$$

where

$$
E=\frac{1}{1+3 x^{2}} \quad \text { and } \quad F=\frac{1}{3+x^{2}}
$$


Wo then lave the thermal eigenvalues,

$$
\Lambda_{1}=3 D=1.854101 \ldots \quad \Lambda_{2}=-2 D=-1.236067 \ldots,
$$

which are identical to the findings of Pinho, Haddad and Salinas, ${ }^{5}$ in zero external ficld. and the magnetic eigenvalues,

$$
\begin{aligned}
& \Lambda_{3}=\frac{2 E}{F}=5.780107 \ldots, \quad \Lambda_{4}=-4\left(E+x^{2} F\right)=-3.854101 \ldots, \\
& \Lambda_{5}=0, \quad \Lambda_{6}=\frac{2 F}{E}=0.692028 \ldots
\end{aligned}
$$

For the Ising model on the diamond lattice with a uniform distribution of exchange interactions (as in the work of Bleher and Zalys), the linearization about the nontrivial fixcd point of Eqs. (21)-(26) leads to the set of three uniform eigenvalues, $\Lambda_{1}=3 D>1, \Lambda_{3}=2 E / F>1$ and $0<\Lambda_{6}=2 F / E<1$ (the external staggered ficld is irrelevant). As in the work of Pinho, Haddad and Salinas, ${ }^{5}$ since $\Lambda_{1}>1$ ancl $\left|\Lambda_{2}\right|>1$. the uniform fixed point is unstable along both thermal directions, and cunnot be reached from physically acceptable initial conditions. This type of Mhivior. in full agreement with the exact analog of the Harris-Luck criterion, still holds for more general lattices with $b=3$ but $m>2$.

In the more recent analyzes of Haddad, Pinho and Salinas, ${ }^{8}$ in addition to the (unstable) uniform fixed point, there is a two-cycle attractor that governs the critical behavior. Recursion relations (21)-(26) are also associated with a two-cycle attractor, located at $y_{A}=y_{B}=z_{A}=z_{B}=1$, and

$$
x_{A}^{*}=0.155117, \ldots, \quad x_{B}^{*}=0.00740154 \ldots,
$$

mat

$$
x_{A}^{*}=0.0287405 \ldots ; \quad x_{B}^{*}=0.191409 \ldots
$$

The lincarization of the second iterates of the recursion relations about this twocyclo attractor leads to the thermal eigenvalues,

$$
\Lambda_{1}=3.255710 \ldots, \quad \text { and } \quad \Lambda_{2}=0.311746 \ldots,
$$

wicre $\left|\Lambda_{2}\right|<1$ indicates that the attractor can be reached from physically acceptable initial conditions, and the magnetic eigenvalues

$$
\Lambda_{3}=34.384598 \ldots, \quad \Lambda_{4}=15.008653 \ldots,
$$

and

$$
\Lambda_{5}=0.267660 \ldots, \quad \text { and } \quad \Lambda_{6}=0 \text {, }
$$

which inclicates the irrelevance of the applied staggered field. These results are consistent with the recent work of Haddad, Pinho and Salinas. ${ }^{8}$ The nontrivial diagonal fixed point cannot be reached. In zero field, a new universal critical behavior is characterized by the eigenvalues about the cycle-two attractor. 
In conclusion, we have investigated a ferromagnetic Ising model with aperiodit: exchange interactions, in the presence of direct and staggered external fields. on a class of Migdal-Kadanoff hierarchical structures. The geometric thuctuations inttroduced by the aperiodic interactions may change the character of the fixed point associated with the critical behavior. For relevant geometric fluctuations, the critical behavior belongs to a new universality class associated with a two-cycle attractor. The inclusion of a magnetic field does confirm these findings.

\section{Acknowlegment}

The authors thank Fundação de Amparo à Pesquisa do Estado de São Paulo for financial support.

\section{References}

1. U. Grimm and M. Baake, Aperiodic Ising models, in The Mathematics of Long-Runge Aperiodic Order, ed. R. V. Moody (Kluwer, Dordrecht. 1997), p. 199.

2. A. B. Harris, J. Phys. C7, 1671 (1974).

3. J. M. Luck, Europhys. Lett. 24, 359 (1993); J. Stat. Phys. 72, 417 (1903).

4. J. Hermisson, U. Grimm and M. Baake, J. Phys. A30, 7315 (1997); J. Hermisson, J. Phys. A33, 57 (2000); F. Igloi, L. Turban, D. Karevski and F. Szalma, Phys. Rev. B56, 11031 (1997).

5. S. T. R. Pinho, T. A. S. Haddad and S. R. Salinas, Braz. J. Phys. 27, 567 (1997); also available at cond-mat/9706234.

6. S. T. R. Pinho, T. A. S. Haddad and S. R. Salinas, Physica A257, 515 (1998)

7. A. C. N. Magalhāes, S. R. Salinas and C. Tsallis, J. Phys. A31, L567 (1998).

8. T. A. S. Haddad, S. T. R. Pinho and S. R. Salinas, Phys. Reu. E61. 3330 (2000).

9. Y. Achiam, T. C. Lubensky and E. W. Marshall, Phys. Rev. B33. 6460 (1986).

10. P. M. Bleher and E. Zalys, Comm. Math. Phys. 120, 409 (1989).

11. M. Kaufman and R. B. Griffiths, Phys. Rev. B24, 496 (1981); inid. B26, 5022 (1982): ibid. B30, 244 (1984). 


\title{
Tricritical behavior in deterministic aperiodic Ising systems
}

\author{
T. A. S. Haddad, * Angsula Ghosh. and S. R. Salinas

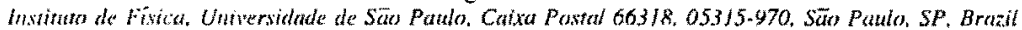 \\ (Received 20 June 2000)
}

\begin{abstract}
We use a mixed-spin undcl, with apcriodic ferromagnetic exchange interactions and crystaline fields, to investigale the effects of deterministic geometric fuctuations on first-order transitions and tricritical phenometa. The imeractions and the crystal-field parameters are distributed according to some two-letter substicution rules. From a Migdal-Kadanoff resi-space renormatization-group calculation, which turns out to be exact on a sutuble hierarchical lattice, we show that the effects of aperiodictly are qualitatively similar for tricritical and simple eritical bchavior. In panicular, the fixed point associated with tricritical behavior becomes fully unstable beyond a certain threshold dimension (which depends on the aperiodicity), and is replaced by a two-cycle that controls a weakened and temperature-depressed tricritical singularity.
\end{abstract}

PACS number(s): 05.50.+q, 05.10.Cc. 05.70.Fh, 64.60.Ak

The introduction of quenched disotder weakens (and sometimes climinates) tirst-order transitions and tricritical singularitis in the phase diagram of statistical models. In wo dimensions, rigorous arguments show that any amount of disorder completely eliminates first-order transitions in [erromagnetic model systems [1]. In thee dimensions. approximate real-space and perturbative renomalization-group analyses $|2|$ as well as numerical simulations, indicate that a finite strength of disorder is required to weaken first-order Innsitions and depress the tricritical lemperature. In particulat. disordered versions of the two-dimensional ferromagnetic $f$-state Pots modid $[3,4]$ (for $y>4$, on the square latlice. the uniform model displays a first-order transition) and the Blume-Emery-Griffiths (BEG) model $[5-7]$ (whose unifom verston displays tricritical and critical-end points), which have been thoroughly investigated, are well adjusted to this sccnario. It remains unclear the important question of what are (if any) the universality classes of the disorderinduced continuous transitions in these systems (see, for example, at recent review by Cardy [8]).

Instend of looking at the (presumahly) more difficult problem posed by fluctuations associated with quenched disarler. in the present publication we consider the effects on ijos-order tratusitions of the geometric flucfuntions introfluced by seterministic but aperiodically distributed exchange interactions. For quenched disordered interactions. the Harris eriterion 101 indicates a change in the critical behavior of simple ferromagnets whenever the critical exponent associated with the singularity of the specific heat of the underlying uniform model is positive. According to a heurislic argument ti Luck [10], which has been checked in a number of cases [ [11] and references therein|, the introdue* lion of aperiodic interactions leads to an analogous criterion of relevance of the geometric huctuations on the critical (second-order) behavior. Some of us have recently shown that a similar criterion may be exactly established for ferromagnetic Pots inodels on Migdal-Kadanoff hierarchical lattices. with a layered distribution of exchange interactions according to a class of two-letter substitution rules $[12,13]$.

*Email address: thaddad@if usp.br
See Fig. I. For relevant geometric fuctuations, there appears a two-cycle of the recursion relations in parameter space that gives rise to a new universality class of (aperiodic) critical behavior [14]. Along the lines of these investigations, we introduce aperiodic interactions in a simple mixed-spin model to analyze the effects on ticritical behavior and firstorder phase boundaries. It should be mentioned that recent extensive Monte Carlo calculations indicate that the phase transition of the eight-state square-lattice Potts model is indeed driven to second order by a layered aperiodic distribution of exchange couplings [15].

Besides the better known BEG model, another simple generalization of the ising model displaying first-order transitions and tricritical points is a mixed-spin system. given by the Hamiltonian

$$
\mathcal{H}=-\sum_{(i, j)} J_{i j} \sigma_{i} S_{j}+\sum_{j} D_{j} S_{j}^{2}
$$

where $\sigma_{i}= \pm 1$, for $i$ belonging to one sublattice of a biparlite lattice, $S_{j}= \pm 1$ or 0 , for $j$ belonging to the other sublat tice, and the first sum is over nearest-neighbor sites on difcerent sublattices. The description of this mixed-spin model demands a larger unit cell than the $B E G$ model in zero field.
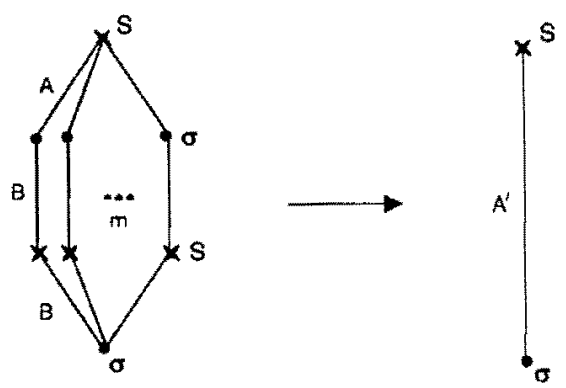

FIC. 1. Example of the hierarchical cell representing part of the Migdal-Kadanoff decimation scheme. Crosses correspond to spins-1, and dots to spins-1/2. By summing over the two internal spins of each of the $m$ branches, we obtain $K_{A}^{*}$ or $\Delta_{A}^{\prime}$. 
This extra difficulty, however, poses no problem to the study of the model under a Migdal-Kadanoff real-space renormalization-group approximation. Moreover, we need just two scaling fields. instead of three as in the BEG model, to describe the even space of parameters. We then take advantage of this model, and of the simplicity of the MigdalKadanoff approximation which turns out to be exact on a suitable hierarchical lattice), to introduce aperiodic interactions for analyzing the effects of geometric fluctuations on the main features of the phase diagram.

To obtain the Migdal-Kadanoff recursion relations, it is convenient to rewrite the Hamiltonian (1) in the equivalent form

$$
\mathcal{H}=-\sum_{(i, j)} J_{i j} \sigma_{i} S_{j}+\frac{1}{2} \sum_{(i, j)} D_{i j} \sigma_{i}^{2} S_{j}^{2}
$$

Many (mainly approximate) results are known for the uniform $\left(J_{i j}=J, D_{i j}=D\right)$ version of this model. On a honeycomb lattice, a star-triangle transtormation (summing over $S_{j}$ ) can be used to reduce the problem to an exactly soluble spin-1/2 Ising model on a simple triangular lattice, in which case, however, the temperature $\left(k_{B} T\right)$ versus "anisotropy" $(D / J)$ phase diagram presents only a line of continuous transitions [16]. For the so-calied union jack lattice, an exact solution can also be found tor a restricted range of parameters. by mapping the model onto an eight-ventex problem [17]. On a lattice of sufficiently high coordination, some effective-field [18] and seif-consistent [19] approximations, as well as a Bethe lattice calculation [20], suggest the existence of a first-order boundary that becomes a $\lambda$ line beyond a tricritical point. A detailed Migdal-Kadanoff renormalization-group calculation [21] predicts the existence of a tricritical point on hypercubic lattices of dimension $d$ $\gtrless 2.1$, which precludes the case of planar lattices. This is also confirmed by renormalization-group calculations in momentum space [21], at the one-loop approximation, that do suppon the existence of the tricritical point predicted by the Curie-Weiss version of the model. Monte Carlo [22] and numerical transfer matrix calculations [23] point out in this direction as well. with no indication of tricritical phenomena in this mixed-spin model on a square lattice.

We now consider Hamiltonian (2) and suppose that $J_{i j}$ (and $D_{i j}$ ) may assume one out of two values, $J_{A}$ or $J_{B}\left(D_{A}\right.$ or $\left.D_{B}\right)$, according to the sequence of letters generated by the iteration of a substitution rule. In this paper, we work with two distinct binary rules,

$$
\text { (i) } A \rightarrow A B B, \quad B \rightarrow A A A
$$

and

$$
\text { (ii) } A \rightarrow A A B, B \rightarrow A A A \text {. }
$$

For example, the iteration of the first rule leads to the following stages:

$$
A \rightarrow A B B \rightarrow A B B A A A A A A \rightarrow \cdots .
$$

Each rule is characterized by a substitution matrix, which relates the number of letters $A$ and $B$ in one stage of the iteration with the corresponding numbers in the previous stage. For the first rule, the substitution matrix is given by

$$
\mathbf{M}=\left[\begin{array}{ll}
1 & 3 \\
2 & 0
\end{array}\right)
$$

with eigenvalues $\lambda_{1}=3$ and $\lambda_{2}=-2$. For the second rult. we have

$$
M=\left(\begin{array}{ll}
2 & 3 \\
1 & 0
\end{array}\right)
$$

with eigenvalues $\lambda_{1}=3$ and $\lambda_{2}=-1$. In a given stage of the iteration. the fluctuation in the number of letters $A$ or $B$ relative to the mean number behaves asynuptotically als $N^{\text {et }}$. where $N$ is the total number of letters in the scquenec. and $\omega=\ln \left|\lambda_{2}\right| / n \lambda_{1}$ is a wandering exponent. We thus see that the first rule, with a wandering exponent $\omega=\ln 2 / \mathrm{h} 3$. gives tist to stronger geometric fluctuations than the second one. will $\omega=0$, and should be more effective in perturbing the critical behavior.

The Migdal-Kadanotf (MK) approximation on il d-dimensional hypercubic lattice turns out to be exact on the hierarchical cell shown in lig. 1. For this type of cell. the MK scheme corresponds to a decimation of the two spins located along each bond, a spin-1/2 and a spin-1. followed by the moving and collapsing of $m$ such bonds. There is also a relationship, $d=1+\ln m / \ln 3$, between the number of branches $m$ and the Euclidean dimension $d$. Note that the renormatization procedure amounts to a reverse application of the substitution rule generated by the aperiodic sequence. Also, note that we can as well perform the more usual trick of bond-moving before decimation (which is also exact on il suitable hierarchical lattice), but the qualitative results should not depend on this choice.

For the first aperiodic rule. $A \rightarrow A B B, B \rightarrow A A A$. the $M K$ procedure yields the recursion relations

$$
\begin{aligned}
K_{A}^{\prime}= & -\frac{m}{2} \ln \left\{\exp \left(K_{A}\right)+\exp \left(-K_{A}\right) \cosh 2 K_{n}\right) \\
& \left.+\cosh \left(K_{B}\right) \exp \left(\frac{\Delta_{A}}{2}+\frac{\Delta_{B}}{2}\right)\right\} \\
& +\frac{m}{2} \ln \left\{\exp \left(K_{A}\right) \cosh \left(2 K_{B}\right)+\exp \left(-K_{.1}\right)\right. \\
& \left.+\cosh \left(K_{B}\right) \exp \left(\frac{\Delta_{A}}{2}+\frac{\Delta_{B}}{2}\right)\right\}
\end{aligned}
$$

$$
\begin{aligned}
K_{B}^{\prime}= & -\frac{m}{2} \ln \left\{\exp \left(K_{A}\right)+\exp \left(-K_{A}\right) \cosh \left(2 K_{A}\right)\right. \\
& \left.+\cosh \left(K_{A}\right) \exp \left(\Delta_{A}\right)\right\}+\frac{m}{2} \ln \left\{\exp \left(K_{A}\right) \cos \ln 2 K_{A}\right) \\
& \left.+\exp \left(-K_{A}\right)+\cosh \left(K_{A}\right) \exp \left(\Delta_{A}\right)\right\}
\end{aligned}
$$

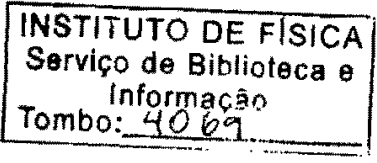




$$
\begin{aligned}
\Delta_{A}= & -m \ln \left[\exp -\Delta_{n}\right)\left[\exp \left(K_{A}\right)+\exp \left(-K_{A}\right) \cosh \left(2 K_{K^{\prime}}\right.\right. \\
& \left.+\cosh \left(K_{n}\right) \exp \left(\frac{\Delta_{A}}{2}+\frac{\Delta_{A}}{2}\right)\right] \exp \left(K_{A}\right) \cosh \left(2 K_{B}\right) \\
& \left.+\exp \left(-K_{A}\right)+\cosh \left(K_{A}\right) \exp \left(\frac{\Delta_{A}}{2}+\frac{\Delta_{B}}{2}\right)\right] \\
& \left.\times\left[2 \cosh \left(K_{A}\right) \cosh \left(K_{B}\right)+\exp \left(\frac{\Delta_{A}}{2}+\frac{\Delta_{B}}{2}\right]\right]^{-2}\right] \\
\Delta_{B}= & -m\left[n \left(\operatorname { e x p } ( - \Delta _ { A } ) \left[\exp \left(K_{A}\right)+\exp \left(-K_{A}\right) \cosh \left(2 K_{A}\right)\right.\right.\right. \\
& \left.+\cosh \left(K_{A}\right) \exp \left(\Delta_{A}\right)\right]\left[\exp \left(K_{A}\right) \cosh \left(2 K_{A}\right)\right. \\
& \left.+\exp \left(-K_{A}\right)+\cosh \left(K_{A}\right) \exp \left(\Delta_{A}\right)\right] \\
& \left.\times\left[2 \cosh \left(K_{A}\right)+\exp \left(\Delta_{A}\right)\right]{ }^{2}\right\}
\end{aligned}
$$

where $K_{I, A}=\beta I_{A, A}$ and $\Delta_{A, n}=\beta D_{A, R}$, with $\beta=1 / k_{R} T$. For all values of $m \geq 1$, these recursion relations have a set of trivial lixed points, given by

$$
P_{+} \equiv\left(K_{i}^{*}, K_{\#}^{*}, A_{4}^{* *}, A_{B}^{*}\right)=(0,0 .-\infty .-\infty),
$$

which is a sirk of high-density paramngnetic phase (where the density is related to the mean value $\left\langle S_{i}^{2}\right\rangle$, so that low density neans the predominance of spin 0 ),

$$
P_{-}=\left(K_{A}^{*}, K_{B}^{*}, \Delta_{A}^{*} \cdot \Delta_{B}^{*}\right)=(0,0, \infty, \infty)
$$

which is a sink of low-density paramagnetic phase.

$$
O=\left(K_{A}^{*}, K_{B}^{*}, \Delta_{A}^{*}, \Delta_{B}^{*}\right)=(0,0,0,0)
$$

corresponding to the high-temperature boundary between the paramagnetic phases.

$$
F_{+}=\left(K_{A}^{*}, K_{B}^{*}, \Delta_{A}^{*}, \Delta_{B}^{*}\right)=(\infty, \infty,-\infty,-\infty) .
$$

issociated with a zero-temperature high-density ferromagnetic phase, and

$$
F_{. .} \equiv\left(K_{i}^{*} \cdot K_{n}^{*}, \Delta_{A}^{*} \cdot \Delta_{A}^{*}\right)=(\infty, \infty, \infty, \infty)
$$

wiln $S_{4, n}^{*} / K_{A, B}^{* k}=2$. which cotresponds to a zero-temperature low-density furromagnetic phase.

For $m>1$ (which corresponds to $d>1$ ), there is a nontrivial fixed point at $\Delta_{A}^{*}=\Delta_{b}^{*}=-\infty$, for $K_{A}^{*}=K_{n}^{*}$ finite. This

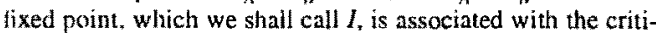
cal belavior of the simple spin-1/2 Ising model since fixing the crystal field (biquadratic exchange) at $-\infty$ completely prevents the $S$ spins to assume 0 values. In this spin-1/2 space. it should be pointed out that the recursion relations also present a moncycle (that is, a set of two fixed points of the second iterate). As discussed in a recent publication [14] this two-cycle is associated with the new universality class of the aperiodic ferromagnetic Ising model. Indeed, the critical behavior of the ising model on the hierarchical lattice underlying the $M K$ approximation. and with aperiodic interactions according to the rule $A \rightarrow A B B, B \rightarrow A A A$, is controlled by this two-cycle. the singularity being weaker as compared with the uniform (periodic) model.

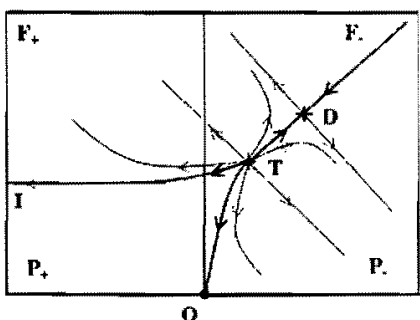

FG. 2. Schematic view of the renornaliation-group flows in parameter space, for the uniform version of the mixed-spin Ising model, with $K$ in the verrical axis, and $\Delta$ in the horizonal. $T$ is the tricritical fixed point, and $D$ is the discontinuty one.

For $m \geq 3.33$ (numerical evidence points in fact to $10 / 3$ ), corresponding to $d \geq 2.1$ (or $\ln 10 / \mathrm{h} 3=2.0959 \ldots$ as suggested by the numerical calculations), there appear two nove nontrivial fixed points. In the uniform case $\left(J_{A}=J_{n}, D_{A}\right.$ $\left.=D_{B}\right)$. Quadros and Salinas [21] have shown that one of them is a discontinuity fixed point, associated with a firstorder phase transition (according to an application of the Nienhuis and Nauenberg criterion for the identification of discontinuity fixed points). On the basis of a detailed analy. sis of the connectivity of the flow lines in parameter space. the other fixed point of the uniform model was snt:ivn [21] to be associated with the tricritical behavior. In ic uniform case, the discontinuity fixed point displays a sadjle character, with an attractive manifold emerging from the zerotemperature high-density ferromagnetic trivial fixed point, and from the tricritical fixed point (see Fig. 2, where a sche. tnatic view of the flows is presented). The repulsive directions flow towards the sink of the low-density paramagnetic phase, and towards the zero-temperature low-density ferromagnetic trivial fixed point. The stable manifold is thus as sociated with a first-order line. The fully unstable tricritical fixed point is connected with the Ising. $D=-\infty$, fixed point, giving rise to a second-order boundary.

In the present aperiodic case, for $m \geq 3.33$, these two fixed points still appear in the $K_{A}=K_{B}, \Delta_{A}=\Delta_{B}$. subspace, but since the parameter space is four dimensional we have to be careful to generalize the overall picture of the last paragraph. In fact, we should pay attention to the fact that now there are four scaling fields: the reduced temperature, tho crystal fields (instead of only one, as in the uniform case), and the strength of the aperiodicity, as measured, for example, by the ratio $r=J_{A} / J_{B}$. This last scaling field, which is of a completely different nature, is the determinant factor for the analysis of stability of the fixed points against aperiodicity. If it turns out to be relevant around a certain fixed point, it means that this fixed point cannot be reached unless $r$ assumes a well-defined value, usually unity, so that any amount of aperiodicity changes the critical behavior controlled by this paricular fixed point. On the other hand. irrelevancy of this scaling field suggests that. whatever the strength of the geometric fluctuations, this fixed point continues to control the critical behavior.

Consider now $m=3.4$ (dimension $d \approx 2.1$ ). The fixed points are at $K_{A}^{*}=K_{B}^{*}=1.5248 \ldots, \Delta_{A}^{*}=\Delta_{B}^{*}=2.2118 \ldots$ (discontinuity fixed point in the uniform model), and $K_{A}^{*}$ 
$=K_{B}^{*}=1.1447 \ldots, \Delta_{A}^{*}=\Delta_{B}^{*}=1.3953 \ldots$ (tricritical fixed point of the uniform case). The Iinearization of the recursion relations $(6)-(9)$, in the neighborhood of this fixed point lead to the eigenvalues

$$
\begin{gathered}
\Lambda_{1}=4.3687 \ldots, \quad \Lambda_{2}=0.7705 \ldots, \\
\Lambda_{3}=-3.8520 \ldots \quad \Lambda_{4}=-0.5825 \ldots .
\end{gathered}
$$

The first two eigenvalues are the same as in the uniform case. The modulus of the last two eigenvalues indicates the preservation of the saddle character of this fixed point. The linearization about the second fixed point yields the eigenvalues

$$
\begin{gathered}
\Lambda_{1}=4.1671 \ldots, \quad \Lambda_{2}=1.2360 \ldots, \\
\Lambda_{3}=-3.7346 \ldots, \quad \Lambda_{4}=-0.9194 \ldots .
\end{gathered}
$$

Again, $\Lambda_{1}$ and $\Lambda_{2}$ assume the same values of the uniform case. The modulus of the third eigenvalue is larger than 1. so far preserving the unstable character of the uniform tricritical fixed point. The last eigenvalue, however, indicates an attractive direction towards this fixed point, in contrast to the uniform model. in which case the tricritical fixed point is fully unstable. However. we have already remarked that a given characteristic fixed point associated with the uniform model still controls the critical behavior of the aperiodic system only if the strength of the aperiodicity is an irrele vant scaling field. This is precisely what is happening in this case. The modulus of $\Lambda_{4}$ asserts that the tricritical fixed point associated with the uniform model can be reached, even in the presence of aperiodicity.

An analysis of the flow lines of the recursion relations in parameter space fully supports the idea that these two fixed points continue to perform exactly the same functions in the aperiodic as well as in the uniform case. In other words, the first one is indeed a discontinuity fixed point, and the other one is associated with the tricritical behavior. In a phase diagram consisting of temperature, crystal fields, and the aperiodicity ratio $r$. there exists then a line of tricritical points extending along the $r$ direction. Finally, we note that $\Lambda_{3}$ and $\Lambda_{4}$ are negative. for both fixed points. This is a common situation for these aperiodic systems [14], which reflects a flipping approximation to (or furthering from) the fixed points. and is related to the discrete nature of the renormalization procedure and to the existence of two competing energy scales, $A$ and $B$.

For larger dimensions (larger values of $m$ ), this whole picture is changed. Take, for example, $m=9$, corresponding to three dimensions. The discontinuity fixed point of the uniform model is located at $K_{A}^{*}=K_{B}^{*}=4.8427 \ldots \Delta_{A}^{*}=\Delta_{B}^{*}$ $=9,0255 \ldots$. The tricritical fixed point is located at $K_{A}^{*}$ $=K_{B}^{*}=0.4514 \ldots, \Delta_{A}^{*}=\Delta_{B}^{*}=0.2190 \ldots$. The linearization of the recursion relations in the neighborhood of these fixed points lead to the eigenvalues

$$
\begin{gathered}
\Lambda_{1}=12.0154 \ldots, \Lambda_{2}=0.0032 \ldots, \\
\Lambda_{3}=-10.5075 \ldots, \Lambda_{4}=-0.0002 \ldots .
\end{gathered}
$$

around the discontinuity fixed point (the first two eigenvalues are the same as in the uniform case), and

$$
\begin{aligned}
& \Lambda_{1}=9.1600 \ldots \quad \Lambda_{2}=2.5865 \ldots \\
& \Lambda_{3}=-9.0707 \ldots \quad \Lambda_{4}=-1.7413 \ldots
\end{aligned}
$$

around the second fixed point (again. the tirst two cigenvalues are the same as in the uniform case). Note that this time the modulus of all of the eigenvalues of the uniform trieritical fixed point are larger than unity. which means that it is fully unstable against any aperiodic perturbations. Hence. it cannot be reached whatever the strengtis of the geometric fluctuations. except in the trivial. uniform case, $J_{A}=J_{n}$. $D_{A}=D_{g}$. As in the case of the spin-1/2 critical lixed poin $\left(D_{A}=D_{B}=-\infty\right)$, there also appears a two-cycle of the recursion relations. This two-cycle is tocated at

$$
\begin{aligned}
& \left(K_{A}^{*} \cdot K_{i}^{*} \cdot \Delta_{A}^{*} \cdot \Delta_{n}^{*}\right)_{1} \\
& \quad=(0,3759 \ldots .4,5304 \ldots 0.1472 \ldots .8,0027 \ldots)
\end{aligned}
$$

and

$$
\begin{aligned}
& \left.\left(K_{A}^{*} \cdot K_{n}^{*} \cdot \Delta_{i}^{*} \cdot\right\lrcorner_{B}^{*}\right)_{2} \\
& \quad=(2.0653 \ldots 0.2772 \ldots 3.4221 \ldots 0.0905 \ldots)
\end{aligned}
$$

As discussed in a previous publication $\mid 1+$. we sinould now study the behavior of the second iterate of the recursion relations around any one of the points belonging to the twocycle. From the linearization of the second iterates of the recursion relations about these points. we have the cigenvalues

$$
\begin{gathered}
\Lambda_{1}=114.3038 \ldots, \quad \Lambda_{2}=82.0353 \ldots . \\
\Lambda_{3}=5.1867 \ldots, \Lambda_{4}=0.0014 \ldots .
\end{gathered}
$$

Now there is at least one eigenvalue with a modulus less than 1. which guarantees that the two-cycle is physically actessible. From a numerical analysis of the connecivity of the flow lines in parameter space. we can check that this twocycle is indeed associated with the tricritical behavior in analogy with the second-order transitions associated with the (wo-cycle in the spin-1/2 subspace).

For $m=27$. corresponding to $d=4$, we have the sime general features. The uniform micritical fixed point is lully unstable, and there appears a two-cycle. which is presumally associated with a novel tricritical behavior. Numerical calcu= lations point out that the two-cycle appears as a kind of bifurcation of the uniform tricritical fixed point, at $m \approx 3.45$ (corresponding to $d \approx 2.13$ ). Further numerical work shows that, for a given ratio $J_{A} / J_{B}$, the temperature that locates the system inside the basin of attraction of the two-cycle (that is. the tricritical temperature) is systematically lower as compared with the tricritical temperature of the uniform model (and thus leads to a smaller first-order region in the phase diagram). These features are also generally present in disordered tricritical systems in three dimensions [5].

For the aperiodic rule $A \rightarrow A A B, B \rightarrow A A A$. with a smaller wandering exponent $(\omega=0$ in comparison with $\omega$ $=\ln 2 / \ln 3$ for the previous sequence), we have a different ser of recursion relations, but the results are simuilar. In this case. the calculations show that the uniform tricritical fixed poitt remains accessible (there is one eigenvalue with modulus 
liss than 1 ) whatever the value of $m$. The smaller eigenvalue around the tricritical fixed point approaches unity as $m$ goes 10 inthity. Weaker geonetric fluctuations are therefore unable to relevantly perurb the system. whose multicritical be havior remains unchanged with respect to the uniform model.

In conclusion, we have studied the effects of deterministic aperiodicity on a simple system that displays first $*$ and secondmorier transition lines and a tricritical point. Using a simple Migdal-Kadamoff approximation. we show that a cerinin cliss of nomindom geometric fuctuations may change lie tricritical behavior (by turning into a fully unstable node the fixed poim associated with the uniform tricritical behav. ion. There is then a two-cycte of the recursion relations that is shown to control the tricritical behavior. Numerical calculations indicate a depression of the tricritical temperatures (as it used to happen in the presence of quenched disorder). In spite of the limitations of the MK approximation (or, alternatively, the artificiality of the hierarchical latrices in which it curns out to be exact), the results of this investigation provide suggestions for the analysis of multicritical behavior in similar systems on realistic Bravais latices.

The authors wish to thank A. P. Vieira for useful discussions. This work has been supported by the Brazilian agency FAPESP.
11/ M. Aizenman and J. Wetr. Pliys. Rev. Leth. 62, 2503 (1989). 121K. Ifui and A. N. Berker. Phys. Rey. Len. 62. 2507 (1989).

II S. Clen. A. M livrenberg, and D. P. Landau. Phys. Rev. Lett 6\%. 1213 (1)12).

[H] J. L. Cardy and J. L. Ialobsen, Pliys. Rev. Lelt. 79, 4063 $11997)$.

[5] A. Fallisos and A. N. Berker, Phys. Rev Lett. 76. 4380 (1996)

61 A. Kahakciaglu and A. N. Berker. Phys. Rev. Leti. 82.2572 II990).

[7] N. S. Brance and B. Boechat, Phys. Rev. B 56. 1/673 (1997)

[B] J, L. Carly. Physica A 263.215 (1099)

19] A. B. Hurris. J. Puys C. $7.1671(1974)$

[10] f. M. Luek. Europhys. Leit. 24. 359 (1093)

111) U. Grimm and M. Baake, in The Mathentaicy of Long Range Aperistic Order, edited by $\mathrm{R}, \mathrm{V}$. Moody (Kluwer, Dordrecht. 1997). P. 199

[12] S. T. R. Pinho, T. A. S. Haddad and S. R. Salinas. Physica A $257.515(1998)$
[13] A. C. N. de Magalhāes, S. R. Salinas, and C. Tsallis, J. Phys. A 31. $2567(1998)$

[14] T. A. S. Haddad, S. T. R. Pinho, and S, R. Salinas, Phys. Rev. E 61, $3330(2000)$.

[15] P. E. Berche, Ch. Chatelain, and B, Berche, Phys. Rev. Let 80. 297 (1998).

[16] L. L. Gonçalves. Phys. Scr. 32, 248 (1985)

[17] A. Lipowski and T. Horiguchi, J. Phys. A 28, L261 (1995)

[18] T. Kancyoshi, J. Phys. Soc. Jpn. 56. 2675 (1987).

[19] N. Benayad, A. Klïmper, J. Ziltartz, and A. Benyoussef, Z. Phys. B: Condens. Matter 77, 339 (1989)

[20] N. R. da Silva and S. R. Salinas, Phys. Rey. B 44. 852 (1921)

[21] S. G. A. Quadros and S. R. Salinas, Physica A 206, 479 (1994).

[22] G. M. Zhang and C. Z. Yang, Phys. Rev. B 48, 9452 (1993).

[23] G. M. Buendia and M. A. Novotny, 3. Phys.; Condens. Matter 9. $5951(1997)$ 


\title{
Critical Behavior of Ferromagnetic Spin Models with Aperiodic Exchange Interactions
}

\author{
T. A. S. Haddad*, S. T. R. Pinho**, and S. R. Salinas* \\ - Instituto de Fisica. Universidude de Sä́o Paulo \\ Caira Postal 66318, CEP 05315-9790, Säo Paulo, SP, Brazil \\ ** Instituto de Física, Universidade Federal da Bahta \\ 40210-340. Salvador; BA, Brazil
}

Received on 15 August, 2000

\begin{abstract}
We revenw recent invertigations of the critical behavior of ferromagnetic $q$ state Potts models on a class of hierarchical lattices, with exchange interactions according to sorne deterministic but aneriodic substitution rules. The problem is formulated in terms of exact recursion relations on ah suinale paranetar space. The analysis of the fixed points of these equations leads to a criterion to finge the relevince of the uperiodic geometric fluctuations. For irrelevant fuctuations, the critical bethuvior remains turchanged with respect to the underlying uniform models. In the presence of relevant fluctuations. a non-trivial symmetric fixed point; associated with the critical behavior of the uriform model, becomes fully unstable, and there appears a twomcycle of the recursion relations. A sivaling analwsis, supporter by direct numerical thermodvmamical calculations, shows the existence of a novel critical universtlity class associated with relevant geometric fluctuations.
\end{abstract}

The discovery of quasicrystals, and the design and investigation of magnetic superlattices, provided strong motivation for the analysis of spin models with aperiodic axchange interactions. Along the lines of the Harris[1] critelion to gauge the influence of quenched clisorder on the critical behavior of simple ferromagnetic systenns. Luck[2] has proposed that sufficiently strong geonetrit: fluctuations, associated with doterministic but aperiodic interactions. may also change the ferronangetic critical behavior of the underlying uniform models. Luck's heuristic criterion has indeod been "herkesl and confirned in a mumber of cases (including the quantun Ising chain[3], and the two-dimensional Isitur model[t]).

In a series of recent publications[5-10], we considered ferromagnetic: Ising and Potts models, with aperivolic exchamge interactions aceording to a varioty of two-letter substitution nules. On hicrarchical MigdalKadanoff lattiecs[11]. Taking advantage of the lattice structure. we were able to derive an exact expression for Lnck's criterion. and to analyze the novel critical bohavion in the presence of relevant goometrical fuctuations. We now present an overview of these calculations.

As an cxample, consider the period-daubling twoletter substitution rule.

$$
\begin{aligned}
& A \rightarrow A B, \\
& B \rightarrow A A,
\end{aligned}
$$

so that the successive application of this inflation rule on letter $A$ produces the sequence

$$
A \rightarrow A B \rightarrow A B A A \rightarrow A B A A A B A B \rightarrow \ldots .
$$

At each stage of this construction, the numbers $N_{A}$ and $N_{B}$, of letters $A$ and $B$, can be obtained from the recursion relations

$$
\left(\begin{array}{l}
N_{A}^{\prime} \\
N_{B}^{\prime}
\end{array}\right)=\mathrm{M}\left(\begin{array}{c}
N_{A} \\
N_{B}
\end{array}\right)
$$

with the substitution matrix

$$
M=\left(\begin{array}{ll}
1 & 2 \\
1 & 0
\end{array}\right)
$$

The cigenvalues of this matrix, $\lambda_{1}=2$, which is the period of the transformation, and $\lambda_{2}=-1$, govern most of the geometrical properties of the sequence. The total number of letters, at a large order $n$ of these constructions, behaves asymptotically as $\lambda_{1}^{n}$. The geonetric fluctuations are of the order $\left|\lambda_{2}\right|^{n}$. It is then convenient to define the wandering exponent of the sequence,

$$
\omega=\frac{\ln \left|\lambda_{2}\right|}{\ln \lambda_{1}}
$$

that expresses the asymptotic dependence of the fluctuations with the total number of letters, $\Delta N \sim N^{\omega}$.

The period-doubling sequence can be used to construct apcriodic spin models on hicrarchical diamondtype lattices with $b=\lambda_{1}=2$ bonds and $m$ branches. 
To go bevond the simple Ising model, and introduce an extra parameter to work with, we consider a $q$-state ferromagnetic Potts model, given by the Hamiltonian

$$
H=-q \sum_{\{i, j)} J_{i, j} \delta_{\sigma_{i}, \alpha_{j}}
$$

where $\sigma_{i}=1,2, \ldots, q$, at all sites of the hierarchical lattice, $J_{i, j}>0$, and the sum refers to nearest-neighbor pairs of sites (for $q=2$. we recover the Ising model). The couplings can take only two values, $J_{A}$ and $J_{H i}$, associated with a sequence of letters produced by the period-doubling substitution. In Fig. 1, we indicate some stages of the construction of this model on a sinnple diamond lattice (with $b=\lambda_{1}=2$ bonds and $m=2$ branches). Note that the clioice of the same interactions along the branches of the diamonds is indeed mimicking an aperiodic layered structure.

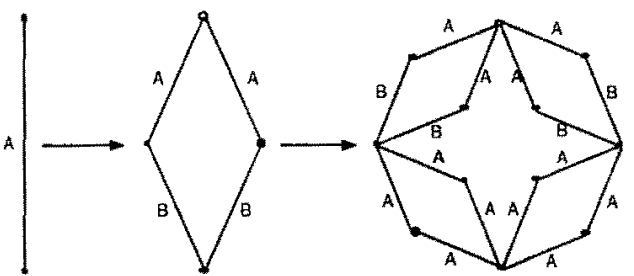

Figure 1: Three sucessive gencrations of the simple diamond latice $(b=m=2)$, Letters $A$ and $B$ indicate the exchange parameters (which are chosen according to the period-doubling sequence).

We may also consider more general substitution rules and basic "diaunonds" with $m$ branches and $b$ bonds along each branch. which leads to a lattice with the intrinsic or fractal dimension

$$
D=\ln (m b) / \ln (b) .
$$

In each one of these structures, aperiodicity may be implemented by a substitution rule of the form

$$
(A, B) \rightarrow\left(A^{n_{1}} B^{b-n_{1}}, A^{n_{2}} B^{b-n_{2}}\right),
$$

with $0 \leq n_{1}, n_{2} \leq b$. These sequences are characterized by a substitution matrix with eigenvalues $\lambda_{1}=b$ and $\lambda_{2}=n_{2}-n_{1}$, which leads to the wandering exponent

$$
\omega=\frac{\ln \left|\lambda_{2}\right|}{\ln \lambda_{1}}=\frac{\ln \left|n_{2}-n_{1}\right|}{\ln b} .
$$

Now we decimate the internal degrees of freedom of the diamonds to write exact recursion relations for the reduced couplings. For the $q$-state Potts model on a lattice with $b=2$ bonds per branch, and with interactions according to the period-doubling rule, given by Eqs. (1) and (2), it is easy to write[8]

$$
x_{A}^{i}=\left(\frac{x_{A} x_{B}+q-1}{x_{A}+x_{B}+q-2}\right)^{m} \text {, }
$$

and

$$
x_{H}^{s}=\left(\frac{x_{1}^{2}+q-1}{2 x_{1}+\eta+2}\right)^{n} .
$$

where $x_{A, H}=\exp \left(q \beta J_{A, H}\right)$, with $\beta=1 / k_{H} T$

In parameter space, besides the trivial lixed point associated with zero and inhinite temperatures. thexe is a non-trivial symmetric fixed point, that governs the critical behavior of the underlying unitorm model (sm the sketch drawn in Fig. 2). The linearization of thr $\mathrm{rm}$ cursion relations about this symmetric tixod point leads to the matrix form

$$
\left(\begin{array}{c}
\Delta x_{H}^{\prime} \\
\Delta x_{H}^{\prime}
\end{array}\right)=C(\eta) \mathrm{M}^{r}\left(\begin{array}{c}
\Delta x_{n} \\
\Delta x_{H}
\end{array}\right)
$$

where $C(q)$ is a $q$-dependent structure factor. aud $\mathrm{M}^{\prime}$ is the transpose of the substitution matrix. The cigumvalues of this linear form may be written nsi

$$
\begin{gathered}
\Lambda_{1}=C(q) \lambda_{1}=C(q) b . \\
\Lambda_{2}=C(q) \lambda_{2}=C(q) \lambda_{1}^{x^{2}}=C(q) b^{2} .
\end{gathered}
$$

and

where we have used the definition of $w$, given by Eq. (6). For irrelevant geometric fluctuations. in which case the critical behavior remains unchanged with respest to the underlying uniform nodel, it is required that $\lambda_{1}>1$. and $\left|\Lambda_{2}\right|<1$ (see Fig. 2n). Therefore, we can write

$$
A_{1}=C(q) b=b^{b T},
$$

with the usual thermal critical exponent associated with the uniform systen,

$$
y=\frac{D}{2-\alpha_{i n}},
$$

where $D$; given by $\mathrm{Eq} .(8)$, is the fractal climension of the lattice, and $\alpha_{n}$ is the critical exponent associatred with the divergence of the specitic heat of the unifom model[12, 13]. From Eqs. (16) ald (17), we have the structure factor

$$
C(q)=b^{\frac{10}{2-n_{11}}-1} .
$$

Inserting this expression into $\mathrm{Eq}$. (15) for the second eigenvalue, we have

$$
\Lambda_{2}=b^{\frac{b}{2-w_{21}}-1+\%}
$$

which leads to an analog of Luck's criterion for a hiorarchical lattice. As we have already mentioned. fluctuations are irrelevant for $\left|\Lambda_{2}\right|<1$. However, if $\left|\lambda_{2}\right|>1$, which corresponds to a fully unstable symmetric tixed point, geometric fluctuations are relevant (see Fig. 2b). Therefore, the critical behavior departs from the uniform case if we have

$$
\left|A_{2}\right|>1 \rightarrow \omega>1-\frac{D}{2-\alpha_{n}} .
$$


which is an txact eriterion of relevance for the MigdalKadanoff himaredical lattices. For the Potts model on the simple thianoned lattice. with $b=2$ bonds and $m=2$ mancless. this criterion can be written as

$$
q>\eta_{c}=4+2 \sqrt{2}=6.828427 \ldots
$$

where $q_{c}$ is the sutme critical value for the relewance of quenetred disorder atcording to a calculation by Derrida and Giadner $[14$ ] in the weak disorder limit (also. note that $\alpha_{n}>0$ for a uniform Potts model on at simple stamond lattice with $q>q_{c}$ ).

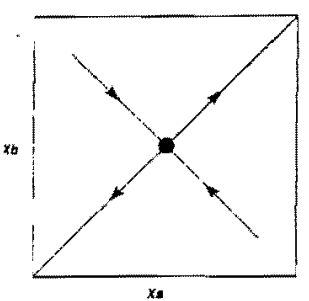

(a)

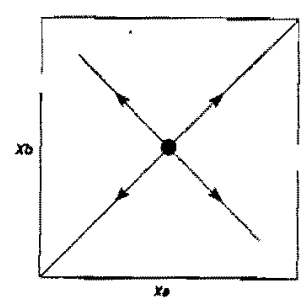

(b)
Figure 2: Schematic represtentation of rie parameter spact and the flow diagrams for irrelevant (a) and relevant (b) geanetric fuctuatious. The non-trivial symmetrit fixed point of saddle-point chumater for irrelevatut fluctuations (a) be cotnes fully mustable in the relevant case (b)

The recursion relations are so simple that it turns out to be rolatively casy to carry out an analysis of the critical bohatior under relevant geometric fluctuations. It is not, difficult to show that, for $q>q_{e}$, in which case the non-tricial summetric fixed point is fully unstable, there is a two-cyck that soms to be the candidate to define a unel rlass of critical behavior[8]. In terms of the scemel it rates of the recursion relations. of which Fied point of this two-cycle is a fixed point, it displays a saddle-point character. with stable and unstable manifolds. Let us use standard scaling arguments to analyze the wowl oritical behavior. In the thermodynamic limit, the roduced fres energy por bond can be written in the scaling form[13. 15]

$$
f(x)=\eta(x)+\frac{1}{b^{2 D}} f\left(x^{\prime \prime}\right)
$$

where $g(x)$ is in regular function. $x^{n}$ is a second iteritte of the rewsion relations, $b$ is the rescaling factor (number of bonds of the diamond hicrarchical lattice), $D$ is the fractal dimension, and we use the factor $b^{2 D}$ because we need two iterates to go back to the neighborhood of the initial point in parameter space. This cquation has the asymptotic solution[15]

$$
f(x) \approx\left|x-x^{*}\right|^{2-\alpha} P\left(\frac{\ln \left|x-x^{*}\right|}{\ln \Lambda_{c y c}}\right)
$$

where $x^{*}$ is one of the points of the two-cyele, $\Lambda_{\text {cyc }}$ is the largest cigenvalue of the linearization of the second itcrate of the recursion relations about any one of the points of the cycle, $P(z)$ is an arbitrary function of period 1 , and the critical exponent $\alpha$, associated with the specific heat, is given by

$$
a=2-2 \frac{\ln b^{D}}{\ln \Lambda_{c y c}}=2-2 \frac{\ln (m b)}{\ln \Lambda_{c y c}} .
$$

All the calculations that we have performed, for a 4 state Potts model on a varicty of Migdal-Kadanoff hicrarchical lattices, with different values of $b$ and $m$, and suitabie substitution sequences, point out that the values of $\alpha$ from this scaling analysis are unequivocally different from the values of $\alpha_{u}$ for the corresponding underlying uniform models[8]. For cxample, for the period-doubling rule and the simple diamond lattice $(0=m=2)$, with $q=7$, the twocycle is located at $\left(x_{A}, x_{B}\right)_{\mathrm{I}}=(5.285 \ldots, 7.642 \ldots)$, and $\left(x_{A}, x_{B}\right)_{2}=(6.697 \ldots, 4.750 \ldots)$, with oigenvalues of the second iterate $\Lambda_{1}=3.933 \ldots$ and $\Lambda_{2}=0.985 \ldots$ from which we have $\alpha=-0.0022 \ldots$, which should be compared with $\alpha_{u}=0.010 \ldots$. With $q=25$, the weakening of the second-order transition is even clearer: the two-cycle is located at $\left(x_{A}, x_{B}\right)_{1}=(6.942 \ldots, 234.34 \ldots)$, and $\left(x_{A}, x_{A}\right)_{2}=(39.023 \ldots, 3.831 \ldots)$, with cigenvalues of the sccond iterate $\Lambda_{3}=4.243 \ldots$ and $\Lambda_{2}=0.343 \ldots$ from which we have $\alpha=0.0817 \ldots$, to be compared with $x_{i s}=0.404 \ldots$

To test the validity of the scaling arguments, and the role of the two-cycle as the responsible for the new eritical behavior, we have performed direct numerical analyses of the singularity of the free energy[8]. In these problems, it is well known that the reduced free cuergy can be expressed as an infinite series $[13,15]$. For the Potts model on the $b=2$ diamond-type lattice, with the period-doubling rule, we have the series

$$
f\left(x_{A}, x_{B}\right)=\sum_{n=0}^{\infty} \frac{1}{(2 m)^{n}}\left[\frac{1}{3} \ln \left(x_{A}^{(n)}+x_{B}^{(n)}+q-2\right)+\frac{1}{6} \ln \left(2 x_{A}^{(n)}+q-2\right)\right],
$$


where $x_{I . B}^{(n)}$ indicate the $n$th iterate of the recursion re lations. As usual, we assurne uniform convergence, and differentiate torm by term to obtain the specific heat per boud. The eritical tomperature can be determined with high precision by inaking use of the existence of the paramagnetic fixed point at $T=0$, corresponding to $x_{A, B}=\infty$, which causes the apparent divergenee of the series if summed without using any regularization trick. Fixing the parameters $q$ and $m$, and also the strengths of $J_{A}$ and $J_{B}$, the criticul temperature thus calculated in fact locates $x_{A} B$ in the attraction basin of the two-cycle. According to the expectations, for irretcvant geonetric fuctuations, or for the uniform model, this method yields a critical temperature that locates the system in the stable manifold of the uniform fixed point.

The singularity in the specific heat can be analyzed by fitting the numerical thermodynamic data to a function of the form $A+B\left|\left(T-T_{c}\right) / T_{c}\right|^{-\alpha}$ over a somewhat arbitrary scaling region. For the irrelevant and uniform cases, we have always obtained very good fittings, in excellent agreennent with the values of $\alpha_{n t}$ predicted by the sealing theory around the uniform fixed point. Of course, these fitted values did not present any dctectable sensitivity on the particular values of $J_{A}$ and $J_{B}$. The Ising model $(q=2)$ on the simple $b=n=2$ diamond lattice, with exchange interactions according to the period-doubling sequence, had been previousiy and independently analyzed by Andrade[16], with tho same conclusions. For larger values of $q$, in which cases the scating analysis predicts positive values of $\alpha$ (although, of course, smaller than the values of $\alpha_{11}$ ), the fittings presented excellent agrcernent with the sealing predictions. For weaker singularities (mainly negative values of $\alpha$, the fitted values were always somewhat bigger than the scaling predictions, with better agreoment for increasing values of $q$. For $b=m=2$, and $q=7$, we obtained $\alpha=-0.005(4)$, to be compared with the scaling result $\alpha=-0.0022 \ldots$ for $q=2 \bar{s}$, we obtaincd $\alpha=0.08(2)$, to be compared with $\alpha=0.0817 \ldots$ From the numcrical calculations, we have seen an 0 scillatory behavior of the specific heat as a function of $T$. The poriod of oscillation is roughly given by the argumett in Eq. (23), with better agreement for increasing values of $q$. These log-periodic oscillations, which are well known phenomena associated with hiorarehical structures, and indicate the need of a more refined scaling analysis, have also been detected in the calculations of Andrade[16, 17].

In conclusion, we have shown the existence of an exact criterion to gauge the relevanee of geometric fluctuations in a class of spin systems on Migdal-Kadanoff hicrarchical lattices. For irrelevant fluctuations, the critical behavior reratins uncturnged with rewper to the underlying uniforn modelis. In the presence of relevent Hirtuations. the non-trivial symmetrie hixnd point. Which is associated with the crirical behavior of the uniform model, becones fully unstable. and there apperars a two cycle of the recursion relutions in peranerer speter. A standard scaling andysis. supported by tires r theme dynamical calculations. shows the existener of a nowe universality class associated with the relewatr gomencic fuctuations.

This work has been supported by the Brazilian agenties EAPESP, CAPES, and CNP4.

\section{References}

[1] A. B. Hartis. J. Phys C7. 1671 (1974).

[2] J. A. Luck, Europhys. Lett. 24. 359 (1993)

[3] J. M. Luck. J. Stitt. Phos 72. 11 T (1093): F. Inlsit. L. Turban and F Szalnia. Plws. Rew B50. Ho3! (1907): J. Hermisson. L. Grimm and M. Brake. J. Plys A30. 7315 (1997).

[4] C. A. Tracy. J. Phys A21, L603 (1985): F. Tglei. If Phys. A21, L011 (1988): L. Turbat1. P. E. Bowrly and B. Berehe, J. Phers A27. 63 H0 (1901).

[0] S. T. R. Pinho. T. A. S. Haddatl and S. R. Salinas, Britz. J. Phys, 27.567 (1997).

(6) S. T. R. Pinho. T. A. S. Huddacd and S. R. Satlinas. Physica A257, 315 (1998).

[7] A. C. N. de Magaihães, S. R. Salinas and C. Tsallis; J. Phys. A31, L567 (1908).

[8] S. T. R. Pinho, T. A. S. Haddad and S. R. Salines. Physs. Rey. E61, 3330 (2000).

[9] Angsula Ghosk, T. A. S. Haddad and S. R. Sulinits. [rut. J. Mod. Phys. B14. 000 (2000); cond-mat/000500

[10] Angsula Ghrosh. T. A. S. Huddad and S. R. Salinas. condenat $/ 0004225$

[11] A. N. Burker and S. Ostlutid. J. Phrs, C12. 4961 (1970); R, B. Griffiths and M. Kinfman. Phys. Rav. B26. $5022(1082)$.

[12] J. R. Melrose. J. Pliss A16. 3077 (1983).

[13] B. Derrida. "Perre and random models of statistical

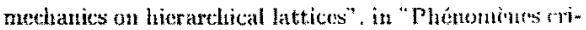
tiques, systèmes alćatoires. thérsies de jange", culited by K. Osterwalder and R. Stora. Les Honches 198.4 s.s.sion XLIII, Elsevior. Ansterdan. p. 989.

[14] B. Derrida aur E. Garduer. J. Plys A17. 3223 (1934).

[15] B. Derrida. J. P. Eckmann and E. Erzan. J. Ply,s A16. 803 (1983).

[16] R. F. S. Andrade, Flyss. Rev. E59. 150 (1990).

[17] R. F. S. Audrade, Phys. Rev. E01. 7106 (2000). 


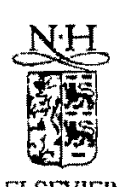

Physica A $306(2002) 98-106$

\title{
PHYSICA
}

\section{Critical behavior of spin and polymer models with aperiodic interactions}

\author{
T.A.S. Haddad, S.R. Salinas *

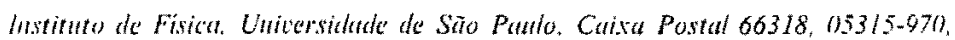 \\ Sũo Putto, SP, Brazil
}

\begin{abstract}
We review and extend some recent investigations of the effects of aperiodic interactions on the critical behavior of ferromagnetic $q$-state Potts models. By considering suitable diamond or necklace hierarchical lattices. and assuming a distribution of interactions according to a class of two-letter substitution rules, the probiem can be formulated in terms of recursion relations in parameter space. The analysis of stability of the fixed points leads to an exact criterion to gauge the relevance of geometric fluctuations. For irrelevant fluctuations, the critical behavior remains unchanged with respect to the uniform systems. For relevant fluctuations, there appears a two-cycle of saddle-point character in parameter space. A scaling analysis, supported by direct numerical themodynamic calculations, shows the existence of novel critical universality classes issociatcd with relevant geometric fluctuations. Also, we show that similar qualitative results are displayed by a simple model of two directed polymers on a diamond hierarchical structure with aperiodic bond interactions. (c) 2002 Elsevier Science B.V. All rights reserved.
\end{abstract}

P.1CS: 64.60.Ak: 05.50.+q: 61.44.Br; $83.80 . \mathrm{Rs}$

Kernterts: Critical behavior: Aperiodic interactions: Spin models

\section{Introduction}

In some rccent publications [1-4], we investigated the critical behavior of a $q$-state ferromagnetic Potts model on a class of hierarchical diamond lattices with aperiodic interactions. Taking advantage of the lattice structure, and assuming a (layered) distribution of exchange interactions according to suitable two-letter substitution rules, we were able to write exact recursion relations in order to characterize the critical

\footnotetext{
"Corresponding author. Tel.: +55(11)818-6931; fax: +55(11)813-4334.

E-mail address: ssalinas@if.usp.br (S.R. Salinas)
}

$0378-437102 . \$$ - see front matter (C) 2002 Elsevier Science B.V. All rights reserved. PII: $S 0378-4371102100489-2$ 
behavior under the intluence of geometric fluctuations. For disordered ferromagnetic systems, the well-known Harris criterion predicts a change in critical bchavior if the underlying uniform system displays a positive specific heat critical exponent. An extension of this heuristic criterion has been proposed by Luck [5] in order to giauge the relevance of geometric fluctuations associated with aperiodicity. We dcrived an exact expression of an analog of Luck's criterion on a hierarchical lattice. For weik fluctuations. there is a nontrivial symmetric fixed point in parameter space that leads to the same critical behavior of the uniform model. For strong enough fluctuations. this symmetric fixed point becomes fully unstable. and there appears a cycle-tivo in parameter space. that is shown to lead to a novel class of (aperiodic) critical behavior [2.3]. As the systems are quite simple, it has been feasible to perform a direct thermodynamic analysis of the free energy to check the predictions of scaling arguments.

Now, we review and extend these calculations. In Section 2. we show that the same results are obtained for a $q$-state Potts model on a necklace hierarchical lattice. Although the critical temperature may change. critical exponents associated with either the symmetric fixed point or the cycle-two attractor do display universal features that do not depend on the particular choice of diamond or necklace hierarchical structures (and on particular values of the interaction energies). In Section 3. we consider a model of two directed polymers on a diamond lattice [6.7] with al (layered) distribution of aperiodic interactions, according to some two-letter substitution rules. The exact recursion relations in parameter space turn out to be very simple. but with a similar structure as in the case of the aperiodic Potts model. We then present some examples to show that, for relevant geometric fluctuations, a symmetric fixed point becomes fully unstable and there is again a novel cycle-two attractor of saddle-point character in parameter space.

\section{Potts model with aperiodic interactions}

The successive application of the period-doubling two-letter rule.

$$
A \rightarrow A B, \quad B \rightarrow A A
$$

on an initial letter $A$, produces the sequence

$$
A \rightarrow A B \rightarrow A B A A \rightarrow A B A A A B A B \rightarrow \cdots .
$$

At each stage of this construction, the numbers $N_{A}$ and $N_{B}$, of letters $A$ and $B$. can be obtained from the recursion relations

$$
\left(\begin{array}{l}
N_{A}^{\prime} \\
N_{B}^{\prime}
\end{array}\right)=\mathbf{M}\left(\begin{array}{l}
N_{A} \\
N_{B}
\end{array}\right)=\left(\begin{array}{ll}
1 & 2 \\
1 & 0
\end{array}\right)\left(\begin{array}{l}
N_{A} \\
N_{B}
\end{array}\right),
$$

where the eigenvalues, $\lambda_{1}=2$ and $i_{2}=-1$, of the substitution matrix $\mathbf{M}$ govern most of the geometric properties of this sequence [8]. At order $n$, we can write

$$
N_{A}^{(n)}=\frac{2}{3} \lambda_{1}^{n}+\frac{1}{3} \lambda_{2}^{n} \quad \text { and } \quad N_{B}^{(n)}=\frac{1}{3} \lambda_{1}^{n}-\frac{1}{3} \lambda_{2}^{n} \text {, }
$$




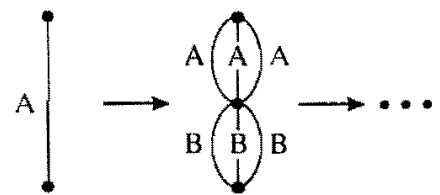

Fig. 1. Some generations of a hierarchical necklace lattice with $b=2$ bonds and $m=3$ branches. Letters $A$ and $b$ indicate the layered distribution of exchange interactions.

from which we have the asymptotic expressions $N_{f}^{(n)} \sim \lambda_{1}^{n}$ and $\Delta N_{f}^{(n)} \sim \lambda_{2}^{n}$, for large values of $n$. where $\Delta N_{+}^{(n)}$ can be regarded as a fluctuation around an asymptotic value. As the total number of letters. at order $n$, is given by $N^{(n)}=N_{d}^{(n)}+N_{B}^{(n)}$, we have \lrcorner $V_{i}^{(n)} \sim\left(N^{(\prime)}\right)^{(\prime)}$. with the wandering exponent

$$
(u)=\frac{\ln \left|i_{2}\right|}{\ln i_{1}}
$$

The ferromagnetic $q$-state Potts model is given by the Hamiltonian

$$
H=-q \sum_{(i, j)} J_{i, j} \delta_{\sigma_{1}, \sigma,},
$$

where $\sigma_{i}=1,2 \ldots, q$, at all sites of a lattice, $J_{i, j}>0$, and the sum refers to nearestneighbor pairs of sites (for $q=2$, we regain the standard Ising model). We now consider a Potts model on a hierarchical necklace lattice, with $b=2$ bonds and $n$ branches, and assume that the couplings can take just two values, $J_{A}$ and $J_{B}$, associated with a sequence of letters produced by the period-doubling substitution. In Fig. I, we indicate some stages of this construction (for $b=2$ and $m=3$ ). Note that the period-doubling sequence is perfectly suitable for a hierarchical lattice with $b=2$ bonds. Also, note that the choicc of the same interactions along the branches turns out to mimic an aperiodic layered strueture in the corresponding Bravais lattice.

Now. We decimate the internal degrees of freedom of the necklace structure and writc exact recursion relations for the reduced coupling parameters,

$$
x_{A}^{\prime}=\frac{x_{A}^{m} x_{B}^{\prime \prime}+q-1}{x_{A}^{\prime \prime}+x_{B}^{\prime \prime}+q-2}
$$

and

$$
x_{B}^{\prime}=\frac{x^{2} t^{m}+q-1}{2 x_{A}^{m}+q-2},
$$

where $x_{A, B}=\exp \left(\beta J_{A, B}\right)$ with $\beta=1 / k_{B} T$.

In parameter space. besides the trivial fixed points, associated with zero and infinite temperature, there is always a nontrivial symmetric fixed point. associated with the critical behavior of the underlying uniform model (see the sketch in Fig. 2a). The linearization of the recursion relations about the symmetric fixed point $x^{*}$ leads to 

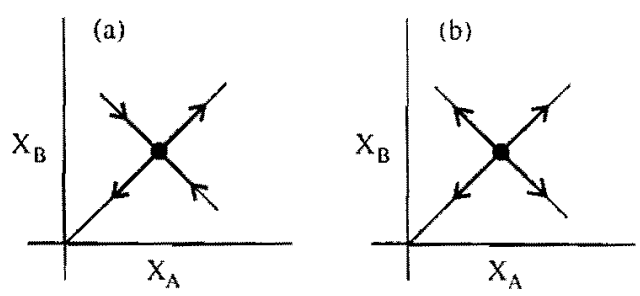

Fig. 2. (a.b) Flow diagrams in the neighborhood of the symmetric fixed point

the matrix form

$$
\left(\begin{array}{l}
\Delta x_{,}^{\prime} \\
\Delta x_{B}^{\prime}
\end{array}\right)=C\left(x^{*}\right) \widetilde{M}\left(\begin{array}{c}
\Delta x_{H} \\
\Delta x_{B}
\end{array}\right) \text {. }
$$

where $C\left(x^{*}\right)$ is a structure factor and $\widetilde{M}$ is the transpose of the stubstitution matrix. The eigenvalues of this linear form are given by

$$
A_{1}=i_{1} C\left(x^{*}\right)=2 C\left(x^{*}\right)
$$

and

$$
A_{2}=i_{2} C\left(x^{*}\right)=-C\left(x^{*}\right) \text {. }
$$

It is easy to show that $A_{1}>1$. Note that we can write $A_{1}=2^{y T}$, with $y_{T}=D\left(D-x_{t l}\right)$. where $D=\ln (2 m) / \ln 2$ is the fractal dimension of the lattice and $x_{4}$ is the specific heat critical exponent of the underlying uniform model. Also, it is easy to show that $\left|A_{2}\right|<1$, for $q<q_{c}$, and $\left|A_{2}\right|>1$, for $q>q_{c}$. In this last case. for $q>q_{c}$. the symmetric fixed point becomes fully unstable, and the geometric fluctuations are relevant (see the sketch in Fig. 2b). For $b=m=2$. both for necklace and diamond structures. we have $q_{c}=4+2 \sqrt{2}=6.828427 \ldots$, which also eorresponds to the eritical number of states for the relevance of disorder in a ferromagnetic Potts model on a fully disordered diamond lattice [9].

For necklace and diamond lattices with $b$ bonds and $m$ branches. and a suituble two-letter substitution sequence with period $\lambda_{1}=b$, we can always write

$$
\Lambda_{1}=2 C\left(x^{*}\right)=b^{D\left(2-x_{u}\right)},
$$

where $D=\ln (m b) / \ln b$ is the fractal dimension of the lattice. $x_{\| \prime}$ is the specific heat critical exponent of the underlying uniform model. and

$$
\lambda_{2}=\lambda_{2} C\left(x^{*}\right)=\lambda_{1}^{(1)} C\left(x^{*}\right)=b^{(1)} C\left(x^{*}\right) .
$$

where the wandering exponent 0 comes from $\mathrm{Eq} .(5)$. We then have

$$
A_{2}=b^{\left.(i)-1+D / 2-\alpha_{11}\right)} \text {, }
$$

that leads to an exact version of Luck's criterion [5] for the relevance of geometric fluctuations,

$$
\omega>1-\frac{D}{2-x_{n}} \text {. }
$$


For the $q$-state Potts model on both diamond and necklace lattices with $b=2$ bonds and $m=2$ branches. this inequality is equivalent to $q>q_{c}=4+2 \sqrt{2}$, as we have pointed in the last paragraph. In this special case, it also corresponds to $z_{11}>0$. which is in agreement with the usual form of Harris criterion for the relevance of disorder [9]. It should be pointed out that, according to the usual expectations, given $q, b$ and $m$. the eigenvalues $A_{1}$ and $A_{2}$ assume the same values for both diamond and necklace structures.

We now turn to the investigation of the critical behavior when the symmetric fixed point is fully unstable. Numerically, we can see that, instead of a hypothetical aperiodic lixed point. there appears a two-cycle, with a saddle-point character, in parameter space. We then invoke scaling arguments to write

$$
f(x)=g(x)+\frac{1}{b^{2 D}} f\left(x^{\prime \prime}\right) .
$$

where $f(x)$ is the reduced free energy per bond. $g(x)$ is a regular function. and $x^{\prime \prime}$ is a second iterate of the recursion relations. Note that the factor $b^{2 D}$ has to be included because we need two iterates to go back to the vicinity of the initial point in parameter space. This equation leads to the asymptotic solution [10]

$$
f(x) \sim\left|x-x^{*}\right|^{2-x} P\left(\frac{\ln \left|x-x^{*}\right|}{\ln A_{\text {cyc }}}\right),
$$

where $x^{*}$ is one of the points of the two-cycle, $A_{\text {cyc }}$ is the largest eigenvalue of the linearization of the second iterate of the recursion relations about any one of the points of the cycle. $P(z)$ is an arbitrary function of period 1 , and the specific heat critical exponent is given by

$$
x=2-2 \frac{\ln b^{D}}{\ln A_{\mathrm{cyc}}}=2-2 \frac{\ln (m b)}{\ln A_{\mathrm{cyc}}} .
$$

Let us show some calculations for the $q$-state Potts model on a necklace lattice, with $h=2$ bonds. $m$ branches, and a distribution of exchange interactions according to the period-doubling two-letter sequence: (i) for $q=7$ and $m=2$, the two-cycle is locited at $\left(x_{*}^{*}, x_{B}^{*}\right)=(2.299 \ldots, 2.764 \ldots)$ and $(2.587 \ldots, 2.179 \ldots)$, with eigenvalues of the second iterate given by $A_{1}=3.993 \ldots$ and $A_{2}=0.985 \ldots$. From Eq. (18), we have $\%=-0.00226 \ldots$ to be compared with the positive value $\varkappa_{11}=0.010 \ldots$ for the uniform system: (ii) for $q=25$ and $m=2$, the two-cycle is located at $\left(x_{A}^{*}, x_{B}^{*}\right)=$ $(2.634 \ldots, 15.308 \ldots)$ and $(6,246 \ldots, 1.957 \ldots)$, with eigenvalues of the second iterate given by $A_{1}=4.243 \ldots$ and $A_{2}=0.343 \ldots$. From Eq. (18), we have $x=0.08174 \ldots$, to be compared with $z_{u}=0.40456 \ldots$, for the corresponding uniform system. For other values of $m$. we find qualitatively similar results. The specific heat exponent is definitely depressed as compared to the values for the underlying uniform system. Also. given $q$, $b$. and $m$. the exponents assume the same values for diamond and necklace structures.

To check the validity of the scaling arguments, and the role of the two-cycle as the responsible for the new critical behavior. we have performed direct numerical analyses of the singularity of the thermodynamic free-energy. For the $q$-state Potts model on the $b=2$ necklace hierarchical lattice, and with the period-doubling rule, we can write 


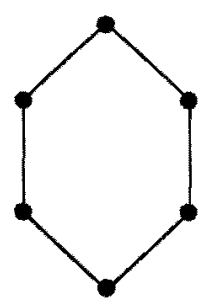

Fig. 3. Diamond hierarchical lattice with $b=3$ bonds and $m=2$ branches.

the free energy per bond as a series expansion.

$$
\begin{aligned}
f\left(x_{A}+x_{B}\right)= & -k_{B} T \sum_{n=0}^{\infty} \frac{1}{(2 m)^{n}}\left\{\frac{1}{3 m} \ln \left[\left(x_{A}^{(n)}\right)^{m}+\left(x_{B}^{(n)}\right)^{m}+q-2\right]\right. \\
& \left.+\frac{1}{6 m} \ln \left[2\left(x_{A}^{(n)}\right)^{m}+q-2\right]\right\} .
\end{aligned}
$$

All of our numerical checks fully confirm the scaling results. For example. for $m=2$ and $q=100$. with $J_{A} / J_{B}=5$, a numerical analysis of the specific heat divergence at the critical temperature leads to $\alpha=0.27 \pm 0.03$, to be compared with the scaling prediction from the two-cycle, $\alpha=0.27204 \ldots$ (which is definitely different from the value for the uniform system, $x_{\mu}=0.64846 \ldots$ ). Within the error estimates, we always obtain the same numerical results for all values of the ratio $J_{A} / J_{B}$. Again, given $q, b$. and $m$, and for all values of the ratio $J_{A} / J_{B}$, the exponents assume the same values for diamond and necklace structures. From the numerical calculations, and particularly for bigger values of $q$, we have been able to detect a log-periodic oscillatory behavior of the thermodynamic functions. The period of oscillation is compatible with Eq. (17). which has also been confirmed in the independent calculations of Andrade [11].

\section{Directed polymers with aperiodic interactions}

Along the lines of a paper by Mukherji and Bhattacharjee [6]. we now consider a model of two interacting directed polymers on a diamond lattice (see Fig. 3). The polymers start at one end of the lattice and meet at the other end. There is an attractive interaction if a bond of the lattice is shared by two polymers.

Consider a diamond lattice ( $b=2$ bonds and $m$ branches). with a layered distribution of interactions. according to the two-letter period-doubling sequence given by Eq. (1). It is easy to write the recursion relations

$$
y_{A}^{\prime}=\frac{1}{m} y_{A} y_{B}+\frac{m-1}{m}
$$

and

$$
y_{B}^{\prime}=\frac{1}{m} y_{A}^{2}+\frac{m-1}{m},
$$


104

where $r_{A B}=\exp \left(\beta v_{, B}\right)$, and $\nu_{A, B}>0$ is the interaction energy at bonds of types $A$ and $B$. respectively. For $y_{A}=y_{B}=y$, we recover the recursion relation for the uniform model.

$$
y^{\prime}=\frac{1}{m} y^{2}+\frac{m-1}{m} .
$$

Besides the trivial fixed points. $y^{*}=1$ and $\infty$. associated with zero and infinite temperatures, there is a nontrivial fixed point, $y^{*}=m-1$, which becomes physically acceptable. and is associated with a binding-unbinding transition, for $m>2$ (there is no phase transition on the simple diamond lattice with $n=2$ branches).

The recursion relations (20) and (21) are so simple, that it easy to see that, for $m>2$. there is no physically acceptable nontrivial fixed points except the symmetric fixed point $y_{A}^{*}=x_{B}^{*}=y^{*}$. The linearization of the recursion relations in the neighborhood of this symmetric fixed point leads to matrix form

$$
\left(\begin{array}{l}
\Delta y_{1}^{\prime} \\
\Delta y_{B}^{\prime}
\end{array}\right)=\frac{y^{*}}{m}\left(\begin{array}{ll}
1 & 1 \\
2 & 0
\end{array}\right)\left(\begin{array}{l}
\Delta y_{A} \\
\Delta y_{B}
\end{array}\right)
$$

with cigenvalues $A_{1}=2 y^{*} / m=2(m-1) / m$, and $A_{2}=-y^{*} / m=-(m-1), m$. Therefore. if $m>2$. we have $A_{1}>1$ and $\left|A_{2}\right|<1$, which shows that the geometric fluctuations are completely irrelevant in this case.

We now turn to a more interesting case. Consider a diamond lattice with $b=3$ bonds and $m$ branches (in Fig. 3, we sketch a diamond lattice with $b=3$ bonds and $m=2$ branches). Suppose that the (layered) interactions are chosen according to the period-3 two-letter sequence, $A \rightarrow A B B$ and $B \rightarrow A A A$. The substitution matrix is characterized by the eigenvalues $i_{1}=b=3$ and $\lambda_{2}=-2$, with the wandering exponent $(t)=\ln 2 / \ln 3=0.630092 \ldots$. The new recursion relations are given by

$$
y_{4}^{\prime}=\frac{1}{m} y_{B} y_{B}^{2}+\frac{m-1}{m}
$$

and

$$
y_{i 3}^{\prime}=\frac{1}{m} y_{i}^{3}+\frac{m-1}{m}
$$

There is just a single nontrivial fixed point, for $m>3$, at a symmetric location,

$$
r_{1}^{*}=y_{B}^{*}=y^{*}=-\frac{1}{2}+\frac{1}{2} \sqrt{4 m-3} .
$$

The linearization in the neighborhood of this fixed point leads to the matrix form

$$
\left(\begin{array}{l}
\Delta y^{\prime} \\
\Delta y_{B}^{\prime}
\end{array}\right)=\frac{\left(y^{*}\right)^{2}}{m}\left(\begin{array}{ll}
1 & 2 \\
3 & 0
\end{array}\right)\left(\begin{array}{l}
\Delta y_{A} \\
\Delta y_{B}
\end{array}\right)
$$

with the eigenvalues

$$
A_{1}=3 \frac{v^{* 2}}{m}=\frac{3}{2 m}[2 m-1-\sqrt{4 m-3}]
$$


and

$$
A_{2}=-2 \frac{y^{* 2}}{m}=-\frac{1}{m}[2 m-1-\sqrt{4 m-3}] .
$$

For $3<m<3+\sqrt{5}$, it is easy to show that $A_{1}>1$. and $\left|A_{2}\right|<1$. As in the case of the simple diamond lattice with $b=2$ bonds. geometric fluctuations are irrelcrant and the critical behavior is identical to the uniform case. However. for $m>3+\sqrt{5}=$ $5.236068 \ldots$, we have $\left|A_{2}\right|>1$. and the symmetric fixed point becomes fully unstable. For example, for $m=5$, we have $y_{A}^{*}=y_{B}^{*}=y^{*}=1.561552 \ldots$, with eigenvalues $A_{1}=$ $2.140568 \ldots$ and $A_{2}=0.951363 \cdots<1$. For $m=6$. however. we have $r_{1}^{* *}=y_{B}^{* k}=$ $y^{*}=1.791287 \ldots$, with eigenvalues $A_{1}=2.573958 \ldots$ and $A_{2}=1.143981 \ldots>1$. As in the case of the Potts model, there is then a cycle-two. of hyperbolic character, in parameter space. It is easy to locate this cycle at $\left(y_{*}^{*}, y_{B}^{*}\right)=(1.419001 \ldots 2.267305 \ldots)$ and $(2.049103 \ldots 1.309541 \ldots)$, with eigenvalues of the second iterate given by $A_{1}=$ $2.624300 \cdots>1$ and $A_{2}=0.772598 \cdots<1$.

\section{Conclusions}

In conclusion. we have taken advantage of suitable diamond and necklace hicrarchical lattices, and used a distribution of (layered) interactions according to a class of two-letter substitution rules, to perform an exact analysis of the effects of geometric fluctuations on the critical behavior of ferromagnetic $q$-state Potts models. We derived an exact expression for an analog of Luck's criterion on a hierarchical lattice. Also. due to the simplicity of the formulation, we have been able to show that the novel critical behavior under the influence of relevant geometric fluctuations is governed by a two-cycle attractor in parameter space. This new universality class can be described by scaling arguments, that are fully supported by direct thermodynamic calculations for the singularity of the free energy (as usual. critical exponents do not depend on details of the systems, as the relative strength of the interactions). It is not difficult to extend these calculations for an Ising model in the presence of direct and staggered liclds [12], to analyze the effects of aperiodicity on the tricritical behavior in at mixed-spin Ising system [13], and to consider some noncommutative sequences [14].

We have also reported some results for the critical behavior of a model of two directed polymers on a diamond lattice with a (layered) distribution of aperiodic interactions (according to suitable two-letter substitution rules). The exact recursion relations in parameter space turn out to be very simple, but with a similar structure as in the case of the aperiodic Potts model. We have presented some examples to show that. for relevant geometric fluctuations, a symmetric fixed point in parameter space becomes fully unstable and there is again a novel cycle-two attractor, of saddlc-point character. that governs a new class of (aperiodic) critical behavior.

\section{Acknowledgements}

This work has been supported by the Brazilian agencies FAPESP and CNPq. 


\section{Artigo $T$}

106

T.A.S. Huthad. S. R. Salinas Phywa A 306 (20)2) $98-1106$

\section{References}

[1] S.T.R. Pinho. T.A.S. Haddad, S.R. Salinas, Braz. J. Phys. 27 (1997) 567 :

S.T.R. Pinho. T.A.S. Haddad. S.R. Salinas, Physica A 257 (1998) 515.

[2] S.T.R. Pinho. T.A.S. Haddad, S.R. Salinas, Phys. Rev. E $6 \mid$ (1998) 3330.

13] S.T.R. Pinho, T.A.S. Haddad, S.R. Salinas, Braz. J. Phys. 30 (2000) 741.

14] A.C.N. de Magalhàes. S.R. Salinas, C. Tsallis, J. Phys. A 31 (1998) L567.

[5] I.M. Luck. Europhys. Lett. 24 (1993) 359;

J.M. Luck. J. Stat. Phys. 72 (1993) 417.

[6] S. Mukherii. S.M. Bhattacharjee, Phys. Rev. E 52 (1905) 1930.

17] S.M. Bhattacharjee. S. Mukherji, Phys. Rev. Lett. 70 (1993) 49;

S. Mukherii. S.M. Bhattacharjee, Phys. Rev. E 48 (1993) 3483.

[8] J.M. Luck. C. Godreche. A Janner, T. Janssen, J. Phys. A 26 (1993) 1951.

[0] B. Derrida. E. Gardner. J. Phys. A 17 (1984) 3223.

[10] B. Derrida. Pure and random models of statistical mechanics on hierarchical lattices, in: K. Osterwalder, R. Stora (Eds.). Phénomènes Critiques, Systèmes Aléatoires. Théories de Jauge, Les Houches. Session XLIII. Elsevier. Ansterdam. 1984. p. 989.

[II] R.F.S. Andrade. Phys. Rev. E 59 (1999) 150; R.F.S. Andrade. Phys. Rev. E 61 (2000) 7196.

112 I Angsula Ghosh. T.A.S. Haddad. S.R. Salinas, Int. J. Mod. Phys. B $14(2000) 1473$.

[13] T.A.S. Haddad. Angsula Ghosh. S.R. Salinas, Phys. Rev. E 62 (2000) 7773.

[14] SR. Salimas. W.F. Wrezisnki. Physica A 297 (2001) 434 



\title{
Critical properties of an aperiodic model for interacting polymers
}

\author{
T A S Haddad ${ }^{1}$, R F S Andrade ${ }^{2}$ and S R Salinas ${ }^{1}$ \\ 'Instifuto de Fisica. Universidade de São Paulo, Caixa Postal 66318, 05315-970 Säo Paulo. \\ SP. Brazil \\ 2 Instituto de Fisica, Universidade Federal da Bahia. Campus da Federação, 40210-340 Salvador, \\ BA, Brazil \\ E-mail: thaddad@if.usp.br
}

Received 1 August 2003. in final form 31 October 2003

Published 19 January 2004

Online at stacks.iop.org/JPhysA/37/1499 (DOI: 10.1088/0305-4470/37/5/003)

\begin{abstract}
We investigate the effects of aperiodic interactions on the critical behaviour of an interacting two-polymer model on hierarchical lattices (equivalent to the Migadal-Kadanoff approximation for the model on Bravais lattices), via renormalization-group and transfer-matrix calculations. The exact renormalization-group recursion relations always present a symmetric fixed point, associated with the critical behaviour of the underlying uniform model. If the aperiodic interactions, defined by substitution rules, lead to relevant geometric fluctuations, this fixed point becomes fully unstable, giving rise to novel attractors of different nature. We present an explicit example in which this new attractor is a two-cycle attractor, with critical indices different from the unitorm model. In the case of the four-letter Rudin-Shapiro substitution rule. we find a surprising closed curve whose points are attractors of period two, associated with a marginal operator. Nevertheless, a scaling analysis indicates that this attractor may lead to a new critical universality class. In order to provide an independent confirmation of the scaling results, we tum to a direct thermodynamic calculation of the specific-heat exponent. The thermodynamic free energy is obtained from a transfer-matrix formalism, which had been previously introduced for spin systems, and is now extended to the two-polymer model with aperiodic interactions.
\end{abstract}

PACS numbers: $64.60 . \mathrm{Ak}, 64.60 . \mathrm{Cn}, 61.44 .-\mathrm{n}$

\section{Introduction}

In some recent publications [ $1-4]$, we have used renormalization-group (RG) and transfermatrix (TM) techniques to investigate the effects of aperiodically distributed (but not 
disordered) interactions on the critical behaviour of ferromagnetic spin models. In a realspace renormalization calculation for simple hierarchical structures, we have written cxact recursion relations in order to show that relevant geometric (aperiodic) fluctuations play a very similar role to disorder. These calculations lead to the formulation of an exact extension for deterministic, aperiodic interactions of the well-known Harris criterion for the relevance of disorder [5], in a form coincident with Luck's heuristic, general derivation of this extension [6]. Also, we have shown that relevant geometric fluctuations give rise to distinct critical exponents. associated with the appearance of new attractors in parameter space. The independent transfermatrix calculations have confirmed these results and provided deeper insight into more refined details of the thermodynamics of aperiodic spin systems, such as log-periodic oscillations of thermodynamic functions.

Now we consider a model of two directed polymers on a diamond hierarchical lattice. with an aperiodic, layered distribution of interaction energies, according to various substitution rules (see $[7,8]$ for extensive reviews of substitution sequences and their applications to statistical models). Although the qualitative description of the critical behaviour is essentially similar, the exact renormalization-group recursion relations in parameter space lum out to be much simpler as compared to the calculations for spin systems. The case of two-letter substitution rules is particularly simple. For irrelevant geometric fluctuations, the critical behaviour is governed by a symmetric fixed point, with no changes with respect to the uniform case. For relevant fluctuations, we show that this symmetric fixed point becomes fully unstable, and the critical behaviour is associated with a novel two-cycle attractor of saddle-point character. However, for more complex substitution rules, such as the RudinShapiro sequence of four letters (which is known to mimic Gaussian random fluctuations in a sense [8]) there appears a surprisingly rich structure in the four-dimensional parameter space. Besides the expected symmetric fixed point, there are non-diagonal fixed points and continuous lines of two-cycle attractors, associated with a marginal operator, which might give rise to non-universal critical exponents. A scaling analysis indicates that this structure is responsible for a novel critical universality class. In order to check these results, we resorted to an independent thermodynamic calculation, on the basis of a transter-matrix scheme.

The layout of this paper is as follows. In section 2, we define the polymer model, and present some renormalization-group calculations for two- and four-letter (Rudin-Shapirv) substitution rules. We show the existence of some surprising structures in parameter space. and, in particular, discuss a number of scaling results for the critical behaviour. We then proceed to formulate an extension of the transfer-matrix scheme for a two-polymer model. Although this technique has already been used for spin systems, its extension for this new situation requires a considerable amount of analytical work, as described in sections 4 and 5 . In section 3, we formulate the transfer-matrix scheme for a two-polymer model. In section 4, we study in great detail the algebraic structure of the transfer matrices, in order to unveil, in section 5 , the existence of a recursion relation for the eigenvalues of the transfer matrices associated with two successive generations of the hierarchical structure. In section 6 , we use the recursion relations in order to write down explicit thermodynamic functions. In section 7 , we present the results for aperiodic models, which are compared to the renormalization-group predictions.

\section{The interacting polymer model}

The binding-unbinding phase transition in a disordered model of two directed and interacting polymers on a hierarchical lattice has been investigated by Mukherii and Bhattacharjee [9], and 
we follow these authors on the detinition of the model. We simply place two directed polymers on a diamond hicrarchical. They start at one end of the lattice and stretch continuously to the other end (the root sites). There is an attractive interaction, $-\epsilon$, whenever a bond of the lattice is shared by a monomer of each polymer. This energy can be made to depend on the position of the bond along a branch, in a random or deterministic fashion. Note that, although seemingly atificial, the model is nothing else than a bona fide Migadal-Kadanoff approximation for the same interacting problem on a genuine Bravais lattice.

In the basic cell of a diamond lattice, with $q$ branches and $p$ bonds per branch, there are configurations of energy $-p \epsilon$, where the two polymers occupy the same $p$ bonds of a branch, and configurations of zero energy, where the polymers stretch along different branches. Using the Boltzmann factor $y=\exp (\beta \epsilon)$ and the combinatorial coefficient $C_{q}^{2}=q(q-1) / 2$, it is easy to write the $R G$ recursion relation

$$
y^{\prime}=\frac{1}{q} y^{\prime}+\frac{q-1}{q} .
$$

Taking $p=2$, lor example, we see that besides the trivial fixed points, $y^{*}=1$ and $\infty$, associatted with zero and infinite temperatures, there is a non-trivial fixed point. $y^{*}=q-1$, which is physically acceptable for $q>2$ (there is no phase transition on the simple diamond latice with $q=2$ branches). Also, from the linearization of the recursion relation about the non-trivial fixed point, we have the thermal eigenvalue

$$
\Lambda=\frac{2(q-1)}{q} \text {. }
$$

In order to obtain the specific-heat exponent, $\alpha$, one should note that, as the polymers are one-dimensional objects, the thermodynamic extensivity of this model relates to the polymer length, instead of the volume. Thus, the important density is the free energy per monomer, which is assumed to behave according to the fundamental scaling relation

$$
f\left(y^{\prime}\right)=p f(y) \text {. }
$$

From this relation, we have the critical exponent associated with the specific heat,

$$
\alpha=2-\frac{\ln p}{\ln \Lambda}
$$

This quanity will be used to characterize the possible universality classes of the model, depending on $q . p$ and the presence of aperiodically distributed interactions.

Consider, for example, for $p=2$, a layered distribution of interactions [1], $\epsilon_{a}$ and $\epsilon_{b}$, chosen according to the two-letter period-doubling sequence,

$$
a \rightarrow a b \quad b \rightarrow a a
$$

In figure I we give an example of the constnuction of a simple diamond lattice with this kind of aperiodicity, starting from the letter $a$. Along each branch the interaction energies are distributed according to the letters of the aperiodic sequence generated by the recursive application of the rule. The same arguments as used in the last paragraph to derive equation (1) for the unilorm case, lead to a pair of recursion relations,

$$
y_{a b}^{\prime}=\frac{1}{q} y_{a} y_{b}+\frac{q-1}{q}
$$

and

$$
y_{b}^{\prime}=\frac{1}{q} y_{i}^{2}+\frac{q-1}{q}
$$




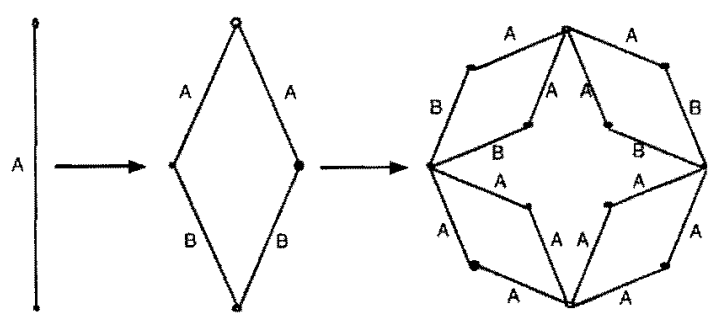

Figure 1. Initial stages of the construction of a Migadal-Kadanoff hierarchical lattice with $y=2$ branches and $p=2$ bonds per branch, and layered aperiodic interactions according to the period doubling rule, $a \rightarrow a b, b \rightarrow a a$ (letters $a$ and $b$ indicate the two possible values of the interaction energy, $\epsilon_{a}$ and $\left.\epsilon_{b}\right)$.

where $y_{a, b}=\exp \left(\beta \epsilon_{a, b}\right)$ and $\epsilon_{a, b}>0$ is the interaction energy at bonds of types $a$ and $b$. respectively. For $y_{a}=y_{b}=y$, we recover the recursion relation associated with the uniform model.

It is easy to see that, for $q>2$, there is no physically acceptable non-trivial fixed point. except the symmetric fixed point, $y_{a . b}^{*}=y^{*}=q-1$. The linearization of the recursion relations (6) and (7) in the neighbourhood of this symmetric fixed point leads to the matrix form

$$
\left(\begin{array}{l}
\Delta y_{a}^{\prime} \\
\Delta y_{b}^{\prime}
\end{array}\right)=\frac{y^{*}}{q}\left(\begin{array}{ll}
1 & 1 \\
2 & 0
\end{array}\right)\left(\begin{array}{l}
\Delta y_{a} \\
\Delta y_{b}
\end{array}\right)
$$

with eigenvalues $\Lambda_{1}=2 y^{*} / q=2(q-1) / q$ and $\Lambda_{2}=-y^{*} / q=-(q-1) / q$. Therefore, if $q>2$, we have $\Lambda_{1}>1$ and $\left|\Lambda_{2}\right|<1$, which shows that the geometric fluctuations are completely irrelevant in this case (since $\Lambda_{1}$ is the same eigenvalue associated with the nontrivial fixed point of the underlying uniform model, and the behaviour is irrelevant along the other direction).

We now tum to a more interesting case. Consider a diamond lattice with $p=3$ bonds and $q$ branches. Suppose that the (layered) interactions are chosen according to al period -3 two-letter sequence, $a \rightarrow a b b$ and $b \rightarrow a a a$. The new recursion relations are given by

$$
y_{a}^{\prime}=\frac{1}{q} y_{a} y_{b}^{2}+\frac{q-1}{q}
$$

and

$$
y_{b}^{\prime}=\frac{1}{q} y_{a}^{3}+\frac{q-1}{q} .
$$

For $q>3$, there is a single non-trivial fixed point, at a symmetric location,

$$
y_{a}^{*}=y_{b}^{*}=y^{*}=-\frac{1}{2}+\frac{1}{2} \sqrt{4 q-3} .
$$

The linearization in the neighbourhood of this fixed point leads to the matrix equation

$$
\left(\begin{array}{l}
\Delta y_{a}^{\prime} \\
\Delta y_{b}^{\prime}
\end{array}\right)=\frac{\left(y^{*}\right)^{2}}{q}\left(\begin{array}{ll}
1 & 2 \\
3 & 0
\end{array}\right)\left(\begin{array}{l}
\Delta y_{a} \\
\Delta y_{b}
\end{array}\right)
$$

with eigenvalues

$$
\Lambda_{1}=3 \frac{y^{* 2}}{q}=\frac{3}{2 q}[2 q-1-\sqrt{4 q-3}]
$$

and

$$
\Lambda_{2}=-2 \frac{y^{* 2}}{q}=-\frac{1}{q}[2 q-1-\sqrt{4 q-3}] .
$$


For $3<q<3+\sqrt{5}$, it is easy to see that $\Lambda_{1}>1$ and $\left|\Lambda_{2}\right|<1$. As in the case of the simple diamond lattice with $p=2$ bonds, geometric fluctuations are irrelevant and the critical behaviour is identical to the uniform case. However, for $q>3+\sqrt{5}=5.236068 \ldots$, we have $\left|\Lambda_{2}\right|>1$, and the symmetric fixed point becomes fully unstable, and, therefore, cannot be reached from arbitrary initial conditions (the values of $\epsilon_{a}$ and $\epsilon_{b}$ ). For example, for $q=5$, we have $y_{a}^{*}=y_{b}^{*}=y^{*}=1.561552 \ldots$ with eigenvalues $\Lambda_{1}=2.140568 \ldots$ and $\Lambda_{2}=0.951363 \ldots<1$. For $q=6$, however, we have $y_{a}^{*}=y_{b}^{*}=y^{*}=1.791287 \ldots$, with eigenvalues $\Lambda_{1}=2.573958 \ldots$ and $\Lambda_{2}=1.143981 \ldots>1$. But, as in the case of spin models on hierarchical lattices [2], there is a two-cycle in parameter space. It is easy to numerically locate this cycle at $\left(y_{a}^{*}, y_{b}^{*}\right)=(1.419001 \ldots, 2.267305 \ldots)$ and $(2.049103 \ldots 1.309541 \ldots)$, with eigenvalues of the linearized second iterate given by $\Lambda_{1}=2.624300 \ldots>1$ and $\Lambda_{2}=0.772598 \ldots<1$. A new critical universality class is therefore expected to be defined by this attractor.

The behaviour in parameter space is much more interesting if we consider the RudinShapiro, four-letter substitution rule, $a \rightarrow a c, b \rightarrow d c, c \rightarrow a b, d \rightarrow d b$. Consider a simple diamond lattice with $p=2$ bonds and $q$ branches. It is straightforward to write four algebraic recursion relations.

$$
\begin{array}{ll}
y_{a}^{\prime}=y_{a} y_{c} / q+(q-1) / q & y_{b}^{\prime}=y_{d} y_{c} / q+(q-1) / q \\
y_{c}^{\prime}=y_{a} y_{b} / q+(q-1) / q & y_{d}^{\prime}=y_{d} y_{b} / q+(q-1) / q
\end{array}
$$

which lead to the symmetric fixed point

$$
y_{a}^{*}=y_{b}^{*}=y_{c}^{*}=y_{d}^{*}=y^{*}=q-1 .
$$

From the linearization about this fixed point, we have the eigenvalues

$$
\Lambda_{1}=2 \frac{q-1}{q} \quad \Lambda_{2}=\sqrt{2} \frac{q-1}{q} \quad \Lambda_{3}=-\sqrt{2} \frac{q-1}{q} \quad \Lambda_{4}=0 .
$$

The introduction of aperiodic interactions becomes relevant for the simple diamond lattice if I $>2+\sqrt{2}=3.41 \ldots$, which corresponds to $\left|\Lambda_{2}\right|=\left|\Lambda_{3}\right|>1$.

Recursion relations (15) and (16) are so simple that we can perform a number of detailed calculations. In particular, it is easy to show the existence of additional, non-diagonal fixed points. given by

$$
\begin{aligned}
& y_{a . d}^{*}=\frac{1}{4(q-1)}\left[q\left(q^{2}-2 q+2\right) \pm q \sqrt{\left(q^{2}-2\right)\left(q^{2}-4 q+2\right)}\right] \\
& y_{h . t}^{*}=q-\frac{q-1}{y_{d . t}^{*}} .
\end{aligned}
$$

The Jacobian matrix associated with the linear form in the neighbourhood of these fixed points can be written as

$$
\frac{1}{q}\left(\begin{array}{cccc}
y_{c}^{*} & 0 & y_{a}^{*} & 0 \\
0 & 0 & y_{d}^{*} & y_{k}^{*} \\
y_{b}^{*} & y_{a}^{*} & 0 & 0 \\
0 & y_{d}^{*} & 0 & y_{b}^{*}
\end{array}\right)
$$

Besides two trivial eigenvalues, $\Lambda_{3}=0$ and $\Lambda_{4}=-1$, there is an additional pair of eigenvalues $\left(\left|\Lambda_{1}\right|>1\right.$ and $\left.\left|\Lambda_{2}\right|<1\right)$ given by the solutions of the quadratic equation

$$
2 q^{4} \Lambda^{2}-4 q^{2}\left(q^{2}+q-1\right) \Lambda+q^{4}+8 q^{3}-4 q^{2}-8 q+4=0
$$


As $\left|\Lambda_{4}\right|=1$, we have a typical case of marginal behaviour, which cannot be analysed without resorting to higher-order calculations. However, the marginal operator does not give rise to a line of fixed points, as could be expected. Instead, with an additional algebraic cffort. it is possible to show the existence of a continuous line whose points are two-cycles, by solving the polynomial equations

$$
y_{a, b . c . d}=y_{a, b . c . d}^{\prime \prime}\left(y_{a}, y_{b}, y_{c}, y_{d}\right)
$$

where $y^{\prime \prime}$ is the second iterate of the recursion relations. Given any $q>2+\sqrt{2}$. these equations lead to a pair of one-parameter algebraic curves, which meet smoothly and form a single, non-intersecting closed curve, containing the non-diagonal fixed points. Any point belonging to this closed curve is mapped onto another point on the curve upon one iteration of the recursion relations, and back to itself upon a further iteration. We have used algebraic computation to check this result very thoroughly. As an example, for $q=4$, we have the equations

$$
\begin{aligned}
& y_{a}=3 \frac{t+4}{4 t-3} \\
& y_{b}=-3 \frac{70 t^{2}+71 t-114 \pm g(t)}{t\left[6 t^{2}-137 t+78 \pm g(t)\right]} \\
& y_{c}=-\frac{6 t^{2}-128 t+114 \pm g(t)}{3 t(t+4)}
\end{aligned}
$$

and

$$
y_{d}=t
$$

with

$$
g(t)=\left(36 t^{4}-2220 t^{3}+15529 t^{2}-27132 t+12296\right)^{1 / 2}
$$

and the parameter $t$ taking values between $1.5142 \ldots$ and $5.4112 \ldots$ ln figure 2 we show a three-dimensional projection of this attractor. The linearization of the second iterates about any point of the curve leads to the eigenvalues $0,-1$ and a conjugate pair, $\left|\Lambda_{1}\right|>1$ and $\left|\Lambda_{2}\right|<1$ (the values of which do not depend on the point about which linearization is being carried out). The effects of the marginal eigenvalues on the specific-heat exponent. related it the existence of an extended attractor in parameter space, have to be checked very caretully. so we turn to the direct thermodynamic analysis of the free-energy singularity.

Before proceeding to the transfer-matrix calculations, however, it is worth remarking that. from a broad renormalization-group perspective, the relevance and irrelevance of aperiodic distributions of couplings is related to the existence or not of a second eigenvaluc with modulus Iarger than unity. The general structure of the recursion relations can be used to derive a relevance criterion which is ultimately based on the geometry of the lattice (that is. the values of $p$ and $q$ ), and some measure of the 'strength' of the aperiodic fluctuations, such as the wandering exponent [6].

\section{Transfer-matrix formulation}

One of us has successfully used a transfer-matrix (TM) technique to obtain the thermodynamic properties of several spin models on fractal lattices $[3,4]$. The essential step of this scheme consists in the derivation of maps relating the eigenvalues of the transfer matrices associated with two subsequent generations, $G$ and $G+I$. In a certain sense, this formalism is equivalent 


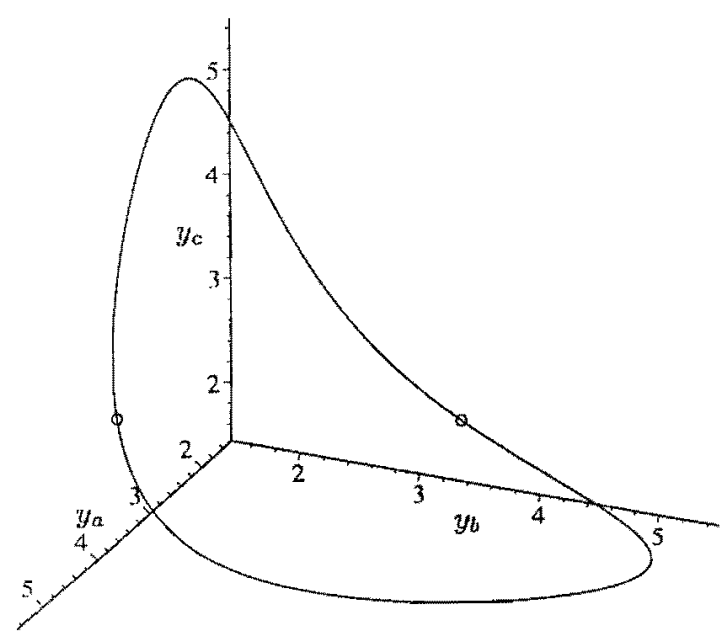

Figure 2. Three-dimensional projection of the attractor of the $\mathrm{RG}$ recursion relations for the Rudin-Slapiro aperiodic sequence, in a latice with $p=2$ and $q=4$. The non-diagonal fixed points are shown as circies.

to a method used by Detrida et al [10] for establishing a map for the free energy, although it enables the calculation of a correlation length, which turns out to be very useful for locating the critical temperature (in spin systems).

In order to introduce the transfer-matrix formulation, let us define the model in a mathematically more precise way. Again, we will consider a simple diamond hierarchical lattice (remembering that it has $q$ branches and $p$ bonds per branch in each basic cell). At a generation $G$ of the hierarchical construction, the lattice has $q^{G}$ branches, each of them formed by $p^{G}$ bonds. A polymer $A$, extending from one root site to the other, is formed by $p^{C}$ connected monomers, and represented by a directed continuous path between the two root sites. A given monomer, labelled $i\left(0 \leqslant i \leqslant p^{G}-1\right)$, occupies one of the $q^{G}$ available branches at the $i$ th position along the path. We may define a numbering for the $q^{G}$ branches of the lattice, and let the variables $a_{i}$ indicate which one is occupied by the $i$ th monomer, clearly, $1 \leqslant a_{i} \leqslant q^{i}$, with analogous definitions for the other polymer, $B$. The two polymers interact at position $i$, with energy $-\epsilon_{i}<0$, if the $i$ th monomers of the two distinct polymers occupy the same bond (note that the energy depends only on the position $i$, since we will consider layered interactions). If the $i$ th monomers occupy distinct bonds, the interaction energy vanishes.

This definition of the two-polymer model can be summarized by the Hamiltonian

$$
\mathcal{H}_{G}=-\sum_{i=0}^{p^{G}-1} \epsilon_{i} \delta\left(a_{i}, b_{i}\right)
$$

where $\delta\left(a_{i}, b_{i}\right)$ indicates a Kronecker delta.

In figure 3, we illustrate the simplest case, for $G=1, p=2$ and $q=2$. Note that, in fact, we are considering a periodic chain of $N$ hierarchical cells, each one grown up to generation $G$. For a single cell, as each monomer can independently occupy any of the $q$ branches, there are $q^{\prime \prime}$ possible configurations for each position $i$ (remember that, as $p=2, i$ can have only two values in each cell), so that a total of 16 possible states can be devised for this specific situation. However, we have to take into account that each polymer is required to form a continuous path between the root sites, so that several configurations have to be excluded. 


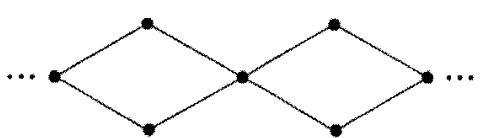

Figure 3. Periodic chain of $N$ hierarchical cells joined by the root sites. each consisting of the first generation of a diamond latice with $p=2$ and $q=2$. This is the initial stage of the construction of the transfer-matrix formalism for the interacting polymer model.

Formally, we may calculate the partition function including these forbidden configurations. if we introduce in the Hamiltonian an additional term of the form $\eta \sum_{i} V_{i}\left(a_{i}, a_{i+1}, b_{i}, b_{i+1}\right)$, with $\eta \rightarrow \infty$, such that $V_{i}=0$ for the acceptable configurations and $V_{i}>0$ whenever $a_{i}$. $a_{i+1}$ and $b_{i}, b_{i+1}$ are not properly constrained. The explicit form of this potential is somewhat cumbersome, and will not be given here.

Although it is straightiorward to write a partition function for the particular case illustrated in figure 3 ,

$$
Z_{1}=\left(2 \mathrm{e}^{g \epsilon_{t}} \mathrm{e}^{\beta \epsilon_{1}}+2\right)^{N}
$$

the calculation of $Z_{G}$, for arbitrary values of $G$, and hence of the thermodynamic properties of the model, represents a much more difficult task. This is the reason to invoke the translermatrix technique. However, this problem of interacting polymers, with interaction energies depending on monomer positions along the bonds, requires a completely new definition of the transfer matrices.

For the sake of simplicity, we restrict the presentation of the formalism to the homogeneous (uniform) system, which requires a smaller number of different types of elementary TMs. It is straightforward to work out an extension for the more complex situation of a model with aperiodic interactions.

With the inclusion of the infinite-energy term, equation (29) can be written in the symmetrized form,

$$
\mathcal{H}_{G}=-\frac{\epsilon}{2} \sum_{i=0}^{p^{c}-1}\left[\delta\left(a_{i}, b_{i}\right)+\delta\left(a_{i+1}, b_{i+1}\right)\right]+\eta \sum_{i=0}^{p^{a}-1} V_{i}\left(a_{i}, a_{i+1}, b_{i}, b_{i+1}\right)
$$

where we impose periodic boundary conditions, $a_{p} c=a_{0}$ and $b_{p^{i}}=b_{0}$. Now we derine the $q^{2 C} \times q^{2 G}$ matrices,

$\left(\mathbf{M}_{G}^{(i)}\right)_{a_{i} b_{i}: a_{i+1} b_{i+1}}=\exp \left\{\frac{\beta \epsilon}{2}\left[\delta\left(a_{i}, b_{1}\right)+\delta\left(a_{i+1}, b_{i+1}\right)\right]+\beta \eta V_{i}\left(a_{i}, a_{i+1}, b_{i}, b_{i+1}\right)\right\}$

and recall that the index $i$ ranges from 0 to $p^{G}-1$ (the length of each polymer in generation $G$ is $p^{G}$ ). Also, it should be remarked that, in the double indices of $\mathbf{M}_{G}^{(i)}$, each term $a_{i} b_{i}$ must be interpreted as a tensor product of the variables $a_{i}$ and $b_{i}$, each of them taking $q^{C}$ independent values. The Boltzmann weights at each $\mathbf{M}_{G}^{(i)}$ relate to the attracting energy between two monomers and to whether the $i$ th monomer, placed at the bond $a_{i}\left(b_{i}\right)$, can be linked to the $(i+1)$ th monomer at the bond $a_{i+1}\left(b_{i+1}\right)$, without violating the continuity constraint. The definition of the TMs in equation (32) leads to the formal identification of the partition function with the trace of a product of TMs,

$$
Z_{G}=\operatorname{Tr} \prod_{i=0}^{p^{G}-1} \mathbf{M}_{G}^{(i)} \equiv \operatorname{Tr} \mathbf{M}_{G}
$$

Note that in this equation we considered $N=1$, since periodic boundary conditions have already been enforced. 
In the following we will show that $\mathbf{M}_{G}$ has one non-zero eigenvalue, which we call $\eta_{G}$, and which is obviously its trace. For the sake of clarity, we now state the result that $\eta_{G}$ is given by a recursion relation,

$$
\eta_{c}=q\left[\eta_{G-1}^{2}+(q-1) \chi_{G-1}^{4}\right]
$$

with

$$
x_{G}=q^{\left(2^{a}-1\right)}
$$

and $\eta_{0}=y^{2}$. The next two sections are devoted to the derivation of this result, and some readers may be interested in skipping directly to section 6 , where we establish recursion relations for the relevant thermodynamic functions.

\section{Detailed structure of the matrices}

The essential difficulty in the evaluation of $Z_{G}$ has been shifted to the calculation of the cigenvalues of a product of different kinds of TMs, $\mathbf{M}_{G}^{(i)}$. In order to emphasize the main idets of the method. let us explore in greater detail the structure of the matrices in the case illustrated in figure 3. where now the partition function is the one given by equation (30), with $\epsilon_{1}=\epsilon_{2}$ (remember we are considering uniform interactions for the time being). Defining now $y=\exp (\beta \epsilon / 2)$, we note that the TMs $\mathbf{M}_{G=1}^{(i)}$ assume the two distinct forms,

$$
\mathbf{M}_{1}^{(1)}=\left(\begin{array}{cccc}
y^{2} & y & y^{2} & y \\
y & 1 & y & 1 \\
y^{2} & y & y^{2} & y \\
y & 1 & y & 1
\end{array}\right)=\left(\begin{array}{ll}
1 & 1 \\
1 & 1
\end{array}\right) \otimes\left(\begin{array}{ll}
y^{2} & y \\
y & 1
\end{array}\right) \equiv \mathbf{L}_{1}^{(1)} \otimes \mathbf{J}_{1}^{(1)}
$$

ind

$$
\mathbf{M}_{1}^{(0)}=\left(\begin{array}{cccc}
y^{2} & 0 & 0 & 0 \\
0 & 1 & 0 & 0 \\
0 & 0 & y^{2} & 0 \\
0 & 0 & 0 & 1
\end{array}\right)=\left(\begin{array}{ll}
1 & 0 \\
0 & 1
\end{array}\right) \otimes\left(\begin{array}{ll}
y^{2} & 0 \\
0 & 1
\end{array}\right) \equiv \mathbf{L}_{1}^{(0)} \otimes \mathbf{J}_{1}^{(0)}
$$

depending on whether the bonds at sites $i$ and $i+1$ meet at a single vertex, where all four bonds are connected, or at two vertices, where the bonds are connected pairwise. Comparing equations (36) and (37), we note that several matrix elements in equation (36), which are equal to $y$ and 1 , are replaced by 0 in equation (37). They result from the presence of the term $\exp (-\beta \eta) \rightarrow 0$ in the Boltzmann weights, indicating that the polymer that arrives at a vertex where only two bonds meet cannot jump to a bond not incident to that vertex. For this simple situation. equation (33) reduces to

$$
Z_{G=1}=\operatorname{Tr}\left(\mathbf{M}_{1}^{(1)} \mathbf{M}_{1}^{(0)}\right)=\operatorname{Tr}\left(\mathbf{L}_{1}^{(1)} \mathbf{L}_{1}^{(0)} \otimes \mathbf{J}_{1}^{(1)} \mathbf{J}_{1}^{(0)}\right)
$$

The lour eigenvalues of $\mathbf{M}_{1}=\mathbf{M}_{1}^{(1)} \mathbf{M}_{1}^{(0)}$ are given by the independent products of the eigenvalues of $L_{1}^{(1)} L_{1}^{(0)}$ (which are 2 and 0 ) and those of $J_{1}^{(1)} J_{1}^{(0)}$ (which are $y^{4}+1$ and 0 ). Thus, $\mathbf{M}_{1}^{(1)} \mathbf{M}_{1}^{(0)}$ has one single non-vanishing eigenvalue, which is $\Lambda=2\left(y^{4}+1\right)$.

Restricting the analysis to $p=2$, we can show that a similar result is valid for any $q$, as $\mathbf{M}_{1}^{(1)}$ and $\mathbf{M}_{1}^{(0)}$ are expressed in terms of Kronecker products of matrices with the sarne structure as those which are present in equations (36) and (37). All elements of the $q \times q$ matrix $\mathbf{L}_{1}^{(1)}$ are equal to unity; $\left(\mathbf{J}_{1}^{(1)}\right)_{1,1}=y^{2} \cdot\left(\mathbf{J}_{1}^{(1)}\right)_{1, l}=\left(\mathbf{J}_{1}^{(1)}\right)_{l, 1}=y$ for $l=2, \ldots, q$, while all other elements are set to unity; $L_{1}^{(0)}$ is the identity $q \times q$ matrix, while $J_{1}^{(0)}$ is a diagonal 


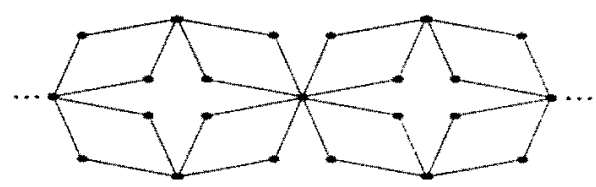

Figure 4. Second stage of the construction of the transfer matrix formalism. Now, each cell on the periodic chain is a diamond latice of the second generation.

matrix with $y^{2}$ in the first entry, and 1 along the rest of the diagonal. The only non-vanishing eigenvalue is $\Lambda=q\left(y^{4}+q-1\right)$, which confirms the previous result for $q=2$.

If we go into the next generation, $G=2$ (see figure 4 ), the basic cell of length $2^{2}$ is associated with three different types of matrices, $\mathbf{M}_{2}^{(j)}, j=0,1,2$. They describe, respectively, the situations where the bonds at position $i$ meet with those at position $i+1$ at 1,2 or 4 distinct vertices, each one with connectivity $2 q^{2}, 2 q$ and $2 q^{0}$. For $q=2$. these matrices are

$$
\begin{aligned}
& \mathbf{M}_{2}^{(2)}=\left(\begin{array}{ll}
1 & 1 \\
1 & 1
\end{array}\right) \otimes\left(\begin{array}{ll}
1 & 1 \\
1 & 1
\end{array}\right) \otimes\left(\begin{array}{llll}
y^{2} & y & y & y \\
y & 1 & 1 & 1 \\
y & 1 & 1 & 1 \\
y & 1 & 1 & 1
\end{array}\right) \\
& \mathbf{M}_{2}^{(1)}=\left(\begin{array}{ll}
1 & 0 \\
0 & 1
\end{array}\right) \otimes\left(\begin{array}{ll}
1 & 1 \\
1 & 1
\end{array}\right) \otimes\left(\begin{array}{llll}
y^{2} & y & 0 & 0 \\
y & 1 & 0 & 0 \\
0 & 0 & 1 & 1 \\
0 & 0 & 1 & 1
\end{array}\right)
\end{aligned}
$$

and

$$
\mathbf{M}_{2}^{(0)}=\left(\begin{array}{ll}
1 & 0 \\
0 & 1
\end{array}\right) \otimes\left(\begin{array}{ll}
1 & 0 \\
0 & 1
\end{array}\right) \otimes\left(\begin{array}{cccc}
y^{2} & 0 & 0 & 0 \\
0 & 1 & 0 & 0 \\
0 & 0 & 1 & 0 \\
0 & 0 & 0 & 1
\end{array}\right)
$$

The presence of 0 in equations (40) and (41), and the form of the matrices for larger values of $q$ follow from the same kind of arguments already used to discuss the generation $G=1$. To evaluate the partition function $Z_{2}$ it is necessary to identify the order in which the factors $\mathbf{M}_{2}^{(1)}, \mathbf{M}_{2}^{(2)}$ and $\mathbf{M}_{2}^{(3)}$ are multiplied to form the matrix $\mathbf{M}_{2}$. This can be easily realized if we recall the association of the different matrix types with the various kinds of vertices along the hierarchical lattice. We thus have

$$
\mathbf{M}_{2}=\mathbf{M}_{2}^{(0)} \mathbf{M}_{2}^{(1)} \mathbf{M}_{2}^{(0)} \mathbf{M}_{2}^{(2)}
$$

from which it is straightforward to calculate $Z_{2}$.

Let us now obtain the structure of the matrices $\mathbf{M}_{G}$ for any $G$. This follows from equation (33), from the hierarchical structure of the lattice and from the detailed discussion of the form of matrices $\mathbf{M}_{1}^{(i)}$ and $\mathbf{M}_{2}^{(i)}$. The first important property related to the structure of the lattice is that, along each branch, there are sites with different connectivities, and they appear according to a well-defined sequence. The difference in connectivities results in local variations of degrees of freedom, since the polymers can choose among different numbers of branches. The inner sites can be of $G$ types, the connectivities of which are $2,2 q, 2 q^{2}, \ldots, 2 q^{G-1}$, while the root sites have connectivity $2 q^{G}$. We identify the type of a site by the variable $s$, such that the connectivity of a particular site is $2 q^{x}$. Let $S_{G}$ be the 
sequence of $p^{G}$ numbers that identifies the order in which the several kinds of sites appear along a branch in generation $G$. For instance, $S_{1}=\{0,1\}$ and $S_{2}=\{0,1,0,2\}$. We note that $S_{G}$ can be oblained by the concatenation of two sequences $S_{G-1}$, replacing the last symbol $(G-1)$ by $G$. Also, we observe that $S_{G}$ contains $2^{G-1}$ symbols $0,2^{G-2}$ symbols 1 and so forth, until one single symbol $G-\mathrm{I}$ (at the central position) and one symbol $G$ at the rightmost position. As equation (42) suggests, the matrix associated with a site of type $s$ is $\mathbf{M}_{G}^{(s)}$, so that $\mathbf{M}_{6}$ decomposes into a product of elementary matrices in a well-defined order,

$$
\mathbf{M}_{G}=\mathbf{M}_{G}^{(0)} \mathbf{M}_{G}^{(1)} \mathbf{M}_{G}^{(0)} \mathbf{M}_{G}^{(2)} \mathbf{M}_{G}^{(0)} \mathbf{M}_{G}^{(1)} \mathbf{M}_{G}^{(0)} \mathbf{M}_{G}^{(3)} \cdots \mathbf{M}_{G}^{(0)} \mathbf{M}_{G}^{(G)}
$$

We now study the structure of the $q^{2 G} \times q^{2 G}$ matrices $\mathbf{M}_{G}^{(i)}$. Each of them can be expressed by the Kronecker product of two $q^{G} \times q^{G}$ matrices, $\mathbf{L}_{G}$ and $\mathbf{J}_{G}$, so that

$$
\begin{aligned}
\mathbf{M}_{G}= & {\left[\mathbf{L}_{G}^{(0)} \mathbf{L}_{G}^{(1)} \mathbf{L}_{G}^{(0)} \mathbf{L}_{G}^{(2)} \mathbf{L}_{G}^{(0)} \mathbf{L}_{G}^{(1)} \mathbf{L}_{G}^{(0)} \mathbf{L}_{G}^{(3)} \cdots \mathbf{L}_{G}^{(0)} \mathbf{L}_{G}^{(G)}\right] } \\
& \otimes\left[\mathbf{J}_{G}^{(0)} \mathbf{J}_{G}^{(1)} \mathbf{J}_{G}^{(0)} \mathbf{J}_{G}^{(2)} \mathbf{J}_{G}^{(0)} \mathbf{J}_{G}^{(1)} \mathbf{J}_{G}^{(0)} \mathbf{J}_{G}^{(3)} \cdots \mathbf{J}_{G}^{(0)} \mathbf{J}_{G}^{(G)}\right] \\
& \equiv \mathbf{Q}_{G} \otimes \mathbf{R}_{G}
\end{aligned}
$$

where the sequence $S_{G}$ controls the numbering order in both $\mathbf{Q}_{G}$ and $\mathbf{R}_{G}$. Then, we note from cquations (39)-(41) that each $L_{G}^{(i)}$ can be further expressed by the Kronecker product of $G$ matrices of order $q$. each of which is either the unit $q \times q$ matrix I or the constant $q \times q$ matrix $K$. with all clements set to unity.

The factor $\mathbf{K}$ expresses allowed transitions of the polymer from a given branch to neighbouring ones, while I indicates a restriction for the polymer to change from one branch to another. So. it is easy to see that $\mathbf{L}_{G}^{(G)}$, which describes the site with connectivity $2 q^{G}$, is lormed by the product of $G$ matrices $K$, while $\mathbf{L}_{G}^{(0)}$, related to sites with connectivity $2 q^{0}$, is formed by products of matrices I only. If we define $A^{\otimes G}$ to be the Kronecker product of $G$ matrices $A$. then we can write the general form of the matrices $L_{G}^{(g)}$ as

$$
\mathbf{L}_{G}^{(g)}=\mathbf{I}^{\otimes(G-g)} \otimes \mathbf{K}^{\otimes g}
$$

Also, it should be noted that, for $g<G$, the matrices $\mathbf{L}_{G}^{(g)}$ and $\mathbf{L}_{G-1}^{(g)}$ are related by

$$
\mathbf{L}_{G}^{(g)}=\mathbf{I} \otimes \mathbf{L}_{G-\mathbf{I}}^{(g)} \text {. }
$$

The matrices $\mathbf{I}_{G}^{(i)}$ cannot be further decomposed in terms of Kronecker products, but they can be expressed as

$$
\mathbf{J}_{G}^{(k)}=\mathbf{L}_{G}^{(k)}+\mathbf{H}_{G}^{(\xi)}
$$

where $\mathbf{H}_{G}^{(\mathrm{H})}$ is given by

$$
\left(\mathbf{H}_{G}^{(g)}\right)_{i j}=\left\{\begin{array}{ll}
y^{2}-1 & \text { if } i=j=1 \\
y-1 & \text { if } i=1 \quad j \in\left\{2, \ldots, q^{g}\right\} \\
y-1 & \text { if } i \in\left\{2, \ldots, q^{g}\right\} \quad j=1 \\
0 & \text { otherwise }
\end{array} .\right.
$$

If $g<G$, it is also possible to see that

$$
\mathbf{H}_{G}^{(g)}=\mathbf{H}_{G-1}^{(g)} \oplus 0 \oplus 0 \oplus \cdots \oplus 0
$$

where 0 indicates the null $q^{G-1} \times q^{G-1}$ matrix, which appears $q-1$ times in the direct sum. This expression can also be written as

$$
\mathbf{H}_{G}^{(\xi)}=\left(\begin{array}{ccccc}
1 & 0 & 0 & \ldots & 0 \\
0 & 0 & 0 & & 0 \\
0 & 0 & 0 & & 0 \\
\vdots & & & \ddots & \vdots \\
0 & 0 & 0 & \ldots & 0
\end{array}\right) \otimes \mathbf{H}_{G-1}^{(g)}
$$


where the first matrix is of order $q$. Combining this last equation with equation (46), we obtain

$$
\mathbf{J}_{G}^{(g)}=\mathbf{I} \otimes \mathbf{L}_{G-1}^{(g)}+\mathbf{H}_{G}^{(g)}=\left(\begin{array}{ccccc}
\mathbf{J}_{G-1}^{(g)} & 0 & 0 & \ldots & 0 \\
0 & \mathbf{L}_{G-1}^{(g)} & 0 & \ldots & 0 \\
0 & 0 & \mathbf{L}_{G-1}^{(g)} & \ldots & 0 \\
\vdots & \vdots & \vdots & \ddots & \vdots \\
0 & 0 & 0 & \ldots & \mathbf{L}_{G-1}^{(g)}
\end{array}\right)
$$

which is valid for $g<G$. In this expression, the 0 represent null matrices of order $q^{(j-1}$. so that $\mathbf{J}_{G}^{(g)}$ is a block-diagonal matrix, with one $\mathbf{J}_{G-1}^{(g)}$ block and $q-1$ blocks $\mathbf{L}_{G-1}^{(k)}$ in the diagonal.

The particular structure of the matrices $L_{G}^{(k)}$ and $J_{G}^{(g)}$ leads to a recurrence relation for the only non-zero eigenvalue of $\mathbf{M}_{G}$ in terms of the corresponding eigenvalue of $\mathbf{M}_{G-1}$. This will be shown in the next section.

\section{Eigenvalues of the matrix $\mathbf{M}_{G}$}

The eigenvalues of $\mathbf{M}_{G}$ are given by all distinct products of the eigenvalues of $\mathbf{Q}_{G}$ and $\mathbf{R}_{G}$. Let us first consider the eigenvalues of $Q_{G}$. According to equation (44), $Q_{G}$ is expressed by the usual matrix products of matrices which are themselves Kronecker products of only two types of matrices, $\mathbf{I}$ and $\mathbf{K}$. Then it is easy to show that

$$
\mathbf{Q}_{G}=\mathbf{K} \otimes \mathbf{K}^{2} \otimes \mathbf{K}^{4} \otimes \cdots \otimes \mathbf{K}^{2^{c-2}} \otimes \mathbf{K}^{2^{G-1}}
$$

Using the relation

$$
\mathbf{K}^{n}=q^{n-1} \mathbf{K}
$$

and the identity

$$
\sum_{g=1}^{G-1}\left(2^{g}-1\right)=2^{G}-G-1
$$

it is possible to write equation (52) as

$$
\mathbf{Q}_{G}=\left(\prod_{g=0}^{G-1} q^{2^{k}-1}\right) \mathbf{K}^{\otimes G}
$$

The rank of $\mathbf{K}$ is unity, and its only non-zero eigenvalue is $q$. It follows that $q^{G}$ is the only non-zero eigenvalue of $\mathbf{K}^{\otimes G}$, so that $\chi_{G}$, the eigenvalue of $\mathbf{Q}_{G}$, is given by

$$
\chi_{G}=q^{\left(2^{G}-1\right)} .
$$

Now, let us calculate the eigenvalues of $\mathbf{R}_{G}$, defined through equation (44). First, we write $\mathbf{R}_{G}$ in the form

$$
\mathbf{R}_{G}=\prod_{l=1}^{2^{G}} \mathbf{J}_{G}^{\left(S_{G}\right) t}=\left(\prod_{l=1}^{2^{G}-1} \mathbf{J}_{G}^{\left(S_{G}\right) t}\right) \mathbf{J}_{G}^{(G)}
$$


wherc $\left(S_{G}\right)$, represents the $l$ th number in the sequence $S_{G}$. Then, we note that the matrix $\mathbf{J}_{G}^{(C)}$ can be written als

$$
\mathbf{J}_{G}^{(G)}=\left(\begin{array}{ccccc}
\mathbf{J}_{G-1}^{(G-1)} & \mathbf{E}_{G-1} & \mathbf{E}_{G-1} & \ldots & \mathbf{E}_{G-1} \\
\mathbf{F}_{G-1} & \mathbf{L}_{G-1}^{(G-1)} & \mathbf{L}_{G-1}^{(G-1)} & \ldots & \mathbf{L}_{G-1}^{(G-1)} \\
\mathbf{F}_{G-1} & \mathbf{L}_{G-1}^{(G-1)} & \mathbf{L}_{G-1}^{(G-1)} & \ldots & \mathbf{L}_{G-1}^{(G-1)} \\
\vdots & \vdots & \vdots & \ddots & \vdots \\
\mathbf{F}_{G-1} & \mathbf{L}_{G-1}^{(G-1)} & \mathbf{L}_{G-1}^{(G-1)} & \ldots & \mathbf{L}_{G-1}^{(G-1)}
\end{array}\right)
$$

where all the elements of the $q^{G-1} \times q^{G-1}$ matrix $\mathbf{E}_{G-1}$ are equal to unity, with the exception of those of the first row, which are equal to $y$. The matrix $\mathbf{F}_{G-1}$ is the transpose of $\mathbf{E}_{G-1}$. For $g<G$, we recall that equation (5I) uncovers the block-diagonal structure of $\mathbf{J}_{G}^{(g)}$, so that

$$
\prod_{l=1}^{2_{i}^{G}} \mathbf{J}_{G}^{\left(S_{G}\right)}=\left(\begin{array}{cccc}
\prod_{l=1}^{2^{G}-1} \mathbf{J}_{G}^{\left(S_{G}\right)} & 0 & \ldots & 0 \\
0 & \prod_{l=1}^{2^{G}-1} \mathbf{L}_{G}^{\left(S_{G}\right)} & \ldots & 0 \\
\vdots & \vdots & \ddots & \vdots \\
0 & 0 & \ldots & \prod_{l=1}^{2^{G}-i} \mathbf{L}_{G}^{\left(S_{G}\right) h}
\end{array}\right)
$$

with $q$ blocks of order $q^{G-1}$ in the diagonal. Let us now introduce the notation

$$
\Pi_{\mathbf{J}}=\prod_{l=1}^{2^{(i-1}} \mathbf{J}_{G-1}^{\left(s_{G)}\right.}
$$

with the analogous definition for the product of the matrices $L_{G}^{(g)}$. Making use of equations $(58)$ and (59), we obtain

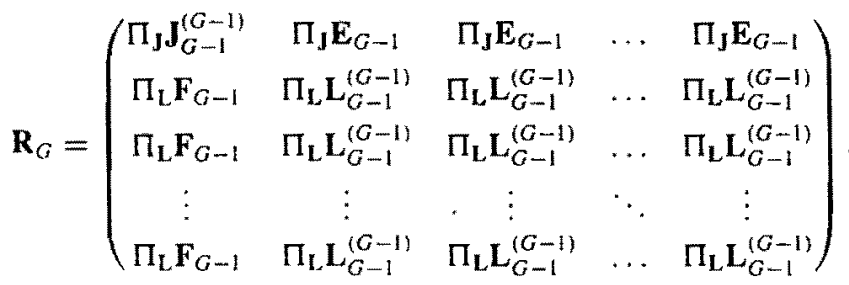

Let us consider the entries of this matrix. Take, for instance,

$$
\begin{aligned}
\Pi_{\mathbf{L}} \mathbf{L}_{G-1}^{(G-1)} & =\left(\prod_{l=1}^{2^{G-1}} \mathbf{L}_{G-1}^{\left(S_{G}\right)}\right) \mathbf{L}_{G-1}^{(G-1)} \\
& =\left(\prod_{l=1}^{2^{G-1}} \mathbf{L}_{G-1}^{\left(S_{G}\right) t}\right)\left(\prod_{l=2^{G+1}+1}^{2^{G-1}} \mathbf{L}_{G-1}^{\left(S_{G}\right)_{l}}\right) \mathbf{L}_{G-1}^{(G-1)}
\end{aligned}
$$

The first factor is clearly $\mathbf{Q}_{G-1}$, as the sequence $S_{G}$ is equivalent to $S_{G-1}$ until the position $l=2^{G-1}$. However, $S_{G}$ is also identical to $S_{G-1}$ between the positions $l=2^{G-1}+1$ and $l=2^{G}-1$, according to the rule to generate $S_{G}$ from $S_{G-1}$. Thus, this factor, multiplied by $\mathbf{L}_{G-1}^{(G-1)}$, also leads to $\mathbf{Q}_{G-1}$,

$$
\Pi_{L} L_{G-1}^{(G-1)}=Q_{G-1}^{2}
$$

Following the same arguments, it is possible to show that

$$
\Pi_{\mathbf{J}} \mathbf{I}_{G-1}^{(G-1)}=\mathbf{R}_{G-1}^{2}
$$


so that

$$
\mathbf{R}_{G}=\left(\begin{array}{ccccc}
\mathbf{R}_{G-1}^{2} & \Pi_{\mathfrak{J}} \mathbf{E}_{G-1} & \Pi_{J} \mathbf{E}_{G-1} & \ldots & \Pi_{\mathfrak{J}} \mathbf{E}_{G-1} \\
\Pi_{L} \mathbf{F}_{G-1} & \mathbf{Q}_{G-1}^{2} & \mathbf{Q}_{G-1}^{2} & \cdots & \mathbf{Q}_{G-1}^{2} \\
\Pi_{L} \mathbf{F}_{G-1} & \mathbf{Q}_{G-1}^{2} & \mathbf{Q}_{G-1}^{2} & \cdots & \mathbf{Q}_{G-1}^{2} \\
\vdots & \vdots & \vdots & \ddots & \vdots \\
\Pi_{L} \mathbf{F}_{G-1} & \mathbf{Q}_{G-1}^{2} & \mathbf{Q}_{G-1}^{2} & \cdots & \mathbf{Q}_{G-1}^{2}
\end{array}\right)
$$

Now we recall that $\mathbf{R}_{G}$ is a product of the matrices $\mathbf{J}_{G}^{(g)}$, including $\mathbf{J}_{i}^{(G)}$. The rank of this last matrix is unity, as one sees from equation (58). Using the Frobenius inequality for the rank of matrices [11], we then see that the rank of $\mathbf{R}_{G}$ is also unity. Then, the only non-zero eigenvalue $\lambda_{G}$ equals the trace of $\mathbf{R}_{G}$, so that

$$
\lambda_{G}=\operatorname{Tr} \mathbf{R}_{G-1}^{2}+(q-1) \operatorname{Tr} \mathbf{Q}_{G-1}^{2} .
$$

However, it is clear that $\operatorname{Tr} \mathbf{R}_{G-1}^{2} \equiv \lambda_{C-1}^{2}$. Also, from equation (56), we have $\operatorname{Tr} \mathbf{Q}_{(i-1}^{2} \equiv$ $\chi_{G-1}^{2}$, so that

$$
\lambda_{G}=\lambda_{G-1}^{2}+(q-1) x_{G-1}^{2} .
$$

As $\lambda_{0}=y^{2}$, this equation gives rise to a recursion relation for the eigenvalues of $\mathbf{R}_{\{;}$. If we call $\eta_{G}$ the only non-zero eigenvalue of $\mathbf{M}_{G}$, we may write

$$
\eta_{G}=\chi_{G} \lambda_{G}=\chi_{G}\left[\lambda_{G-1}^{2}+(q-1) \chi_{G-1}^{2}\right] \text {. }
$$

From equation (33), one sees that $Z_{G}=\eta_{G}$, since the trace is just this non-zero eigenvalue. Now, using equation (56), we have

$$
\chi_{G}=q \chi_{G-1}^{2}
$$

from which we are finally led to the map

$$
\eta_{G}=q\left[\eta_{G-1}^{2}+(q-1) x_{G-1}^{4}\right] \text {. }
$$

\section{Thermodynamic functions}

If we take the Boltzmann constant $k_{B}=1$, the free energy per monomer of the system may be written as

$$
f_{G}=-\frac{T}{2^{G}} \ln Z_{G}=-\frac{T}{2^{G}} \ln \eta_{G}
$$

Defining an auxiliary map, $K_{G}=\chi_{G}^{2} / \eta_{G}$, we have

$$
f_{G}=f_{G-1}-\frac{T}{2^{G}} \ln \left(1+(q-1) K_{G-1}^{2}\right)-\frac{T}{2^{G}} \ln 2
$$

where

$$
K_{G}=\frac{q K_{G-1}^{2}}{1+(q-1) K_{G-1}^{2}}
$$

The recursive iteration of equations (72) and (73), with the intial conditions $f_{0}=-\epsilon$ and $K_{0}=\exp (-\beta \epsilon)$, leads to the free energy per monomer for any generation $G$, which converges to a well-defined free energy in the thermodynamic limit, $G \rightarrow \infty$. Maps for additional thermodynamic functions, such as the entropy and the specific heat, can be obrained by taking 


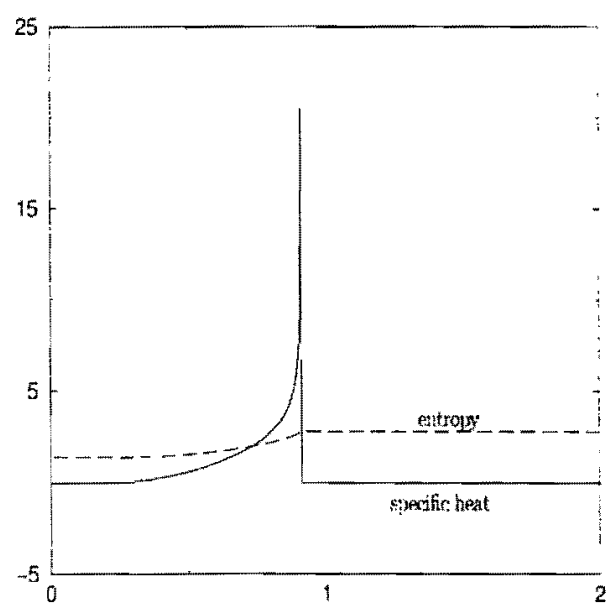

Figure 5. Entropy and specific heal for a uniform model, in a lattice with $p=2$ and $q=4$. calculated using the transfer-matrix technique. In this figure $\epsilon / k_{B}=1$.

the derivative of equations (72) and (73) with respect to temperature. For the entropy per monomer, tor example, we obtain

$s_{G}=s_{G-1}+\frac{1}{2^{G}} \ln \left(1+(q-1) K_{G-1}^{2}\right)+\frac{T}{2^{G}} \frac{2(q-1) K_{G-1}}{1+(q-1) K_{G-1}^{2}} \frac{\partial K_{G-1}}{\partial T}+\frac{1}{2^{G}} \ln 2$

where

$$
\frac{\partial K_{G}}{\partial T}=\frac{2 q K_{G-1}}{\left(1+(q-1) K_{G-1}^{2}\right)^{2}} \frac{\partial K_{G-1}}{\partial T}
$$

As an example, in figure 5 we show the results for the entropy and specific heat of a uniform model on the lattice with $p=2$ and $q=4$. Numerical analysis shows there is a genuine singularity, associated with a divergence of the specific heat at a critical temperature. Note the interesting bchaviour of the system above the transition temperature, with a constant entropy per monomer, and. consequently, zero specific heat. On physical grounds, this result should have been anticipated, since the polymers are completely unbound on the high-temperature phase, and the maximum amount of disorder is attained independently of temperature. The RG approach, however, does not yield such a global picture of the thermodynamics, which is possible only in the TM framework.

To check the reliability of the method, and its compatibility with the RG results, we may compare the critical temperature and exponent it yields with those predicted by the renormalization-group calculation. For any value of $q$, the fixed point $y^{*}=q-1$, with $y=(\exp \beta \epsilon)$, gives the critical temperature

$$
T_{C}=\frac{\epsilon}{k_{B}} \frac{1}{\ln (q-1)}
$$

with a critical exponent given by equations (4) and (2). For $q=4$ and $\epsilon / k_{B}=1$, we have $T_{C}=0.910239 \ldots$ and $\alpha=0.290488 \ldots$ The numerical analysis of data in figure 4 leads to $T_{C} \simeq 0.910239$ and $\alpha \simeq 0.2905$, which confirms the accuracy of the method.

Now we remark that the models we are interested in include more than one interaction energy, depending on the position $i$ along the path between the root sites. The basic steps 
of the TM scheme can be adapted in order to obtain the corresponding maps, although much attention has to be paid to all the details. For instance, if we consider an aperiodic model with the presence of two distinct interaction energies, which are placed along the lattice according to the period-doubling sequence $a \rightarrow a b, b \rightarrow a a$, the method requires the definition of two matrices $\mathbf{M}_{G}^{a}$ and $\mathbf{M}_{G}^{b}$, the eigenvalues of which are $\eta_{G}^{(a)}$ and $\eta_{G}^{(b)}$. The maps for $\eta_{G}^{(i))}$ and $\eta_{i}^{(f)}$ are written as

$$
\eta_{G}^{(a)}=q\left[\eta_{G-1}^{(a)} \eta_{G-1}^{(b)}+(q-1) \chi_{G-1}^{4}\right]
$$

and

$$
\eta_{G}^{(b)}=q\left[\left(\eta_{G-1}^{(a)}\right)^{2}+(q-1) \chi_{G-1}^{4}\right]
$$

Note that each one of these eigenvalues gives rise to a different partition function, associated with the choice of $a$ or $b$ as the initial letter to be iterated according to the inflation rule. Wo are always interested in sequences generated by the recursive application of the rule 10 the initial letter $a$.

If the aperiodicity is induced by the four-letter Rudin-Shapiro sequence, $a \rightarrow a c$. $b \rightarrow d c, c \rightarrow a b, d \rightarrow d b$, the set of four maps for the eigenvalues is given by

$$
\begin{aligned}
& \eta_{G}^{(a)}=q\left[\eta_{G-1}^{(a)} \eta_{G-1}^{(c)}+(q-1) \chi_{G-1}^{4}\right] \\
& \eta_{G}^{(b)}=q\left[\eta_{G-1}^{(c)} \eta_{G-1}^{(d)}+(q-1) \chi_{G-1}^{4}\right] \\
& \eta_{G}^{(c)}=q\left[\eta_{G-1}^{(a)} \eta_{G-1}^{(b)}+(q-1) \chi_{G-1}^{4}\right]
\end{aligned}
$$

and

$$
\eta_{G}^{(d)}=q\left[\eta_{G-1}^{(b)} \eta_{G-1}^{(d)}+(q-1) \chi_{G-1}^{4}\right]
$$

The free energy per monomer, along with its temperature derivatives, can be similarly defined, so that the singularity at the phase transition can be analysed directly.

\section{Discussions and results}

As discussed in section 2, the RG analysis of the uniform model indicates the presence of a second-order phase transition for $q>2$, with the specific-heat critical exponent given by equation (4). In the case of irrelevant aperiodicity, that is, when the diagonal fixed point has one relevant eigenvalue, $\alpha$ is given by the same expression. For the period-3 sequence. however. the diagonal fixed point is completely unstable, and the two-cycle should be responsible for the critical behaviour, as in the case of the spin models [2]. In this case, the scaling analysis must be somewhat adapted to take into account that two renormalization-group iterations are needed in order that the system goes back to the vicinity of one of the two points that are part of the two-cycle [10]. The result is simply that the specific-heat critical exponent is now given by

$$
\alpha=2-2 \frac{\ln p}{\ln \Lambda}
$$

where $\Lambda$ is the leading eigenvalue of the linearized second-iterate of the $R G$ recursion relations about any one of the two points of the attractor. The results of this analysis have already been given elsewhere [1], and will not be repeated here.

For the model with Rudin-Shapiro aperiodic interactions, we remarked above that there exist two non-diagonal fixed points together with the curve composed of two-cycles, and that 


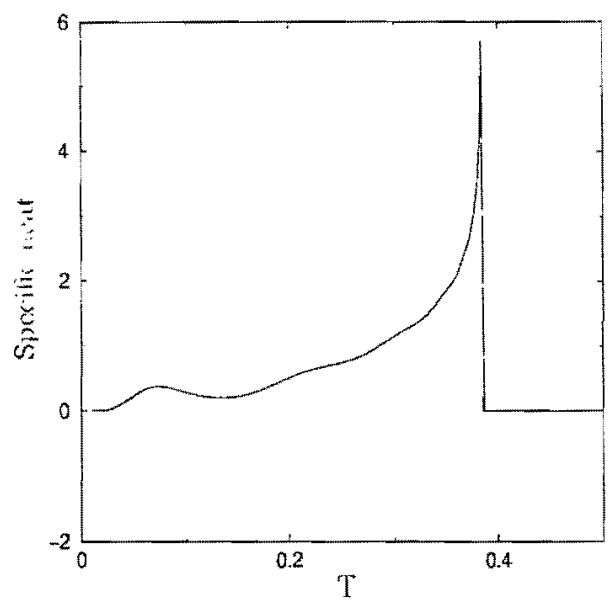

Figure 6. Specitic heat of the model with Rudin-Shapiro aperiodicity, in a latice with $p=2$ and $q=4$. calculated using the transfer-matrix technique. In this figure $\epsilon_{d}$ is 100 times greater than the other energies.

the linearization of the second iterates of the recursion relations about any point on the twocycle curve gives the same eigenvalues. For each $q>2+\sqrt{2}$, we may therefore determine numerically which value of $\alpha$ equation (83) predicts, and then compare it with the direct analysis of the singularity which comes from the TM method. It is also possible to obtain $\alpha$ in the usual way, linearizing the recursion relations (first iterate) about the non-diagonal fixed points, using the leading eigenvalue that comes from the solution of equation (22). The coincidence of the values is already an important hint of the correctness of scaling predictions, and we have indeed verified it for several choices of $q$.

In figure 6 we show the TM results for the specific heat in a lattice with $q=4$, with a certain choice of interaction energies. The first interesting feature is the appearance of log-periodic oscillations in the low-temperature phase, as in spin models [3]. This is a natural consequence of the discrete scale-invariance of the aperiodic sequence (due to its self-similar character), which implies a natural rescaling factor in the renormalization group [12]. Several different values of the interaction energies must be separately analysed, and the net result is an exponent $\alpha=0.252 \pm 0.08$. Two points must be carefully stressed: first, that some choices for the energies ( $\epsilon_{a}=\epsilon_{d}$ and $\epsilon_{b}=\epsilon_{c}$, for instance) give rise to an effectively periodic model, because of the symmetries of the Rudin-Shapiro rule, and should therefore be kept out of the analysis; second, $\alpha$ does not show any important dependence on the values (provided they are not of the form that makes the model effectively periodic, of course), which points to a true 'aperiodic universality class' associated with the Rudin-Shapiro geometrical perturbation of the model. Now, for $q=4$, the scaling result is $\alpha=0.253692 \ldots$, in striking agreement with the TM value. The same scenario is present for several other values of $q$ we have tested, which leads us to believe in the correctness of the methods.

In conclusion, we have presented detailed renormalization-group and transfer-matrix calculations for a class of interacting polymer models on diamond-like hierarchical lattices, with aperiodically distributed coupling constants. Although straightforward, the exact renormalization-group analysis has revealed a surprising family of attractors in the case of Rudin-Shapiro aperiodicity, and this prompted us to resort to the transfer-matrix formalism 
to check the scaling results. However, we had to develop a complete reformulation of this method, in order to apply it to the polymer problem. The transfer-matrix calculations have confirmed the results of the simple scaling analysis, but have also revealed peculiaritics of the transition that were not accessible to the renormalization-group study. What is most impontant is to note that aperiodic perturbations may lead to new universality classes, adding up to the usual criteria of dimensionality and symmetry. In a sense, the breakdown of translation invariance may be relevant to the determination of new types of universal behaviour. and the particular way in which this invariance is broken must be taken into account. The introduction of disorder, for example, is a way of breaking translation invariance. and there are several instances in which its effects on critical behaviour are well known. Aperiodic distributions ol couplings are another way of accomplishing this, and, although more difficult to implement physically, they are amenable to more controlled calculations, such as those presented in this paper.

\section{Acknowledgments}

We thank André P Vieira and Suani T R Pinho for usetul discussions. This work has been supported by Brazilian agencies Fapesp and $\mathrm{CNPq}$.

\section{References}

[1] Haddad T A S and Salinas S R 2002 Physica A 30698

[2] Haddad T A S, Pinho S T R and Salinas S R 2000 Phys. Rev. E 613330

[3] Andrade R. F S 2000 Phys. Rev. E 617196

[4] Andrade R F S 1999 Phys. Rev. E 59150

[5] Harris A B 1974 J.Phys. C: Solid State Phys. 71671

[6] Luck J M 1993 Europhys. Lett. 24359

[7] Grimm $U$ and Baake M 1997 Aperiodic Ising models The Mathematics of Long Range Aperiodic Orter ed R Y Moody (Amsterdam: Kluwer) p 199

[8] Queffélec M 1987 Substitution Dynamical Systems-Spectral Anatyis (Lecture Noter in Mathematics vol 1294) (Berlin: Springer)

[9] Mukheriji S and Bhattacharjee S M 1995 Phyx. Rev. E 521930.

[10] Derrida B, Eckmann J-P and Erzan A 1983 J. Phys. A: Math. Gen. 16893

[11] Marcus M and Mink H 1992 A Survey of Matrix Theory and Matrix Imequalitien (New York: Dover) 27

[12] Sornette D 1998 Phys. Rep. 297239 


\title{
Remarks on disorder and aperiodicity in a model for interacting polymers *
}

\author{
T. A. S. Haddad ${ }^{a, 1}$, R. F. S. Andrade ${ }^{b}$ and S. R. Salinas ${ }^{a}$ \\ ${ }^{a}$ Instituto de Física, Universidade de São Paulo, Caixa Postal 66318, 05315-970- \\ São Paulo, SP, Brazil \\ b Instituto de Física, Universidade Federal da Bahia, 40210-340, Salvador, BA, \\ Brazil
}

\begin{abstract}
The present a comparative study of the effects of random and aperiodically distributed interactions on the critical behavior of a model for two interacting polymers on a diamond hierarchical lattice. The problem is formulated in terms of exact renomalization-group recursion relations. In the disordered case, it is possible to develop a perturbative treatment in order to obtain the fixed points of the moments associated with the random distribution of interactions. Fully incorrelated disorder may become relevant, driving the system away from a homogeneous fixed point. Layered disorder may lead to a breakdown of the perturbative treatment. In the case of aperiodic interactions, we also show some examples of relevance and irrelevance of geomentric fluctuations, and further investigate the models by resorting to an independent transfer-matrix analysis, which fully corroborates the scaling results.
\end{abstract}

Kry words: Interacting polymers, inhomogeneous media, disordered systems, aperiodic systems, critical behavior

PACS: 64.60.Ak, 61.41.+e, 61.43.-j, 61.44.-n

\section{Introduction}

The presenec of impuritics and defects in statistical models, leading to inhomogencitics and the brcakdown of translational invariance, is a continuous source of new concepts and questions. The introduction of quenched disorder, in the form of random distributions of interactions, dilution, random fields,

\footnotetext{
ऋ Work supported by Brazilian agencies Fapesp and CNPq.

1 Corresponding author.
} 
and a host of other realizations, gives rise to extensively studied problems. It is known [1.] that some implementations of quenched disorder may be classified as relcvant or irrelevant from the point of view of changes in the critical propertics of statistical systems. In some recent publications [2]-[5], wo have used renormalization-group (RG) and transfer-matrix (TM) techniques to investigate the effects of aperiodically distributed (but not disordered) interactions on the critical bchavior of a number of model systems. Wc thus refer to a different instance of lack of translational invariance, which may also be classiticd as relevant or irrelevant in terms of the critical behavior [6].

In this note we briefly review our previous work [2,3] for a (very simple) modd of two directed polymers on diamond-like hicrarchical lattices, with apcriodic layered distributions of interaction energies, according to various substitution rules. The results will be compared to calculations for the disordered comterparts of this model. In Sec. 2 we introduce the model and discuss the RG behavior for uniform interactions. In Scc. 3 we consider disordered versions of the model, showing that it is possible to analyze the fixed-point probability distributions perturbatively, and that they strongly depend on the geometric characteristics of the lattice and on whether disorder is correlated (lavered) or not. In Sec. 4 we consider aperiodic cases, from the RG point of view and then using TM methods, and present several examples of relevant and irrclevant aperiodicity. We go beyond the scaling calculations, in order to achicve a better understanding of the RG flux structure in the relevant case and characterize the new (relevant) universality classes.

\section{The interacting polymer model}

The binding-unbinding phase transition in a disordered model of two directed and interacting polymers on a hierarchical lattice has becn investigated by Mukherji and Bhattacharjee [7]. Each polymer is regarded as a directed random-walk, starting at one end of the lattice and stretching continuously to the other end (the root sites). There is an attractive interaction, $-\epsilon$, whenever a bond of the lattice is shared by a monomer of each polymer, which can be made to depend on the position of the bond along a branch.

In the basic cell of a diamond lattice, with $q$ branches and $b$ bonds per branch, there are configurations of cnergy $-b \epsilon$, where the two polymers occupy the same $b$ bonds of a branch, and configurations of zero encrgy, where the polymers stretch along different branches. Using the Boltzmann factor $y=$ $\exp (\beta \epsilon)$, it is possible to write the recursion relation [2], $y^{\prime}=y^{b} / q+(q-1) / q$. Taking $b=2$, for example, we see that besides the trivial fixed points. $y^{*}=1$ and $\infty$, there is a nontrivial fixed point, $y^{*}=q-1$, which is physically acceptable for $q>2$ (this polymer model does not have a phasc transition on the sim- 
ple diamond lattice with $q=2$ branches). Also, from the linearization about the nontrivial fixed point, we have the thermal cigenvalue, $\Lambda=2(q-1) / q$. Lsing a standard scaling assumption [7], the critical cxponent associated with the specific heat is giren by $\alpha=2-\ln b / \ln \Lambda$.

\section{Effects of disorder}

Consider a fully disordered model on a lattice with arbitrary $b$ and $q$, that is, a case in which the interaction energies are independent, identically distributed random variables. Following Mukherji and Bhattacharjec [7], we write the recursion relation

$$
y^{\prime}=\left[y^{(11)} y^{(12)} \ldots y^{(1 b)}+\ldots+y^{(q 1)} y^{(q 2)} \ldots y^{(q b)}\right] / q^{2}+(q-1) / q
$$

where $y^{(i j)}$ is the Boltzmann weight of the $j$-th bond $(j=1, \ldots, b)$ of the $i$-th branch $(i=1, \ldots, q)$ of the diamond lattice. This equation can be analyzed perturbatively if we restrict to small amounts of disorder. Thus, we define the small deviation $\delta^{(i j)}=y^{(i j)}-y^{*}$, where $y^{*}$ is the (physical) fixed point of the uniform system. It is now straightforward to writc recursion relations for the moments of the new random variable $\delta^{(i j)}$. Unlike the case of disordered spin systems on this kind of lattice, the polymer model has the advantage that each moment depends only on the lower-order ones, so that it is not necessary to invoke truncation schemes, as the weak-disorder expansion [8]. For $b=2$, for example, the recursion relations for the first and second-order moments are given by

$$
\begin{gathered}
M_{1}^{\prime}=\frac{2(q-1)}{q} M_{1}+\frac{1}{q} M_{1}^{2} \\
M_{2}^{\prime}=\frac{2(q-1)^{2}}{q^{3}} M_{2}+\frac{1}{q^{3}}\left[10(q-1)^{2} M_{1}^{2}+M_{2}^{2}+4(q-1) M_{1} M_{2}\right]+ \\
+\frac{8(q-1)}{q^{3}} M_{1}^{3}+\frac{2}{q^{3}} M_{1}^{4} .
\end{gathered}
$$

For $b=2$ and all values of $q$, the physically acceptable fixed point, located at $M_{1}^{*}=M_{2}^{*}=\ldots=0$, leads to the anticipated thermal cigenvalue of the uniform model, $\Lambda_{1}>1$, and to a set of smaller cigenvalues, $\Lambda_{2}, \Lambda_{3}, \ldots<1$, which shows that disorder is alwavs irrelevant. For $b=3$, however, the situation is morc interesting. The lincar stability analysis reveals that the (uniform) fixed point, $M_{1}^{*}=M_{2}^{*}=\ldots=0$, bccomes unstable along a second direction bcyond a certain value of $q$. Indeed, for $q>q_{c}$, there is a novel fixed point, with $M_{2}^{*}>0$ and $\Lambda_{2}<1$, which is then associated with a new (disordered) universality class of this systcm (with the same thermal exponent, however). The analysis of the higher-order moments may give a hint into the nature of the fixed-point probability distribution. 
In order to make closer contact with the aperiodic examples, we now consider a case of correlated disorder, with a laycred distribution of interactions. The first bond of every branch is associated with the same (random) value of the interaction energy, the second bond of every branch is associated with another value, and so on, if we have $b>2$ bonds. In analogy with the previous derivation $[2,7]$, we have

$$
y^{\prime}=\left[y^{(1)} y^{(2)} \ldots y^{(b)}\right] / q+(q-1) / q
$$

from which we obtain a set of recursion relations for the moments of the small deviation $\delta^{(i)}=y^{(i)}-y^{*}$ about the fixed point $y^{*}$ of the uniform system. Again, each moment depends only on the lower-order ones. For $b=2$, for example. the recursion relations for the first two moments are given by

$$
\begin{gathered}
M_{1}^{\prime}=\frac{2(2-q)}{q} M_{1}+\frac{1}{q} M_{1}^{2}, \\
M_{2}^{\prime}=2\left(\frac{q-1}{q}\right)^{2} M_{2}+\frac{1}{q^{2}}\left[2(q-1)^{2} M_{1}^{2}+M_{2}^{2}+4(q-1) M_{1} M_{2}^{2}\right] .
\end{gathered}
$$

For $q=2$, there is no transition. For $q=3$, the (uniform) fixed point, located at $M_{1}^{*}=M_{2}^{*}=\ldots=0$, is associated with the thermal cigenvaluc, $A_{1}=$ $2(q-1) / q=4 / 3$, and with $\Lambda_{2}=8 / 9<1$, which shows that disorder is irrelevant. For $q=4$, howevcr, $\Lambda_{1}=3 / 2>1$, and $\Lambda_{2}=18 / 16>1$, indicating

that this fixed point is no longer acceptable. In this casc, there is indeed a new fixed point, at $M_{1}^{*}=0$ and $M_{2}^{*}=-4 \neq 0$, associated with $\Lambda_{2}=7 / 8<1$. However, since $M_{2}^{*}<0$, this fixed point cannot be reached from physical initial conditions, and secms to indicate a breakdown of the perturbative trcatment. This is the typical picture for $q \geqslant 4$, and large values of $b$. Also. it secnis to be the prevalent picture in perturbative calculations for the effects of quencheel correlated disorder in many statistical model systems $|9|$.

\section{Effects of aperiodicity}

\section{Renormalization-group calculations}

Consider, for cxample, a lattice with $b=2$ bonds, and a layered distribution of interactions $[3,4], \epsilon_{a}$ and $\epsilon_{b}$, chosen according to the two-letter period-doubling sequence, $a \rightarrow a b, b \rightarrow a a$. Along each branch the interaction encrgies arc distributed according to the aperiodic scquence gencrated by this rulc. The same arguments as used above to treat the uniform case, lead to a pair of recursion rclations, $y_{a}^{\prime}=\left[y_{a} y_{b}\right] / q+(q-1) / q$, and $y_{b}^{\prime}=y_{a}^{2} / q^{2}+(q-1) / q$. where $y_{a, b}=\operatorname{cxp}\left(\beta \epsilon_{a, b}\right)$, and $\epsilon_{a, b}>0$ is the interaction cnergy at bonds of 
types $a$ and $b$, respectivcly. It is easy to sce that, for $q>2$, there is no physically acceptable nontrivial fixed point, except the symmetric fixed point, $y_{a, b}^{*}=y^{*}=q-1$. The lincarization about this symmetric fixcd point leads to the cigenvalues $\Lambda_{1}=2 y^{*} / q=2(q-1) / q$, and $\Lambda_{2}=-y^{*} / q=-(q-1) / q$. If $q>2$, we have $\Lambda_{1}>1$ and $\left|\Lambda_{2}\right|<1$, which shows the irrelcvance of the geometric fluctuations.

The behavior in parameter space is much more interesting if we consider the Rudin-Shapiro, four-lctter substitution rule, $a \rightarrow a c, b \rightarrow d c, c \rightarrow a b, d \rightarrow d b$ [2]. Take a simple diamond lattice with $b=2$ bonds and $q$ branches. In analogy to the previous cases, it is possible to write four algebraic recursion rclations, $y_{a}^{\prime}=y_{a} y_{c} / q+(q-1) / q, y_{b}^{\prime}=y_{d} y_{c} / q+(q-1) / q, y_{c}^{\prime}=y_{a} y_{b} / q+(q-1) / q$, and $y_{d}^{\prime}=y_{t} y_{b} / q+(q-1) / q$, which lead to the symmetric fixed point, $y_{a}^{*}=y_{b}^{*}=$ $y_{c}^{*}=y_{d}^{*}=y^{*}=q-1$. From the lincarization about this fixcd point, we have the cigenvalues $\Lambda_{1}=2(q-1) / q, \Lambda_{2}=\sqrt{2}(q-1) / q, \Lambda_{3}=-\sqrt{2}(q-1) / q$, and $\Lambda_{1}=0$. The introduction of apcriodic interactions becomes relevant if $q>2+\sqrt{2}=3.41 \ldots$, which corresponds to $\left|\Lambda_{2}\right|=\left|\Lambda_{3}\right|>1$. Thesc recursion relations are so simple that we can perform a number of detailed calculations. In particular, it is easy to show the existence of additional, non-diagonal fixed points, given by

$$
y_{a, d}^{*}=\frac{1}{4(q-1)}\left[q\left(q^{2}-2 q+2\right) \pm q \sqrt{\left(q^{2}-2\right)\left(q^{2}-4 q+2\right)}\right]
$$

where $y_{b, c}^{\times}=q-(q-1) / y_{d, a}^{*}$. Besides two trivial eigenvalues, $\Lambda_{3}=0$ and $\Lambda_{4}=$ -1 , in the neighborhood of this fixed point wo also have an additional pair of cigenvalues. $\left|\Lambda_{1}\right|>1$ and $\left|\Lambda_{2}\right|<1$, given by the solutions of a simple quadratic cquation [2]. As $\left|\Lambda_{4}\right|=1$, we have a typical casc of marginal bchavior, which cannot be analyzed without resorting to higher-order calculations. However, the marginal operator does not give rise to a line of fixed points, as could be cxpected. Instead, with an additional algcbraic cffort, from the solutions of the polynomial cquations $y_{a, b, c, d}=y_{a, b, c, d}^{\prime \prime}\left(y_{a}, y_{b}, y_{c}, y_{d}\right)$, where $y^{\prime \prime}$ is the second itcrate of the recursion relations, it is possible to show the cxistence of a continuous line whose points are two-cycles. Given any $q>2+\sqrt{2}$, these equations lead to a pair of onc-parametcr algebraic curves, which meet smoothly and form a single, non-intersecting closed curve, containing the nondiagonal fixed points. Any point belonging to this closed curve is mapped into another point on the curve upon one iteration of the recursion relations, and back to itself upon a further iteration. The linearization of the second iterates about any point of the curve leads to the eigenvalues $0,-1$, and a conjugate pair. $\left|\Lambda_{1}\right|>1$ and $\left|\Lambda_{2}\right|<1$, with values that do not depend on the point about which the linearization is performed. The effects of the marginal eigenvalues on the specific-heat exponent have to be checked very carcfully, so we turn to the direct thermodynamic analysis of the frec energy. 
Transfer-matrix calculations

One of us has successfully used a transfer matrix (TM) technique to obtain the thermodynamic properties of several spin models on fractal lattices [5]. The cssential step of this scheme consists in the derivation of maps relating the cigenvalues of the transfer matrices associated with two subsequent gencrations of the hicrarchical construction. $G$ and $G+1$. For the interacting polymer model, the very definition of transfer matrices is much subtler, since the system lacks any obvious Hamiltonian formulation. Although technically involved, it is possible to construct a TM for the uniform model [2], whose only non-vanishing cigenvalue $\eta_{G}$ comes from the relation $\eta_{G}=q\left[\eta_{G-1}^{2}+(q-1) \chi_{G-1}^{4}\right]$, where $\chi_{G}=q^{\left(2^{G}-1\right)}$, and $\eta_{0}=y=\exp (\beta c)$. With the definition $f_{G}=-\left[k_{B} T \ln \eta_{G}\right] / 2^{G}$, we have a recursion relation for the free energy per monomer.

We now recall that the models we are investigating include more than one interaction energy, depending on the position along the path between the root sites. The basic steps of the TM scheme can be adapted in order to obtain the corresponding maps, although much attention has to be paid to all of the details. If the aperiodicity is induced by the four-letter Rudin-Shapiro sequence, $a \rightarrow a c, b \rightarrow d c, c \rightarrow a b, d \rightarrow d b$, wc will have in fact four difforent kinds of transfer matrices, and thus four coupled maps for the eigenvalues [2].

As we have pointed out, the RG analysis of the uniform model indicates the presence of a sccond-order phase transition for $q>2$, with a well-defined scaling expression for the specific-heat critical cxponent $\alpha$. In case of irrelevant apcriodicity, $\alpha$ is given by this same expression. However, when aperiodicity is relevant, and two-cycles become responsible for the critical behavior. as in the case of spin models [4], the scaling analysis must be adapted to take into account that two renormalization-group itcrations are necded in order that the system gocs back to the vicinity of one of the two points that are part of the two-cycle [10]. The result is simply that the specific-heat critical exponent is now given by $\alpha=2-2 \ln b / \ln \Lambda$, where we should note the presence of the factor 2 , and $\Lambda$ is the leading cigenvaluc of the lincarized sccond-itcratc of the recursion relations about any one of the two points of the attractor.

For the model with Rudin-Shapiro apcriodic interactions, there are two nondiagonal fixed points together with the curve of two-cycles. The lincarization of the second iterates about any point on this curve gives the same cigenvalues. For each choice of $q>2+\sqrt{2}$, we may determine numerically which value of $\alpha$ is predicted by the scaling form, and then use the TM method in order to compare with a direct analysis of the singularity. It is also possible to obtain $\alpha$ in the usual way, linearizing the recursion relations (first itcratcs) about the non-diagonal fixcd points, and using the leading cigenralue that cones 
from the solution of the quadratic equation that we have mentioned. We have checked and confirmed the coincidenee of the values of $\alpha$ for several choices of q.

An interesting feature revealed by the TM analyses is the appearance of logperiodic oscillations of the specific-heat in the low-temperature phase, as in the case of spin models [5]. Also, the TM numcrical results show that the specificheat vanishes above the critical temperature, diverging from below, a fact related to the cntropy becoming constant (when the polymers get unbound, maximum disorder is immediatcly attained). To extract a sensible value for the specific-heat exponent, several different choices of the interaction energies must be scparately analyzed. For $q=4$, for example, the net result is an cxponent $\alpha=0.252 \pm 0.08$, which points to a truc "aperiodic universality class" associated with the Rudin-Shapiro geometrical perturbation of the model. We now consider the scaling result, $\alpha=0.253692 \ldots$, for $q=4$, in striking angreement with the TM value. This scenario is present for several other values of $q$ that we have tested, which leads us to believe in the correctness of the methods and. morcover, to point out that highly non-trivial attractors may replace simple fixed points in apcriodic models, although the scaling analysis is still straightforward.

\section{References}

[1] A. B. Harris, J. Phys. C: Solid State Phys. 7, 1671 (1974).

|2| T. A. S. Haddad. R. F. S. Andrade and S. R. Salinas, J. Phys. A: Math. Gen. 37. 1499 (2004).

[3| T. A. S. Haddad and S. R. Salinas, Physica A 306, 98 (2002).

[4] T. A. S. Haddad, S. T. R. Pinho and S. R. Salinas, Phys. Rev. E 61, 3330 (2000).

[5] R. F. S. Andrade, Phys. Rev. E 61, 7196 (2000); Phys. Rev. E 59, 150 (1999).

|6] J. -M. Luck, Europhys. Lett. 24, 359 (1993).

[7] S. Mukherji and S. M. Bhattacharjee, Phys. Rev. E 52, 1930 (1995).

[8] B. Derrida and E. Gardner, J. Phys. A.: Math. Gen. 17, 3223 (1984).

[9] P. T. Muzy, A. P. Vieira and S. R. Salinas, Phys. Rev. E 65, 046120 (2002).

[10] B. Derrida, J. -P. Eckmann and A. Erzan, J. Phys, A: Math. Gen. 16, 893 (1983). 



\title{
Some remarks on $p$-spin interaction models in a random field *
}

\author{
T. A. S. Haddad *, A. P. Vieira and S. R. Salinas \\ Instituto de Física, Universidade de São Paulo, Caixa Postal 66318, 05315-970 - \\ São Paulo, SP, Brazil
}

\begin{abstract}
We present some calculations for the thermodynamic behavior of mean-field ferromagnetic: $p$-spin interaction models in the presence of quenched random fields. For both Ising and spherical spin variables, we use the law of large numbers, without recourse to the replica trick, to obtain a free-energy functional in terms of the order parameter and an extra non-ordering density. In the spherical limit, we show that the transition is continuous for $p=2$, but turns into first order for $p \geq 3$, regardless of the probability distribution of the random fields. In the Ising case, for $p=2$, we recover previously known results. The free-energy functional obtained in this treatment can be used as a starting point for a dynamical study of these models.
\end{abstract}

hey worls: Random-field problems, $p$-spin interaction models, spin glasses, splierical model, structural glasses

PACS: 64.60.Cn, 75.50.Lk, 64.70.Pf .

\section{Introduction}

In the last decade or so, mean-ficld $p$-spin glass models have been frequently used in the phenomenological study of the dynamic anomalies associated with relaxational phenomena in supercooled liquids and real glasses [1]. Among the most intcresting features presented by these systems, and capturcd by the dynamic versions of $p$-spin glass models, are aging and the breakdown of the fluctuation-dissipation theorem. The reason of their success in reproducing

\footnotetext{
* Work supported by Brazilian agencies Fapesp, Capes and CNPq.

* Corresponding author.

Email address: thaddadeif usp.br (T. A. S. Haddad).
} 
these phenomena has generally been credited to the striling formal resenblance that their non-perturbative solutions that can be achicyed on the spherical-model limit [2] ) bear to the microscopic modc-coupling cquations of liquids and real glasses [3]. Unfortunatcly, the dynamic calculations are usually very involved, and sometimes the solutions can only be found numcrically [4].

With this in mind, we became interested on simpler versions of $p$-spin intcraction models, which are perhaps more amenable to analytic calculations of dynamic propertics. As a very preliminary stcp of this program, we present a detailed study of the thermodynamic behavior of such simplificd $p$-spin interaction models, both in the casc of Ising spins and in the spherical-model limit. Our model consists of a Hamiltonian with a Curic-Wciss term, coupling cvery $p$-uplets of spins with uniform (non-random) ferromagnetic strength, and a random-ficld term. We make no use of the replica trick to write down a frec-cnergy functional for these modcls, rccurring instcad to a sadelle-point cvaluation of the density of states.

In the next section, we define the models and put them in perspective with the traditional $p$-spin glass. Wc then present the calculations for the static bchavior of the Ising version, followed by the spherical-model limit, which is more amenable to a complcte study for any value of $p$. Finally, we present some preliminary conclusions.

\section{Definition of the model}

In its original form [5], the p-spin interaction model describes a system of $x$ Ising spins interacting through the Hamiltonian

$$
\mathcal{H}=-\sum_{1 \leq i_{1}<i_{2}<\ldots<i_{p} \leq N} J_{i_{1} i_{2} \ldots i_{p}} S_{i_{1}} S_{i_{2}} \ldots S_{i_{p}}-\sum_{i=1}^{N} H_{i} S_{i}
$$

where $p \geq 2$ is an integer, and the couplings are independently chosen from a quenched Gaussian probability distribution, properly normalized. For $p=2$, in a uniform filcd, this system reduces to the traditional Sherrington-Kirkpatrick spin-glass model [6], with no forro- or antifcrromagnetic bias. As it was clear from its inception, the $p$-spin glass was intended to be a generalization of the standard mean-ficld spin glass, with the aim of shedding some light on the workings of replica symmetry brcaking schemes. It was shown $[7]$ that for any $p>2$ there is a well-defincd first-order phase transition (with no latent heat) to a spin glass low-tcmpcraturc phase. and just onc stcp of replica symmetry breaking (in the Parisi scheme [8]) makes this phase stable down to a lower temperaturc. This temperature, which marks the onset of the De Almcida- 
Thouless instability, approaches zcro with growing $p$. In the limit $p \rightarrow \infty$, we recorer the so called random encrgy model [9], whose spin-glass phase is stable down to zcro temperature and which has the attracting feature of being soluble without recourse to the replica-trick.

In this work, it is our purpose to study the altcrnative $p$-spin interaction Hamiltonian,

$$
\mathcal{H}=-\frac{J}{p ! N^{p-1}}\left(\sum_{i=1}^{N} S_{i}\right)^{p}-\sum_{i=1}^{N} H_{i} S_{i}
$$

where $J>0$ and the set of fields $\left\{H_{i}\right\}$ is chosen from a probability distribution (as yot unspecificd). The interaction term is written on an explicit CurieWeiss form, with a prefactor that cnsures extensivity. Due to the absence of randomness in the couplings, this model can be solved without replicas for any value of $p$. For Ising spins, $S_{i}= \pm 1$. In the spherical limit, the spins are coutinuous real variables, with the spherical constraint $\sum_{i=1}^{N} S_{i}^{2}=N$. In the next section, we analyze the thermodynamic phase diagram of this $p$-spin random-field Curic-Woiss model, given by Eq. (2), in both Ising and spherical cases.

\section{Thermodynamic solutions of the model}

\subsection{Ising case}

For Ising spins, the partition function associated with Eq. (2) can be written als

$$
Z=\sum_{\left\{S_{i}\right\}} \operatorname{cxp}\left[\frac{\beta J}{p ! N^{p-1}}\left(\sum_{i=1}^{N} S_{i}\right)^{p}+\beta \sum_{i=1}^{N} H_{i} S_{i}\right],
$$

where $\beta=1 / k_{B} T$. Defining

$$
m \equiv \frac{1}{N} \sum_{i=1}^{N} S_{i} \quad \text { and } \quad Q \equiv \frac{1}{N} \sum_{i=1}^{N} H_{i} S_{i},
$$

we rewritc Eq. (3) as

$$
\begin{aligned}
Z= & \int d m \int d Q \operatorname{cxp} N\left(\frac{\beta J}{p !} m^{p}+\beta Q\right) \\
& \times\left[\sum_{\left\{S_{i}\right\}} \delta\left(N m-\sum_{i=1}^{N} S_{i}\right) \delta\left(N Q-\sum_{i=1}^{N} H_{i} S_{i}\right)\right] .
\end{aligned}
$$


We now define a density of states,

$$
\Omega(m, Q) \equiv \sum_{\left\{S_{i}\right\}} \delta\left(N m-\sum_{i=1}^{N} S_{i}\right) \delta\left(N Q-\sum_{i=1}^{N} H_{i} S_{i}\right) \sim \mathrm{e}^{N \phi}
$$

where $\phi$ is a real function of $m$ and $Q$. Thus, the calculation of the partition function is reduced to the cvaluation of a simple saddlc-point integral.

Using an intcgral representation of the delta function, it is not difficult to writc

$$
\Omega=\iint \frac{d k_{1} d k_{2}}{(2 \pi)^{2}} \operatorname{cxp}(N \Phi)
$$

wherc

$$
\Phi=-i k_{1} m-i k_{2} Q+\frac{1}{N} \sum_{j=1}^{N} \ln \left[2 \cos \left(k_{1}+k_{2} H_{j}\right)\right]
$$

Now we assume that the probability distribution of the magnetic ficlds laas in finite variance. In the thermodynamic limit, we invoke the law of large numbers in order to write the final expression

$$
\Phi=-i k_{1} m-i k_{2} Q+\left\langle\ln \left[2 \cos \left(k_{1}+k_{2} H_{j}\right)\right]\right\rangle_{H},
$$

where \langle\rangle$_{H}$ represents the mean-value with respect to the random-ficle distribution. To give an example, taking a bimodal distribution for the randons ficlds, with zcro mean and variance $H^{2}$, we obtain

$$
\Phi=-i k_{1} m-i k_{2} Q+\frac{1}{2} \ln \left[2 \cos \left(k_{1}+k_{2} H\right)\right]+\frac{1}{2} \ln \left[2 \cos \left(k_{1}-k_{2} H\right)\right] .
$$

According to this procedure, the integral in Eq. (7) can be calculated via a stecpest-descents method, which amounts to the extremization of $\Phi$. given by Eq. (10), with respect to $k_{1}$ and $k_{2}$. Note also that $\phi(m, Q)$, introduced in $\mathrm{Eq}$. (6), is just this extremum value of $\Phi$.

Extremizing $\Phi$ we get a pair of saddle-point equations, which can be plugged into Eq. (10) to yicld

$$
\begin{aligned}
\dot{\phi}(m, Q)= & -\frac{1}{2}\left(m+\frac{Q}{H}\right) \tanh ^{-1}\left(m+\frac{Q}{H}\right) \\
& -\frac{1}{2}\left(m-\frac{Q}{H}\right) \tanh ^{-1}\left(m-\frac{Q}{H}\right)+\ln 2 \\
& -\frac{1}{4} \ln \left[1-\left(m+\frac{Q}{H}\right)^{2}\right]-\frac{1}{4} \ln \left[1-\left(m-\frac{Q}{H}\right)^{2}\right] .
\end{aligned}
$$


Finally, the partition function is written as a simple saddle-point integral,

$$
Z=\int d m \int d Q \exp \left[N\left(\phi+\frac{\beta J}{p !} m^{p}+\beta Q\right)\right] .
$$

The argument of the exponential leads to the effective free-energy functional, whose stability has to be analyzed (in terms of temperature and field variance). For $p=2$, we recover an expression previously obtained by Salinas and Wreszinski [10] through a different approach, and which has been shown to vicld a tricritical point on the temperature versus field variance phase diagram. We note that in the same paper it was proven that a Gaussian distribution of random fields. which gives rise to a slightly different form of $\phi$, precludes the existence of the tricritical point. Now we turn to the much easier case of a splierical model.

\subsection{Syherical-model birtit.}

In the spherical-nodel limit. the partition function associated with Eq. (2), including the splierical constraint, is given by

$$
\begin{aligned}
Z= & {\left[\prod_{i=1}^{N} \int_{-\infty}^{+\infty} d S_{i}\right] \delta\left(N-\sum_{i=1}^{N} S_{i}^{2}\right) } \\
& \times \exp \left[\frac{\beta J}{p ! N^{p-1}}\left(\sum_{i=1}^{N} S_{i}\right)^{p}+\beta \sum_{i=1}^{N} H_{i} S_{i}\right] .
\end{aligned}
$$

Following exactly the same steps as in the previous Ising case, the problem consists in calculating the density of states,

$$
\begin{aligned}
\Omega(m, Q) \equiv & {\left[\prod_{i=1}^{N} \int_{-\infty}^{+\infty} d S_{i}\right] \delta\left(N-\sum_{i=1}^{N} S_{i}^{2}\right) \delta\left(N m-\sum_{i=1}^{N} S_{i}\right) } \\
& \times \delta\left(N Q-\sum_{i=1}^{N} H_{i} S_{i}\right),
\end{aligned}
$$

with $m$ and $q$ defined as above. Whatever the probability distribution we take for the random fields, as long as it has zero mean and finite variance, in the themodynamic limit, if we invoke again the strong law of large numbers, it is not difficult to obtain the simple result

$$
O(m, Q)=\frac{1}{2}(1+\ln 2 \pi)+\frac{1}{2} \ln \left(1-m^{2}-\frac{Q^{2}}{H^{2}}\right)
$$


with $\phi$ defined in Eq. (6), which leads to a very different scenario in relation to the Ising casc.

We then study the partition function

$$
Z=\int d m \int d Q \operatorname{cxp}(-N \beta J g)
$$

with the effective free-energy functional

$$
g=-\frac{1}{\beta J} \phi(m, Q)-\frac{1}{p !} m^{p}-\frac{1}{J} Q .
$$

Introducing the definitions

$$
q \equiv \frac{Q}{J}, \quad h \equiv \frac{H}{J} \quad \text { and } \quad t \equiv \frac{1}{\beta J} .
$$

we obtain the equations of statc.

$$
m\left[1-m^{2}-\frac{q^{2}}{h^{2}}\right]^{-1}=\frac{m^{p-1}}{t(p-1) !}
$$

and

$$
\frac{q}{h^{2}}\left[1-m^{2}-\frac{q^{2}}{h^{2}}\right]^{-1}=\frac{1}{t} .
$$

In the ordered phase, with $m \neq 0$, it is straightforward to show that $q$ is always related to $m$ through the cquation

$$
q=\frac{h^{2}(p-1) !}{m^{p-2}} .
$$

In the paramagnetic phase, $m=0$, one can also show that $q$ is always different from zero, so that the phase diagram is entircly determined by $m$ alone.

If we now substitute Eq. (21) into Eq. (19), we can show that $m$ obers the following relation throughout the whole "ferromagnetic" phase,

$$
m^{2(p-1)}-m^{2(p-2)}+t(p-1) ! m^{p-2}=-h^{2}(p-1) !^{2} .
$$

If $p=2$, we sec that $m$ goes smoothly to zero over the critical line given by

$$
t=1-h^{2}
$$

On the other hand, if $p \geq 3$, it is easy to see that $m$ cannot go smoothly to zero, which prevents the occurrence of a second-order phase transition. Also. we can write an expression for the limit of stability of the $m=0$ solution. which penetrates into a region of the phase diagram where $m \neq 0$ is still a stable solution. Thus, from a simple numcrical calculation, we show that. for $p \geq 3$, there is a line of first-order transitions, as illustrated in Fig. 1. 


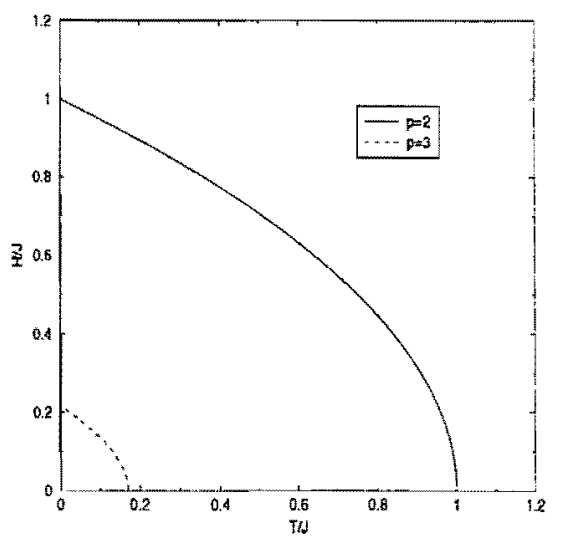

Figure 1. Phase diagram on the $h$ (scaled random-field variance) versus $t$ (scaled tomperature) plane for the spherical limit of our model. The solid line, for $p=2$, represents continuons transitions: the dashed line is first-order, as are all transitions for $p \geq 3$.

\section{Conclusions}

Wo obtained analytical cxpressions for the thermodynamic potential associated with mean-ficld ferromagnetic $p$-spin intcraction models in a random field. For $p=2$, we regain previously known results for Ising spins. The sphericalmodel limit is particularly simple in order to provide a starting point for a preliminary analysis of the dynamic behavior of these systems, in terms of the order parameter $(m)$ and a non-ordering density $(q)$.

\section{References}

|1] T. R. Kirkpatrick and D. Thirumalai, Phys. Rev. B 36, 5388 (1987).

|2| A. Crisanti. H. Horner and H. -J. Sommers, Z. Phys. B 92, 257 (1993).

(3) L. F. Cugliandolo, "Slow relaxation and nonequilibrium dynamics in condensed matter". In: J. -L. Barrat et al. (eds), Les Houches Session 77, cond-mat/0210312.

14| B. Kim and A. Latz, Europhys. Lett. 53, 660 (2001).

[5] D. J. Gross and M. Mezard, Nucl. Phys. B 240, 431 (1984).

|6| D. Sherrington and S. Kirkpatrick, Phys. Rev. Lett. 32, 792 (1975).

[7] E. Gardner, Nucl. Phys. B 257, 747 (1985).

18] G. Parisi. Phys. Rev. Lett. 43, 1754 (1979).

|9| B. Derrida. Phys. Rev, Lett. 45, 79 (1980).

[10] S. R. Salinas and W. F. Wreszinski, J. Stat. Phys. 41, 299 (1985). 
